\title{
A Study on the Unsteady Aerodynamic Forces around an Ahmed Reference Model
}

by

\author{
Andréane Lafrenière \\ A thesis submitted to \\ the Faculty of Graduate Studies and Research \\ in partial fulfilment of \\ the requirements for the degree of \\ Master of Applied Science
}

Ottawa-Carleton Institute for

Mechanical and Aerospace Engineering

Department of Mechanical and Aerospace Engineering

Carleton University

Ottawa, Ontario, Canada

June 2008

Copyright (C)

2008 - Andréane Lafrenière 


$\begin{array}{ll}\begin{array}{l}\text { Library and } \\ \text { Archives Canada }\end{array} & \begin{array}{l}\text { Bibliothèque et } \\ \text { Archives Canada }\end{array} \\ \begin{array}{l}\text { Published Heritage } \\ \text { Branch }\end{array} & \begin{array}{l}\text { Direction du } \\ \text { Patrimoine de l'édition }\end{array} \\ \begin{array}{l}\text { 395 Wellington Street } \\ \text { Ottawa ON K1A 0N4 } \\ \text { Canada }\end{array} & \begin{array}{l}\text { 395, rue Wellington } \\ \text { Ottawa ON K1A 0N4 } \\ \text { Canada }\end{array}\end{array}$

Your file Votre référence

ISBN: 978-0-494-44049-0

Our file Notre référence

ISBN: 978-0-494-44049-0

NOTICE:

The author has granted a nonexclusive license allowing Library and Archives Canada to reproduce, publish, archive, preserve, conserve, communicate to the public by telecommunication or on the Internet, loan, distribute and sell theses worldwide, for commercial or noncommercial purposes, in microform, paper, electronic and/or any other formats.

The author retains copyright ownership and moral rights in this thesis. Neither the thesis nor substantial extracts from it may be printed or otherwise reproduced without the author's permission.
AVIS:

L'auteur a accordé une licence non exclusive permettant à la Bibliothèque et Archives Canada de reproduire, publier, archiver, sauvegarder, conserver, transmettre au public par télécommunication ou par l'Internet, prêter, distribuer et vendre des thèses partout dans le monde, à des fins commerciales ou autres, sur support microforme, papier, électronique et/ou autres formats.

L'auteur conserve la propriété du droit d'auteur et des droits moraux qui protège cette thèse. $\mathrm{Ni}$ la thèse ni des extraits substantiels de celle-ci ne doivent être imprimés ou autrement reproduits sans son autorisation.
In compliance with the Canadian Privacy Act some supporting forms may have been removed from this thesis.

While these forms may be included in the document page count, their removal does not represent any loss of content from the thesis.
Conformément à la loi canadienne sur la protection de la vie privée, quelques formulaires secondaires ont été enlevés de cette thèse.

Bien que ces formulaires aient inclus dans la pagination, il n'y aura aucun contenu manquant.

\section{Canada}




\section{Abstract}

This research was aimed at determining if unsteady aerodynamic forces exist around an Ahmed body, a model used to represent a road vehicle body. After their detection, the objective was to determine which type of forces were present and if the unsteady forces were due to an instability in the wake or if they were motion induced forces.

To achieve these objectives, tests were performed on a free-to-respond model in the $5 \mathrm{~m}$ Vertical Wind Tunnel of the National Research Council Canada (NRC) where the displacement of the model was measured in several degrees of freedom of the oscillation and the aerodynamic damping and stiffness of the model were determined.

In the second phase of the study, a stationary test was performed to measure the steady-state forces and moments applied on the body as well as high frequency surface pressure measurements to quantify the unsteady variations of the aerodynamic force coefficient with time. A high frequency response pressure probe was used to perform measurements of the flow fluctuations in the wake of the model. The tests for this second phase were conducted in the $2 \mathrm{~m} \times 3 \mathrm{~m}$ Wind Tunnel at NRC.

Subsequently, a dynamic model of the Ahmed body mounted on springs was developed using the different parameters measured during the two phases of the experimentation. It led to a conclusion on the type of unsteady aerodynamic forces present and a proposed experimental and/or numerical modeling approach.

A small excitation was found in the wake of the Ahmed body reference model, but motion-induced forces were also influencing the dynamics of the model. 
À Jean-Luc et Pauline, pour leur soutien, leur amour et leur présence constants, À Carole, Mathieu et Maxime, 


\section{Acknowledgments}

Et voilà, je l'ai finie. J'ai finalement terminé cette thèse que j'ai mille fois maudite. Mais, je dois l'avouer, j'en retire cent fois plus de positif que de négatif.

Je dois remercier, en tout premier lieu, Dr Guy Larose, sans qui je n'aurais pas commencé ce projet de fou, mais sans qui je n'aurais jamais pu envisager de le terminer. Guy, tu vaux cent fois ton pesant d'or! Ta gentillesse, ta patience, ton empathie et ta confiance en les gens font de toi une personne très spéciale que tout le monde adore côtoyer, moi y compris. Ta grande capacité à partager ton savoir, ton écoute, ton enthousiasme et ta disponibilité ont été la clé de mon succès. Merci d'avoir cru en moi, même quand je n'y croyais plus et de m'avoir laissé croire que tu y croyais toujours. J'espère que nous aurons de nouveau la chance de faire équipe!

De ces quelques années, je garderai des amitiés profondes pour des personnes qui m'ont soutenue, poussée et presque transportée sur leurs épaules durant les moments les plus durs. Et qui savaient quand ne pas me parler de ma thès! Des personnes pour qui j'espère avoir la chance d'être là quand ils en auront besoin autant qu'ils ont été là pour moi. Alanna, Albert, Calvin, Dom, Francine, Johanne, John, Peter, Stéphane and Suzette, thank you.

Un gros merci à tous les gens du Conseil national de recherches du Canada (CNRC) qui m'ont offert support technique et encouragements au cours des cinq dernières années : Bernard, Brian, Henri, Keith J., Mario, Mike, Paul, Rick, Stephen and Vinh. 
Je désire aussi remercier Jerzy Komorowski, directeur général de l'Institut de recherche en aérospatiale du CNRC, et Steve Zan, directeur du Laboratoire d'aéronautique, de m'avoir offert la chance d'effectuer mes travaux de recherches dans des installations uniques au Canada et de m'avoir appuyée financièrement.

Thank you, Professor Robert Langlois for your input and support through this degree. I really appreciated your interest, your standpoint with a dynamics perspective and your questions that make me rethink a lot on this project.

A special thank you to the department of Mechanical and Aerospace Engineering at Carleton University for their support, and especially to Professors Johnson and Afagh for their comprehension and Marlene, Nancy and Christie for their patience.

Et Allan, qui m’a donné la chance de vivre une expérience unique et sans qui je n'aurais pas accepté mes bourses d'études... Tak.

Finalement, les derniers mais non les moindres, ma famille. Pour leur support, leur présence et leurs encouragements, je les remercie. Leur confiance en moi m'a aidée à atteindre des objectifs qui me paraissaient inatteignables. Carole, Maxime, Mathieu, Pauline, Jean-Luc, Anne-Marie, Luc, Gaétan, Laurence et Amélie, merci. 


\section{Table of contents}

$\begin{array}{ll}\text { Abstract } & \text { iii }\end{array}$

Acknowledgments $\quad$ v

Table of contents vii

List of tables $\quad$ xi

List of figures $\quad$ xii

$\begin{array}{ll}\text { Nomenclature } & \text { xix }\end{array}$

1 Introduction $\quad 1$

1.1 Impetus for the research . . . . . . . . . . . . . 1

1.2 Parallel with flow-induced vibration studies of long span bridges . . . 4

1.3 Literature review . . . . . . . . . . . . . . . 5

1.3.1 Stationary measurements . . . . . . . . . . . . 5

1.3.2 Non-stationary wind tunnel models . . . . . . . . . . . 6

1.4 Objectives . . . . . . . . . . . . . . . . . 15

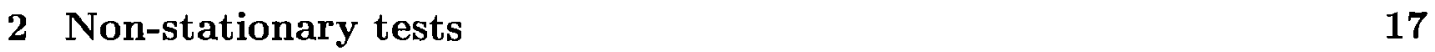

2.1 Model . . . . . . . . . . . . . . . . . . . . . . 17

2.1 .1 Reference model . . . . . . . . . . . . . . . . 17 
2.1.2 Manufacturing of the model . . . . . . . . . . . 19

2.2 Experimental set-up . . . . . . . . . . . . . . . 20

2.2 .1 Wind tunnel . . . . . . . . . . . . . . . . 20

2.2.2 Experimental model set-up . . . . . . . . . . . . . 20

2.2.3 Springs selection . . . . . . . . . . . . . . . 23

2.2.4 Springs used in the experiment . . . . . . . . . . 28

2.2 .5 Instrumentation . . . . . . . . . . . . . . . . . 29

2.3 Experimental data . . . . . . . . . . . . . . . . . . 30

2.3.1 Test program and procedure . . . . . . . . . . . 30

2.3.2 Aerodynamic damping . . . . . . . . . . . . . . 31

2.3.3 Aerodynamic stiffness . . . . . . . . . . . . . . . . 37

2.3 .4 Build up traces . . . . . . . . . . . . . 40

2.3.5 Amplitude of the displacement . . . . . . . . . . . . . 46

2.4 Conclusions regarding the non-stationary test . . . . . . . . . 50

3 Stationary tests $\quad 51$

3.1 Model .............................. 51

3.1 .1 Model geometry ................. 51

3.1.2 Manufacturing of the model . . . . . . . . . . . 51

3.2 Experimental set-up . . . . . . . . . . . . . . . 54

3.2.1 Wind tunnel . . . . . . . . . . . . . . 54

3.2 .2 Experimental model set-up . . . . . . . . . . . . . . 54

3.2.3 Attachment of the model on the force balance . . . . . . 55

3.2 .4 Instrumentation . . . . . . . . . . . . 56

3.2.5 Pressure measurements . . . . . . . . . . . . 57

3.3 Experimental data . . . . . . . . . . . . . . . 60

3.3.1 Test program and procedures ............ 60 
3.3.2 Force balance measurements . . . . . . . . . . . . 61

3.3.3 Pressure integration . . . . . . . . . . . . 68

3.3.4 Visualization of the pressures ............ 74

3.3.5 Wake measurement . . . . . . . . . . . 77

3.4 Conclusions regarding the stationary test . . . . . . . . . . . 93

4 Dynamic model $\quad 94$

4.1 Model . . . . . . . . . . . . . . . . . . . . . . . 94

4.1.1 Development of the model . . . . . . . . . . . . . . 94

4.1 .2 General formulation of the model . . . . . . . . . . . . . 98

4.2 Model solution . . . . . . . . . . . . . . . . . . 99

4.2 .1 Euler method . . . . . . . . . . . . . . . . 99

4.3 Validation of the model . . . . . . . . . . . . . . . 101

$4.3 .1 \quad$ Decay traces . . . . . . . . . . . . . . . . . . . 101

4.3.2 Application of a steady force and moment . . . . . . . . . 106

4.3.3 Self-induced movement . . . . . . . . . . . . . . . 111

4.4 Conclusions regarding the dynamic model . . . . . . . . . . . 115

5 Concluding remarks $\quad 116$

5.1 Motion induced forces . . . . . . . . . . . . 116

5.2 Shape sensitive . . . . . . . . . . . . . . . . 117

5.3 Other dynamic model . . . . . . . . . . . . . . . 117

5.4 Future work . . . . . . . . . . . . . . . . . 118

$\begin{array}{lr}\text { List of references } & 120\end{array}$

$\begin{array}{lll}\text { Appendix A Location of the pressure taps } & 123\end{array}$

$\begin{array}{ll}\text { Appendix B Balance data } & 126\end{array}$ 
Appendix C Measurements of the frequency response of the pressure measurement system

Appendix D Graphs of the dynamic model 


\section{List of Tables}

1 Specifications of the springs $\ldots \ldots \ldots \ldots \ldots$

2 Different configurations tested during the non-stationary tests. . . . 32

3 Frequencies associated with the different D.O.F. . . . . . . . 39

4 Different configurations tested during the stationary tests. . . . . . 61 


\section{List of Figures}

1 The Alfa Romeo of Count Ricotti (1914) on the left; on the right, two typical Jaray cars $(1933-1934) \ldots \ldots \ldots 2$

2 Diagram of the forces and moments. . . . . . . . . . . 3

3 Geometry of the Ahmed body with the different slant angles . . . . 6

4 Experimental apparatus for dynamic wind tunnel tests on a scale model car ............................ 7

5 Frequency and damping ratio varying with speed f....... 8

6 Davis model geometry and dimensions . . . . . . . . . . . . 9

$7 \quad$ Static side force and yawing moment derivatives of a Davis model for different wind speeds . . . . . . . . . . . . . . 9

8 The two degrees of freedom shaker developed at RUAG by itself and installed in a model . . . . . . . . . . . . . . 10

9 Lift coefficient as a function of the ride height for one period at $10 \mathrm{~Hz}$

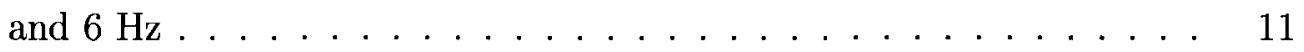

10 Simplified car model mounted on the rotating platform . . . . . . . 12

11 Crossflow fields at $\mathrm{X} / \mathrm{L}=0.36$. Comparison between the static and dynamic results . . . . . . . . . . . . . . . . . 13

12 Unsteady tomographies of total pressure (From left to right, top to bottom . . . . . . . . . . . . . . . . . 14

13 Geometry of the Ahmed reference model. . . . . . . . . . . . 18 
14 Ahmed reference model dimensions . . . . . . . . . . . . . . . 19

15 Diagram of the forces and moments on the vertical model. . . . . . . 21

16 H-shape support of the model . . . . . . . . . . . . . . . . 22

17 View of the spring suspension system attached to the $1.83 \mathrm{~m}$ steel ring 23

18 Sketch of the installation of the springs on the model . . . . . . . . 24

19 Experimental set-up for the determination of the mass moment of inertia 27

20 Positioning of the Micro Laser Sensors . . . . . . . . . . . . . . 30

21 Decay trace in heave mode, without wind . . . . . . . . . . . 33

22 Variation of the total damping in heave . . . . . . . . . . . . . 34

23 Variation of the total damping in pitch . . . . . . . . . 35

24 Variation of the total damping in yaw . . . . . . . . . . . 36

25 Variation of the total stiffness in heave . . . . . . . . . . 38

26 Variation of the total stiffness in pitch . . . . . . . . . . . . 39

27 Variation of the stiffness in yaw . . . . . . . . . . . . . 39

28 Amplitude build up traces in heave and pitch for several wind speeds $(3$ to $8 \mathrm{~m} / \mathrm{s}) \ldots \ldots \ldots \ldots 4 \ldots \ldots \ldots$

29 Amplitude build up traces in heave and pitch for several wind speeds $(9$ to $14 \mathrm{~m} / \mathrm{s}) \ldots \ldots \ldots \ldots \ldots$. . . . . . . . . . . . . . . . 42

30 Variation of the total damping in heave as a function of the wind speed 43

31 Variation of the total damping in pitch as a function of the wind speed 43

32 Amplitude build-up traces for the case with large weight at $7 \mathrm{~m} / \mathrm{s}$. . 44

33 Amplitude build-up traces for the case with large weight at $11 \mathrm{~m} / \mathrm{s}$. 45

34 Amplitude build-up traces for the case with large weight at $14 \mathrm{~m} / \mathrm{s} \quad$. $\quad 45$

35 Peak and mean value of the response as a function of the wind speed for the small weight case . . . . . . . . . . . . . . 47

36 Peak and mean value of the response as a function of the wind speed for the large weight case in heave and pitch . . . . . . . . . . 48 
37 Peak and mean value of the response as a function of the wind speed for the large weight case in side and yaw . . . . . . . . . . . . 49

38 Stationary test model . . . . . . . . . . . . . . . . . 52

39 Ahmed body in the $2 \mathrm{~m} \times 3 \mathrm{~m}$ Wind Tunnel . . . . . . . . . . 55

40 Adjustment of the ride height of the model . . . . . . . . . . . . 56

41 Pressure taps position . . . . . . . . . . . . . . 58

42 Frequency response curves for all pneumatic tubes of this study . . . 59

43 Static force and moment coefficients as a function of ride height in $\mathrm{mm} 64$

44 Static force and moment coefficients as a function of pitch angle in degrees ................................ 65

45 Static force and moment coefficients as a function of yaw angle in degrees at a constant pitch angle . . . . . . . . . . . 66

46 Static force and moment coefficients as a function of yaw angle in degrees at a ride height of $25 \mathrm{~mm}$ and a wind speed of $15 \mathrm{~m} / \mathrm{s} . \ldots 67$

47 Areas on the model for the pressure integration . . . . . . . . . 69

48 Time series of the forces integrated from the pressure measurements, reference configuration, $15 \mathrm{~m} / \mathrm{s} \ldots \ldots 71$

49 Time series of the unsteady pressure measurement, reference configu-

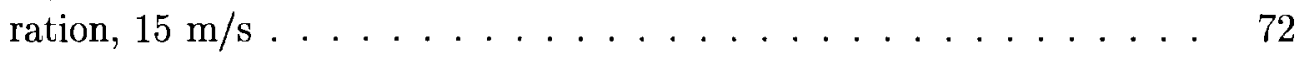

50 Spectrum of the time series, reference configuration, $15 \mathrm{~m} / \mathrm{s} \ldots 73$

51 Visualization of the mean and peak pressure coefficients for each pressure tap for the three ride heights. . . . . . . . . . . . 75

52 Visualization of the mean and peak pressure coefficients for each pressure tap for the five pitch angles. . . . . . . . . . 76

53 Positions of the Cobra probe for the wake measurements. . . . . . . 77

54 Spectrum of the $u$-component of the wake at reference configuration at 5,11 and $17 \mathrm{~m} / \mathrm{s} . \ldots \ldots \ldots \ldots \ldots$ 
55 Spectrum of the $v$-component of the wake at reference configuration at 5,11 and $17 \mathrm{~m} / \mathrm{s} \ldots \ldots \ldots \ldots \ldots \ldots$

56 Spectrum of the $w$-component of the wake at reference configuration at 5,11 and $17 \mathrm{~m} / \mathrm{s} \ldots \ldots \ldots \ldots$. . . . . . . . . . . . 81

57 3-D carpet plot of the $w$-component of the wake as a function of wind speed for the reference configuration . . . . . . . . . . 83

58 Spectrum of the $u$-component of the wake with a mixed configuration at 5,11 and $17 \mathrm{~m} / \mathrm{s} \ldots \ldots \ldots \ldots \ldots$

59 Spectrum of the $v$-component of the wake with a mixed configuration at 5,11 and $17 \mathrm{~m} / \mathrm{s} \ldots \ldots \ldots \ldots$

60 Spectrum of the $w$-component of the wake with a mixed configuration at 5,11 and $17 \mathrm{~m} / \mathrm{s} \ldots \ldots \ldots \ldots \ldots$

613 -D carpet plot of the $w$-component of the wake as a function of wind speed for a mixed configuration . . . . . . . . . . . .

62 Spectrum of the $u$-component of the wake with a mixed configuration for different yaw angles . . . . . . . . . . . . . . . . 90

63 Spectrum of the $v$-component of the wake with a mixed configuration for different yaw angles . . . . . . . . . . . . . . . . 91

64 Spectrum of the $w$-component of the wake with a mixed configuration for different yaw angles . . . . . . . . . . . . . . . . 92

65 Diagram of the springs and dampers used for the simulation. . . . . 95

66 Free body diagram of the forces in heave. . . . . . . . . . . . 96

67 Comparison between the decay trace of the dynamic model and the experimental one in heave for the small weight case. . . . . . . . 102

68 Comparison between the decay trace of the dynamic model and the experimental one in pitch for the small weight case. . . . . . . . 103 
69 Comparison between the decay trace of the dynamic model and the experimental one in heave for the large weight case. . . . . . . . . . . 104

70 Comparison between the decay trace of the dynamic model and the experimental one in pitch for the large weight case. . . . . . . . 105

71 Graph of the simulation of the displacement in heave and pitch of the small weight case at $11 \mathrm{~m} / \mathrm{s}$ for a constant force input, structural coefficients. . . . . . . . . . . . . . 106

72 Graph of the simulation of the displacement in heave and pitch of the small weight case at $13 \mathrm{~m} / \mathrm{s}$ for a constant force input, structural coefficients. . . . . . . . . . . . . . 107

73 Graph of the simulation of the displacement in heave and pitch of the small weight case at $15 \mathrm{~m} / \mathrm{s}$ for a constant force input, structural

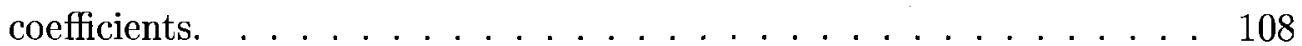

74 Graph of the simulation of the displacement in heave and pitch of the small weight case at $11 \mathrm{~m} / \mathrm{s}$ for a constant force input . . . . . . . . 109

75 Graph of the simulation of the displacement in heave and pitch of the large weight case at $11 \mathrm{~m} / \mathrm{s}$ for a constant force input . . . . . . . .

76 Graph of the simulation of the small weight model position as a function of time at $11 \mathrm{~m} / \mathrm{s} \ldots \ldots \ldots 111$

77 Time series of the displacement as a function of time as measured for the small weight case at $11 \mathrm{~m} / \mathrm{s} \ldots \ldots \ldots$. . . . . . . . . . . 112

78 Graph of the simulation of large weight model position in function of time at $13 \mathrm{~m} / \mathrm{s} \ldots \ldots \ldots \ldots \ldots \ldots \ldots$

79 Time series of the displacement in function of time as measured, large

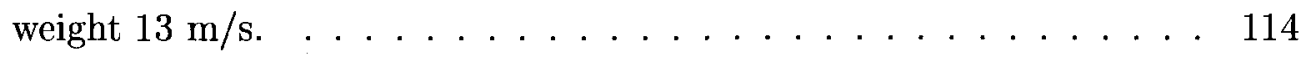

80 Positioning of the pressure taps (top) . . . . . . . . . . . . 123

81 Positioning of the pressure taps (side and bottom) . . . . . . . . . 124 
82 Positioning of the pressure taps (front and back) . . . . . . . . 125

83 Static force and moment coefficients as a function of yaw angle in degrees at a ride height of $25 \mathrm{~mm}$ and a wind speed of $11 \mathrm{~m} / \mathrm{s} . ~ \ldots . ~ 127$

84 Static force and moment coefficients as a function of yaw angle in degrees at a ride height of $25 \mathrm{~mm}$ and a wind speed of $13 \mathrm{~m} / \mathrm{s}$. . . . 128

85 Static force and moment coefficients as a function of yaw angle in degrees at a ride height of $18 \mathrm{~mm}$ and a wind speed of $11 \mathrm{~m} / \mathrm{s}$. . . 129

86 Static force and moment coefficients as a function of yaw angle in degrees at a ride height of $18 \mathrm{~mm}$ and a wind speed of $13 \mathrm{~m} / \mathrm{s} . \ldots 130$

87 Static force and moment coefficients as a function of yaw angle in degrees at a ride height of $18 \mathrm{~mm}$ and a wind speed of $15 \mathrm{~m} / \mathrm{s}$. . . .

88 Static force and moment coefficients as a function of yaw angle in degrees at a ride height of $33 \mathrm{~mm}$ and a wind speed of $11 \mathrm{~m} / \mathrm{s}$. . . 132

89 Static force and moment coefficients as a function of yaw angle in degrees at a ride height of $33 \mathrm{~mm}$ and a wind speed of $13 \mathrm{~m} / \mathrm{s}$. . . 133

90 Static force and moment coefficients as a function of yaw angle in degrees at a ride height of $33 \mathrm{~mm}$ and a wind speed of $15 \mathrm{~m} / \mathrm{s}$. . . 134

91 Schematic illustration of the set-up of the pressure tap calibration system 136

92 Graph of the simulation of the displacement in heave and pitch of the large weight case at $11 \mathrm{~m} / \mathrm{s}$ for a constant force input, structural coefficients.

93 Graph of the simulation of the displacement in heave and pitch of the large weight case at $13 \mathrm{~m} / \mathrm{s}$ for a constant force input, structural coefficients. . . . . . . . . . . . . . . . . . 138

94 Graph of the simulation of the displacement in heave and pitch of the large weight case at $15 \mathrm{~m} / \mathrm{s}$ for a constant force input, structural coefficients. 
95 Graph of the simulation of big weight model position in function on the time at $11 \mathrm{~m} / \mathrm{s} \ldots \ldots \ldots \ldots$. . . . . . . . . . . 140

96 Graph of the simulation of big weight model position in function on the time at $15 \mathrm{~m} / \mathrm{s} \ldots \ldots \ldots \ldots \ldots \ldots \ldots$ 


\section{Nomenclature}

$\delta \quad$ Logarithmic decrement of total damping

$\varepsilon \quad$ Total damping in percentage of critical [\%]

$\omega \quad$ Damped natural frequency $[\mathrm{rad} / \mathrm{s}]$

$\omega_{N} \quad$ Natural frequency $[\mathrm{rad} / \mathrm{s}]$

$A \quad$ Frontal area of the model $\left[\mathrm{m}^{2}\right]$

$A_{0} \quad$ Amplitude of the signal at nominal cycle $0[\mathrm{~m}]$

$A_{N} \quad$ Amplitude of the signal at $\mathrm{N}$ cycles [m]

$C_{D} \quad$ Drag coefficient

$C_{L} \quad$ Lift coefficient

$C_{M} \quad$ Pitching moment coefficient

$C_{P} \quad$ Pressure coefficient

$C_{R} \quad$ Rolling moment coefficient

$C_{S} \quad$ Side force coefficient

$C_{Y} \quad$ Yawing moment coefficient

$D \quad$ Drag force [N]

$F_{A H} \quad$ Aerodynamic force in heave [N]

$F_{D H} \quad$ Damping force in heave $[\mathrm{N}]$

$F_{S H} \quad$ Stiffness force in heave $[\mathrm{N}]$

$L \quad$ Lift force [N]

$L_{c} \quad$ Wheelbase [m]

$L_{L} \quad$ Length of the drag link of the model [m]

$N \quad$ Number of cycles [cycles]

$F_{A P} \quad$ Aerodynamic moment in pitch [Nm]

$F_{D P} \quad$ Damping moment in pitch [Nm] 
$F_{S P} \quad$ Stiffness force in pitch $[\mathrm{Nm}]$

$P \quad$ Peak response

$P_{i} \quad$ Surface pressure at tap $i$ on the model [kPa]

$P I \quad$ Static pressure reference $[\mathrm{kPa}]$

$P M \quad$ Pitching moment $[\mathrm{Nm}]$

$R \quad$ Rolling moment [Nm]

$S \quad$ Side force $[\mathrm{N}]$

$T \quad$ Tension in the drag link $[\mathrm{N}]$

$T_{0} \quad$ Period for one oscillation (mass moment of inertia test) [s]

$Y \quad$ Yawing moment $[\mathrm{Nm}]$

$a \quad$ Acceleration of the model $\left[\mathrm{m} / \mathrm{s}^{2}\right]$

$b \quad$ Half of the distance between the wires (mass moment of inertia test) [m]

$c \quad$ Damping coefficient $[\mathrm{Ns} / \mathrm{m}]$

$c_{c r} \quad$ Critical damping coefficient $[\mathrm{Ns} / \mathrm{m}]$

$c_{h} \quad$ Damping coefficient in heave $[\mathrm{Ns} / \mathrm{m}]$

$d_{t} \quad$ Body's initial position [m]

$d_{t+\Delta t}$ Body's final position [m]

$f \quad$ Frequency of the system $[\mathrm{Hz}]$

$g \quad$ Gravitational acceleration $\left[\mathrm{m} / \mathrm{s}^{2}\right]$

$k_{T} \quad$ Total spring constant $[\mathrm{N} / \mathrm{m}]$

$k_{i} \quad$ Spring constant of spring $i[\mathrm{~N} / \mathrm{m}]$

$k \quad$ Aerodynamic stiffness $[\mathrm{N} / \mathrm{m}]$

$k_{h} \quad$ Aerodynamic stiffness in heave $[\mathrm{N} / \mathrm{m}]$

$k_{p} \quad$ Aerodynamic stiffness in pitch $\left[\mathrm{Nm} /{ }^{\circ}\right]$

$l \quad$ Length of the wires (mass moment of inertia test) $[\mathrm{m}]$

$m \quad$ Mass [kg]

$q \quad$ Dynamic pressure $[\mathrm{kPa}]$

$r \quad$ Distance of the spring attachment on the model $[\mathrm{m}]$

$v_{t} \quad$ Body's initial velocity $[\mathrm{m} / \mathrm{s}]$

$v_{t+\Delta t}$ Body's final velocity $[\mathrm{m} / \mathrm{s}]$

$x_{h} \quad$ Position of the body in heave [m]

$x_{p} \quad$ Position of the body in pitch [ $\left.{ }^{\circ}\right]$ 


\section{Chapter 1}

\section{Introduction}

\subsection{Impetus for the research}

In 1911, when Riedler gave vehicle aerodynamics its first rational basis with an analysis of the tractive resistance of road vehicles, he triggered a long iterative process to understand and decrease the drag force on cars [1].

The first vehicle shapes were based on those borrowed from other fields such as marine transportation or aviation, such as shown in Figure 1. To adapt the shapes of the vehicles to the three-dimensional (3-D) character of the flow field, more streamlined bodies were developed. They subsequently led to the development of the general form and to detail optimization techniques which are more compatible with the automobile stylist's vision. Through this evolution, the understanding of the flow field around the car and the different techniques to investigate it have been developed to a point never expected by the early ground vehicle aerodynamicists.

In spite of these improvements in the science, it is still impossible to determine precisely the aerodynamic coefficients of a car without testing it in a wind tunnel or doing a computational fluid dynamics study of its shape. In fact, unlike airplane wings, cars are bluff bodies. Their flow field is governed by regions of flow separations, with a wide wake behind the body which is difficult to predict. Also, the different 


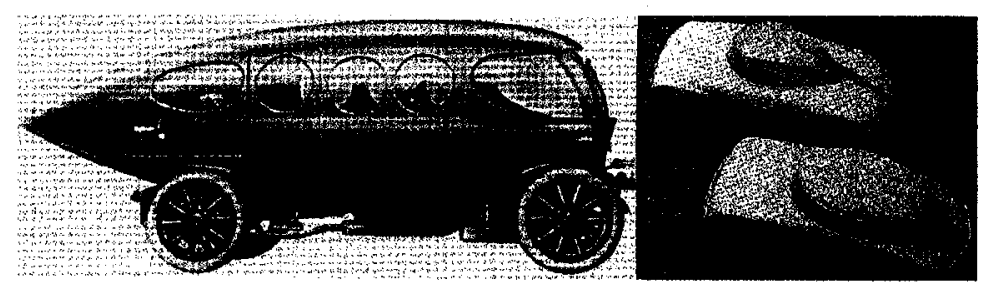

Figure 1: The Alfa Romeo of Count Ricotti (1914) on the left; on the right, two typical Jaray cars (1933-1934) [1].

parts of the body can be studied separately only up to a certain point because they are all interacting. Therefore, the overall shape must be considered to optimize the general behaviour of the car, which must also take into consideration, due to the relatively low clearance between the vehicle and the ground, the interaction of the flow field with the ground.

The aerodynamicists can prevent, control, or delay the separation of the flow around the body by modifying the radius of curvature of certain parts, or by adding a spoiler, in combination or in sequence. The stylistic design is always the starting point of the aerodynamic design of a car, therefore the aerodynamicists must optimize the body details to reach their objectives without compromising the style set by the designers.

Over the last century, most of the efforts have been made to decrease vehicle drag in order to increase fuel efficiency, reduce vehicle noise, and improve the general performance. The lift and the side force, as well as the three moments (yaw, pitch and roll) are also known to influence the drivability. These are illustrated in Figure 2. This is especially true if there is interference in the flow, such as when the car is passing another car, a tractor-trailer, or a large bus.

Until recently, the majority of wind tunnel testing was performed to acquire steady-state values of the aerodynamic loads and moments of interest. Researchers were not aware of the presence of unsteady phenomena. Also, there was very little understanding of the real meaning of this high frequency data, or of the influence of 


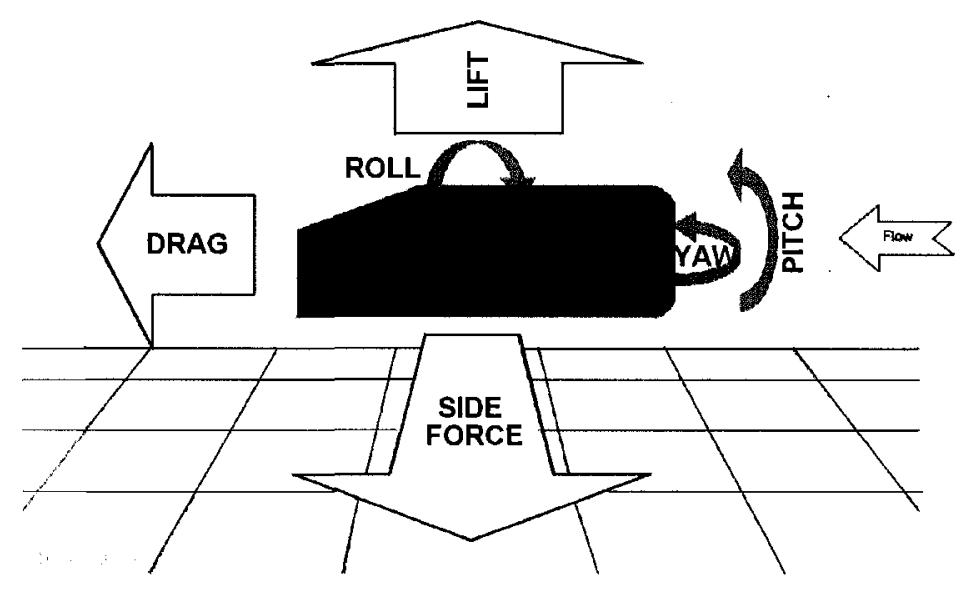

Figure 2: Diagram of the forces and moments.

the variations of the coefficients on the drivability of the vehicle, and no methodology to acquire this type of data was available.

Since there is very little understanding of the phenomena, the easiest way to correct the problem, if it occurs, is to modify the vehicle shape until the unsteady forces disappear. However, this is only a limited solution and better comprehension of the phenomena would allow researchers to determine the real impact of these forces, as well as the impact on the drivability of the car. Testing with high frequency data acquisition allows for the observation of unsteady aerodynamic forces. This can be detected with a low frequency data acquisition system by repeating each test many times and comparing the variation of the coefficients or, sometimes, by observing the variation of the static coefficient curves with yaw angles and looking for non-symmetry or other odd behaviour.

The increasing trend towards more contoured and rounded body shapes, more powerful propulsion, and lower vehicle weight tends to produce vehicles that are more sensitive to unsteady aerodynamic forces. It is important to start studying 
these phenomena before they become a threat to the safety of drivers and passengers.

The main objective of this research was to study the different types of aerodynamic forces acting on an automobile-like shape for the purpose of enhancing our understanding of the effects of the unsteady aerodynamic forces on the movement of a ground vehicle.

\subsection{Parallel with flow-induced vibration studies of long span bridges}

There are three families of unsteady aerodynamic phenomena for ground vehicles: i) aero-elastic problems caused by the vehicle moving in a moving fluid, which can create dynamic forces that increase or decrease the movement; ii) responses to dynamic forces when the vehicle is subject to perturbations like gusts of wind, crossing another vehicle, or in the wake of a large truck or bus; and iii) unsteady aerodynamic forces created by vortices shedding in the wake of the vehicle affecting the behaviour.

The unsteady aerodynamics of bridges is a field that has been widely explored and is very well mastered, whereas unsteady aerodynamics of ground vehicles is a relatively new research topic. One of the techniques [2] to study the unsteady aerodynamics of a bridge deck is to mount a typical segment of the middle span on springs at each corner to suspend the model in its original position. The bridge deck experiences a force from the wind that is transmitted to the springs. If the force is unsteady, the bridge deck will move according to this force. It is therefore possible to measure this force and its fluctuations over a period of time, and to study it to obtain the frequency or frequencies excited by this force, which are critical to the structure.

Therefore, by using similar techniques, it was considered possible to investigate the unsteady aerodynamics of ground vehicles. The modifications required for the 
conventional bridge test present some technical challenges because, for ground vehicles, the model must be supported only at its base.

This innovative approach allowed us to test a vehicle not fixed to the wind tunnel ground, allowing free movement of the model in four directions. The data obtained will help in the understanding of aerodynamic loads and, ultimately, make the simulation and modelling of the motion observed with a dynamic numerical model possible.

\subsection{Literature review}

\subsubsection{Stationary measurements}

The aerodynamics of the Ahmed body, the vehicle form that was selected for this study, has been widely investigated. The initial experiments were performed by Ahmed, Ramm, and Faltin [3] in 1984. They designed the model (Figure 3) and made pressure and force measurements on the body and investigated the wake. Their main objective was to determine the effect of the variation of the slant angle on the drag of the body. They concluded that most of the drag is generated at the rear end of the model and that for a high drag configuration, the flow in the wake is unstable and presents strong edge vortices, a separation bubble on the base slant surface, and a separation bubble from the vertical rear end base.

This model became a widely used simple shape model. Experimental and computational investigations have been performed using a force balance to measure its aerodynamic characteristics, including study of its wake, for different slant angles. Bayraktar, Landman, and Baysal [5] have compared the computational and experimental results for back angles of $0^{\circ}, 12.5^{\circ}$, and $25^{\circ}$ with each other and with the data in the literature. The tests were performed at six different Reynolds numbers $\left(2.2 \times 10^{6}\right.$ to $13.2 \times 10^{6}$ ) based on the model length. For this range of Reynolds numbers the drag 

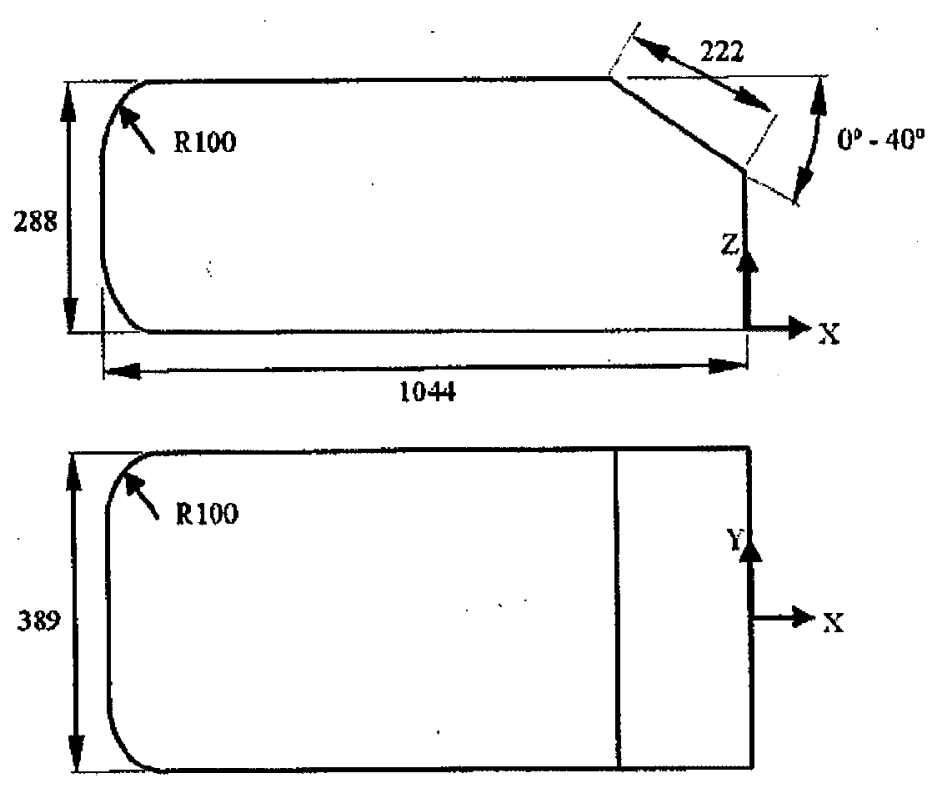

Figure 3: Geometry of the Ahmed body with the different slant angles (dimensions $\mathrm{mm})[4]$.

coefficients were decreased by up to $3.5 \%$ and the lift coefficients stayed within a $2.0 \%$ variation, except for the $0^{\circ}$ slant angle. The tests were performed for yaw angles from $-15^{\circ}$ to $15^{\circ}$ in increments of $3^{\circ}$ to $4^{\circ}$ with a $0^{\circ}$ pitch angle. A difference between the right and left yaw measurements was also observed during the tests with the $12.5^{\circ}$ slant angle. This could have been caused by hysteresis, where the forces and the moments are dependant of the time history of the attitude [6].

\subsubsection{Non-stationary wind tunnel models}

Conventional testing in a wind tunnel represents a limited simulation of the real world. In particular, most wind tunnel tests do not consider the dynamic motion of the car relative to the ground nor the effects of non-stationary flows on the aerodynamics of the vehicle [7]. Two different techniques can be used to represent the dynamic motion of the vehicle during wind tunnel testing. The model can either be forced to oscillate 
at a known amplitude and frequency, or similar to the technique used with the bridge dynamic sectional models, the model can be supported on springs and allowed to respond to the unsteady loads and moments created by the airflow around it.

\section{Free Oscillating Model}

Cheli, Dellach, Mandelli and Zasso [8] performed wind tunnel test on a static model and on a free oscillating apparatus with a two-degree of freedom pitching and lifting motion. The acquired data provided aerodynamic characteristics that were implemented in a vehicle model developed using a program for multibody dynamic analysis called ADAMS [8]. The measurement of time decays following system excitation allowed the determination of the aeroelastic characteristics of the model used, which was a scaled model of a car, as shown in Figure 4. They also studied the effect of the side winds with the ADAMS program.

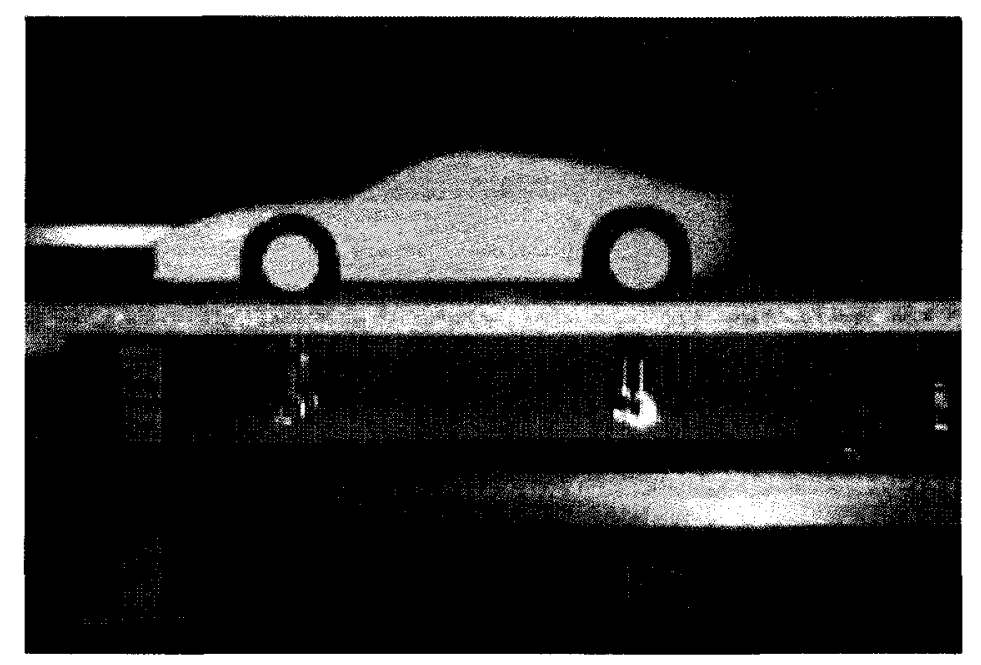

Figure 4: Experimental apparatus for dynamic wind tunnel tests on a scale model car $[8]$.

Their analysis showed a significant influence of aerodynamic stiffness and damping terms on the dynamic characteristics of the vehicle. The frequency critical ratios of the system decreased as velocities increased. This is due to a decrease of the total 
torsion stiffness defined as the structural stiffness plus the aerodynamic stiffness. This trend could lead to a possible instability of the vehicle. For the same speeds, the damping ratios increased (Figure 5). These frequency and damping ratios caused by aerodynamics could affect the handling and the comfort of the vehicle.
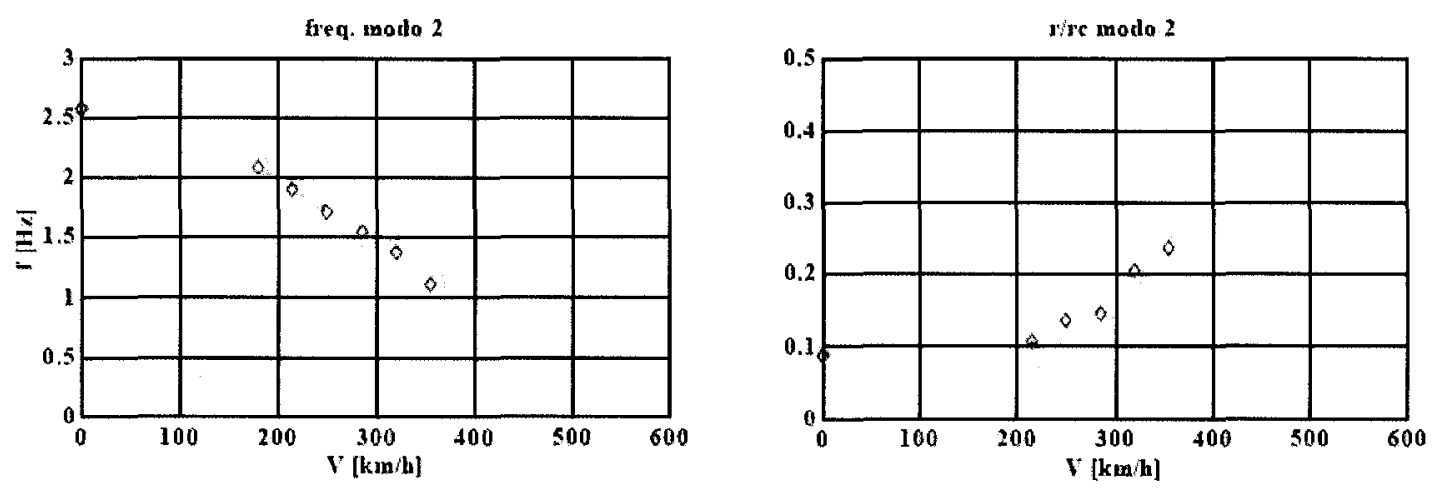

Figure 5: Frequency(left) and damping ratio(right) varying with speed [8].

The conclusion of the project is that comfort and handling characteristics are both strongly affected by the aerodynamic non-steady and lateral wind forces, and that the use of a dynamic analysis program implemented with the aerodynamics of a car could be a useful tool.

Passmore and Mansor [9] used an oscillating model testing rig with a single degree of freedom yawing motion, and measured the angular displacement of the model for different wind speeds. The experimental set-up and the geometry of the Davis model used for this project are presented in Figure 6. The tests were performed over a Reynolds number range of $4.3 \times 10^{5}$ to $1.7 \times 10^{7}$ based on the length of the model.

The objective was to determine the aerodynamic stiffness and the damping derivatives for different models to determine the effect of the slant angle by inducing an initial movement of the vehicle model. The tests were performed with different springs to modify the oscillation frequency [10]. For slant angles of zero and $40^{\circ}$, the sideforce derivative was at its maximum, and the $20^{\circ}$ slant angle model presented the 


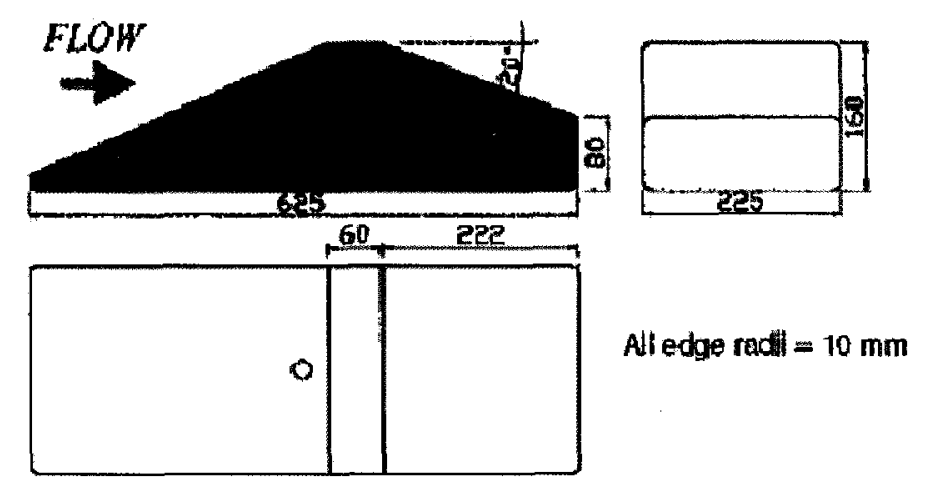

Figure 6: Davis model geometry and dimensions ( $\mathrm{mm})[9]$.

largest yawing moment derivative as seen in Figure 7.
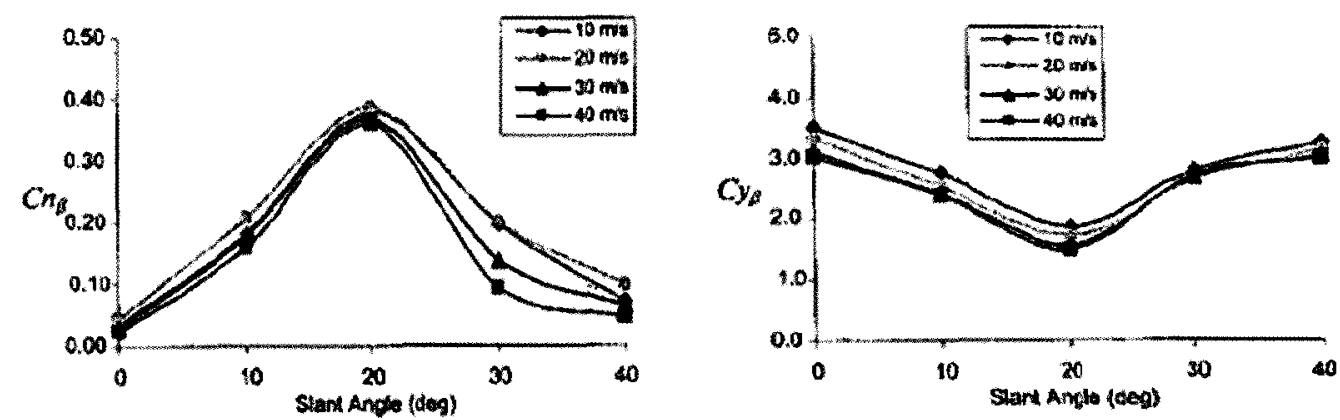

Figure 7: Static yawing moment (left) and side force (right) derivatives of a Davis model for different wind speeds [9].

For wind speed lower than the critical wind speed, the model was damped, but when it reached the critical speed, the oscillations ceased to be damped and the movement of the body was self-sustained. Passmore and Mansor [9] conclude that the unsteadiness seen in self-sustained oscillations was strongly dependent on the rear slant angle. The oscillations could not have been detected if the model had been tested with conventional methods. 


\section{Forced oscillation model in pitch and heave}

RUAG Aerospace, a Swiss company operating three wind tunnels for different application in the automotive field, has developed a freely programmable dynamic model manipulator, also called a shaker (Figure 8). By using the shaker with an internal 6-component balance, RUAG can measure the effect of model motion on the aerodynamics, effects that can be important and not predictable by pure static testing. It can also address stability issues in an unprecedented and realistic manner [11].
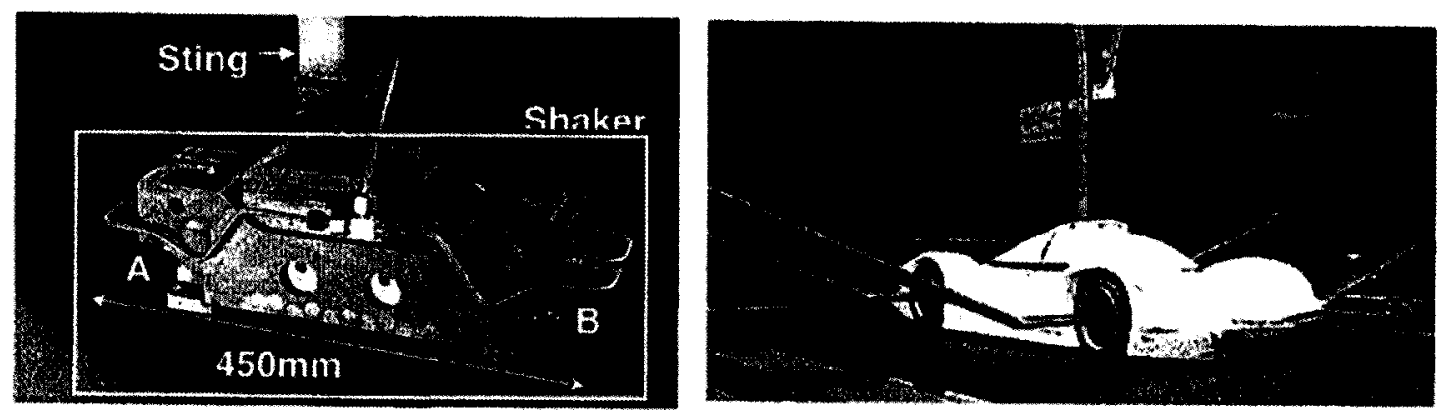

Figure 8: The two degrees of freedom shaker developed at RUAG by itself (left) and installed in a model (left) [7].

The set-up allows independent pitch and heave (vertical) motions at frequencies up to $25 \mathrm{~Hz}$ for a range of approximately $\pm 3^{\circ}$ in pitch and $\pm 10 \mathrm{~mm}$ in heave for a $30 \%$ to $50 \%$ scale model. The aerodynamic loads are separated from the inertia loads in the data reduction phase using the inertia characteristics of the model measured during a wind-off reference test [12].

RUAG has investigated the dynamic effects on the heave due to the model motion with a former LeMans type race car model. As seen in Figure 9, the lift coefficients vary differently when the ride height is increasing and decreasing. The motion affects the flow on the underbody and the diffuser, and the shape of the curve is dependant on the frequency.

The difference between the dynamic tests and the steady state tests is also affected by the frequency of the motion and the amplitude. The results show that the 

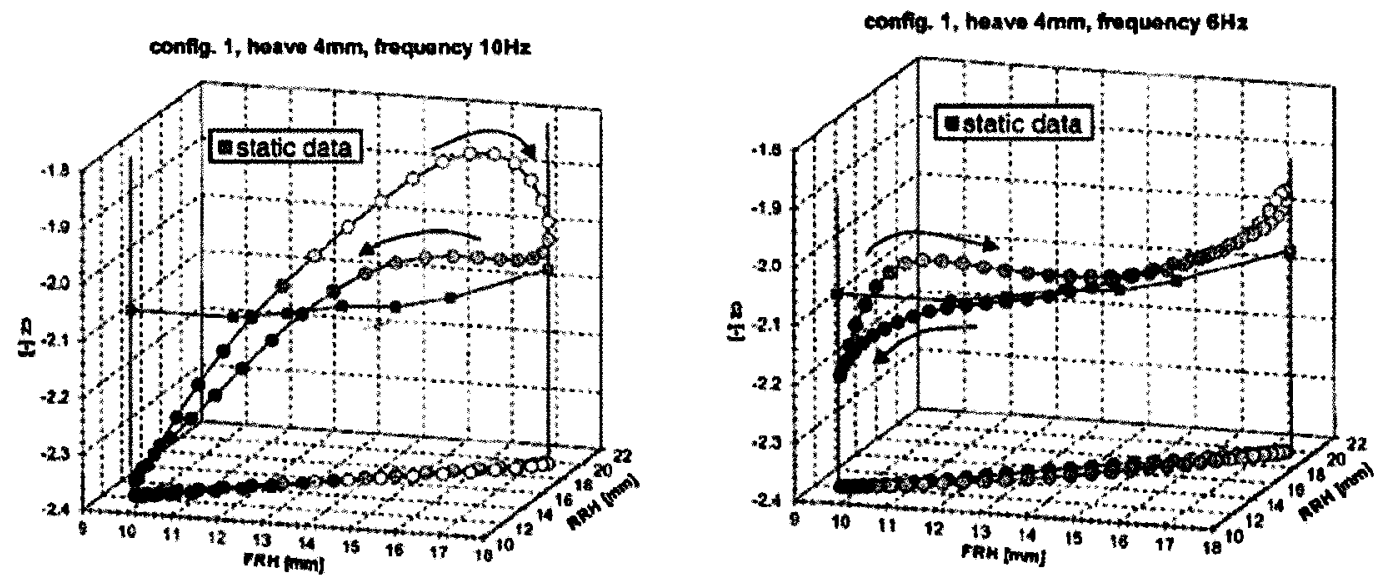

Figure 9: Lift coefficient as a function of the ride height for one period at $10 \mathrm{~Hz}$ (left) and $6 \mathrm{~Hz}$ (right) [7].

effects due to the moving model are important, and that better optimization of the aerodynamics could be taken further with the shaker than with static tests only. It is important to mention that the tests performed with the shaker result in a large amount of data [7]. To the author's knowledge, the method is still at an experimental stage and is not yet routinely used in wind tunnel testing of race cars.

\section{Forced oscillation model in yaw}

Ferrand et al [13] studied the instability of a ground vehicle in an unsteady crosswind. To represent experimentally the response of the vehicle to a lateral wind gust, they imposed an oscillation movement in yaw to the model in a steady wind. The oscillation movement was quasi sinusoidal from $-10^{\circ}$ to $10^{\circ}$. They observed a Strouhal number of 0.07 for the vehicle form investigated (see Figure 10). The Strouhal number is a dimensionless quantity relating the frequency of shedding of the vortices to the velocity of the flow, and a characteristic dimension of the body - in this case, its length. 


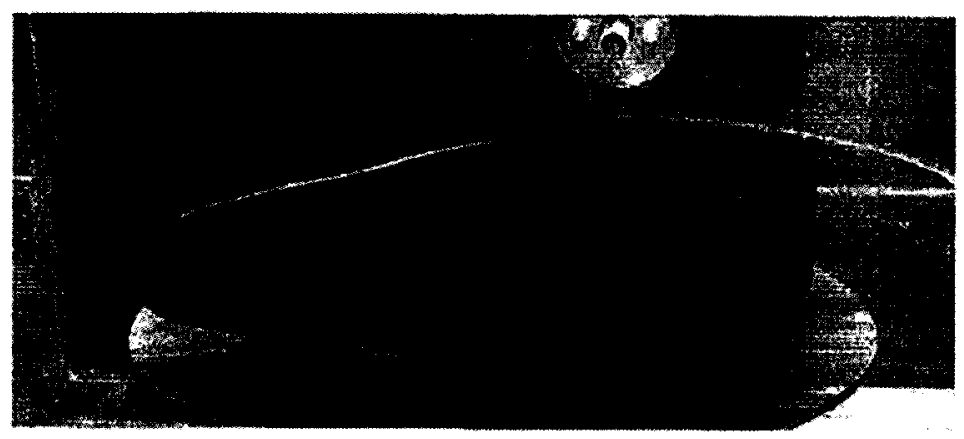

Figure 10: Simplified car model mounted on the rotating platform [13].

Using Particle Image Velocimetry (PIV) techniques, they surveyed the wake behind the model. One of their conclusions can be observed during a dynamic movement backward and forward, where the velocity field is very different depending on the orientation of the movement for the same angle of the model. A rotational structure induced after reaching an extremity of the movement will stay in the return wake longer than in the static case, creating a phase lag and a non-symmetry on the velocity field at an angle of $\beta=0^{\circ}$ (Figure 11).

Chomedon et al. [14] also succeeded in reconstituting films of the unsteady tomographies of total pressure (Figure 12). Tomography is an imaging technique which gathers projection data from multiple directions, and feeds it into a computer to observe a specified section or area. Once again, the presence of hysteresis and phase shifting phenomena can be observed.

The tests performed by Chometon and his colleagues show that a quasi-steady approach cannot be used to study the behaviour of a vehicle in the presence of an unsteady crosswind. They conclude that it is the aerodynamics engineer's responsibility to determine if static measurements are sufficient in a given situation, or if dynamic measurements will be needed for the analysis of the stability behaviour. 


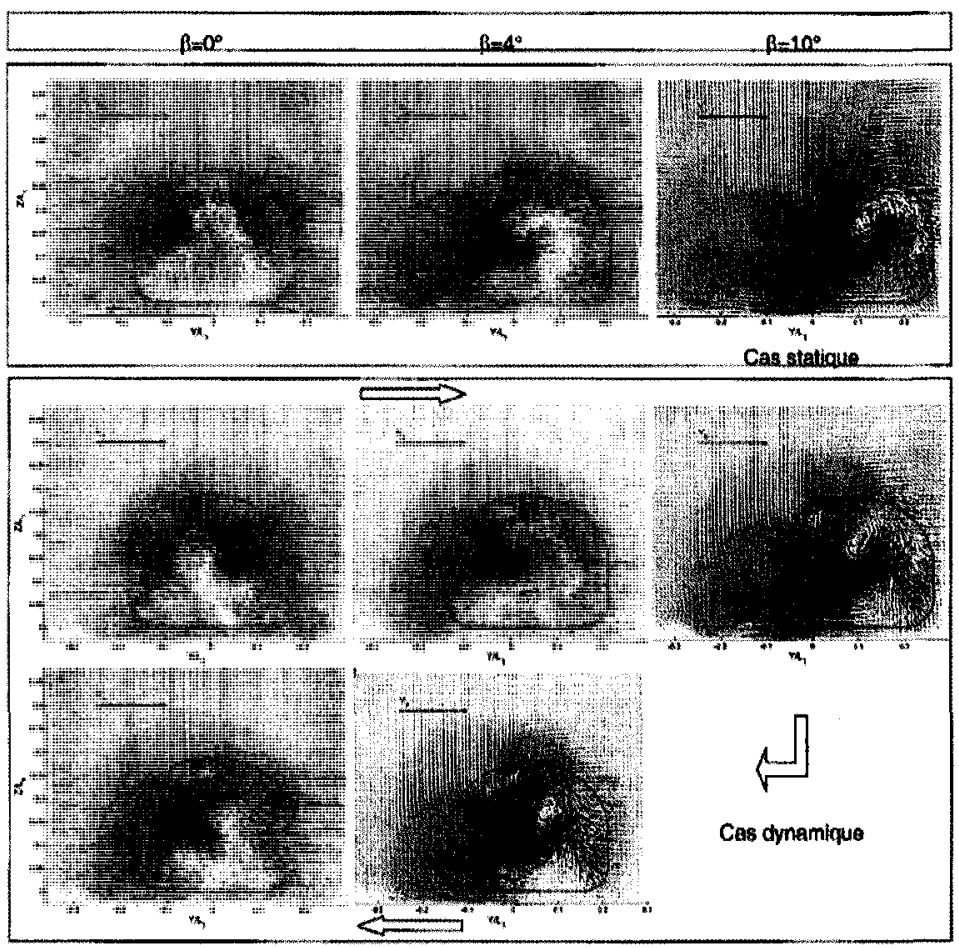

Figure 11: Crossflow fields at $X / L=0.36$. Comparison between the static and $d y-$ namic results [13]. 

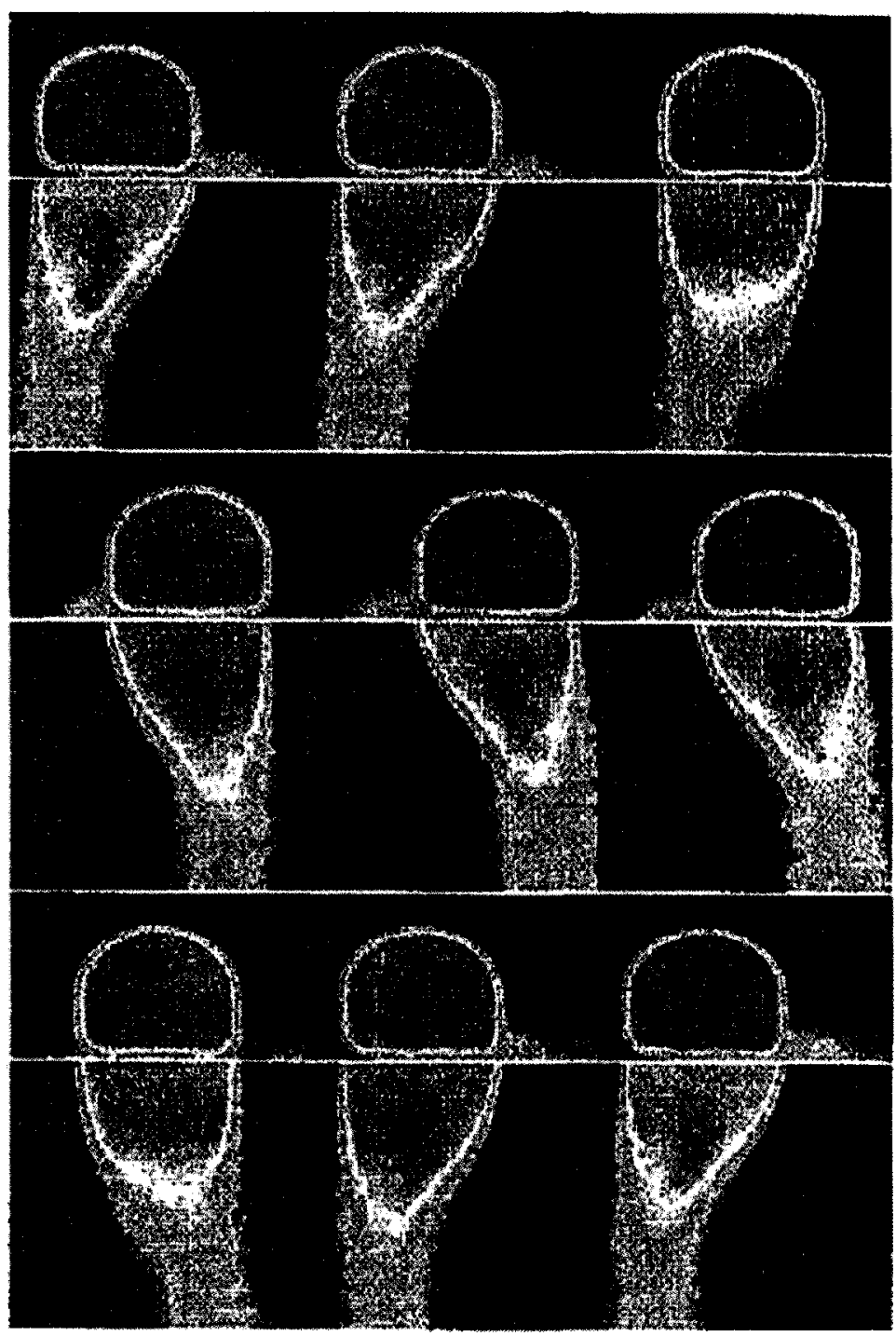

Figure 12: Unsteady tomographies of total pressure (From left to right, top to bottom) [14]. 


\subsection{Objectives}

The drivability of a car is affected by three interdependent factors:

- vehicle aerodynamics;

- vehicle dynamics;

- driver behaviour.

It is well known that the driver has an influence on the response of the vehicle to an aerodynamic input [15]. However, in this study, the focus was put on the aerodynamic forces affecting the vehicle. If the aerodynamic forces cannot be completely removed, their impact can at least be reduced.

This research was aimed at determining if unsteady aerodynamic forces exist around an Ahmed body. If their presence was detected, the objective included determining which type of forces were present and if the unsteady forces were due to an instability in the wake or if they were motion-induced forces.

To achieve these objectives, tests were performed on a free-to-respond model in the $5 \mathrm{~m}$ Vertical Wind Tunnel of the National Research Council Canada (NRC) where the displacement of the model was measured in the respective degrees of freedom of the oscillation and the aerodynamic damping and stiffness of the model was determined. In the second phase of the study, a stationary test was performed to measure the steady-state forces and moment applied on the body as well as high frequency surface pressure measurements to quantify the unsteady variations of the aerodynamic force coefficient with time. The tests for this second phase were conducted in the $2 \mathrm{~m} \mathrm{x} 3 \mathrm{~m}$ Wind Tunnel at NRC.

Subsequently, a dynamic model of the Ahmed body mounted on springs was developed using the different parameters measured during the two phases of the experimentation. It allowed drawing conclusions on the type of unsteady aerodynamic forces 
present and led to a proposed experimental and/or numerical modeling approach.

This thesis presents a detailed account of the work done during this study. Chapters 2 and 3 will present the experimental set-up and results of aerodynamics measurements and associated analysis. In Chapter 4, a dynamic model based on the data acquired during the experimentations will be defined and analyzed. Discussion and conclusions are provided in Chapter 5. 


\section{Chapter 2}

\section{Non-stationary tests}

The first stage of this study was to perform non-stationary tests in the $5 \mathrm{~m}$ Vertical Wind Tunnel at the NRC using a reference model that has been used throughout the entire project.

\section{$2.1 \quad$ Model}

\subsubsection{Reference model}

The reference models referred to as "simple bodies" in the literature have proved to be very useful in the understanding of fundamental flow phenomena relating to automobiles, from the control of drag to the use of a diffuser [16]. They are commonly used for their simplicity, ease of set-up, and the ability to accommodate systematic shape changes.

Throughout this project, the Ahmed body was used. As shown in Figure 13, the model consists of three parts: a fore body with rounded edges to separate a free flow over the surface, a mid section with a constant rectangular cross section with sharp edges, and a rear end with a base slant.

This shape has been developed to generate the essential features of the flow field 


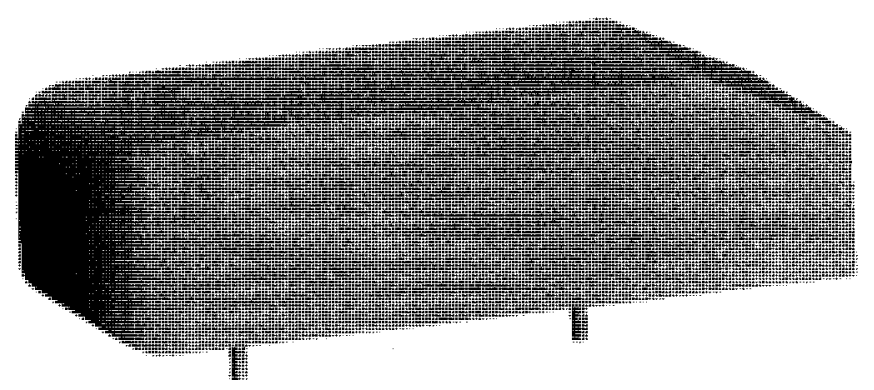

Figure 13: Geometry of the Ahmed reference model.

around a vehicle. It generates a strong three-dimensional displacement flow in the front, a relatively uniform flow in the mid section, and a large structured wake. The influence of the rotating wheels, the passenger and engine compartments, and the rough underside have been neglected to simplify the research.

This model has been chosen because it has been used for 25 years and there are extensive data available in the literature. It provides the same flow regime as a production car even if the Ahmed body is slightly longer and thinner than family-car proportions.

\section{Model geometry}

To perform our investigation, we used a 1:10 scale Ahmed body with a $25^{\circ}$ base slant angle. This angle is smaller than the critical backlight angle of $30^{\circ}$ where Ahmed et al [3] observed a high drag value. At a $25^{\circ}$ base slant angle, the flow is still stable compared to the flow at the critical backlight angle. The $25^{\circ}$ base slant angle is thus more representative of the aerodynamics of modern cars.

The model, as shown in Figure 14, is $41.8 \mathrm{~cm}$ long, $11.5 \mathrm{~cm}$ high, and $15.6 \mathrm{~cm}$ wide. The front edges are rounded with a radius of $4 \mathrm{~cm}$. The slanted part is $8 \mathrm{~cm}$ long by $3.8 \mathrm{~cm}$ high, resulting in an angle of $25.4^{\circ}$. The ground clearance is $2 \mathrm{~cm}$. The four supports are $18.8 \mathrm{~cm}$ apart, $6.5 \mathrm{~cm}$ from the centre line with the front support 

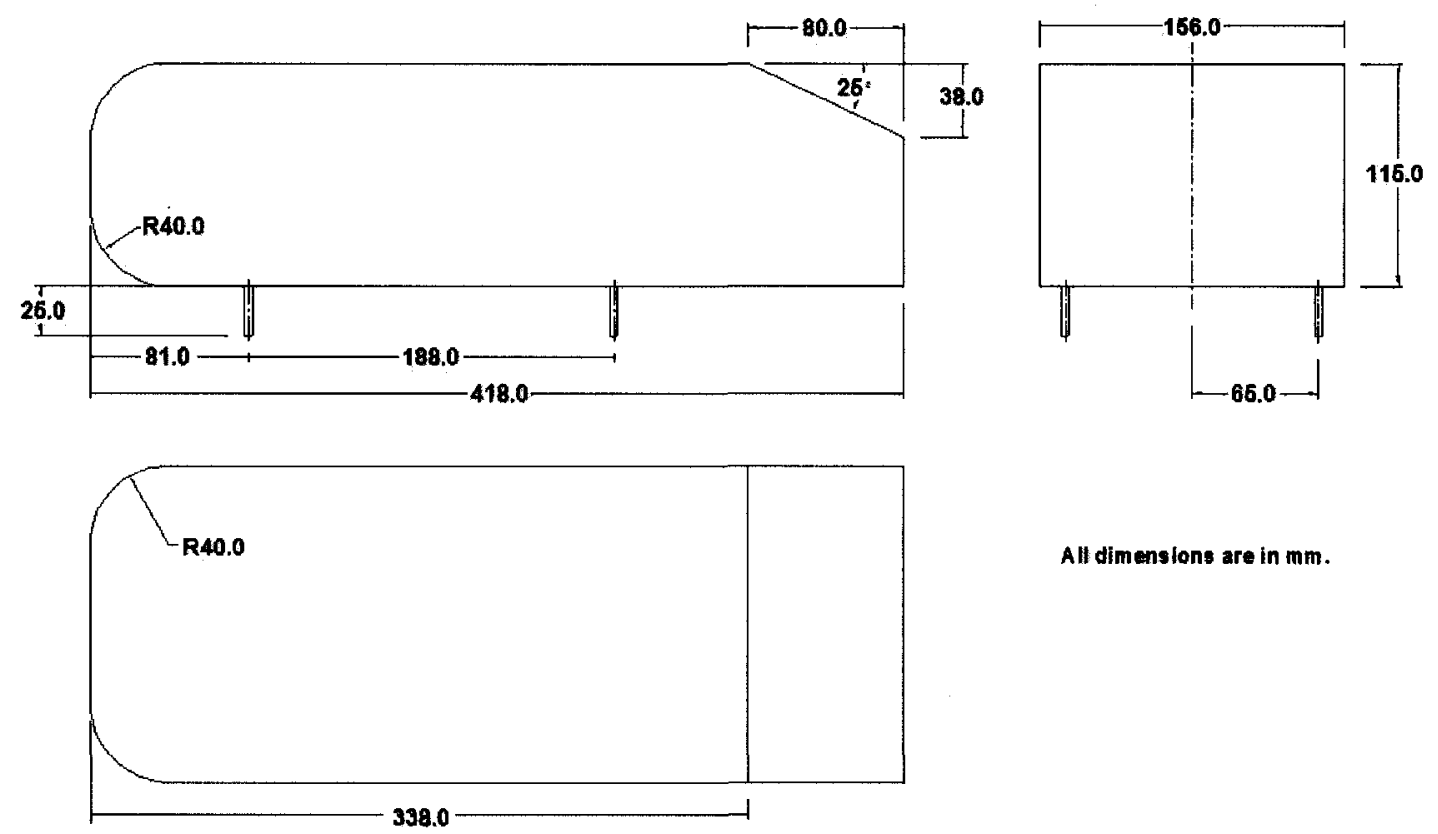

All dimenstons are in $\mathbf{m m}$.

Figure 14: Ahmed reference model (1:10 scale) dimensions in mm.

placed $8.1 \mathrm{~cm}$ from the front of the model.

\subsubsection{Manufacturing of the model}

The model for the non-stationary test is made of low density foam to minimize the weight as much as possible. The foam was covered with a layer of glazing putty to fill up the porosities and the inequalities on the surfaces. To obtain a uniform surface finish, the model was painted.

The final model weighted 458 grams. This really light weight was selected to obtain a larger dynamic response for an equal aerodynamic force and does not represent the mass of a 1:10 scale model of a car. Following dimensional analysis [17], a model mass representative of a full scale car would be $1 / 10^{3}$ smaller. For a $1300 \mathrm{~kg}$ production car, the 1:10 scale model mass would be approximatively 1300 grams. 


\subsection{Experimental set-up}

\subsubsection{Wind tunnel}

The NRC's $5 \mathrm{~m}$ Vertical Wind Tunnel facility, that was used to perform the nonstationary tests, is also called a spin tunnel and was originally used to observe the characteristics of aircraft in free flight spin. Visual observation of flutter and flight instability was performed in this wind tunnel as early as in the 1950's.

The NRC's $5 \mathrm{~m}$ Vertical Wind Tunnel is a closed return wind tunnel with a sixbladed fan with fixed pitch powered by a 450 HP DC electric motor. This wind tunnel can be operated with an open round test section $5.6 \mathrm{~m}$ in diameter or as an open or closed rectangular test section of $2.13 \mathrm{~m} \times 3.05 \mathrm{~m}$. In its closed test section configuration, the wind tunnel can achieve speeds up to $21 \mathrm{~m} / \mathrm{s}$ [18]. The closed test section has been chosen to provide a support to the experimental set-up and to reproduce the effect of the proximity between the ground and the model. There is no force balance installed in this wind tunnel.

The turbulence grid was removed from the wind tunnel to obtain a low turbulence intensity $(0.5 \%)$ of the same order as the turbulence intensity in the NRC's $2 \mathrm{~m} \mathrm{x}$ $3 \mathrm{~m}$ Wind Tunnel, where the stationary tests subsequently presented in Chapter 3 were performed.

\subsubsection{Experimental model set-up}

The general objectives of the experimental set-up of the non-stationary tests were to suspend the model on springs to allow the model to respond freely and linearly to the forces applied to it and to remove the effect of gravity, since the forces due to gravity were expected to be of a much larger order than the forces applied by the flow. The governing assumption for these experiments is that the unsteady aerodynamic forces 
and the motion induced forces are functions of the model geometry only and can be depicted for a model of any mass and any oscillation frequencies. This assumption has been verified in many instances in the context of bridge aerodynamics [19].

In the wind tunnel, the flow is displaced vertically. The suspension system held the model pointing downwards using a long steel wire attached to the top frame of the walls of the wind tunnel and four springs. Figure 15 shows the degrees of freedom of the system.

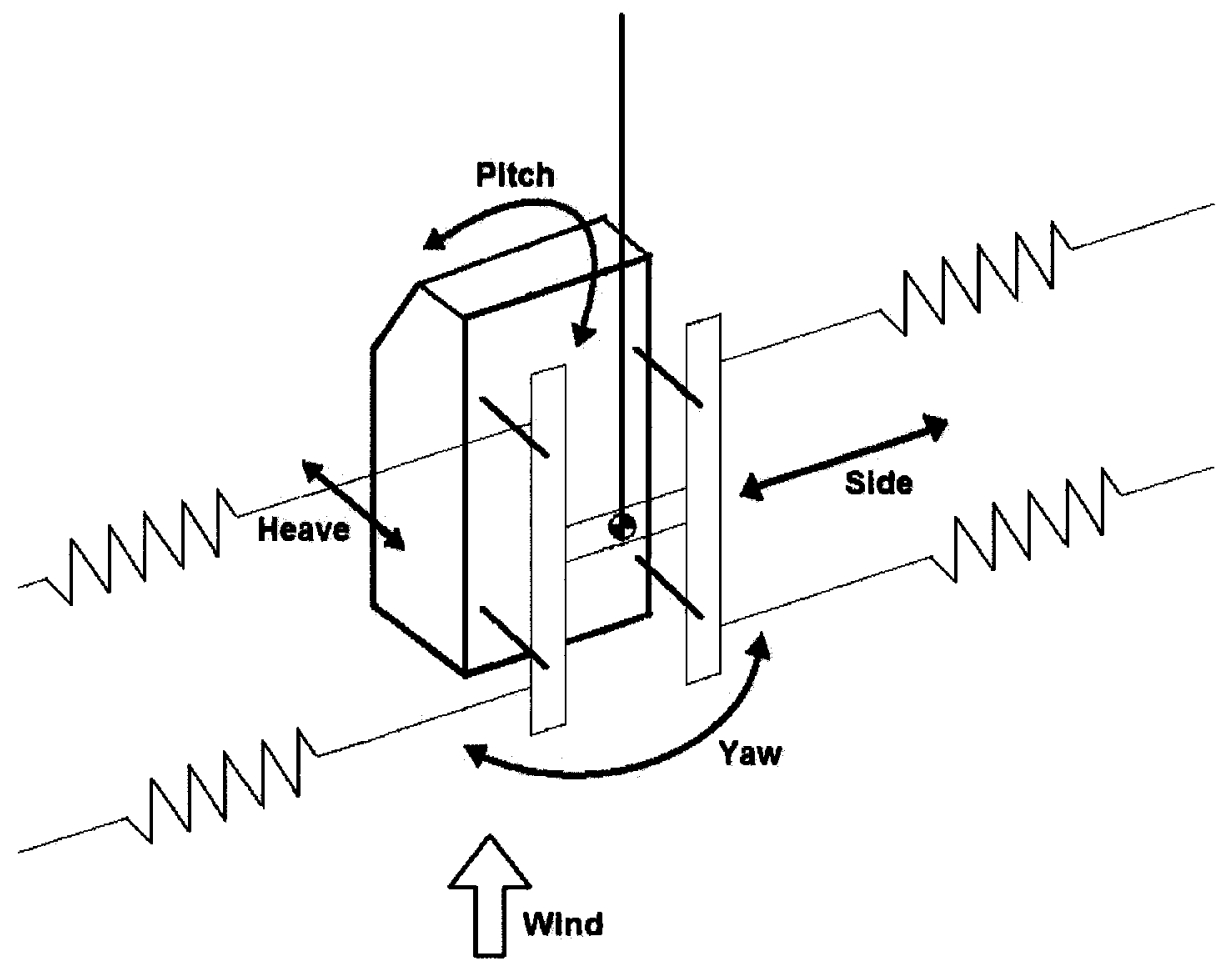

Figure 15: Diagram of the forces and moments on the vertical model.

The Ahmed body had to be the only part of the set-up inside the wind tunnel test section to avoid interference in the flow or an increased aerodynamic force on the set-up. Therefore, the reference model was mounted on rods, through the plexiglass windows of the Vertical Wind Tunnel and attached to an H-shaped $3 \mathrm{~mm}$ thick aluminum 6061 support as shown in Figure 16. The central member of the support 
was also used to support the additional weight needed to control the position of the centre of gravity in pitch.

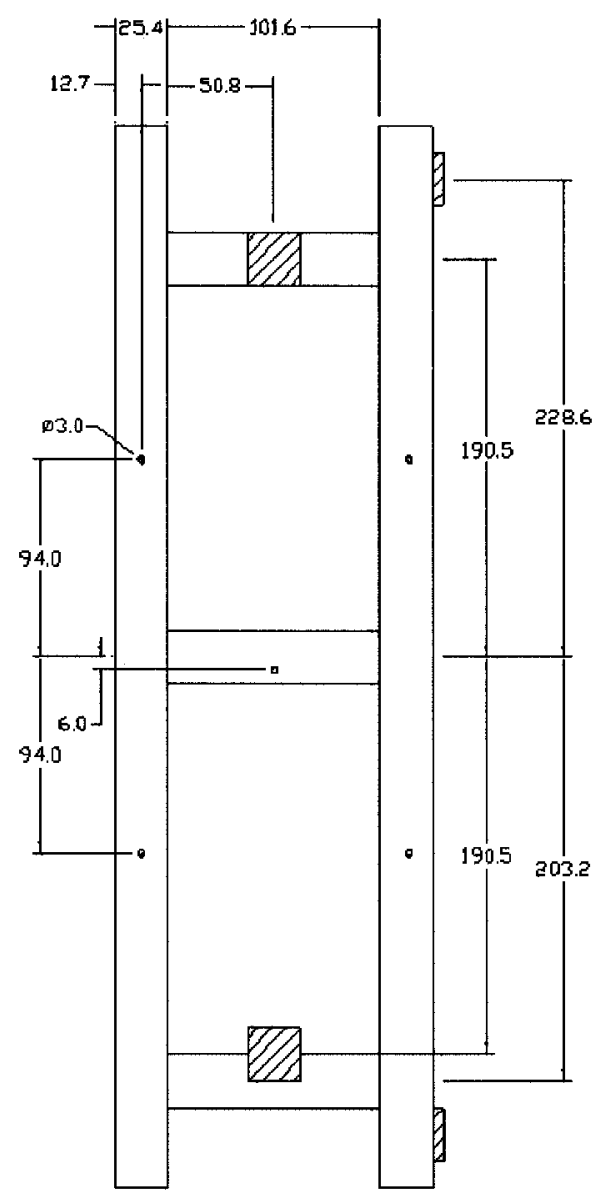

Figure 16: H-shape support of the model. Dimensions are in $\mathrm{mm}$. The hatched area indicates the position of the laser displacement transducer target.

The second part of the set-up had to be an apparatus, outside of the wind tunnel test section, to which the model could be attached. A $1.83 \mathrm{~m}$ diameter ring, made of $38 \mathrm{~mm}$ diameter steel tube, $3 \mathrm{~mm}$ thick, was installed on three pulleys on the North wall of the wind tunnel. On this ring, two parallel L-bars were fastened, $1.5 \mathrm{~m}$ apart as shown in Figure 17. Four springs were attached to the L-bars to link the aluminum support of the model to the wall set-up. The spring tension was adjusted 
using stainless steel lock wire and eye-with-hook turnbuckles. The spring tension was adjusted to ensure a restraining force linearly proportional to the displacement to avoid non-linear effects related to the sagging of the springs as described in [17].

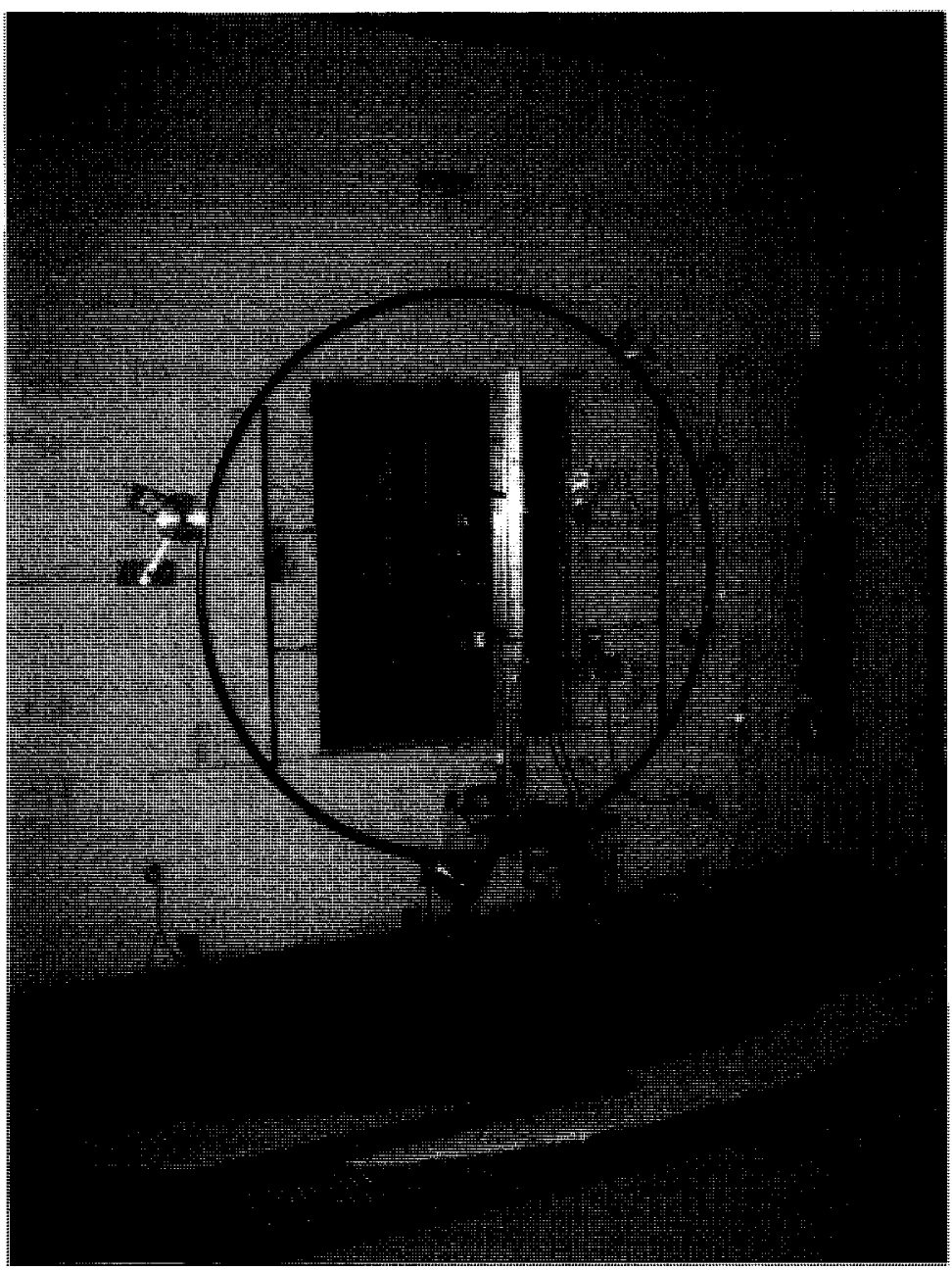

Figure 17: View of the spring suspension system attached to the $1.83 \mathrm{~m}$ steel ring mounted to the outside of the $5 \mathrm{~m}$ Vertical Wind Tunnel test section wall.

\subsubsection{Springs selection}

The selection of the springs on which the model was mounted had many objectives. It allowed the selection of the frequency at which the model was excited in side 
movement. The distance between the attachment points of the springs was also determining the frequency of the yawing motion. To obtain a smooth sinusoidal signal, four springs with the same spring constant had to be chosen and installed as shown in Figure 18.

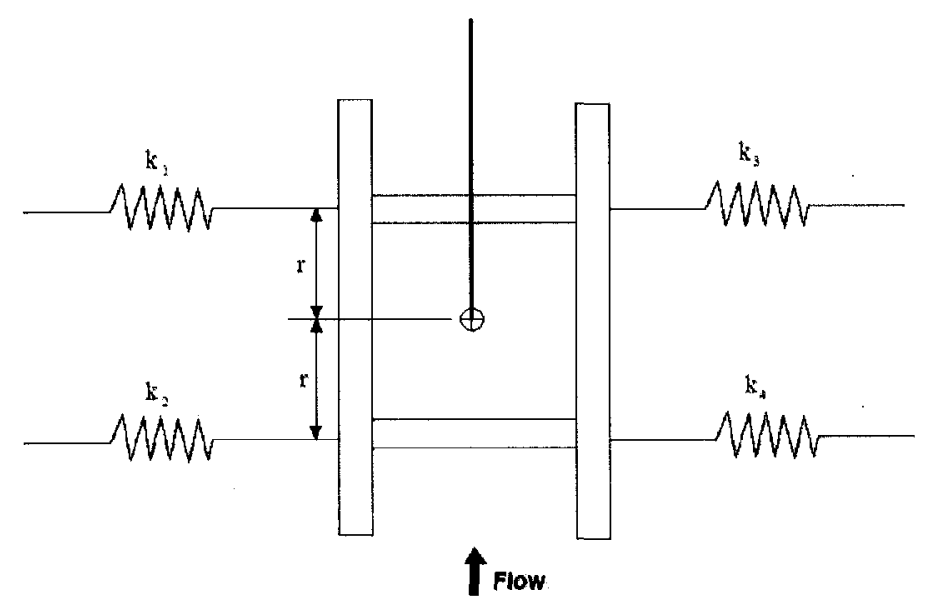

Figure 18: Sketch of the installation of the springs on the model.

The targeted frequencies were $1.5 \mathrm{~Hz}$ in side and $1.7 \mathrm{~Hz}$ in yaw. It has been impossible to find precise information on the excited frequencies and the frequency ratio between side motion and yawing motion of a real car, therefore the frequencies have been estimated based on observations. Given that for these experiments the frequencies of oscillation could be arbitrary chosen, the approach taken was to select a suspension rig stiffness that would allow the observations of wind induced vibrations of the model (if any) in the $5-18 \mathrm{~m} / \mathrm{s}$ wind speed range of the wind tunnel.

The spring constant of the springs, $k_{T}$, was determined using the targeted frequency in side motion, $f$, and the mass, $m$, of the system:

$$
k_{T}=m \omega^{2}
$$

where $\omega$ is the frequency in $\mathrm{rad} / \mathrm{s}$ obtained from 


$$
\omega=2 \pi f
$$

The moving mass consists of the mass of the model, including the mass of the H-support (900 grams) and one-third of the mass of the springs (112 grams) for a total of $1.012 \mathrm{~kg}$.

The springs are positioned in parallel, therefore the equivalent spring constant for the four springs can be defined as:

$$
k_{T}=k_{1}+k_{2}+k_{3}+k_{4}
$$

In order to obtain a smooth sinusoidal movement of the model, the two springs on the same side of the model had to have the same spring constant. To simplify the set-up, the four springs used simultaneously were identical. Therefore, using the Equations (1) and (3), it was possible to calculate the spring constants for the springs to be $22 \mathrm{~N} / \mathrm{m}$ each.

$$
k_{1}=k_{2}=k_{3}=k_{4}=22 \mathrm{~N} / \mathrm{m} \text {. }
$$

The spacing between the attachment points on both sides of the H-support, shown as $r$ in Figure 18 was determined by the frequency in yaw of the system. The relationship is governed by:

$$
\omega_{\theta}^{2}=\frac{k_{\theta}}{I_{\theta}}
$$

where

$$
k_{\theta}=k_{T} r^{2}
$$

and 


$$
I_{\theta}=J
$$

Combining Equations (5) through (7):

$$
r=\sqrt{\frac{\omega^{2} J}{k_{T}}} .
$$

Therefore, $r$ is dependant on the equivalent spring constant, the yawing frequency and the mass moment of inertia of the model, $I_{\theta}$. To evaluate the mass moment of inertia of the model, a simple experiment was conducted based on the torsional pendulum principle described by

$$
J=\frac{m g b^{2}}{l}\left(\frac{T_{0}}{2 \pi}\right)^{2}
$$

where:

- $m$ is the mass of the model, including the mass of the suspension system;

- $g$ is the gravitational acceleration;

- $b$ is the distance between the centre of rotation and the wires, holding the model;

- $l$ is the length of the wires holding the model; and

- $T_{0}$ is the period for one oscillation cycle around the vertical axis.

The variables $b, l$ and $T_{0}$ are dependant of the experimental set-up as presented in Figure 19.

The experiment consists in inducing a rotational oscillation around the vertical axis and measuring the time required by the model to go through a fixed number of cycles. The test was repeated seven times, each repetition including between 8 and 20 cycles to evaluate the effect of the damping. This effect was minimal since the moment of inertia varied only by a maximum of $0.5 \%$ over 7 repetitions. 


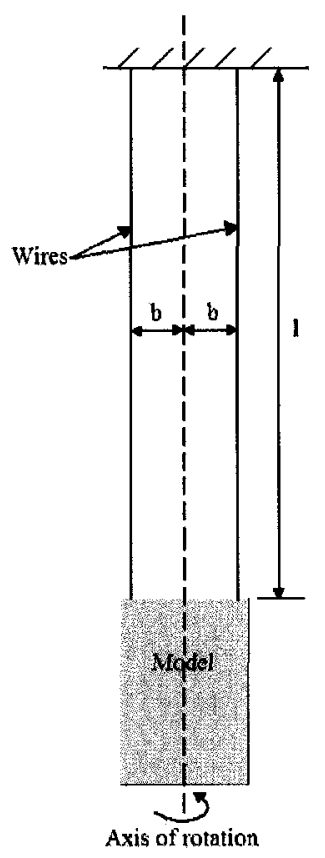

Figure 19: Experimental set-up for the determination of the mass moment of inertia.

The following parameters were used to determine the value of the mass moment of inertia of the model, including the H-support:

- $m=0.803 \mathrm{~kg}$

- $b=0.063 \mathrm{~m}$

$\bullet l=1.372 \mathrm{~m}$

- $T_{0}=5.2$ seconds.

Therefore, the mass moment of inertia of the model determined with this method was $0.0159 \mathrm{~kg} \cdot \mathrm{m}^{2}$. It has been compared with the mass moment of inertia calculated in the model analysis of the three-dimensional drawing software, Pro-Engineering (Pro-E). The mass moment of inertia of the model analysis was $0.0139 \mathrm{~kg} \cdot \mathrm{m}^{2}$. The difference between the two results of $12.7 \%$ can be explained by a possible difference 
in the theoretical and real density of the foam and the fact that the software doesn't consider the glazing putty and the paint added on the model to obtain a nice finish. The Pro-E model included the Ahmed body and the H-support.

Using the mass moment of inertia obtained experimentally and replacing in Equation (5) $\omega, k_{\theta}$ and $I_{\theta}$ with Equations (2), (6) and (7), a new equation can be formulated

$$
(2 \pi f)^{2}=\frac{k_{T} * r^{2}}{J}
$$

For the given frequency in yaw, $1.7 \mathrm{~Hz}$, the required $r$, based on Equation (10), is $0.144 \mathrm{~m}$.

\subsubsection{Springs used in the experiment}

The spring selection determined that very soft springs were needed to allow excitation of the model in the wind tunnel in the lower part of the speed range. Exploratory experiments were conducted with the very soft springs allowing motion in many degrees of freedom. It was rapidly concluded that these springs could not be used in this experiment because large displacements were induced at low wind tunnel speeds. Therefore, the range of wind speeds that could have been used would have been limited and the displacement at the top speeds would have been very large. A limited range of wind speeds can make data acquisition at different steps of the response more difficult because changes will occur rapidly and drastic variation can be observed. Very large displacements are not desirable at relatively low wind speed because they can result in contact between the wall and the model. Also, the hypothesis that the system is linear is only valid for small displacements.

For all these reasons, stiffer springs were used during the wind tunnel tests, with the same frequency ratio as the one obtained with the two initial frequencies targeted. The characteristics of the springs are presented in Table 1. 
Table 1: Specifications of the springs

\begin{tabular}{|c|c|}
\hline Part & McMaster number 9654K456 \\
\hline Material & Steel Extension spring zinc-plated \\
\hline Length & $203 \mathrm{~mm}\left(8^{\prime \prime}\right)$ \\
\hline Outside Diameter & $5.15 \mathrm{~mm}\left(13 / 64^{\prime \prime}\right)$ \\
\hline Wire Diameter & $0.66 \mathrm{~mm}\left(0.026^{\prime \prime}\right)$ \\
\hline Load & $16.06 \mathrm{~N}(3.61 \mathrm{lbs})$ \\
\hline Deflection @ load & $203 \mathrm{~mm}\left(8^{\prime \prime}\right)$ \\
\hline Initial tension & $2.89 \mathrm{~N}(0.65 \mathrm{lb})$ \\
\hline Spring constant & $64.7 \mathrm{~N} / \mathrm{m}(0.37 \mathrm{lb} /$ inch $)$ \\
\hline Weight & $11.1 \mathrm{gram} / \mathrm{spring}$ \\
\hline
\end{tabular}

The expected frequencies, using the springs of Table 1 and the equations from Section 2.2.3, were $2.57 \mathrm{~Hz}$ for side motion and $2.94 \mathrm{~Hz}$ in yaw, with $r$, the distance between the attachment point of the spring and the centre of rotation still at $0.144 \mathrm{~m}$. The frequency ratio was preserved, decreasing by only $0.94 \%$ from 0.882 to 0.874 , the ideal spring case.

\subsubsection{Instrumentation}

The instrumentation used to perform the non-stationary test in the $5 \mathrm{~m}$ Vertical Wind Tunnel was, for most part, the standard equipment of the wind tunnel. The dynamic pressure was measured with a $1 \mathrm{kPa}$ Datametrics barocel transducer and a Pitot tube installed at the inlet of the test section. The barometric pressure was measured with a Druck transducer (DPI 261), with an accuracy of $\pm 0.04 \%$ for a range between 1 and 3.4 MPa. The total temperature was measured in the settling chamber with a resistive thermal device capable of measuring with an accuracy of $\pm 0.1^{\circ} \mathrm{C}$.

Four Micro Laser Sensors LM10 were used; two to measure the lateral displacement and two to measure the movement in heave. The displacement sensors were installed at $25 \mathrm{~cm}$ from the targets installed on the model when the model is at its initial position (see Figures 18 and 20). The measurable range was $\pm 150 \mathrm{~mm}$. The light 
source was a laser diode with a wavelength of $685 \mathrm{~nm}$. The device was used at a sampling frequency of $100 \mathrm{~Hz}$; therefore the resolution was of $\pm 500 \mu \mathrm{m}( \pm 0.5 \mathrm{~mm})$. The linearity error has a maximum $\pm 1.0 \%$. The advantage of such laser sensors was that they have a large measurable range comparatively to other laser displacement sensors.

The positioning of the Micro Laser Sensors is presented in Figure 20.

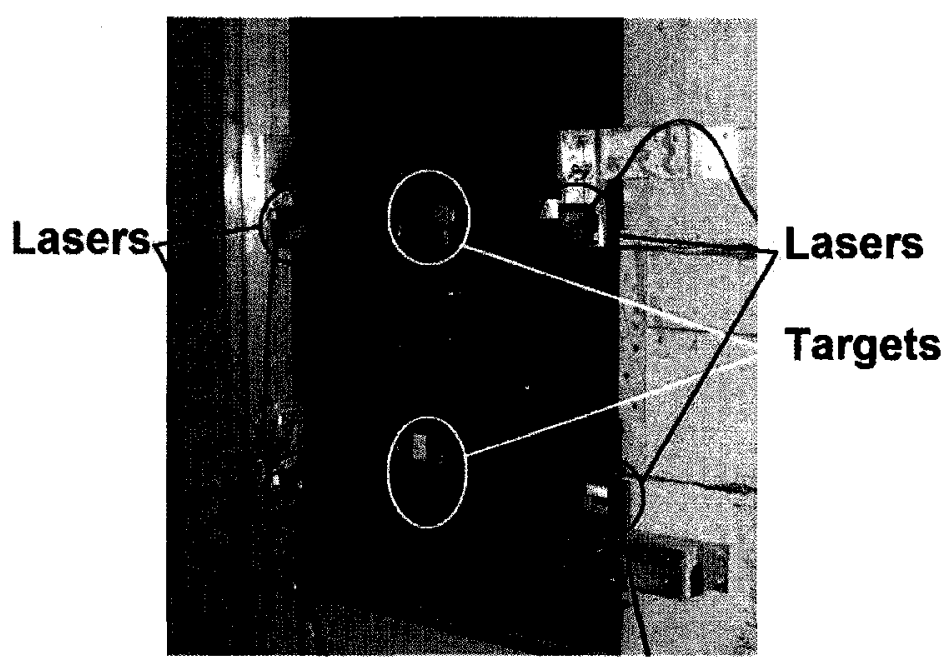

Figure 20: Positioning of the Micro Laser Sensors.

\subsection{Experimental data}

\subsubsection{Test program and procedure}

The non-stationary test was composed of five different tests performed for three different configurations. The first configuration used very stiff springs for preliminary testing. Given the large number of experimental set-up changes made during preliminary tests, this test series was not considered relevant and it is not described in this thesis. 
The two other configurations used the $64.7 \mathrm{~N} / \mathrm{m}$ springs of Table 1 . The difference between the two configurations is the position of the centres of rotation. In the first configuration, the weight used to counterbalance the weight of the model was minimal, at $260 \mathrm{~g}$, and the centres of rotation in pitch and in yaw were separated by $3.2 \mathrm{~cm}$ in the horizontal plane.

In the second configuration, the weight was increased to $1942 \mathrm{~g}$, and the centres of rotation of both the pitching and yaw motion were at the same position. By increasing the weight, the dynamics of the system were changed to allow the observation of the presence of aerodynamic excitation in roll.

Five tests were performed for the non-stationary part of the project:

1. damping traces without wind;

2. damping traces with wind;

3. build up traces with wind;

4. stabilization of the movement (to reach stationary amplitude); and

5. time histories at steady state.

The damping traces with and without wind were performed to extract the variations of aerodynamic damping and stiffness with wind speed. The build up traces qualified the energy transferred from the wind to the dynamic system. The stabilization tests were performed to determine the settling time necessary to acquire time histories at a steady state and to determine the amplitude of the movement.

Table 2 presents the different configurations tested in this part of the project.

\subsubsection{Aerodynamic damping}

The aerodynamic damping is the damping resulting from the aerodynamic forces induced by the motion of the model in a fluid in motion. This damping generally 
Table 2: Different configurations tested during the non-stationary tests. Note that tests for Configuration 1 are not reported in this thesis.

\begin{tabular}{|l|l|l|l|l|l|l|}
\hline $\begin{array}{l}\text { Configu- } \\
\text { ration }\end{array}$ & $\begin{array}{l}\text { Number } \\
\text { of D.O.F. } \\
\text { tested }\end{array}$ & Springs & D.O.F. & $\begin{array}{l}\text { Centres of } \\
\text { rotation for } \\
\text { pitch and } \\
\text { yaw }\end{array}$ & $\begin{array}{l}\text { Ballast } \\
\text { weight }\end{array}$ & $\begin{array}{l}\text { Total } \\
\text { weight }\end{array}$ \\
\hline 1 & 2 D.O.F. & $250 \mathrm{~N} / \mathrm{m}$ & $\begin{array}{l}\text { heave } \\
\text { pitch }\end{array}$ & different & $\begin{array}{l}\text { small } \\
260 \mathrm{~g}\end{array}$ & $1063 \mathrm{~g}$ \\
\hline 2 & 3 D.O.F & $64.7 \mathrm{~N} / \mathrm{m}$ & $\begin{array}{l}\text { heave } \\
\text { pitch } \\
\text { yaw }\end{array}$ & different & $\begin{array}{l}\text { small } \\
260 \mathrm{~g}\end{array}$ & $1063 \mathrm{~g}$ \\
\hline 3 & 3 D.O.F. & $64.7 \mathrm{~N} / \mathrm{m}$ & $\begin{array}{l}\text { heave } \\
\text { pitch } \\
\text { yaw }\end{array}$ & coincident & $\begin{array}{l}\text { large } \\
1942 \mathrm{~g}\end{array}$ & $2745 \mathrm{~g}$ \\
\hline
\end{tabular}

varies with wind speed, the ratio of change is a function of the geometry of the body and it is hard to determine it analytically. The aerodynamic damping is always subcritical since the damping ratio is always smaller than unity, $\varepsilon<1$.

Positive aerodynamic damping will cause the amplitude of the movement to decrease with time whereas negative aerodynamic damping will allow the amplitude of the movement of the model to increase with time.

The aerodynamic damping can be expressed as an equivalent viscous damping coefficient determined from a decay trace acquired from an initial release. A damping measure of an elementary oscillator is determined by the amplitude reduction after one cycle of vibration [20].

Even if it is possible to estimate the global damping of a system with two consecutive measurements, it is possible to increase the accuracy of the process by evaluating the damping over several cycles. After many cycles, the amplitude of the signal will have decreased more significantly and the difference in amplitude over this period of time will be more easily measured, as shown in Figure 21.

The equation to evaluate the logarithmic decrement total damping [21] is: 


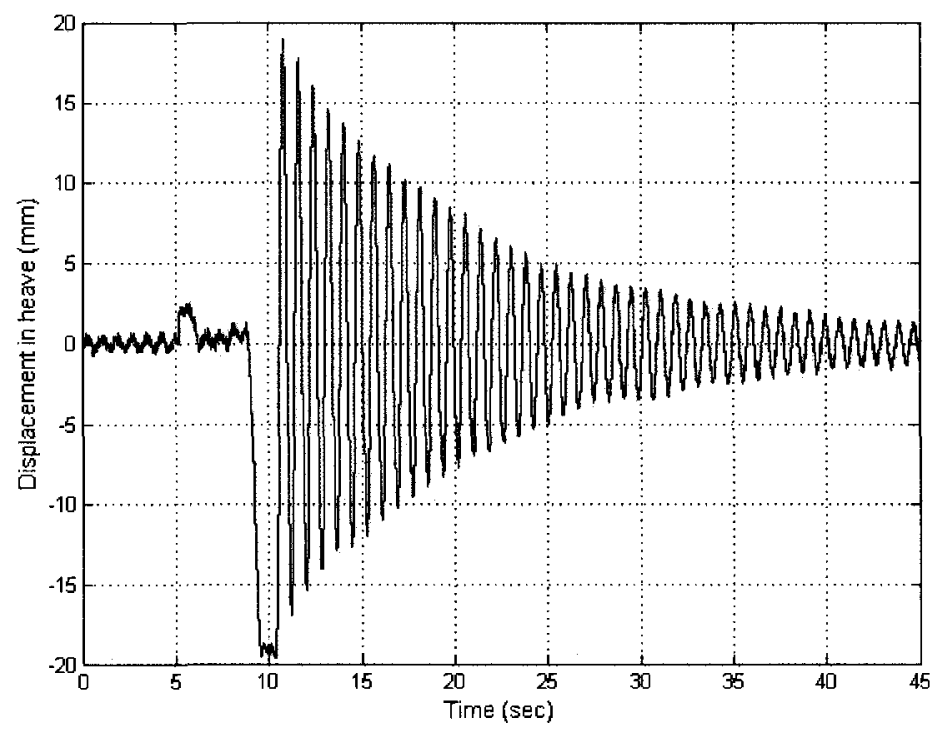

Figure 21: Decay trace in heave mode, without wind.

$$
\delta=\frac{1}{N} \ln \left(\frac{A_{0}}{A_{N}}\right)
$$

where $A_{0}$ and $A_{N}$ are the amplitude of the signal at the nominal cycle 0 and at $\mathrm{N}$ cycles later.

The total damping can also be expressed as a percentage of critical damping as follows $[20]$ :

$$
\varepsilon=\frac{\delta}{2 \pi}=\frac{1}{2 \pi N} \ln \left(\frac{A_{0}}{A_{N}}\right)
$$

The variations of total damping with wind velocity are provided in Figures 22 through 24. The total damping includes the structural damping (damping in still air) and the aerodynamic damping. Given that the structural damping can be considered constant at the amplitude of motion investigated, the variations in damping are due to the movement of the body in a moving fluid. Two cases were investigated. The small weight case represents the case when the centres of rotation are different for yaw 
and pitch; and the large weight case represents the case when the centres of rotation coincided.

For the case of heave, when the centres of rotation were not in the plane of the springs (the small weight case) the model was more unstable. The aerodynamic damping increased for speeds up to $6 \mathrm{~m} / \mathrm{s}$, but decreased rapidly for higher speeds as shown in Figure 22. The negative damping for the small weight case means that the system was unstable and there was probably coupling between the heave and pitch modes. It was difficult to obtain a pure heave mode with this set-up because the centres of rotation did not match and the length of the suspension wire was limited, creating a pendulum effect.

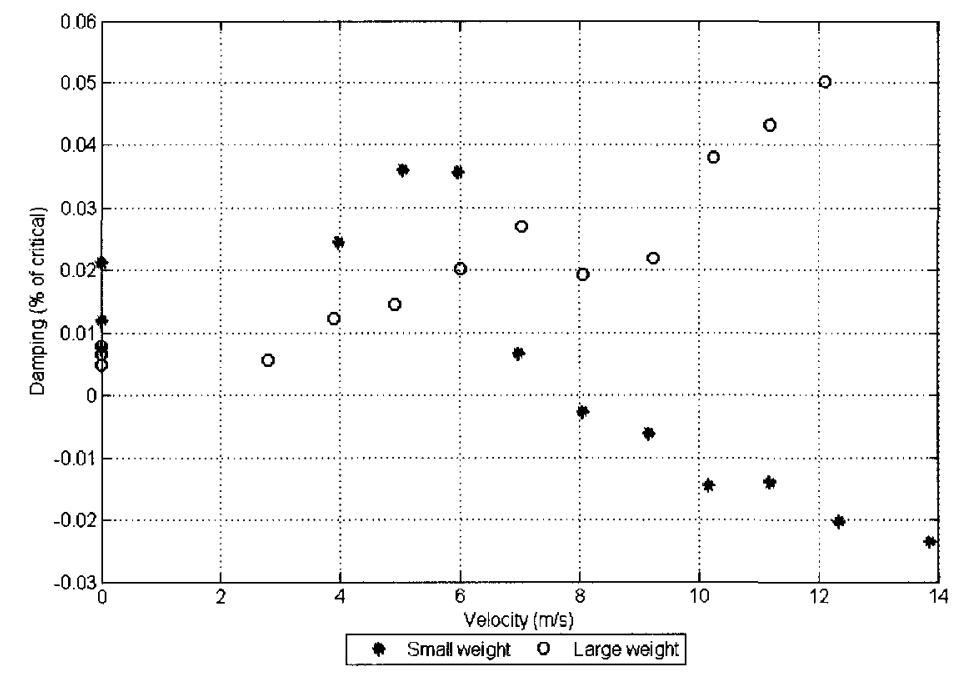

Figure 22: Variation of the total damping in heave.

The aerodynamic damping in pitch, in the case of the small weight, as shown in Figure 23, decreases between 0 and $7 \mathrm{~m} / \mathrm{s}$. For speeds higher than $7 \mathrm{~m} / \mathrm{s}$, the effect of the heave movement was visible. When the total damping in heave became negative, the movement of the model in this plane disturbed the decay traces. In the wind tunnel, the movement in pitch was often important and the model touched the wall at high speeds. When the centres of rotation coincided (in the case with the larger 
weight), the total damping in heave stayed positive and it was possible to measure the damping in pitch for higher speeds. Once again, the system was more stable with the large weight and the pitch damping stayed positive.

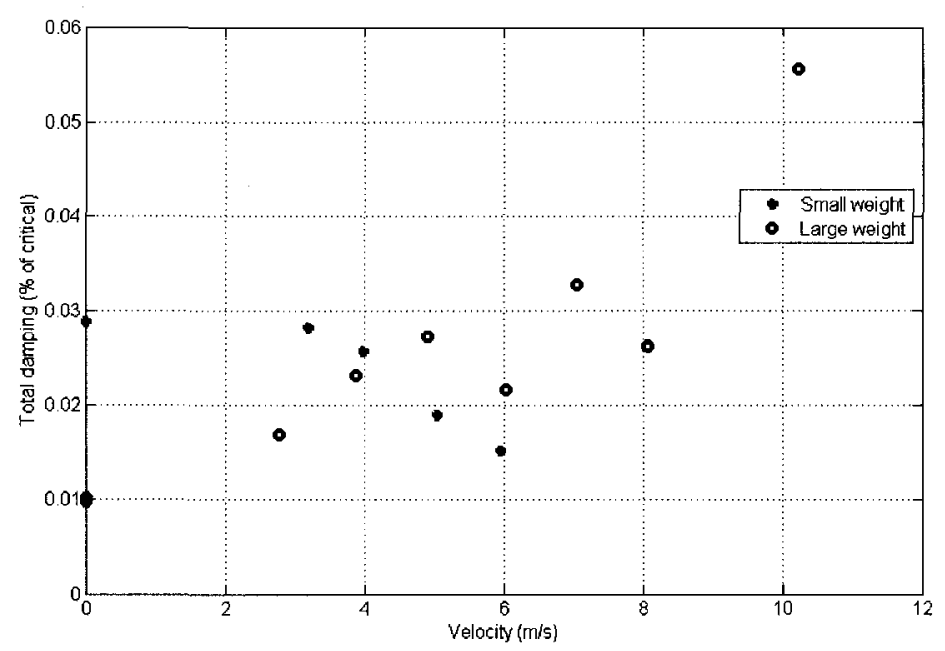

Figure 23: Variation of the total damping in pitch.

In Figure 24, the damping in yaw for the case where the centres of rotation were different slightly increased with increasing wind speed. When the centres of rotation coincided, the damping increased for speeds up to $7 \mathrm{~m} / \mathrm{s}$ and decreased after that, but always stays in the positive range.

One of the objectives when the large weight was installed on the set-up was to be able to obtain a good representation of the side-to-side motion. Even if the model was moving relatively smoothly for the observer, it was impossible to determine the total damping as a function of the wind speed. There was coupling with the yaw movement and the signal was relatively noisy, making the evaluation of the damping erratic.

It can be concluded from these damping experiments that the fluid in motion exerted a force on the Ahmed reference model that significantly affected the damping of the system. This is in agreement with the observations of Cheli et al [8] and 


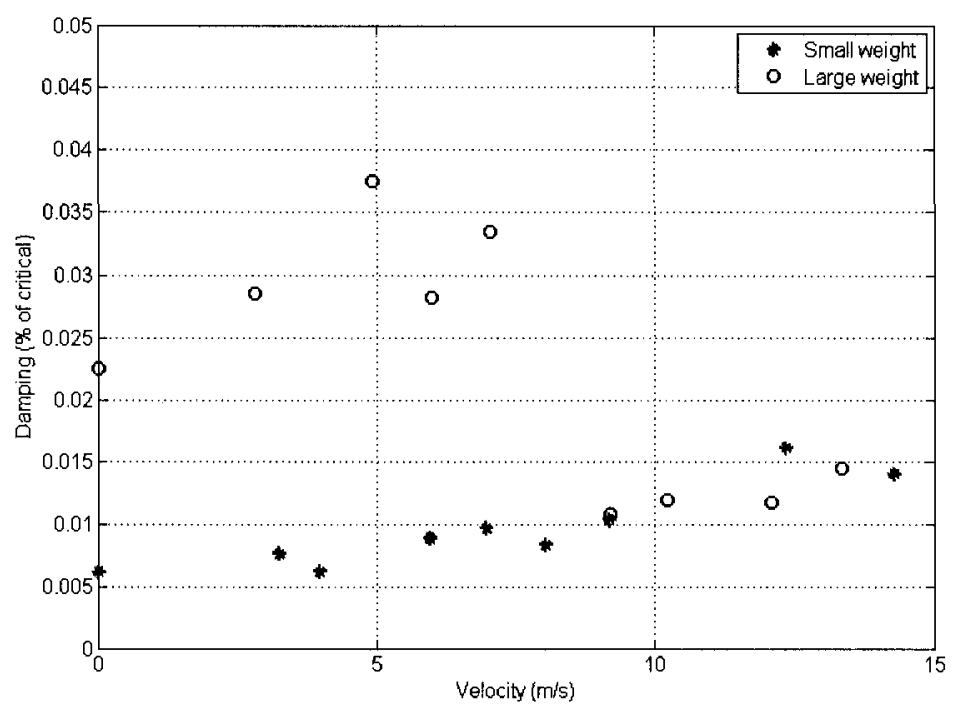

Figure 24: Variation of the total damping in yaw.

Passmore and Mansor [9] for similar bodies. 


\subsubsection{Aerodynamic stiffness}

The aerodynamic stiffness is the stiffness resulting from the aerodynamic forces induced by the motion of the model in the wind. It has the same effect on the system as changing the spring constant of a normal spring: it increases or decreases the force required to displace the model by a known distance.

The fundamental frequency of a system is a function of the structural stiffness and the mass of the system. The natural frequency of an elementary single degree of freedom linear system, comprised of a spring and mass, is defined by Equation (1).

Rearranging Equation (1), the equation to determine the structural stiffness becomes:

$$
k=\omega_{N}^{2} * m
$$

The natural frequency was determined by analysis of the decay traces

$$
\omega_{N}=\frac{1}{2 \pi} \frac{N}{\Delta T}
$$

where $\Delta T$ was the time necessary to go through $\mathrm{N}$ cycles. The natural frequencies were calculated, as often as possible, on a period of 7 cycles.

The aerodynamic stiffness of the system was found to be almost constant in heave, as shown in Figure 25 since the frequency of the oscillations did not vary much with the wind speed in both cases.

In Figure 26, it can be observed that the total stiffness in pitch decreased by approximately $20 \%$ between the two set-ups. A part of the difference between the total stiffness in the two cases could be due to the coupling between modes in the set-up. It can also be due to an increase in tension of almost all links used to suspend the model. For motion out of the plane of the springs, the stiffness $(k)$ is proportional to the tension $(T)$ in the link and inversely proportional to the length of the link 
$\left(L_{L}\right)$ :

$$
K=\frac{T}{L_{L}}
$$

Therefore, by adding a substantial mass to the model, the tension in the drag wire, supporting the weight of the model, was increased by a factor of 2.5 .

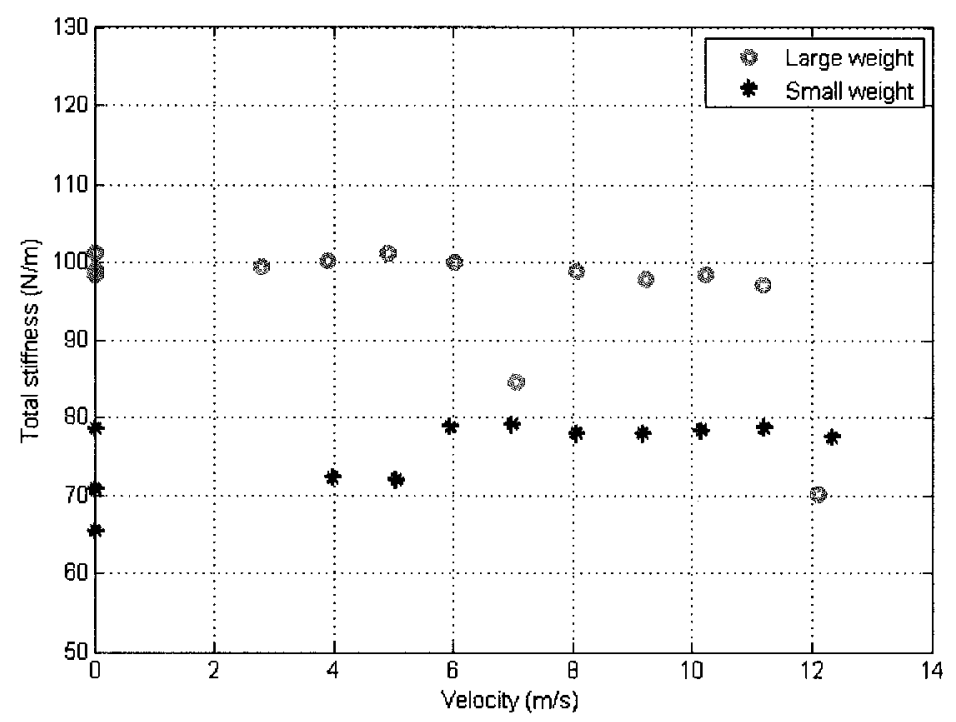

Figure 25: Variation of the aerodynamic stiffness in heave.

It was observed, in yaw (Figure 27), that the total stiffness decreased by almost $8 \%$ between 4 and $14 \mathrm{~m} / \mathrm{s}$ when the centres of rotation are different, the natural frequency decreased from $3.79 \mathrm{~Hz}$ to $3.68 \mathrm{~Hz}$. When the centres of rotation are coincident, the total stiffness decreases by $10.8 \%$ between 7 and $9 \mathrm{~m} / \mathrm{s}$.

Table 3 presents the range of natural frequencies for Configurations 2 and 3 for each degree of freedom. 


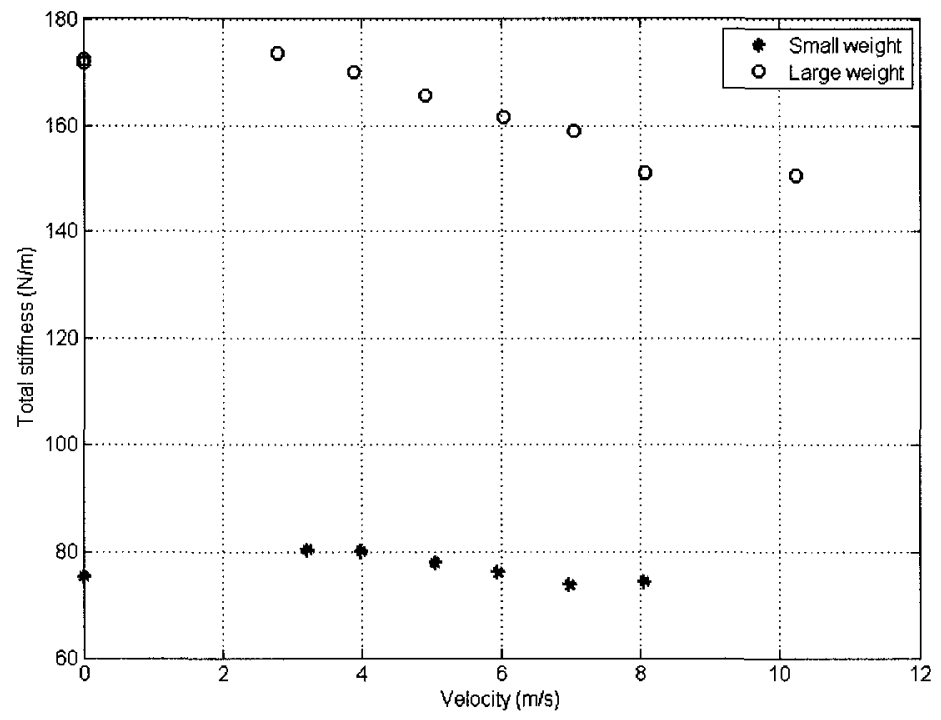

Figure 26: Variation of the aerodynamic stiffness in pitch.

Table 3: Frequencies associated with the different D.O.F.

\begin{tabular}{|c|c|c|c|c|c|c|c|}
\hline Config. & $\begin{array}{c}\text { Springs } \\
(\mathrm{N} / \mathrm{m})\end{array}$ & $\begin{array}{c}\mathrm{r} \\
(\mathrm{m})\end{array}$ & $\begin{array}{c}I_{\theta, \text { yaw }} \\
\left(\mathrm{kg} \cdot \mathrm{m}^{2}\right)\end{array}$ & $\begin{array}{c}I_{\theta, \text { pitch }} \\
\left(\mathrm{kg} \cdot \mathrm{m}^{2}\right)\end{array}$ & $\begin{array}{c}f_{\text {heave }} \\
(\mathrm{Hz})\end{array}$ & $\begin{array}{c}f_{\text {pitch }} \\
(\mathrm{Hz})\end{array}$ & $\begin{array}{c}f_{\text {yaw }} \\
(\mathrm{Hz})\end{array}$ \\
\hline 2 & 64.7 & 0.14 & 0.0159 & 0.027 & 1.22 to 1.34 & 1.39 to 1.33 & 3.83 to 3.68 \\
\hline 3 & 64.7 & 0.14 & 0.0159 & 0.014 & 0.97 to 0.95 & 1.22 to 1.18 & 1.41 to 0.52 \\
\hline
\end{tabular}

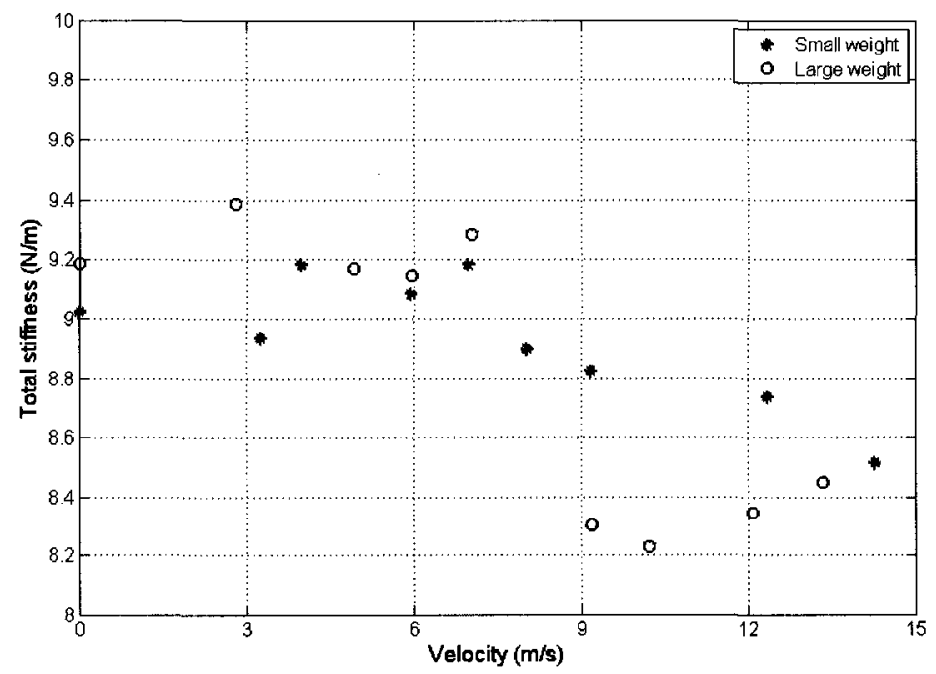

Figure 27: Variation of the aerodynamic stiffness in yaw. 


\subsubsection{Build up traces}

The build up trace tests were performed to represent the energy input to the system by the wind. This test consisted of releasing the model from the neutral position and letting the wind initiate (or not) movement of the model.

The more significant the energy input from the wind is, the steeper the slope of the envelope of the displacement curve. In Figures 28 and 29, the movements in heave and pitch are initiated at a wind speed of $7 \mathrm{~m} / \mathrm{s}$ with a really low amplitude and a flat slope. The slope increased more and more as the wind speed increased.

From those experiments, it was possible to determine the total damping as a function of wind speed, as shown in Figures 30 and 31. In both cases, the total damping decreased rapidly.

The negative values of the total damping indicated that the amplitude of the movement of the model will increase with time and will lead to an instability. To prevent oscillations, structural damping equivalent to the total negative damping would need to be added to the system. 

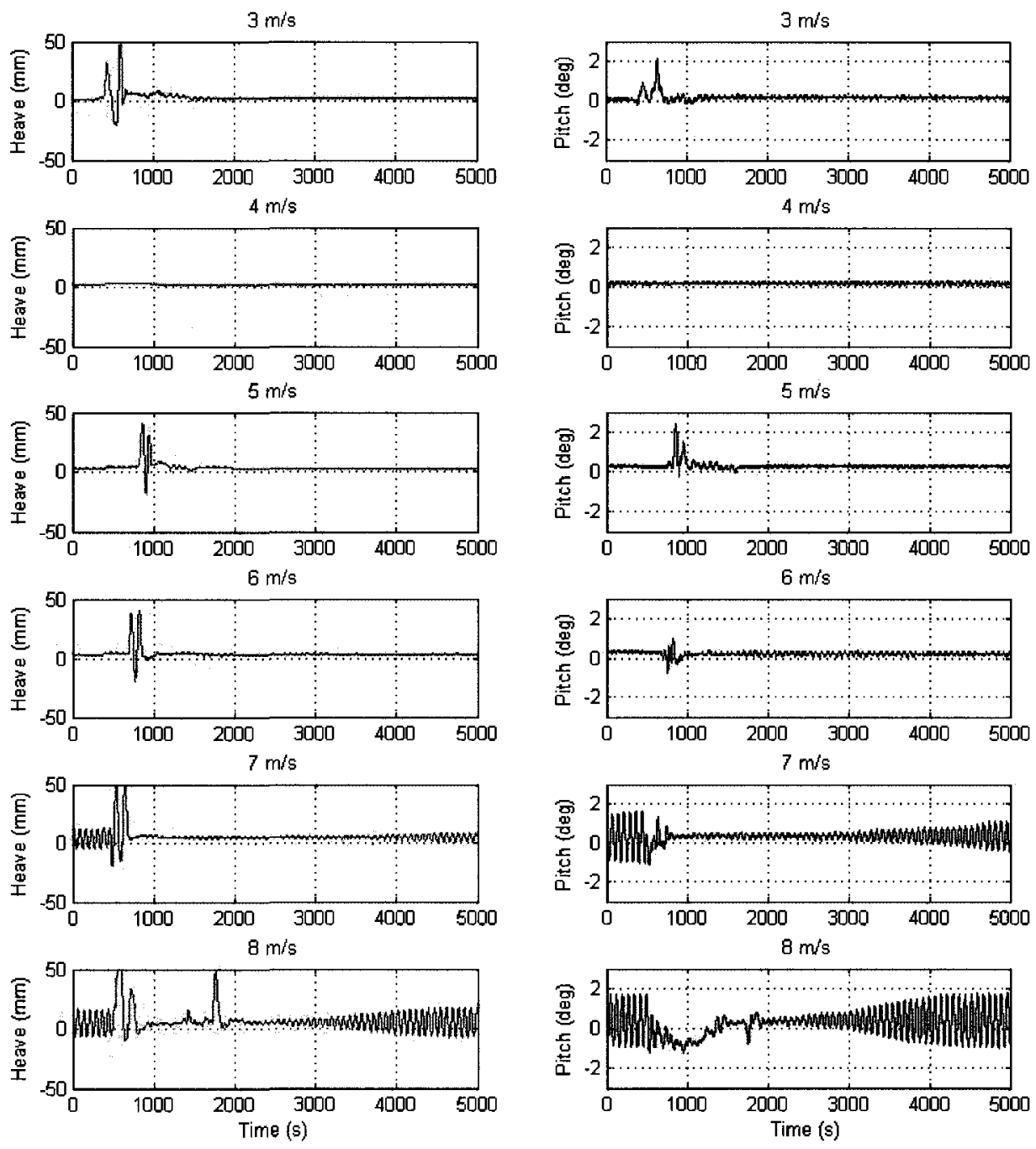

Figure 28: Amplitude build up traces in heave (left) and pitch (right) for several wind speeds $(3$ to $8 \mathrm{~m} / \mathrm{s})$. The peaks at the beginning of each time series are the disturbances of the model due to the hand stabilization procedure. 

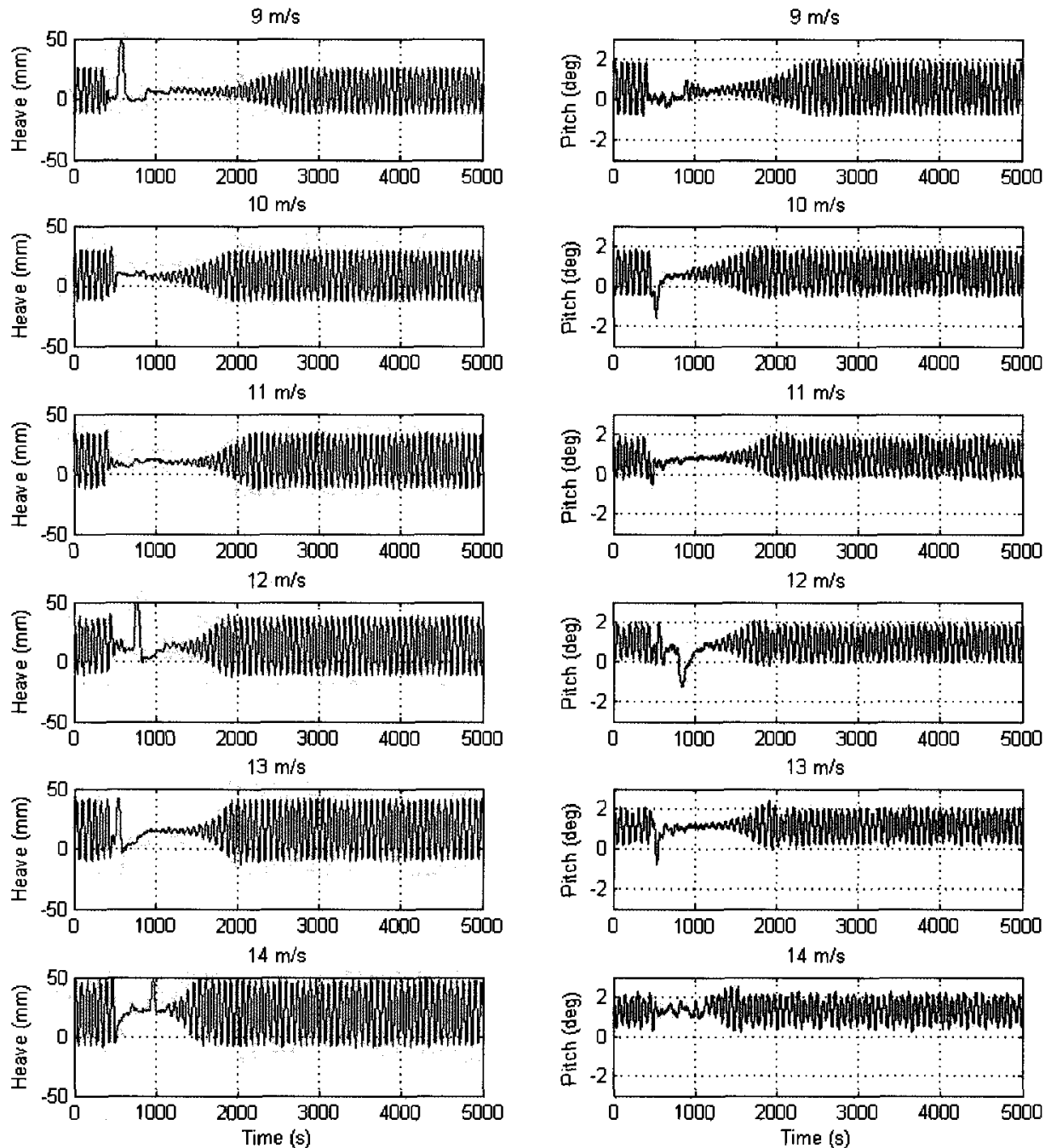

Figure 29: Amplitude build up traces in heave (left) and pitch (right) for several wind speeds ( 9 to $14 \mathrm{~m} / \mathrm{s}$ ). The peaks at the beginning of each time series are the disturbances of the model due to the hand stabilization procedure. 


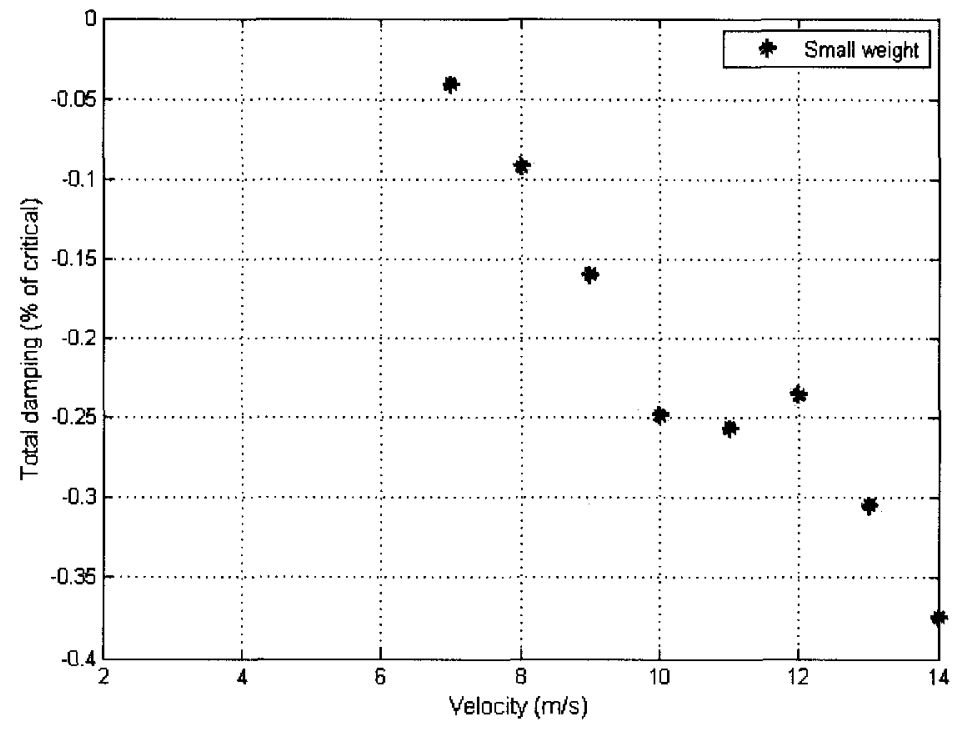

Figure 30: Variation of the total damping in heave as a function of the wind speed.

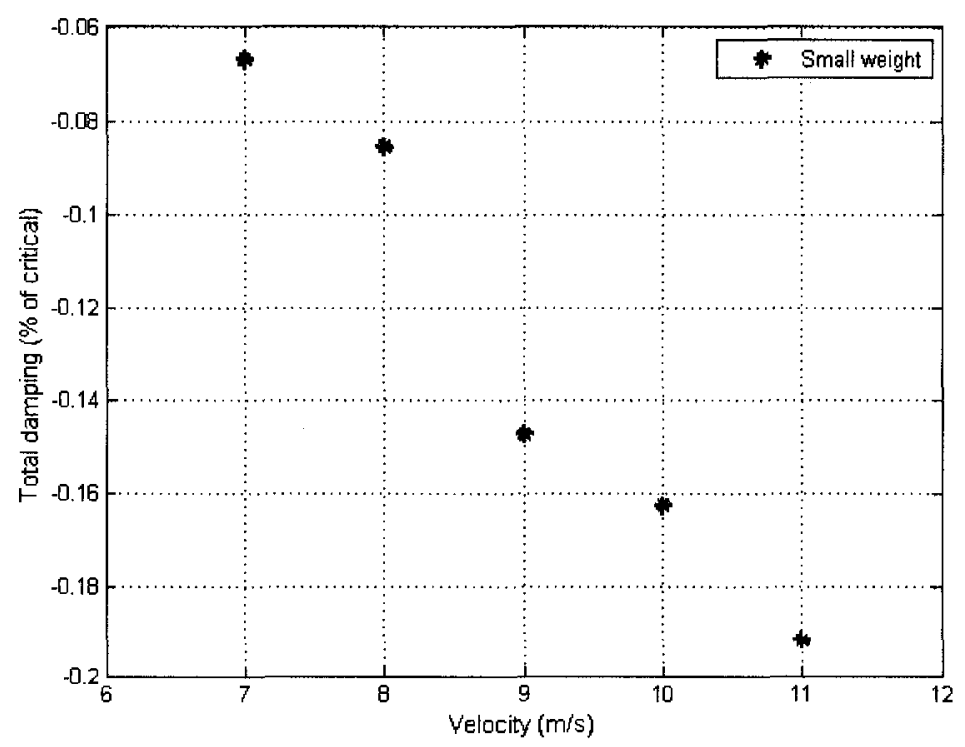

Figure 31: Variation of the total damping in pitch as a function of the wind speed. 
For the large weight case, it was not possible to extract the total negative damping from each time series to present it as a function of the wind speed because the amplitude of the movement was increasing rapidly and the model contacted the wall after a couple of oscillations. Figures 32, 33 and 34 represent the movement in each direction of the model from a stationary neutral position when released.

It can be observed that the model was pushed away from the wall as the wind speed increased. The oscillations were also more significant as the wind speed increased but stayed of relatively low amplitude.
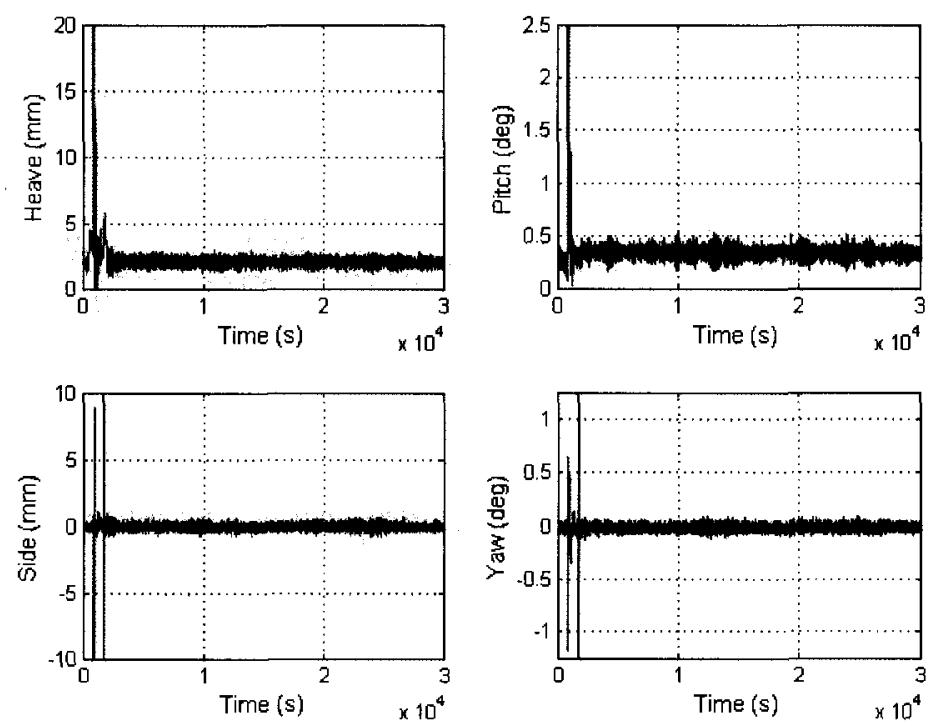

Figure 32: Amplitude build-up traces for the case with large weight at $7 \mathrm{~m} / \mathrm{s}$. 

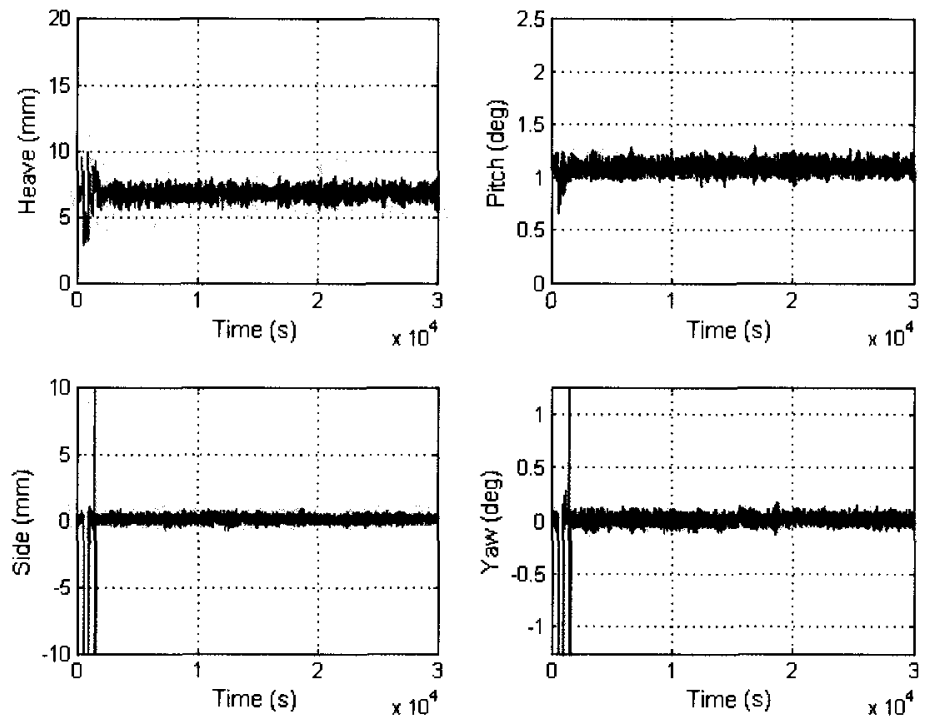

Figure 33: Amplitude build-up traces for the case with large weight at $11 \mathrm{~m} / \mathrm{s}$.
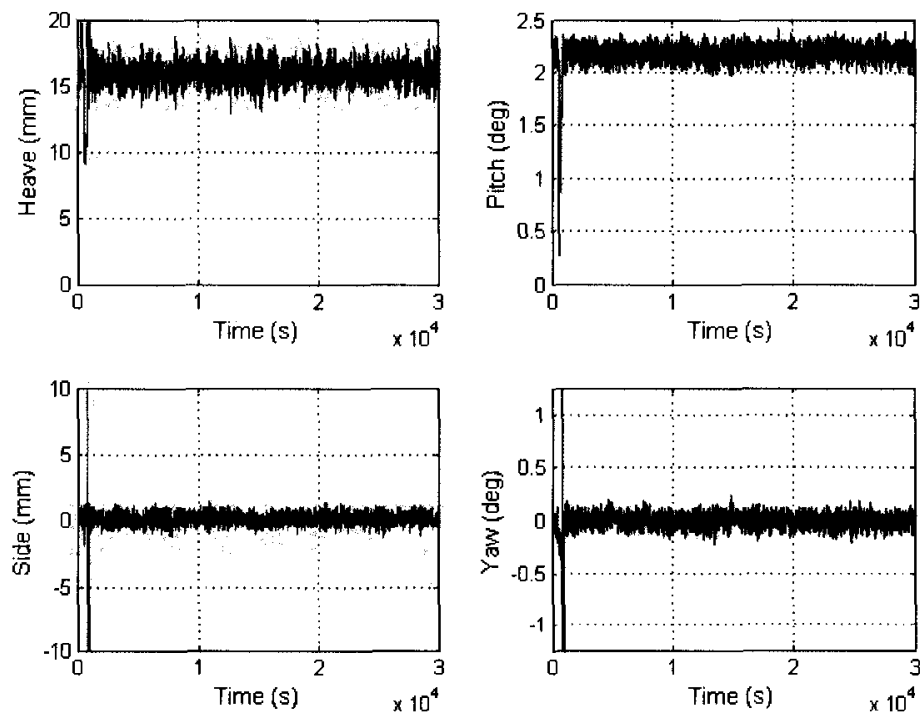

Figure 34: Amplitude build-up traces for the case with large weight at $14 \mathrm{~m} / \mathrm{s}$. 


\subsubsection{Amplitude of the displacement}

Tests to determine the amplitude of the displacement of the model have been performed to determine the range of motion as a function of the wind speed at steady state and to determine if there was hysteresis in the system.

The test procedures to obtain the response curves of Figure 35 were as follows:

- Measurement of wind off displacement signals (tare).

- Establishment of a steady wind speed.

- Delay time for stabilization of the amplitude of motion (if any). This delay was fixed to 9 minutes after an analysis of a 20 minute time series to insure that the steady state amplitude is reached.

- Data acquisition for 300 seconds at $100 \mathrm{~Hz}$.

- Increase or decrease wind speed to the next step and continue.

Figure 35 presents the mean and peak response of the model as a function of wind speed for the case when the centre of rotations were non coincidental (light weight case). The peak response is defined here as:

$$
P=\frac{\max -\min }{2}
$$

The peak response was found to be much larger than the mean response, indicating a large range of motion around the mean value. No hysteresis was found in the system since the response curve with increasing wind speed matched well the curve when the wind speed was decreasing for the peak and mean responses.

For the large weight set-up, Figure 36 shows that even if the model was displaced a lot in the wind tunnel, the oscillations were found to have small amplitude. This is probably due to the increased total damping in the system, as presented in Section 

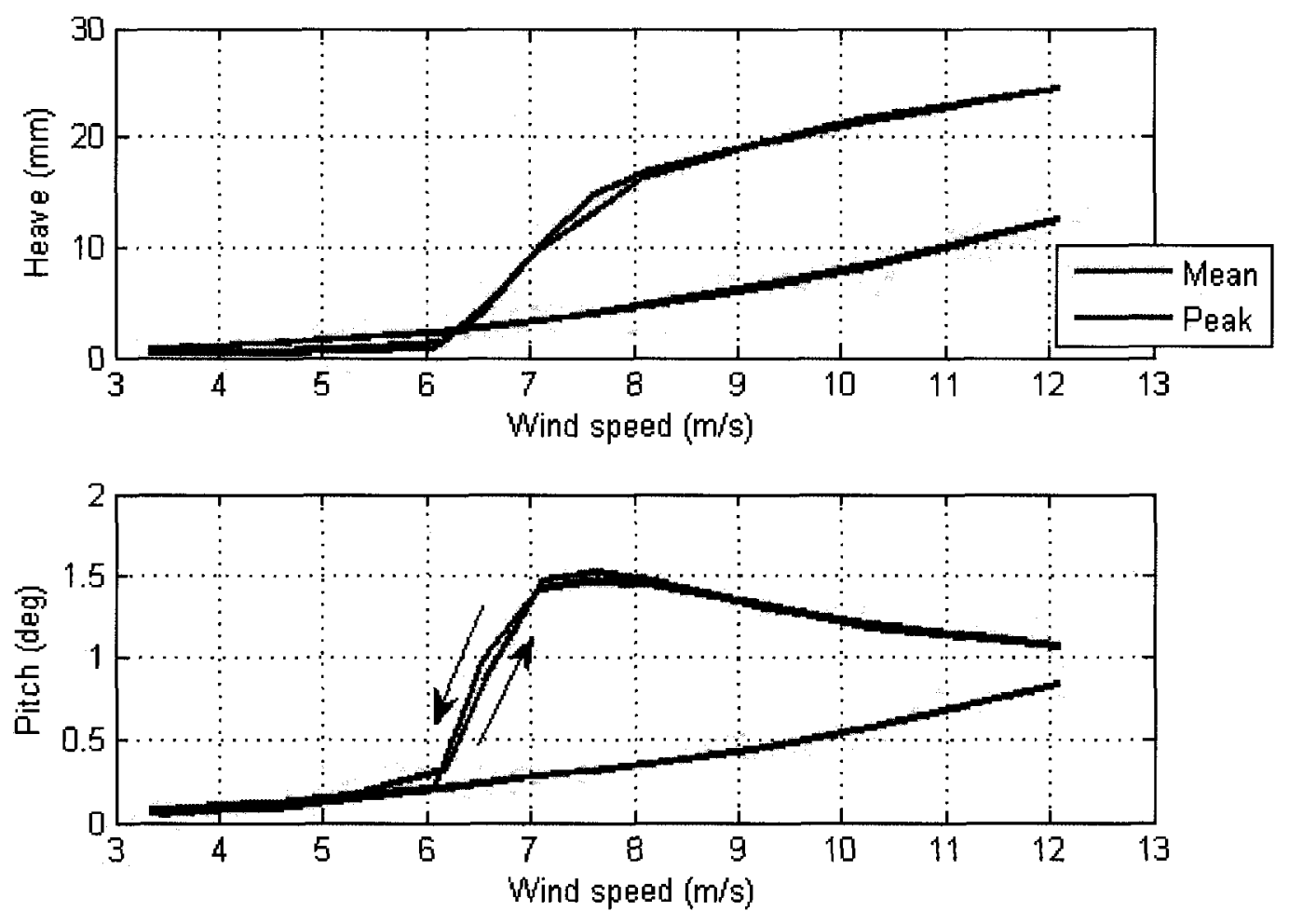

Figure 35: Peak and mean value of the response as a function of the wind speed for the small weight case.

2.3.2. In side and pitch (Figure 37) some movement was observed with a low amplitude, close to the resolution of the displacement lasers at low speeds. The model was oscillating around its neutral position.

The movement observed during this test and the different tests performed in the $5 \mathrm{~m}$ Vertical Wind Tunnel show the unsteadiness of the flow around the body. This unsteadiness can be the source of large oscillations even if the mean displacement is small, like in the small weight case, and can create a rapid change of the conditions of the flow around the body due to the rapid variations of the ride height or the pitch angle. 

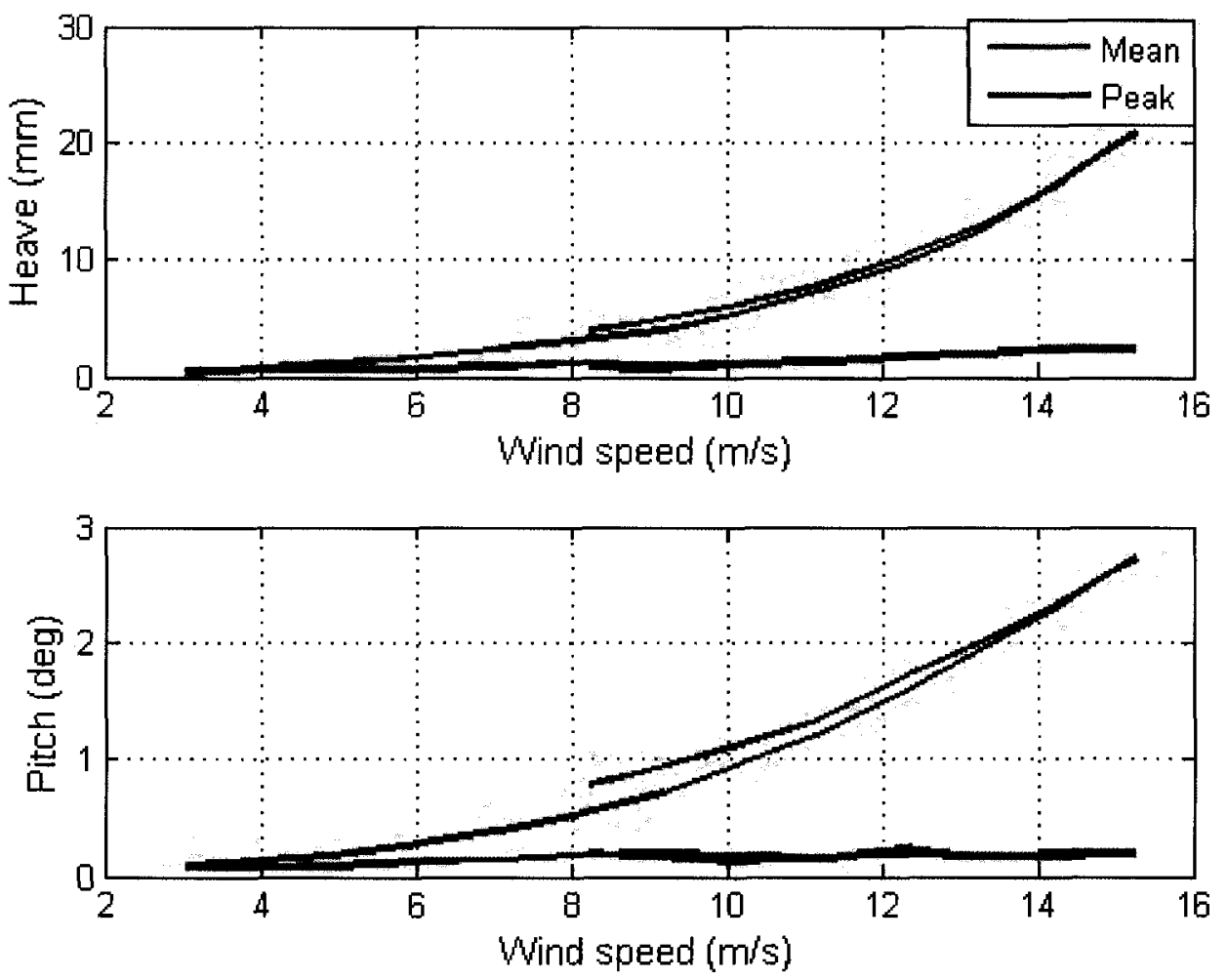

Figure 36: Peak and mean value of the response as a function of the wind speed for the large weight case in heave and pitch. 

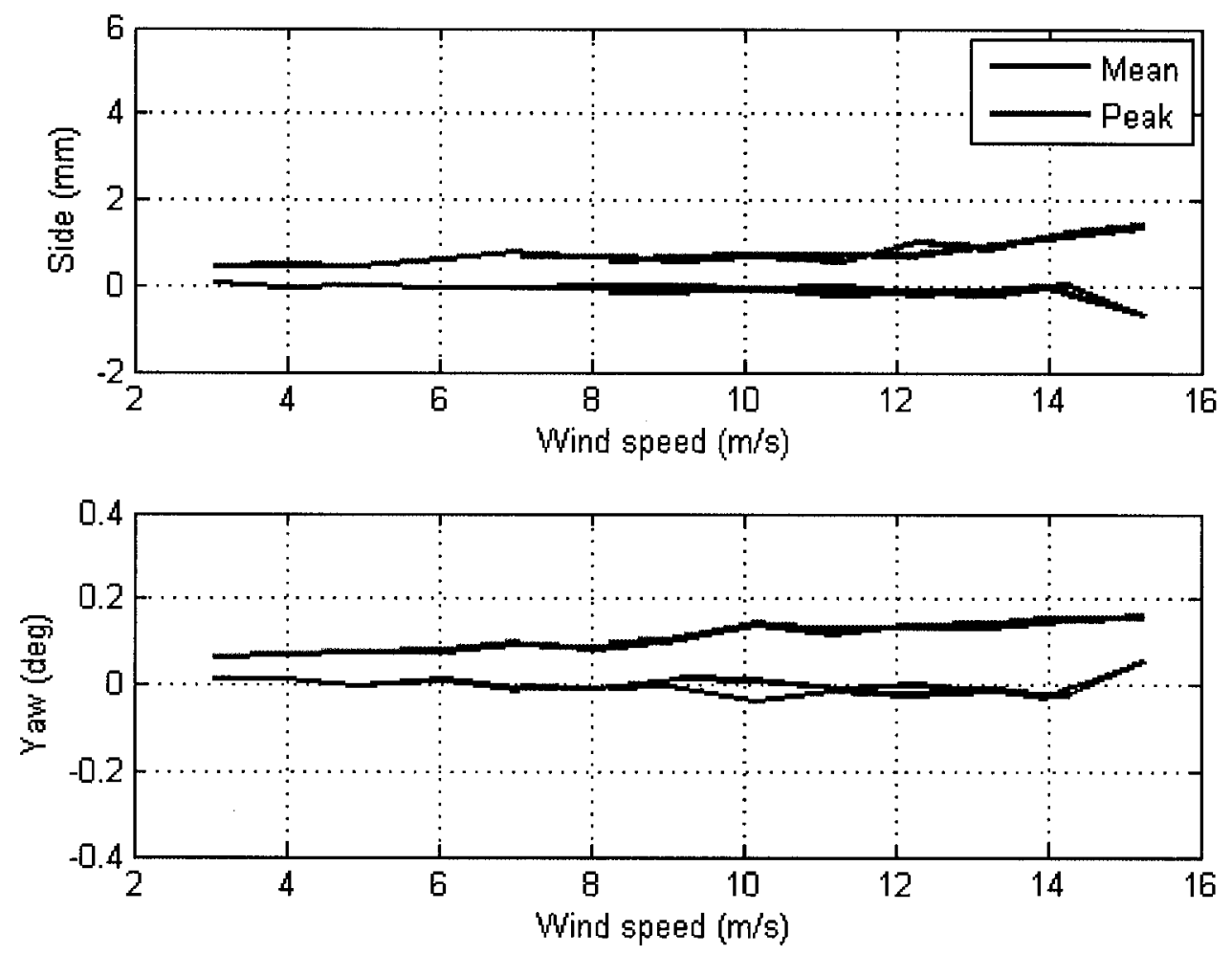

Figure 37: Peak and mean value of the response as a function of the wind speed for the large weight case in side and yaw. 


\subsection{Conclusions regarding the non-stationary test}

Movement in side and yaw directions was expected at the beginning of the project. During the preliminary tests, significant displacements were observed in pitch and heave and it was determined that it would be difficult to modify the set-up to observe movement in the other degrees of freedom due to the required softness of the springs.

The movement was probably caused by the shape of the model. In the small weight case, the excitation was amplified by the weight of the model which was lower than the scaled weight. When the centre of gravity has been modified, the mass of the model was larger than the scaled weight. In this case, the amplitude of the response excitation was reduced but the movement in pitch and heave was still large. This means that the excitation in those two degrees of freedom was very strong.

Also, the fast changes in amplitude in the small weight case made the observation of the variation in the total damping and stiffness of the set-up more difficult. The large weight case allowed measuring total damping and stiffness over a wider range of speeds, facilitating the observation of the shape of the variation as a function of the increasing speed. 


\section{Chapter 3}

\section{Stationary tests}

The second stage of this study was to perform stationary tests in the $2 \mathrm{~m} \mathrm{x} 3 \mathrm{~m}$ Wind Tunnel at the NRC. The aerodynamic characteristics of the Ahmed body and the steady and unsteady pressure distributions were determined for different configurations. The effect of the ride height and of the pitch angle on the forces were also evaluated.

\subsection{Model}

\subsubsection{Model geometry}

The model used to perform the stationary tests was constructed at exactly the same scale $(1: 10)$ as the model used in the non-stationary tests of Chapter 2. The same geometrical scale and the same speed range were used to keep the Reynolds number constant across both tests.

\subsubsection{Manufacturing of the model}

A new model was manufactured to meet the requirements of the stationary test. The new model had to be hollow to allow the installation of the pressure transducers to 
measure the surface pressure and had to allow the adjustment of the ride height and the pitch angle of the model.

The model was hollow, with a wall thickness of $3 \mathrm{~mm}$. To increase the stiffness of the walls and to facilitate the installation of the pressure taps, ribs were added on both sides and to the bottom panel of the model. Large ribs were added to insert axles to allow the rotation of the supports, as shown in Figure 38.

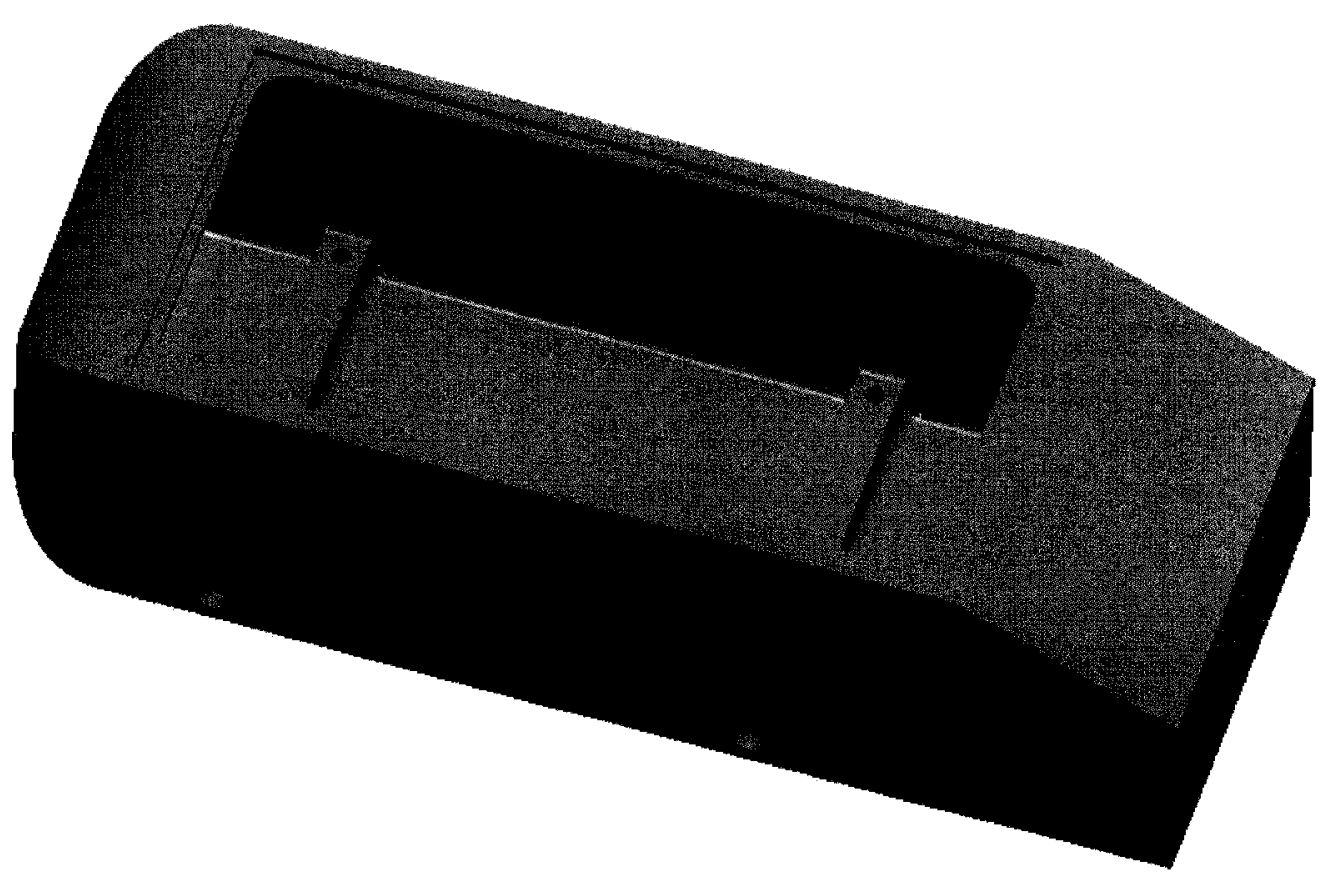

Figure 38: Stationary test model.

The model was built at NRC using a rapid prototyping method called selective laser sintering (SLS). This technique produced a detailed three-dimensional model in a short period of time based on a single three-dimensional digital drawing.

The SLS system consists of a laser, a control system and a part chamber which includes a build platform, powder cartridge and a leveling roller. The SLS uses the laser to merge, layer-by-layer, the powder-based material spread in thin layers across 
the platform of the chamber and leveled by the leveling roller. The powder-based material, once exposed to the laser, forms a solid model.

The model has to cool down in the machine to minimize the distortion while still hot, particularly if the walls are thin. After removing the model from the part chamber, the loose material had to be removed and the surfaces smoothed.

The dimensional accuracy of the model was lower than expected, the dimensions varied by up to $\pm 6 \mathrm{~mm}$ and the slant angle was off by $0.8^{\circ}$. Furthermore, the model was not perfectly symmetrical. It was considered, however, that this inaccuracy would not significantly affect the aerodynamics of the Ahmed body and the model was considered equivalent to the model used in the dynamic test reported in Section 2.

The lid of the SLS model was machined out of RenShape to facilitate its installation and improve its longevity. This material has been chosen because the threads would have been rapidly damaged as the fasteners would have been screwed and unscrewed in the powder-based material used in the SLS machine to access the interior of the model. The installation of inserts was not an adequate solution.

The 63 holes to install the pressure taps to measure the surface pressure were drilled on a milling machine to improve the accuracy of their positioning by using the numerical display.

Pressure taps were installed. The metal inserts and the plastic tubes were assembled and inserted in the holes where they were glued. The edge of the metal inserts had to stick slightly out of the model wall. After pressurizing the lines to keep the dust outside the tubes, the metal inserts were sanded to be absolutely flush with the wall.

While the plastic tubes were still pressurized, the model was painted to obtain the same surface finish as the first model and to provide a uniform surface for the two different materials. 


\subsection{Experimental set-up}

\subsubsection{Wind tunnel}

The stationary tests were performed in the NRC $2 \mathrm{~m} \times 3 \mathrm{~m}$ Wind Tunnel. It is an aeronautic type closed circuit wind tunnel. It was built in 1942 and is powered by a 2000 HP DC motor, with a $4.6 \mathrm{~m}$ diameter fan and a contraction ratio of 8.6:1 [18].

The tunnel has a closed, rectangular test section $1.9 \mathrm{~m}$ high, $2.7 \mathrm{~m}$ wide and 5.2 m long [22]. It can achieve speeds up to $500 \mathrm{~km} / \mathrm{h}(135 \mathrm{~m} / \mathrm{s})$ with an empty test section. The flow in the test section is uniform with a turbulence level of $0.13 \%$.

The wind tunnel is equipped with an external pyramidal 6-component balance used to measure mean forces and moments. A ground board was installed in the entire length and width of the test section to limit the height of the floor boundary layer at the model location. With the ground board installed, the turbulence intensity of the longitudinal component of the turbulence is $0.3 \%$. A suction system is also available to decrease the height of the boundary layer approaching the model. It is usually used during automobile tests, but it was not used during this present study because no such system was available in the Vertical Wind Tunnel. Therefore, the experiments were conducted in conditions as close as possible to the conditions of the Vertical Wind Tunnel.

\subsubsection{Experimental model set-up}

The general objectives of this experimental set-up were to provide balance and pressure measurements on the model when the model was fixed to the ground.

The model was installed in the wind tunnel directly over the centre of the balance and on the turn table allowing the variation of yaw angle of the model around its centre of rotation. 
Figure 39 shows a view of the model in the wind tunnel.

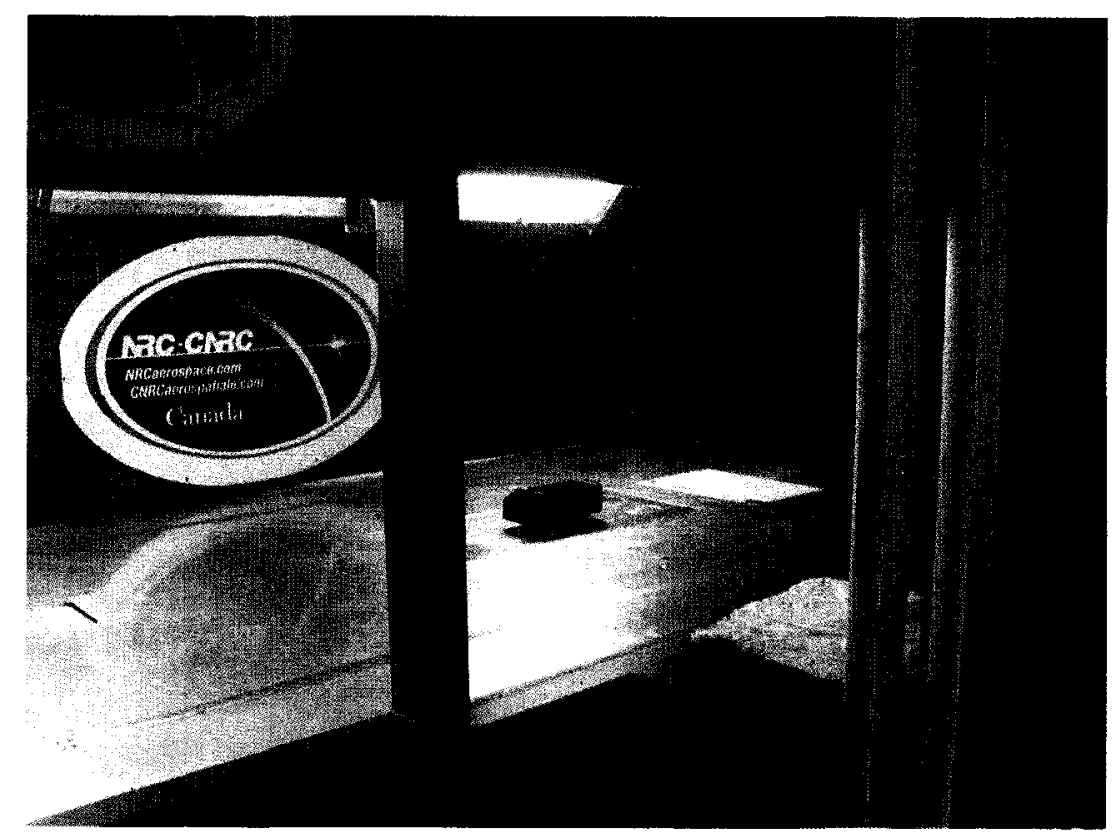

Figure 39: Ahmed body in the $2 \mathrm{~m} \times 3 \mathrm{~m}$ Wind Tunnel.

\subsubsection{Attachment of the model on the force balance}

The model is attached to a load plate mounted on the force balance. To allow the modification of the distance between the model and the ground, the ride height, two sets of legs were made. They were bolted on the load plate and the model was inserted on the top of them. The height of the model was adjusted using set screws, as shown in Figure 40. By adjusting the legs at a different height at the front and at the back, it was also possible to modify the pitch angle.

The ride height was measured using a digital caliper at the middle point between the legs with an accuracy of $\pm 0.25 \mathrm{~mm}$ and the pitch angle was measured using an MD Building Products Pro 360 Digital Protractor with an accuracy of $\pm 0.1^{\circ}$. 


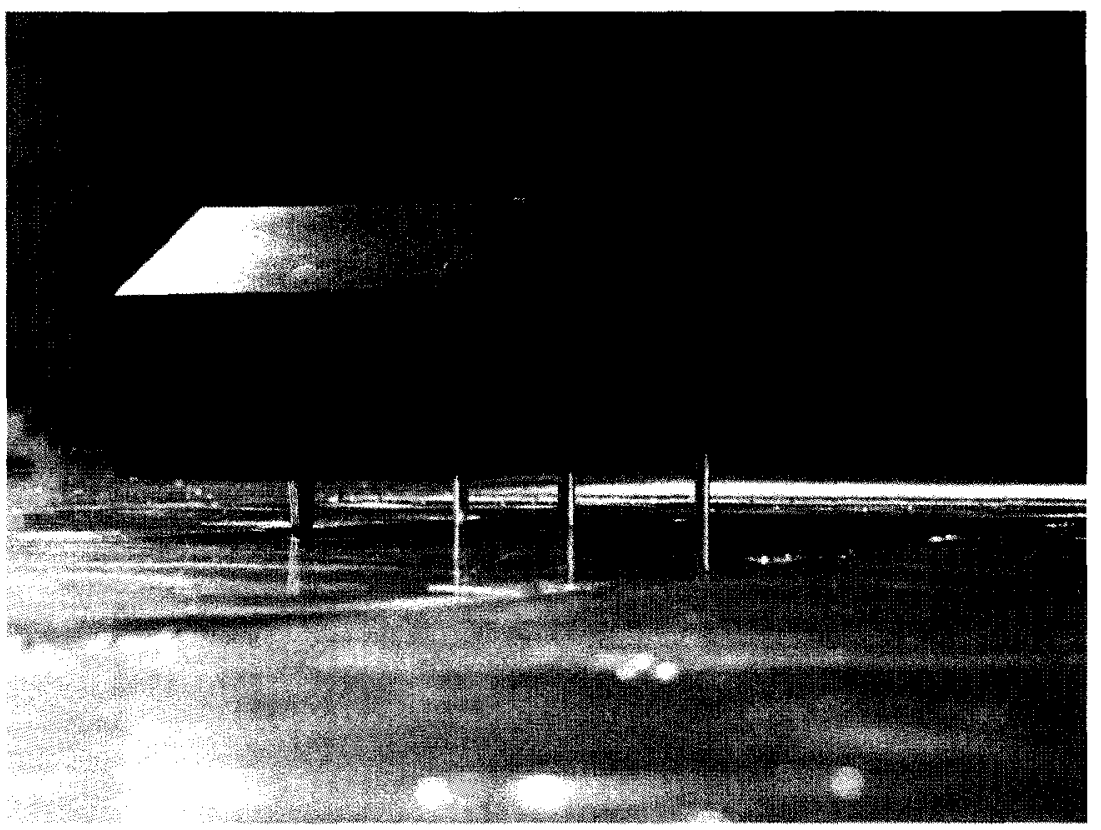

Figure 40: Adjustment of the ride height of the model.

\subsubsection{Instrumentation}

The standard instrumentation in the wind tunnel was used during the stationary tests performed. The total pressure was measured by three systems in the wind tunnel, after the contraction, just at the inlet of the test section. There was an MKS Barocel model 270100 tor, a 100 tor Barocel Edwards and, because the ground board was installed, a third one was used, a Datametric $10 \mathrm{kPa}$. A detailed description of the dynamic pressure measurement system for this facility can be found in [23].

The tunnel temperature is measured at the top and on the side of the settling chamber by two resistive thermal devices capable of measuring with an accuracy of $\pm 0.1^{\circ} \mathrm{C}$. The barometric pressure is measured by two Druck transducers DPI 261 .

A Cobra probe (Turbulent Flow Inc.) was used to perform measurements of the flow fluctuations in the wake of the model. This device is a 4-hole pressure probe that provides the three components of the velocity fluctuations and local pressure measurements with a fast dynamic response. It can be used for wind speeds higher 
than $2 \mathrm{~m} / \mathrm{s}$ and can acquire data at a frequency up to $2000 \mathrm{~Hz}$.

\subsubsection{Pressure measurements}

One of the main objectives of the stationary tests was to acquire surface pressure data on a non-moving model. A total of 63 pressure taps were installed on the whole body. They form four rings in three directions and more taps were added towards the end of the model since the wake was expected to have an important impact on the dynamic behaviour of the vehicle. The position of the pressure taps is presented in Figure 41 and the dimensions associated with the pressure tap locations are presented in Appendix A.

The taps were installed as described in Section 3.1.2. The metal inserts and the polyurethane tubes were connected to a Scanivalve Corp ZOC33/64Px embedded directly in the model to reduce the length of the pneumatic tubing. A ZOC33/64Px, also called ZOC, is a module containing 8 sensor packs. Each pack contains 8 sensors, for a total of 64 silicon pressure sensors, an excitation board, a calibration valve and a high speed multiplexer $(50 \mathrm{kHz})[24]$. The calibration valve allows the ZOC to be automatically calibrated on-line using the four modes of operations available: operate, calibrate, purge, leak test.

The thermal unit containing the ZOC was opened and the top part removed during the test. This had the advantage of decreasing the diameter of the connector that had to go through the bottom panel of the model, decreasing the size of the opening that had to be drilled and decreasing the disturbance of the flow field.

The output of each sensor was directed to the multiplexer/amplifier and the Scanivalve Corp High-scan system, which performs the data acquisition using the binary address assigned to each channel.

All pneumatic tubes used to connect the inserts to the ZOC were $25 \mathrm{~cm}$ long to obtain frequency responses as uniform as possible and had a $1.02 \mathrm{~mm}(0.040 ")$ inside 

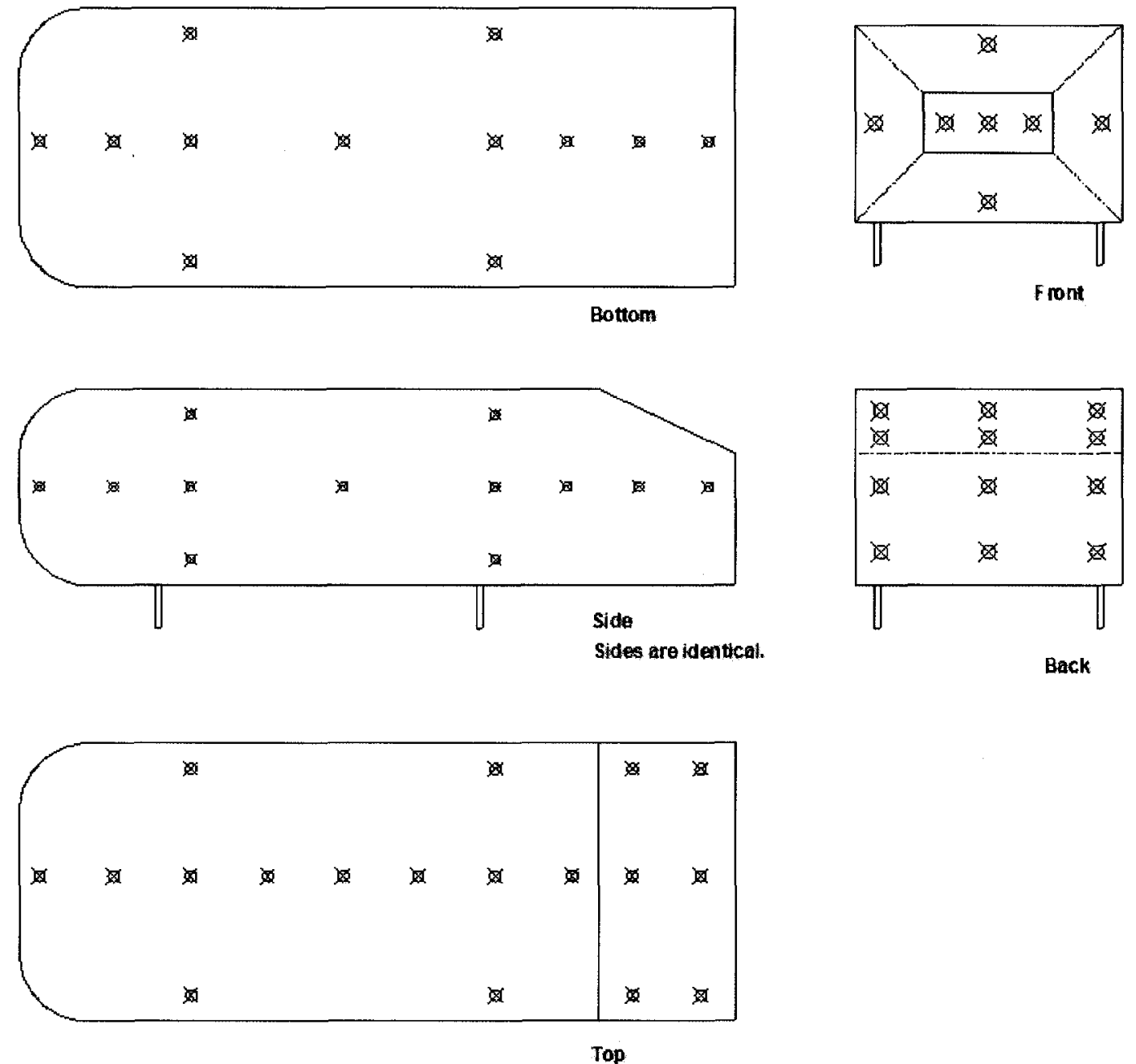

Figure 41: Pressure taps positions on the Ahmed body. 
diameter to minimize the volume of the set-up. Even if the tubes connecting the metal insert to the $\mathrm{ZOC}$ were all the same length, a calibration of the frequency response was requested for each tube. The bend in the metal insert, a possible variation of the inside diameter of the tubing and variations of the length of the pneumatic connection inside the thermal unit could create a variation in the response specific to each tube.

Therefore, calibration was performed on every single pressure tap on the model as presented in Appendix C. The result of this calibration is shown in Figure 42 representing the amplification factor of the tubes as a function of frequency.

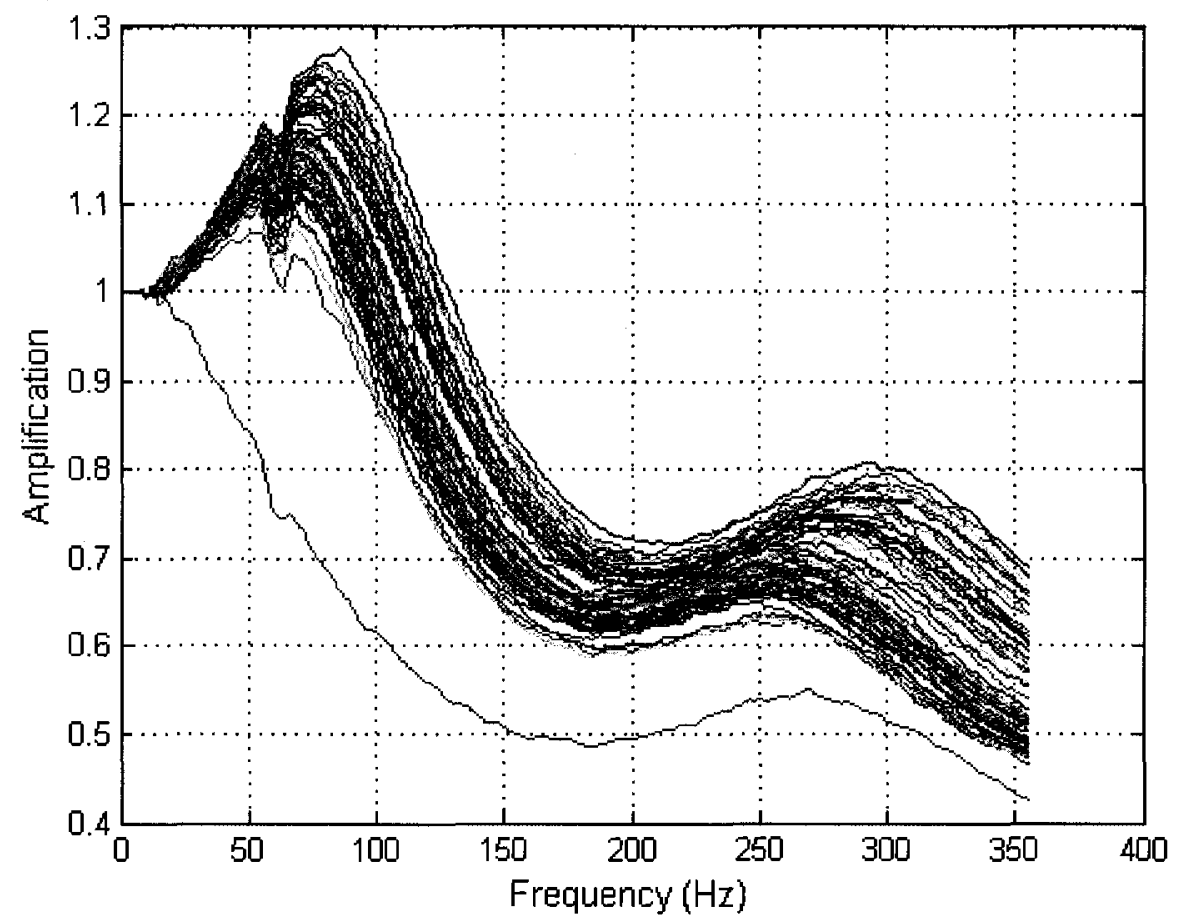

Figure 42: Frequency response curves for all pneumatic tubes of this study.

The frequency response curves were used to correct the pressure signals acquired during the experiments using the method developed by Irwin et al and described in Larose et al [25].

The sampling frequency of the pressure data acquisition was $710.2 \mathrm{~Hz}$ using the 
full capacity of the multiplexer, for a sampling time of 45.1 seconds. The Nyquist frequency for this set-up is $355.1 \mathrm{~Hz}$, which is much higher than the frequency content expected in the wake and around the body. The energy in the flow is very low after $200 \mathrm{~Hz}$ and no peaks were observed at a frequency higher than $60 \mathrm{~Hz}$ as shown by Sims-William and Duncan [26] using hot-wire velocimetry in the wake of an Ahmed model.

\subsection{Experimental data}

\subsubsection{Test program and procedures}

The stationary tests were initially planned to be conducted as a series of runs with changes in configuration of ride height and pitch angle. For each run, it was planned that the balance and the pressure measurement data were to be acquired simultaneously. Due to some technical problems in the wind tunnel (a cable left from a previous experiment causing mechanical interference in the balance), both measurements had to be done separately. Therefore, each configuration was tested for pressure measurements and the entire programme had to be repeated to measure the corresponding overall aerodynamic forces on the model with the external balance.

As mentioned before, the effects of the ride height and the pitch angle of the model were evaluated. Therefore, the different configurations were varying these two parameters separately and simultaneously.

The basic configuration of the model was a pitch angle of $0^{\circ}$ and a ride height of 25 $\mathrm{mm}$, corresponding to the nominal conditions of the non-stationary tests of Section 2. Four other pitch angles were tested with the $25 \mathrm{~mm}$ ride height: $-4^{\circ},-2^{\circ},+2^{\circ}$ and $+4^{\circ}$. For a constant pitch angle of $0^{\circ}$, two more ride heights were tested: $18 \mathrm{~mm}$ and $33 \mathrm{~mm}$. A series of combinations of ride height and pitch angle were studied. Table 
Table 4: Different configurations tested during the stationary tests.

\begin{tabular}{|c|c|c|c|c|}
\hline Ride Height & Pitch Angle & Yaw angles & Wind speeds & Comments \\
\hline \multirow{5}{*}{$18 \mathrm{~mm}$} & $-4^{\circ}$ & $-4^{\circ}$ to $+10^{\circ}$ & 11,13 and $15 \mathrm{~m} / \mathrm{s}$ & \\
& $-2^{\circ}$ & $-4^{\circ}$ to $+10^{\circ}$ & 11,13 and $15 \mathrm{~m} / \mathrm{s}$ & \\
& $0^{\circ}$ & $-4^{\circ}$ to $+10^{\circ}$ & 11,13 and $15 \mathrm{~m} / \mathrm{s}$ & \\
& $+2^{\circ}$ & $-4^{\circ}$ to $+10^{\circ}$ & 11,13 and $15 \mathrm{~m} / \mathrm{s}$ & \\
& $+4^{\circ}$ & $-4^{\circ}$ to $+10^{\circ}$ & 11,13 and $15 \mathrm{~m} / \mathrm{s}$ & \\
\hline \multirow{5}{*}{$25 \mathrm{~mm}$} & $-4^{\circ}$ & $-4^{\circ}$ to $+10^{\circ}$ & 11,13 and $15 \mathrm{~m} / \mathrm{s}$ & \\
\cline { 2 - 6 } & $-2^{\circ}$ & $-4^{\circ}$ to $+10^{\circ}$ & 11,13 and $15 \mathrm{~m} / \mathrm{s}$ & \\
\cline { 2 - 6 } $33 \mathrm{~mm}$ & $0^{\circ}$ & $-4^{\circ}$ to $+10^{\circ}$ & 11,13 and $15 \mathrm{~m} / \mathrm{s}$ & Reference \\
\cline { 2 - 6 } & $+2^{\circ}$ & $-4^{\circ}$ to $+10^{\circ}$ & 11,13 and $15 \mathrm{~m} / \mathrm{s}$ & \\
& $+4^{\circ}$ & $-4^{\circ}$ to $+10^{\circ}$ & 11,13 and $15 \mathrm{~m} / \mathrm{s}$ & \\
& $-4^{\circ}$ & $-4^{\circ}$ to $+10^{\circ}$ & 11,13 and $15 \mathrm{~m} / \mathrm{s}$ & \\
& $-2^{\circ}$ & $-4^{\circ}$ to $+10^{\circ}$ & 11,13 and $15 \mathrm{~m} / \mathrm{s}$ & \\
& $0^{\circ}$ & $-4^{\circ}$ to $+10^{\circ}$ & 11,13 and $15 \mathrm{~m} / \mathrm{s}$ & \\
& $+2^{\circ}$ & $-4^{\circ}$ to $+10^{\circ}$ & 11,13 and $15 \mathrm{~m} / \mathrm{s}$ & \\
& $+4^{\circ}$ & $-4^{\circ}$ to $+10^{\circ}$ & 11,13 and $15 \mathrm{~m} / \mathrm{s}$ & \\
\hline
\end{tabular}

4 presents all the configurations tested during the stationary tests.

For each configuration a yaw sweep was performed from $-4^{\circ}$ to $+10^{\circ}$ by increments of $2^{\circ}$. The sign convention used is the same as the one presented in Figure 2 of Chapter 1. The tests were performed at $11 \mathrm{~m} / \mathrm{s}, 13 \mathrm{~m} / \mathrm{s}$ and $15 \mathrm{~m} / \mathrm{s}$, three wind speeds corresponding to the higher range of the wind speeds studied in Chapter 2. The lower speeds were not reproduced during the stationary tests due to the low dynamic pressure on the model that would be below the measuring capability of the pressure transducers. Also, the ride heights and the pitch angles were chosen to cover the range of the displacements observed during the dynamic tests.

\subsubsection{Force balance measurements}

The six-component pyramidal force balance of the $2 \mathrm{~m} \mathrm{x} 3 \mathrm{~m}$ Wind Tunnel at NRC allowed the acquisition of the 3 forces and 3 moments. The signals from the balance were acquired by the data acquisition system through the balance control system. The data acquisition system also acquired the dynamic pressure, the temperature 
and the static pressure in the tunnel as well as the atmospheric pressure. All this information was sent to reduction software based on that used for automobile tests at NRC. The reduced data could subsequently be analyzed.

The six-component balance provides measurements at a maximum rate of $7 \mathrm{~Hz}$. Given this low frequency response, it can't resolve unsteady phenomena occurring at high frequency and can only provide a precise measurement of the mean aerodynamic forces and moments.

The balance data was used, in this test, to observe the general impact of the different configurations on the forces and moments applied on the model and to evaluate the ratio between the balance forces and the forces obtained by the integration of the pressures on the whole model. In this manner, any unsteady aerodynamic phenomena captured by the dynamic surface pressure measurements were correlated with the overall aerodynamic forces applied on the entire model as measured by the external force balance.

The three force coefficients, drag $\left(C_{D}\right)$, lift $\left(C_{L}\right)$ and side $\left(C_{S}\right)$, and three moment coefficients, pitch $\left(C_{M}\right)$, yaw $\left(C_{Y}\right)$ and roll $\left(C_{R}\right)$, measured with the balance are calculated as follow:

$$
\begin{gathered}
C_{D}=\frac{D}{q A}, \\
C_{L}=\frac{L}{q A}, \\
C_{S}=\frac{D}{q A}, \\
C_{M}=\frac{P M}{q A L_{c}},
\end{gathered}
$$




$$
\begin{aligned}
& C_{Y}=\frac{Y}{q A L_{c}}, \\
& C_{R}=\frac{R}{q A L_{c}},
\end{aligned}
$$

where $D, L$, and $S$ are the drag, lift and side force, $P M, Y$, and $R$ the three moments, $q$, the dynamic pressure, $A$, the frontal area and $L_{c}$, the characteristic length. For all tests the frontal area was set at $A=0.01794 \mathrm{~m}^{2}$ and the wheelbase $L_{c}=0.188 \mathrm{~m}$ was used as the characteristic length for the calculation of the coefficients.

Figures 43 and 44 present the variations of the static force and moment coefficients as a function of the variation in ride height and pitch angle when only one parameter was varied.

In Figure 43, we can observe that the drag, side and pitching and rolling moment coefficients have been affected by the low ride height at lower speed, while the yawing moment coefficient has been decreased at higher Reynolds number for the higher ride height.

The effect of the pitch angle on the mean coefficients was found to be less important, as observed in Figure 44. The pitching moment coefficient was the only one affected and more repetitions would be required to determine if there were unsteady forces at the origin of the variations. It can be observed from Figure 44, the point at $2^{\circ}$ and $11 \mathrm{~m} / \mathrm{s}$ is an outlyer and cannot be considered representative of the variations of the pitching and rolling moment coefficients with pitch angle.

Figures 45 and 46 present the variations of the static force and moment coefficients as a function of the yaw angle for a constant pitch angle or ride height, at $15 \mathrm{~m} / \mathrm{s}$. On Figure 46, it can be observed that the lift coefficient is strongly influenced by the pitch angle. 

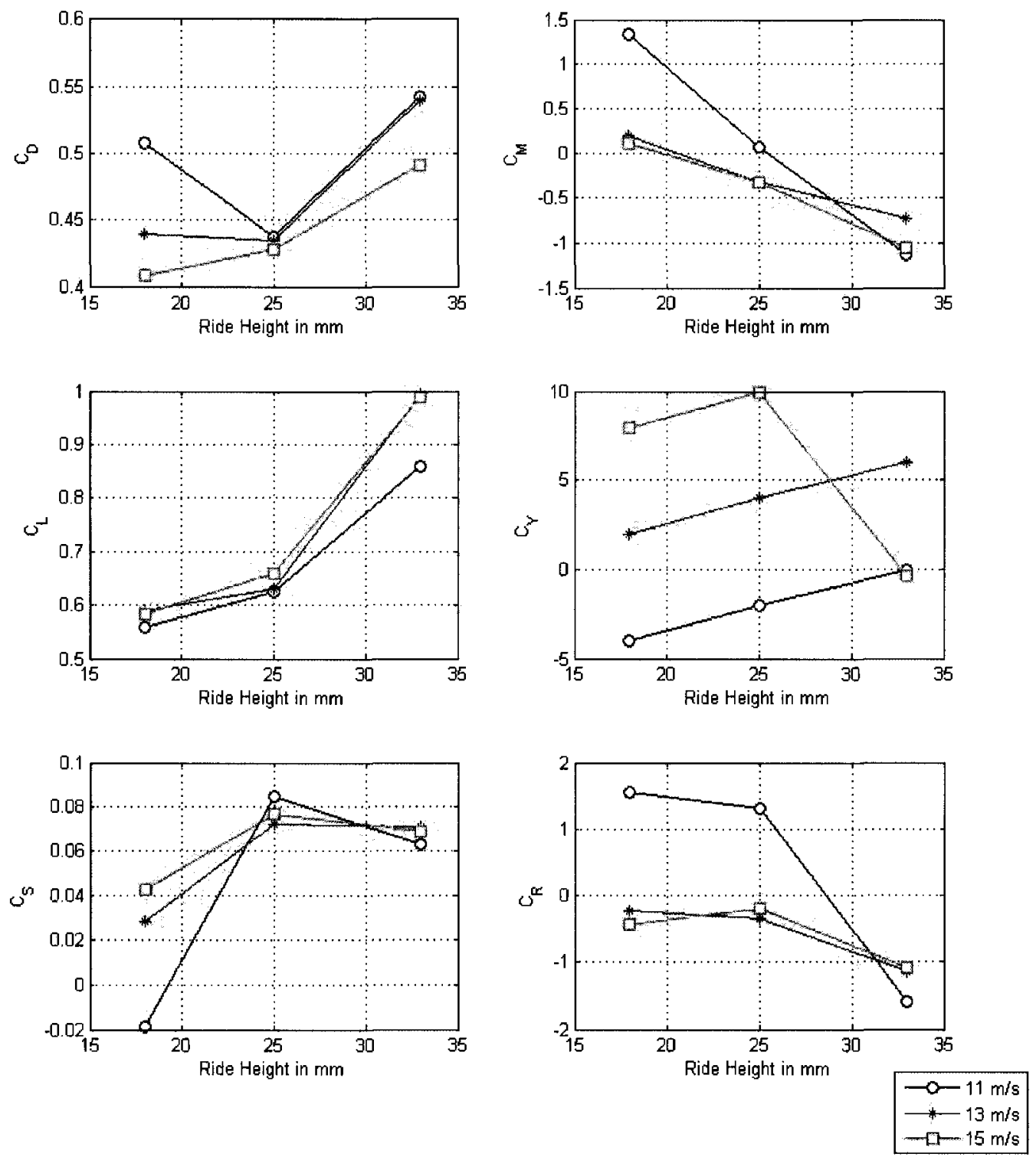

Figure 43: Static force and moment coefficients as a function of ride height in $\mathbf{m m}$, for a pitch angle of $0^{\circ}$ at $0^{\circ}$ yaw angle. 

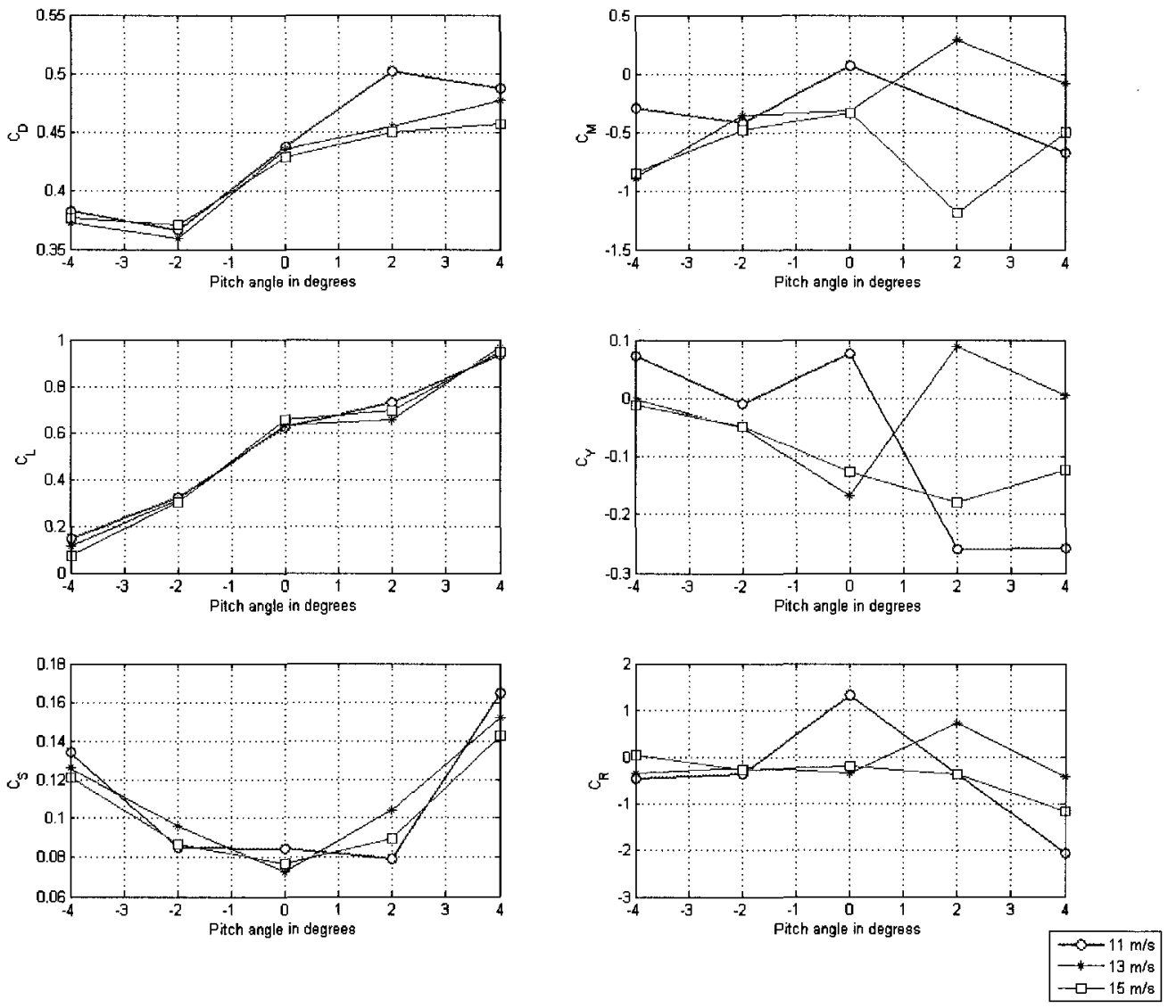

Figure 44: Static force and moment coefficients as a function of pitch angle in degrees, for a constant ride height of $25 \mathrm{~mm}$ and a yaw angle of $0^{\circ}$. 

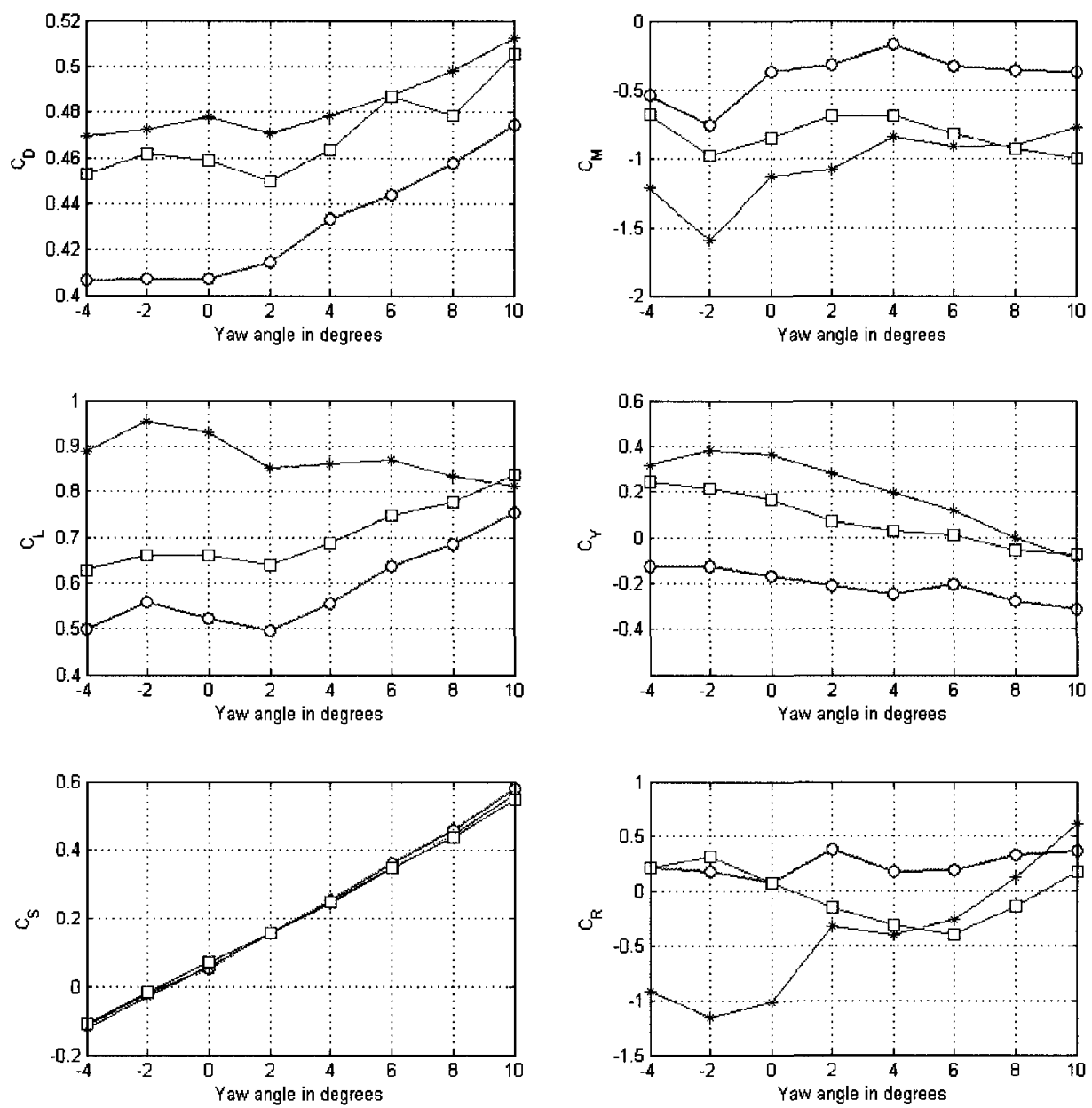

$-0-18 \mathrm{~mm} \rightarrow-25 \mathrm{~mm} \rightarrow \square-33 \mathrm{~mm}$

Figure 45: Static force and moment coefficients as a function of pitch angle in degrees, for three ride heights at a constant pitch angle of $0^{\circ}$ and a constant wind speed of $15 \mathrm{~m} / \mathrm{s}$. 

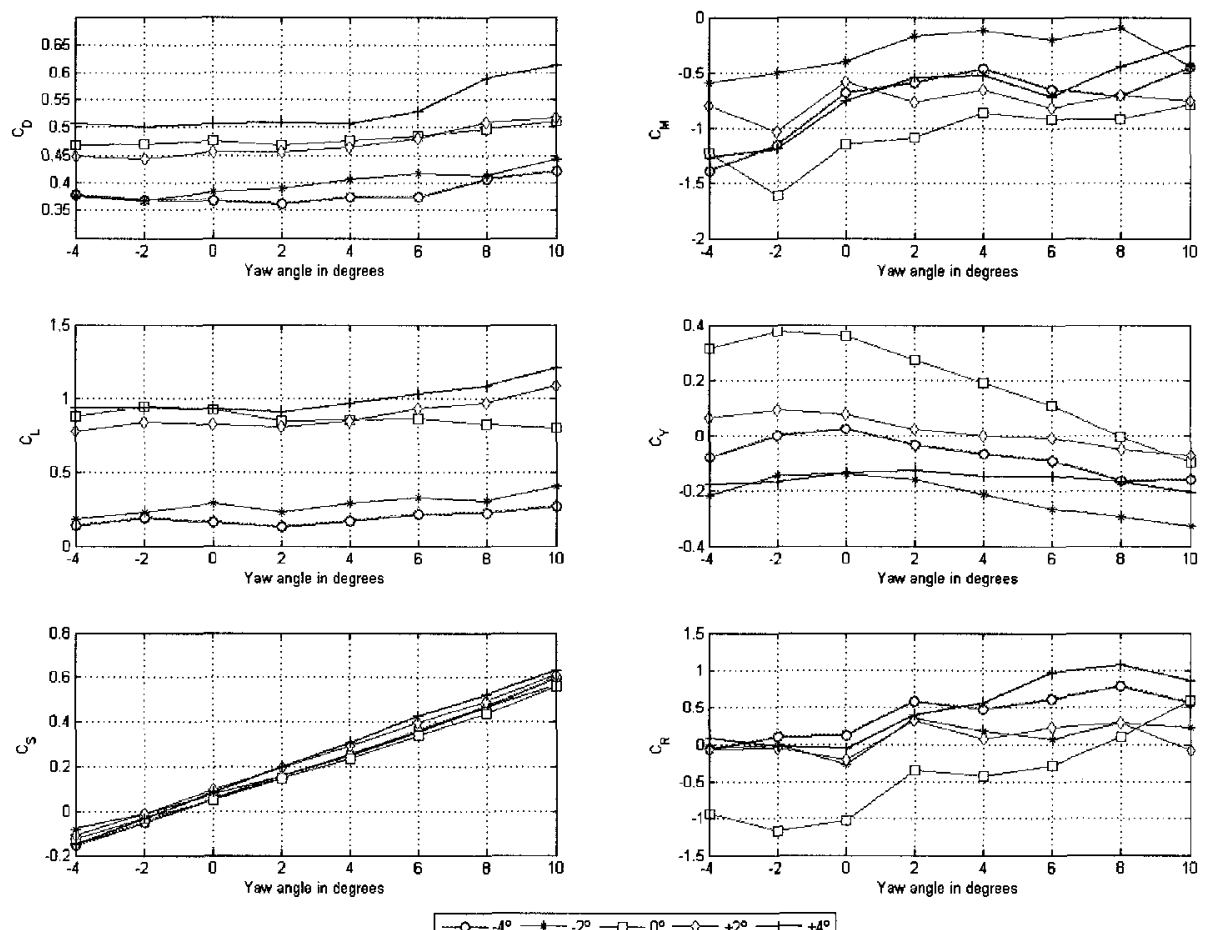

Figure 46: Static force and moment coefficients as a function of pitch angle in degrees, for five pitch angles at a constant ride height of $25 \mathrm{~mm}$ and a constant wind speed of $15 \mathrm{~m} / \mathrm{s}$. 


\subsubsection{Pressure integration}

The 63 pressure taps installed on the whole surface of the model provided the surface pressure at the exact point where they were located on the model. To integrate the pressure to calculate the forces and moments on the Ahmed body, the assumptions that the pressure at this location was the same as on the surface surrounding the pressure tap must be made.

By dividing the area of the body in small sectors, as shown in Figure 47, it was possible to integrate the pressures on each surface and using their position on the body, to determine their effect on each force (drag, lift and side) and moment (yaw, pitch and roll). The force applied on one sector can have an impact on many forces and moments.

The pressure integration was carried out assuming that the acquisition on the 63 channels was done simultaneously. There was only 0.00002 second elapsed between the acquisition of two consecutive channels which was considered insignificant compared to the time required for the flow to pass around the body.

\section{Forces and moments}

The forces and moments resulting from the integration of the pressures were of the same magnitude as the forces measured by the external force balance, but are less precise due to the assumptions described above. To measure precisely the forces and moments on the model with the pressure taps, it would have required a really large number of taps and a few ZOC to decrease the size of each area of integration to a minimum. It would have also been difficult to fit all the tubes in the model. Therefore, the pressure taps were used to measure the variations in the forces and moment at a high frequency response. The force balance data were used to scale the unsteady forces time series by comparing the mean coefficients. 

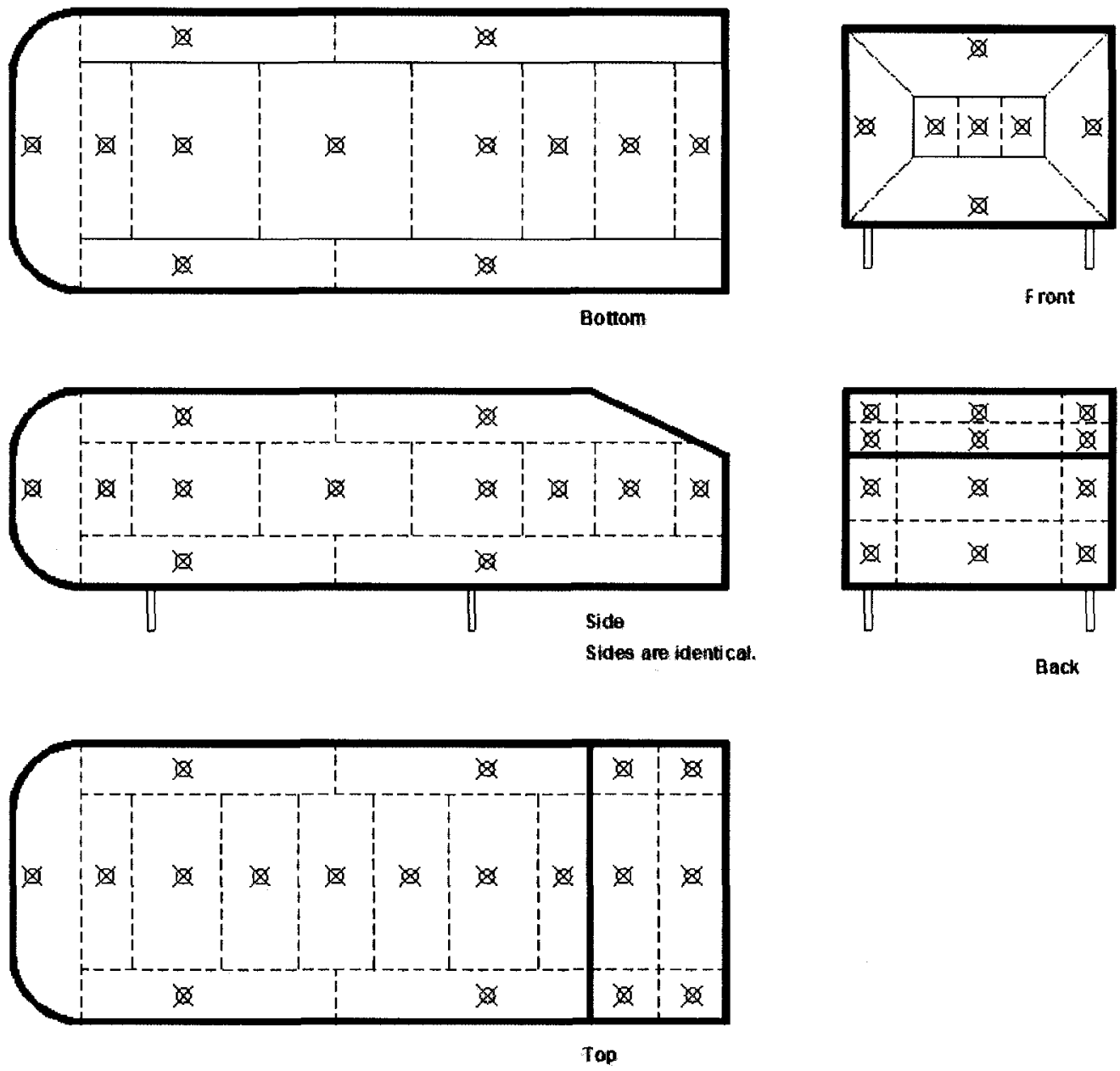

Figure 47: Areas on the model for the pressure integration. 
The integration of the pressures on the surface of the model gave forces and moments in drag, heave and pitch within about $60 \%$ of the force balance data. The small number of taps and the symmetry of the model, inducing forces of the same order on both sides of the model, led to really small forces after integration of the pressures.

The moments in roll and yaw were small and the placement of the taps on the model did not favor a precise integration in those planes. Therefore, the data in roll and yaw were calculated as zero by the integration program and were ignored in the treatment of the data.

\section{Unsteady measurements}

Figure 48 presents an example of time series data for the unsteady aerodynamic forces on the model compared with the mean forces and moments of the balance, when the model has a pitch angle of $0^{\circ}$, a ride height of $25 \mathrm{~mm}$, the reference configuration, and the wind tunnel speed is $15 \mathrm{~m} / \mathrm{s}$. The difference is due to the assumption that the pressure measure at one point is the same on the area associated to this pressure tap.

Figure 49 presents an example, over a short time period, of the variations in the unsteady pressure measurements presented in Figure 48.

From the time series, it is possible to create a spectrum showing the frequencies excited, as shown in Figure 50.

Figures 48 and 50 are an example of the unsteady pressure data. There have been 360 files of pressure data acquired during the test. Those files will be useful as input for the dynamic model of Section 4 to cover the different orientations of the model. 

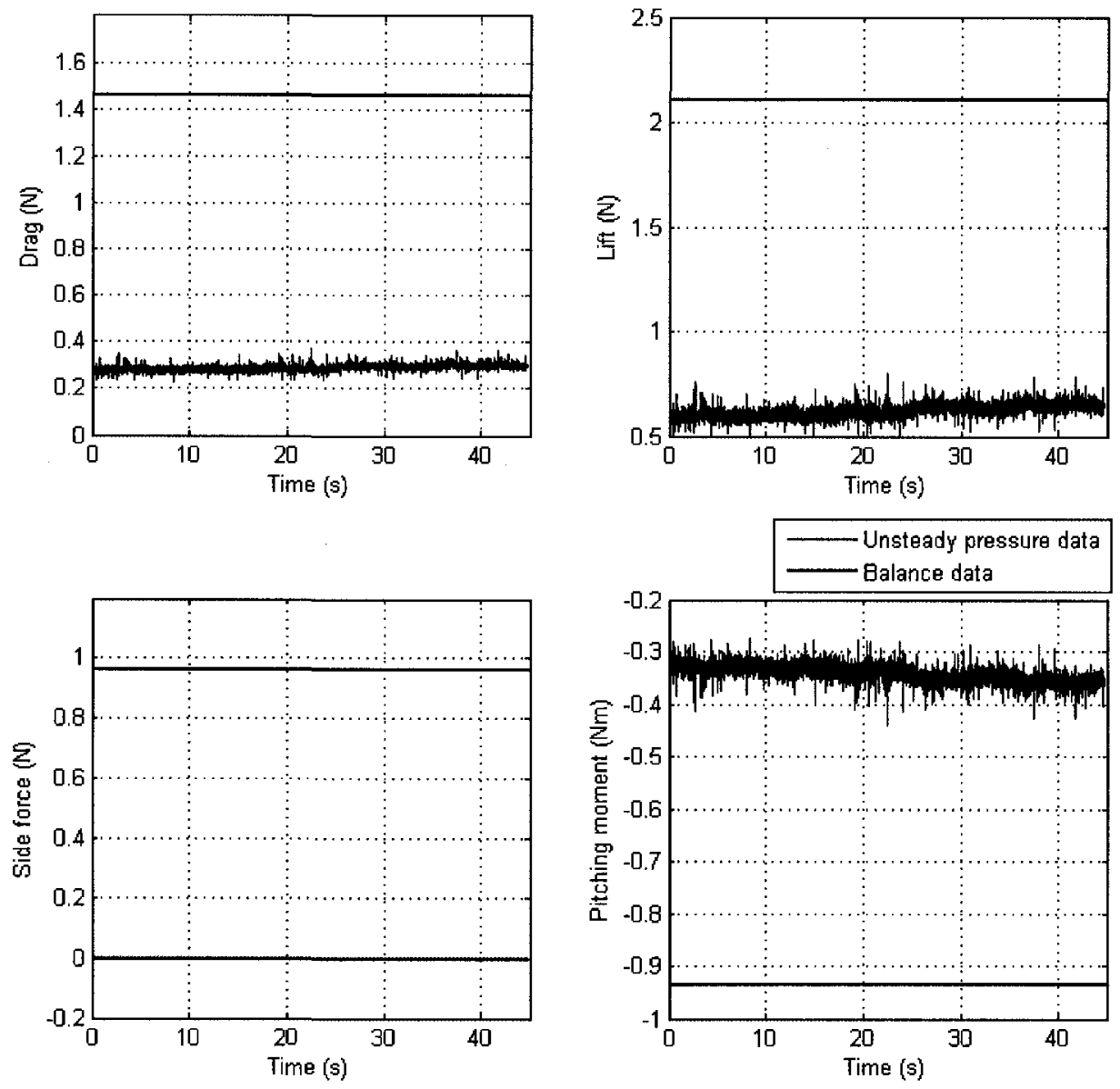

Figure 48: Time series of the forces integrated from the pressure measurements, reference configuration, $15 \mathrm{~m} / \mathrm{s}$. 

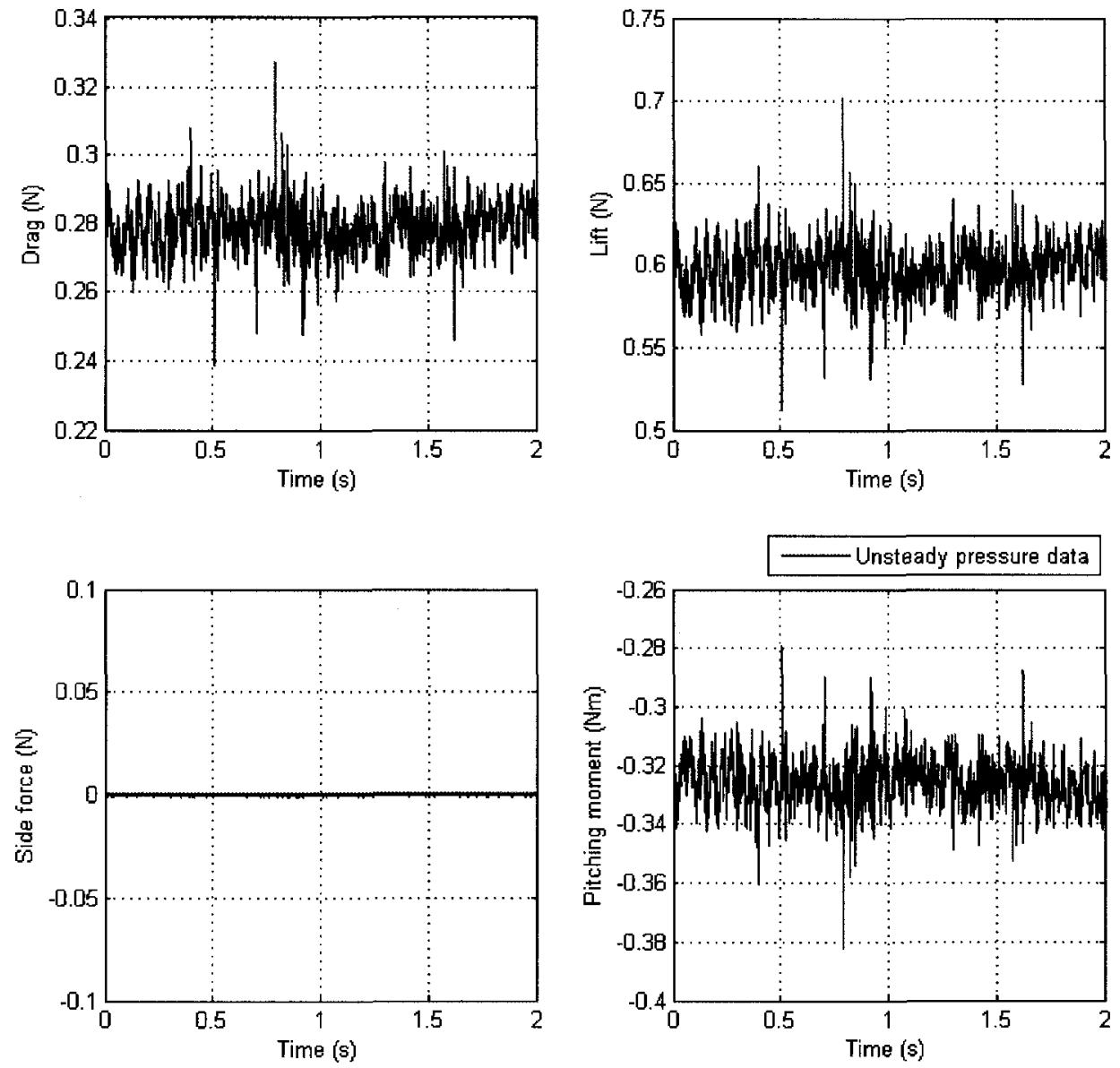

Figure 49: Time series of the unsteady pressure measurement, reference configuration, $15 \mathrm{~m} / \mathrm{s}$. 

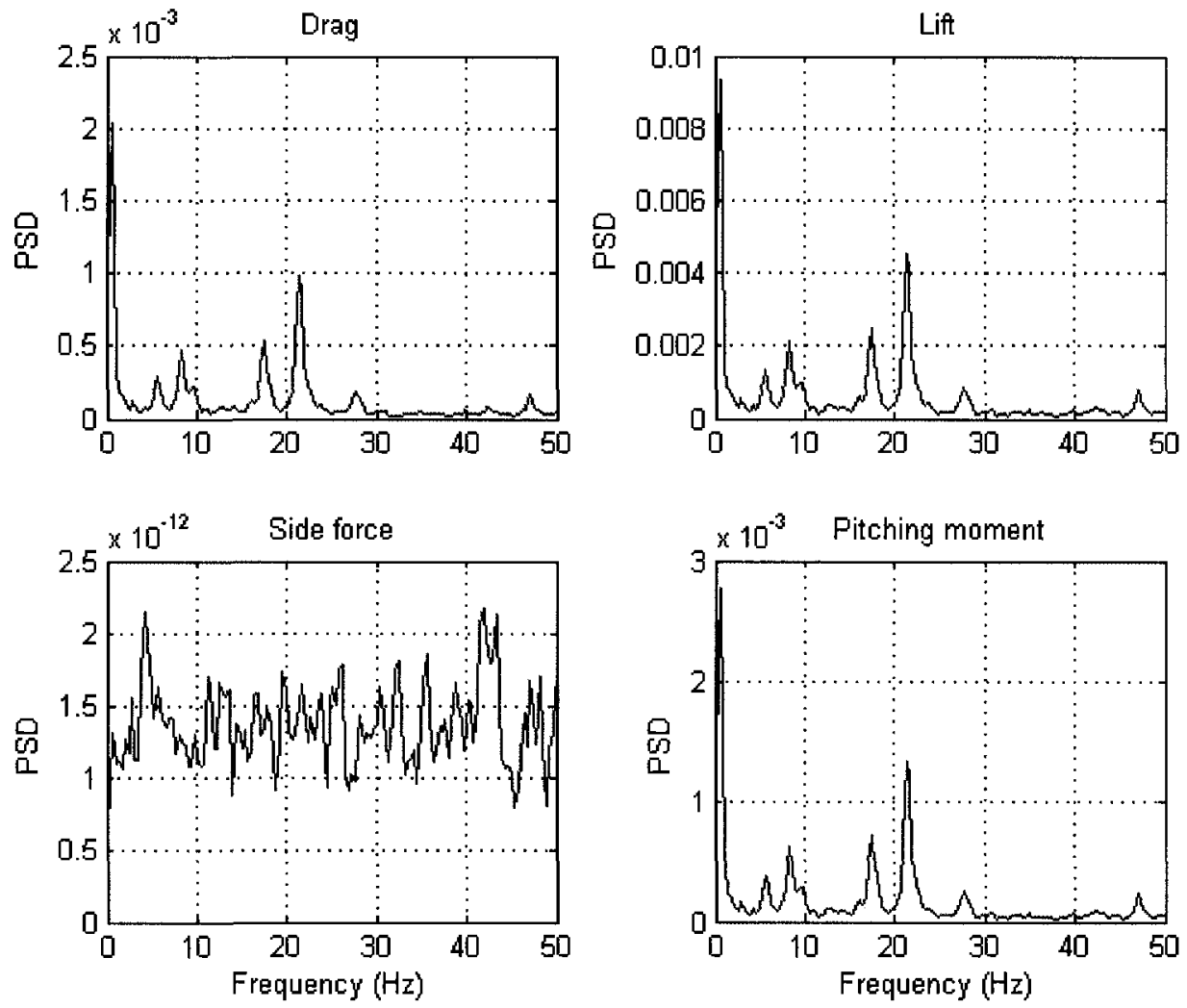

Figure 50: Spectrum of the time series, reference configuration, $15 \mathrm{~m} / \mathrm{s}$. 


\subsubsection{Visualization of the pressures}

The surface pressure measurements were presented using pressure coefficient $C_{p}$ defined as:

$$
C_{p}=\frac{P_{i}-P I}{q}
$$

where:

- $P_{i}$ is the local pressure at the pressure tap $i$;

- PI is the static pressure reference; and

- $q$ is the dynamic pressure.

The mean and peak coefficients are presented in Figures 51 and 52. The left column presents the mean coefficients and the right column presents the peak coefficients calculated as:

$$
C_{p, p e a k}=\frac{\max \left(\mathrm{C}_{\mathrm{p}}\right)-\min \left(\mathrm{C}_{\mathrm{p}}\right)}{2}
$$

The mean pressure coefficient represents the static portion of the signal and the peak coefficient represents the dynamic portion of the signal. Therefore, the variation of the pressure coefficients can be compared with the mean coefficients.

In Figure 51, the mean coefficient increased for a higher ride height but the peak coefficient is higher at a smaller ride height.

The pressure distribution at a pitch angle of $4^{\circ}$, as observed in Figure 52, is different than the distribution observed for other angles. There is a strong variation of the mean pressure coefficients under the body and higher peak coefficients on the top for smaller mean pressure coefficients. Therefore, on top, the variation in the pressure coefficient is about $100 \%$ the mean pressure coefficient, and for some taps, 

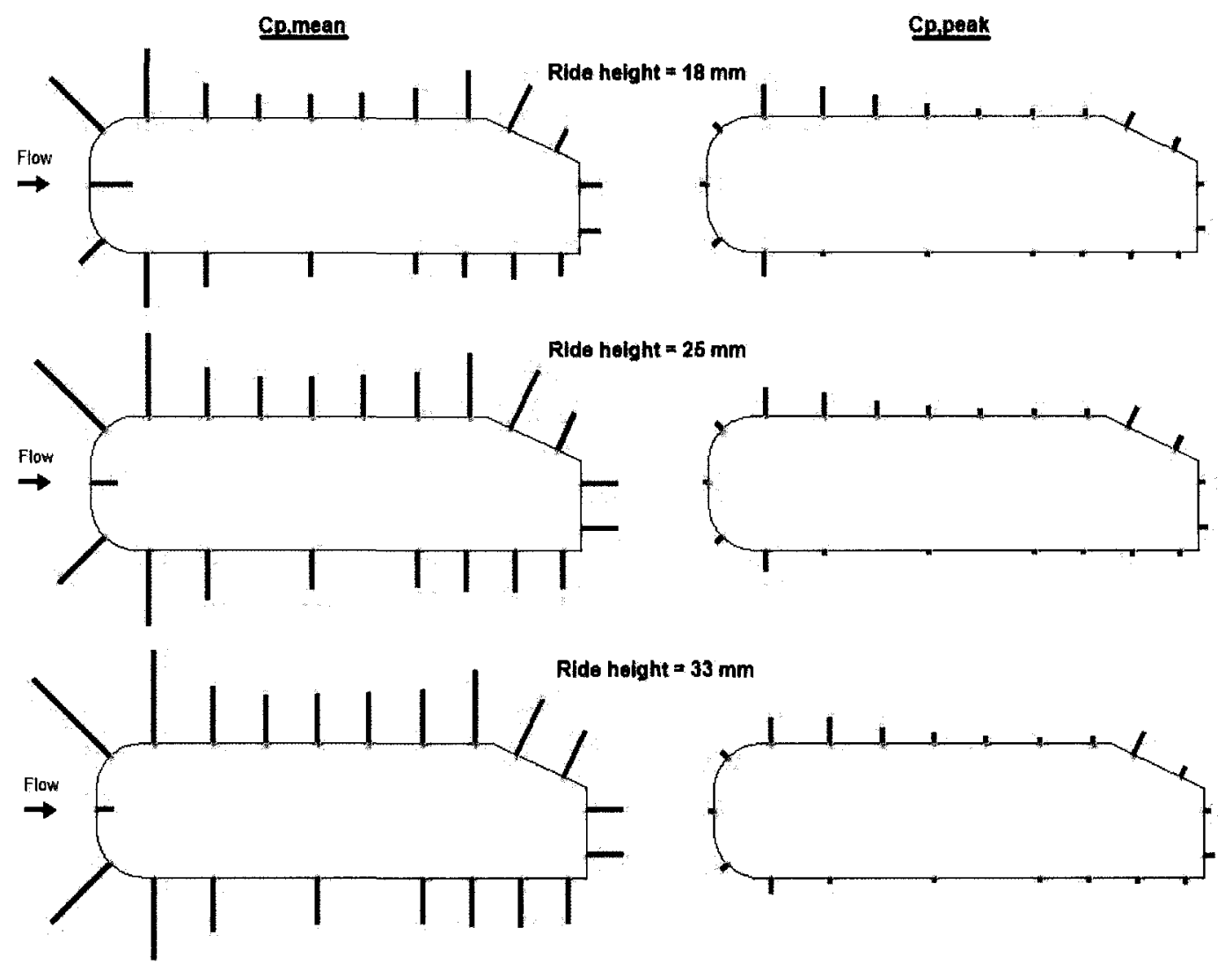

Figure 51: Visualization of the mean (left) and peak pressure (right) coefficients for each pressure tap for the three ride heights at $15 \mathrm{~m} / \mathrm{s}$, pitch angle of $0^{\circ}$. 

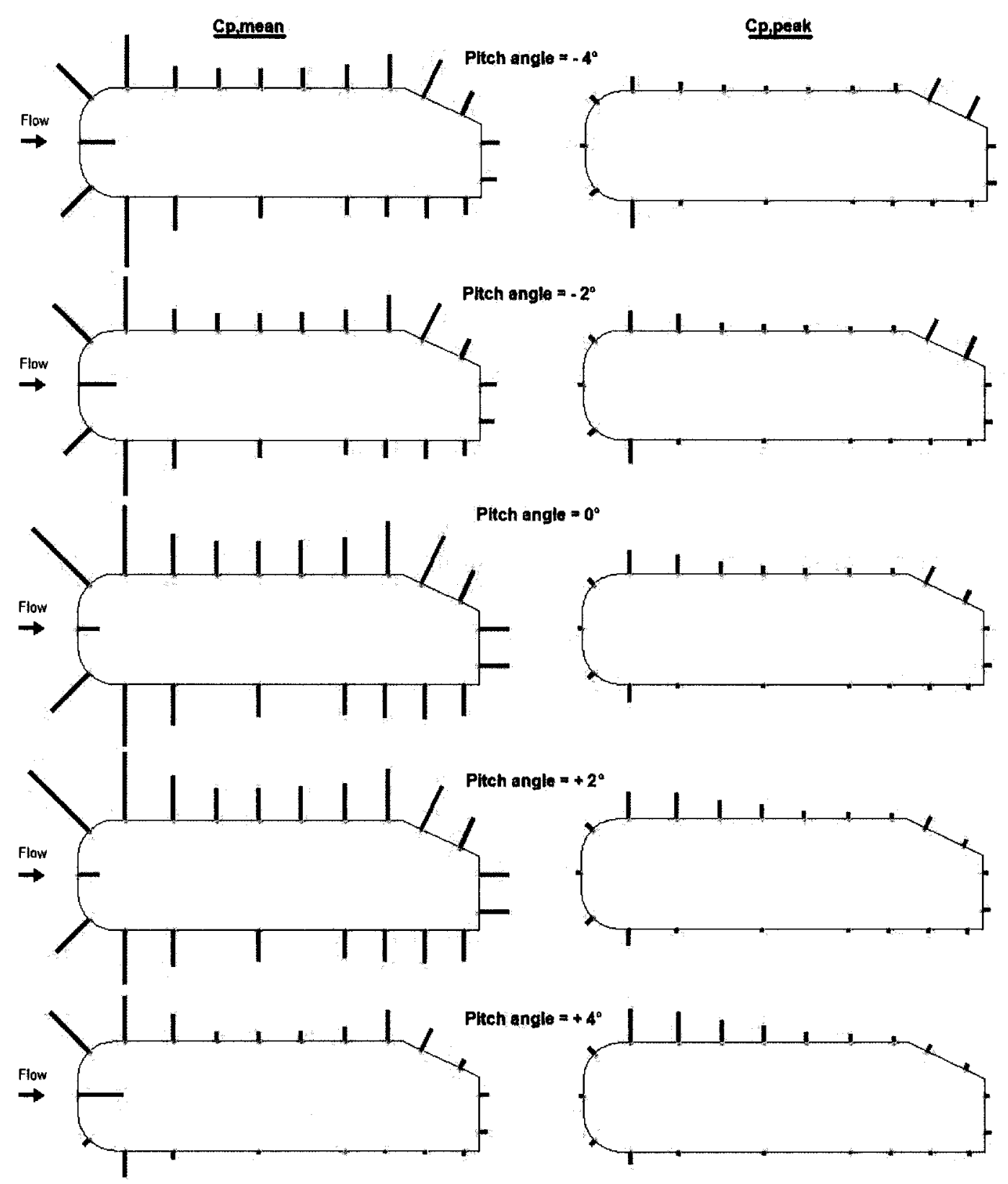

Figure 52: Visualization of the mean (left) and peak pressure (right) coefficients for each pressure tap for the five pitch angles at $15 \mathrm{~m} / \mathrm{s}$, ride height of $25 \mathrm{~mm}$. 

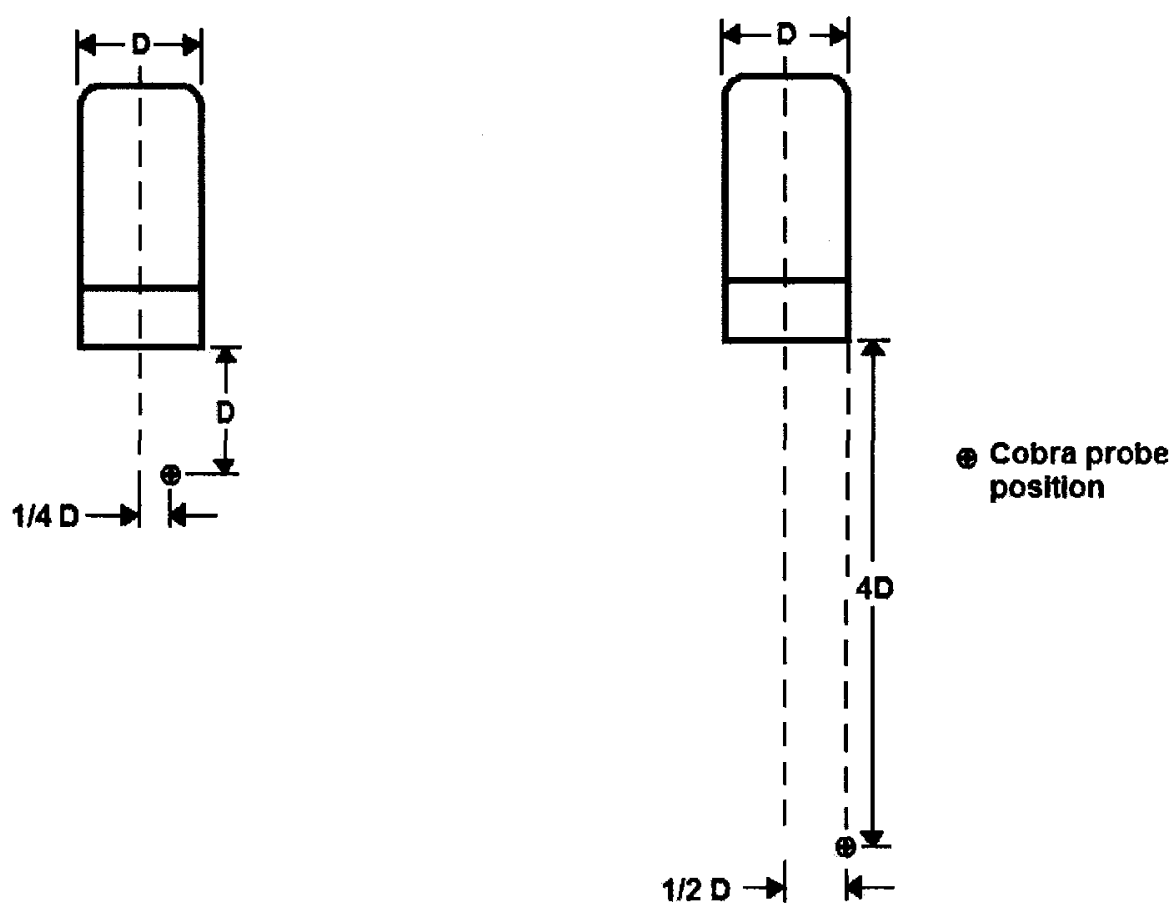

(a) First position

(b) Second position

Figure 53: Positions of the Cobra probe for the wake measurements.

more. The peak coefficients on the top of the body increase as the pitch angle is increased.

\subsubsection{Wake measurement}

Measurements in the wake of the model were made using a Cobra probe as described in Section 3.2.4. The measurements were performed for 60 seconds at a frequency of $2500 \mathrm{~Hz}$. Data was gathered at two different positions: one at $1 / 4$ of the width D perpendicular to the centreline of the model, $1 \mathrm{D}$ behind the model and $101 \mathrm{~mm}$ from the ground and the second position on the side line of the model, $4 \mathrm{D}$ behind the model at a height of $51 \mathrm{~mm}$, as shown in Figure 53. The static pressure was measured at the same height as the Cobra probe, but closer to the wall. 
Three tests were performed with the Cobra probe. At the first position, data were acquired in the wake of the model for speeds between $5 \mathrm{~m} / \mathrm{s}$ and $17 \mathrm{~m} / \mathrm{s}$ at increments of $2 \mathrm{~m} / \mathrm{s}$, for the reference configuration of the model, ride height of $25 \mathrm{~mm}$ and a pitch angle of $0^{\circ}$, and for a mixed configuration, ride height of $18 \mathrm{~mm}$ and pitch angle of $2^{\circ}$.

The second test was perform at a constant speed, but the yaw angle was varied from $-4^{\circ}$ to $10^{\circ}$ in increments of $2^{\circ}$. The Cobra probe was positioned at the second position as shown on Figure 53 and the model was tested with the same mixed configuration as for the first test. This test was performed at $11 \mathrm{~m} / \mathrm{s}, 13 \mathrm{~m} / \mathrm{s}$ and $15 \mathrm{~m} / \mathrm{s}$.

Finally, data was acquired in the wake, at the second position for the same mixed configuration of the model, during the ramp down of the wind tunnel.

\section{Reference configuration of the model}

Figures 54,55 and 56 present the spectrum of the longitudinal $u$, lateral $v$, and vertical $w$ components of the model wake for three wind tunnel speeds, $5 \mathrm{~m} / \mathrm{s}, 11 \mathrm{~m} / \mathrm{s}$, and $17 \mathrm{~m} / \mathrm{s}$.

Large peaks are present at $0.3 \mathrm{~Hz}$ for all three components, but mostly for the vertical one. The formation of peaks at $1.526 \mathrm{~Hz}$ can be observed in Figure 56 at 11 $\mathrm{m} / \mathrm{s}$ and $17 \mathrm{~m} / \mathrm{s}$. This frequency corresponds to the frequency range excited in the non-stationary test presented in Chapter 2. This excitation also corresponds to heave movement, the degree of freedom excited. A peak can also be observed at $1.221 \mathrm{~Hz}$ at $17 \mathrm{~m} / \mathrm{s}$ in the longitudinal direction, but it was probably not contributing to the movement of the model.

The use of the Cobra probe allowed the acquisition of data at speeds as low as $4 \mathrm{~m} / \mathrm{s}$, which was not possible with the pressure taps. It also shows the variation of frequency content in the wake with speed. 

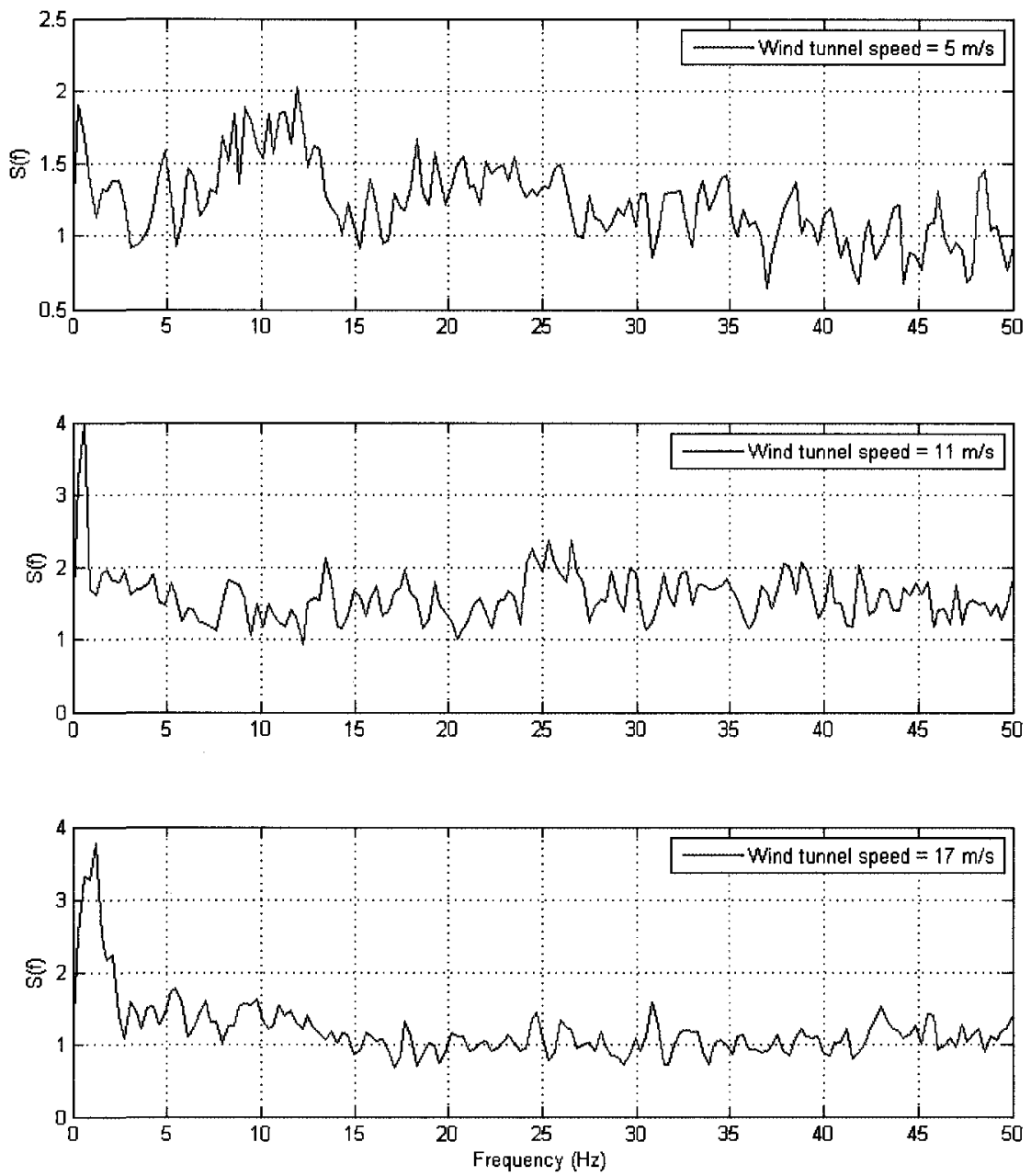

Figure 54: Spectrum of the $u$-component of the wake at reference configuration at 5,11 and $17 \mathrm{~m} / \mathrm{s}$. Ride height $=25 \mathrm{~mm}$, pitch angle $=0^{\circ}$. 

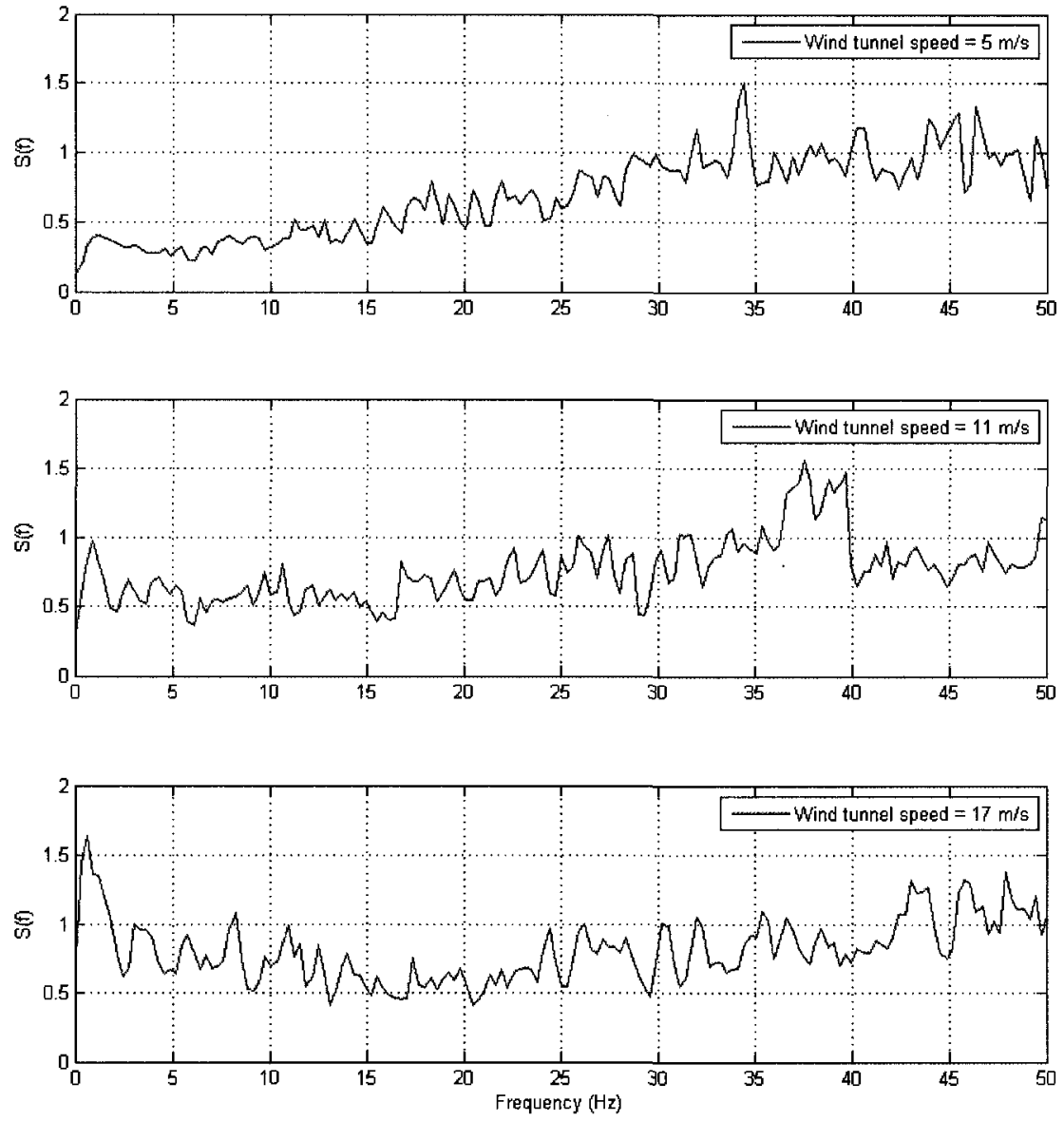

Figure 55: Spectrum of the $v$-component of the wake at reference configuration at 5,11 and $17 \mathrm{~m} / \mathrm{s}$. Ride height $=25 \mathrm{~mm}$, pitch angle $=0^{\circ}$. 

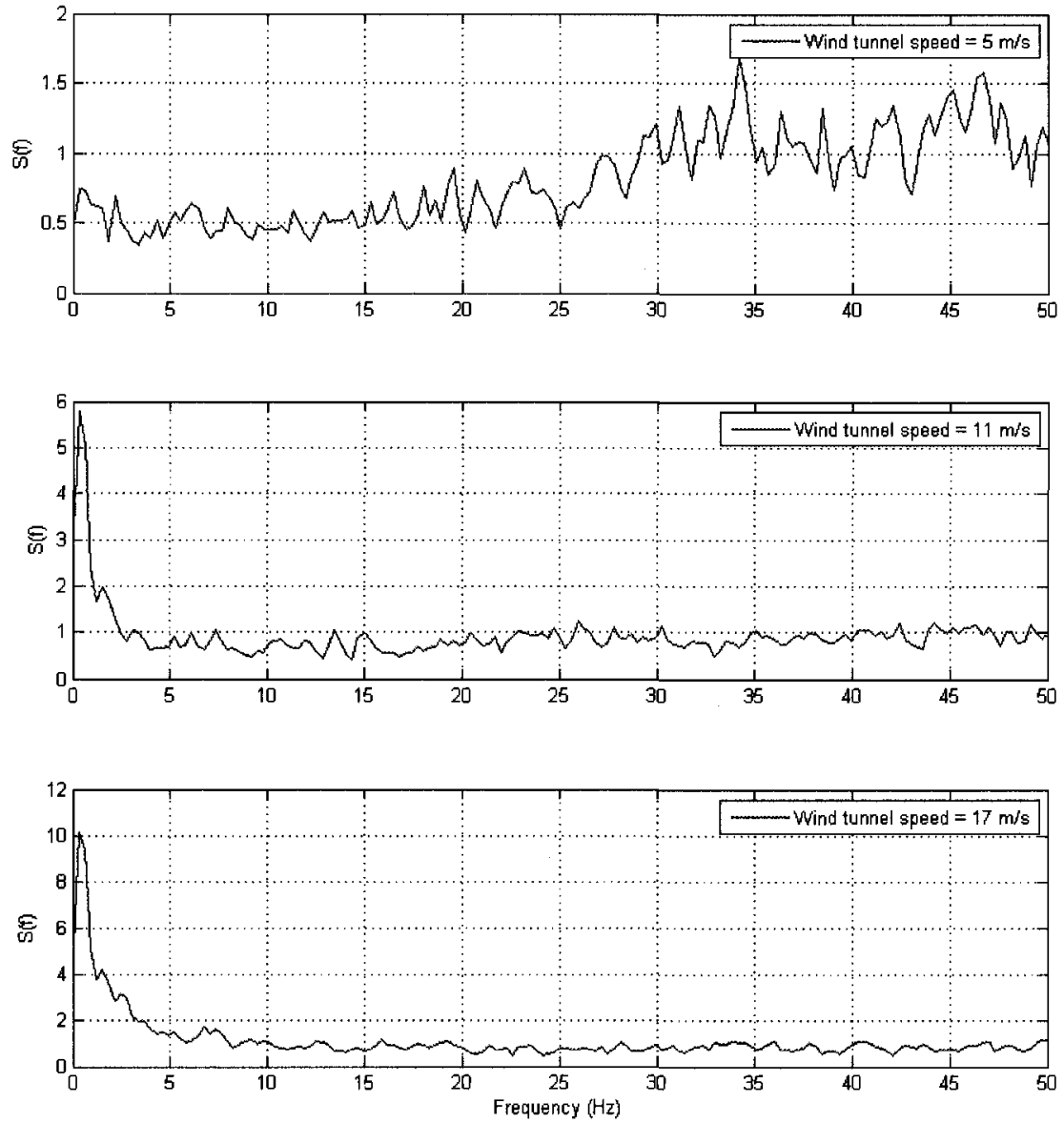

Figure 56: Spectrum of the $w$-component of the wake at reference configuration at 5,11 and $17 \mathrm{~m} / \mathrm{s}$. Ride height $=25 \mathrm{~mm}$, pitch angle $=0^{\circ}$. 
Figure 57 presents the spectrum of the vertical component for all the wind speeds at which data was acquired. On the top figure, the spectrum is presented over the frequency range $0-30 \mathrm{~Hz}$. A large peak is present at $0.3 \mathrm{~Hz}$ and a smaller one is increasing with the wind speed at $1.5 \mathrm{~Hz}$, just beside it. Since this frequency corresponds to the frequency excited during the non-stationary test, the bottom figure is presented with a frequency range of $1-30 \mathrm{~Hz}$. The peak at $1.5 \mathrm{~Hz}$ is increasing with wind speed and is particularly large after $9 \mathrm{~m} / \mathrm{s}$ compared to the frequency content at higher frequencies. This is consistent with the observations from Chapter 2. 


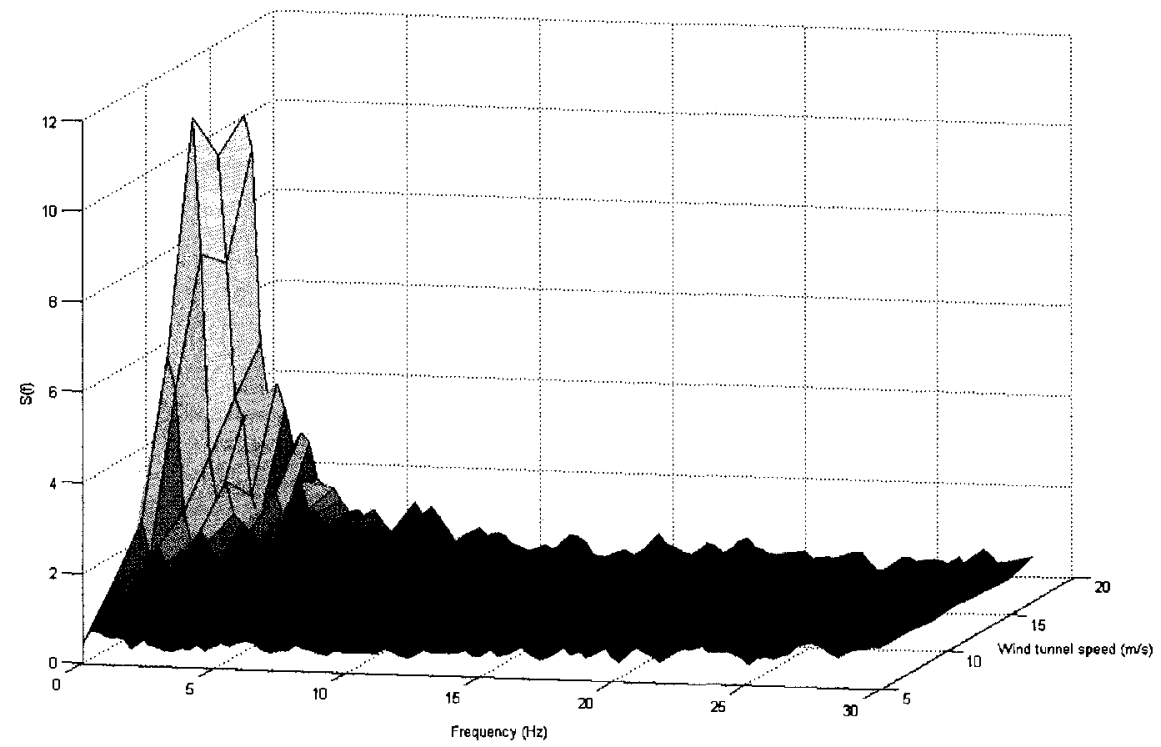

(a) Frequency range $0-30 \mathrm{~Hz}$

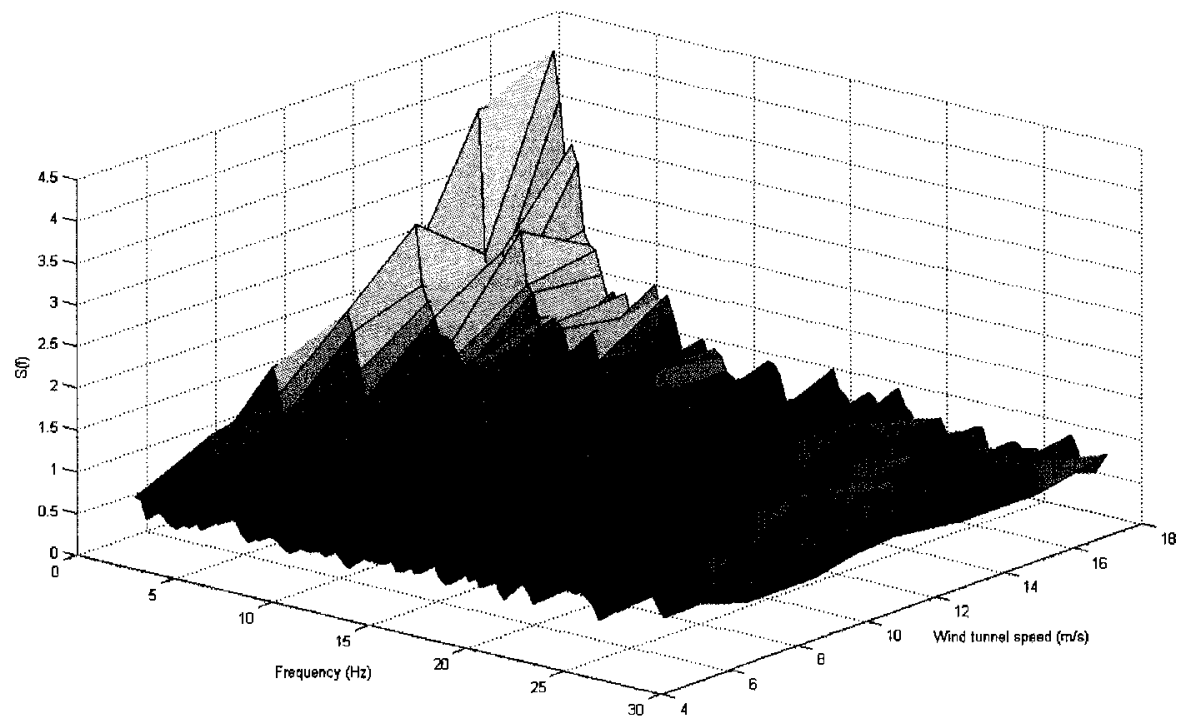

(b) Frequency range $1-30 \mathrm{~Hz}$

Figure 57: 3-D carpet plot of the $w$-component of the wake as a function of wind speed for the reference configuration. (The top figure is plotted with a frequency ranging from 0 to $30 \mathrm{~Hz}$ while the bottom one starts at $1 \mathrm{~Hz}$.) 


\section{Mixed configuration of the model}

Figures 58, 59 and 60 present the evolution of the three components of the wake as a function of the wind tunnel speed for a mixed configuration, ride height of $18 \mathrm{~mm}$ and pitch angle of $2.2^{\circ}$. Once again, a peak at $1.5 \mathrm{~Hz}$ at $17 \mathrm{~m} / \mathrm{s}$ can be observed on the vertical component spectrum on Figure 60. Another peak is observed at $2.441 \mathrm{~Hz}$ at $11 \mathrm{~m} / \mathrm{s}$ on the same figure.
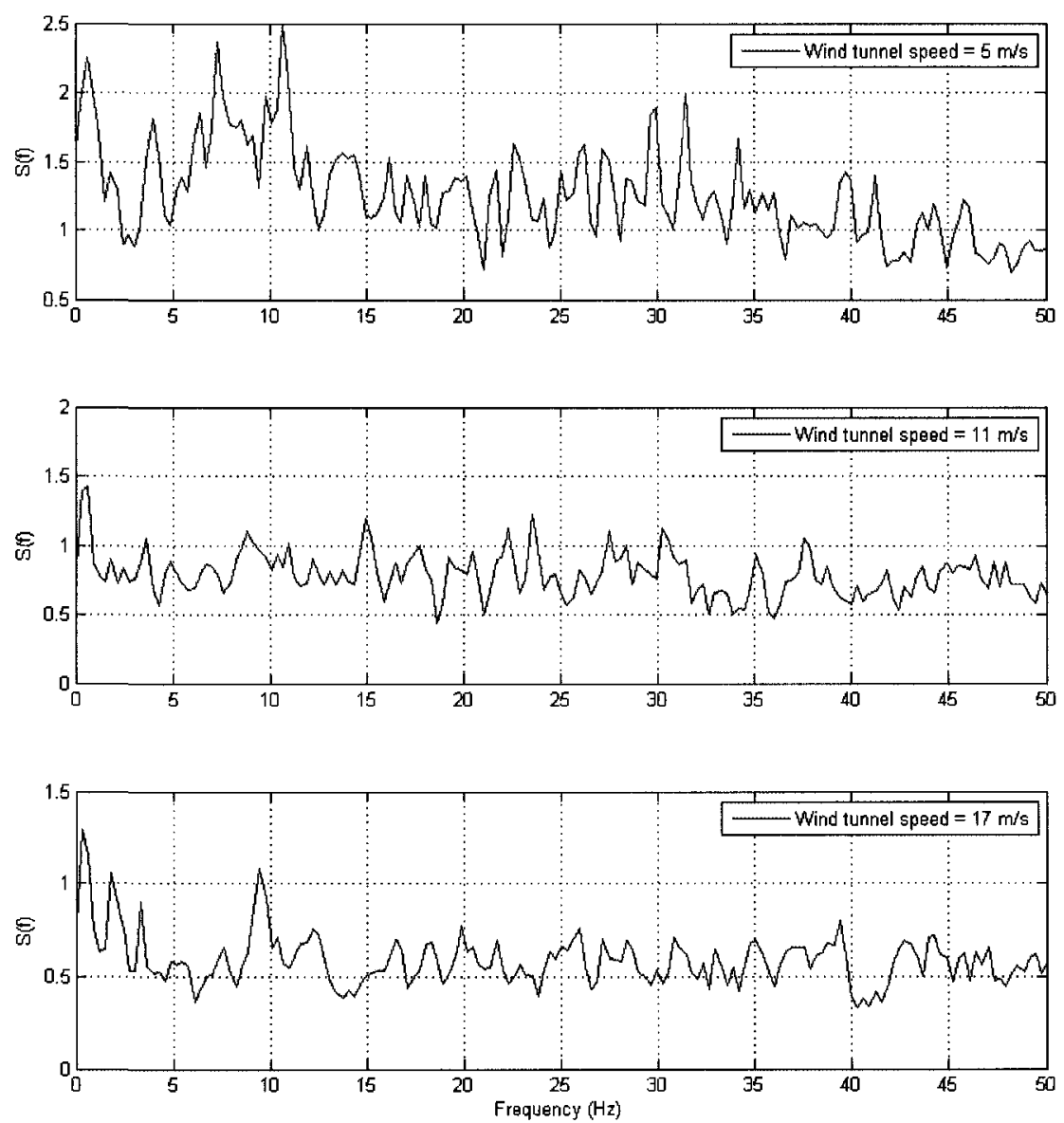

Figure 58: Spectrum of the $u$-component of the wake with a mixed configuration at 5,11 and $17 \mathrm{~m} / \mathrm{s}$. Ride height $=18 \mathrm{~mm}$, pitch angle $=2.2^{\circ}$. 

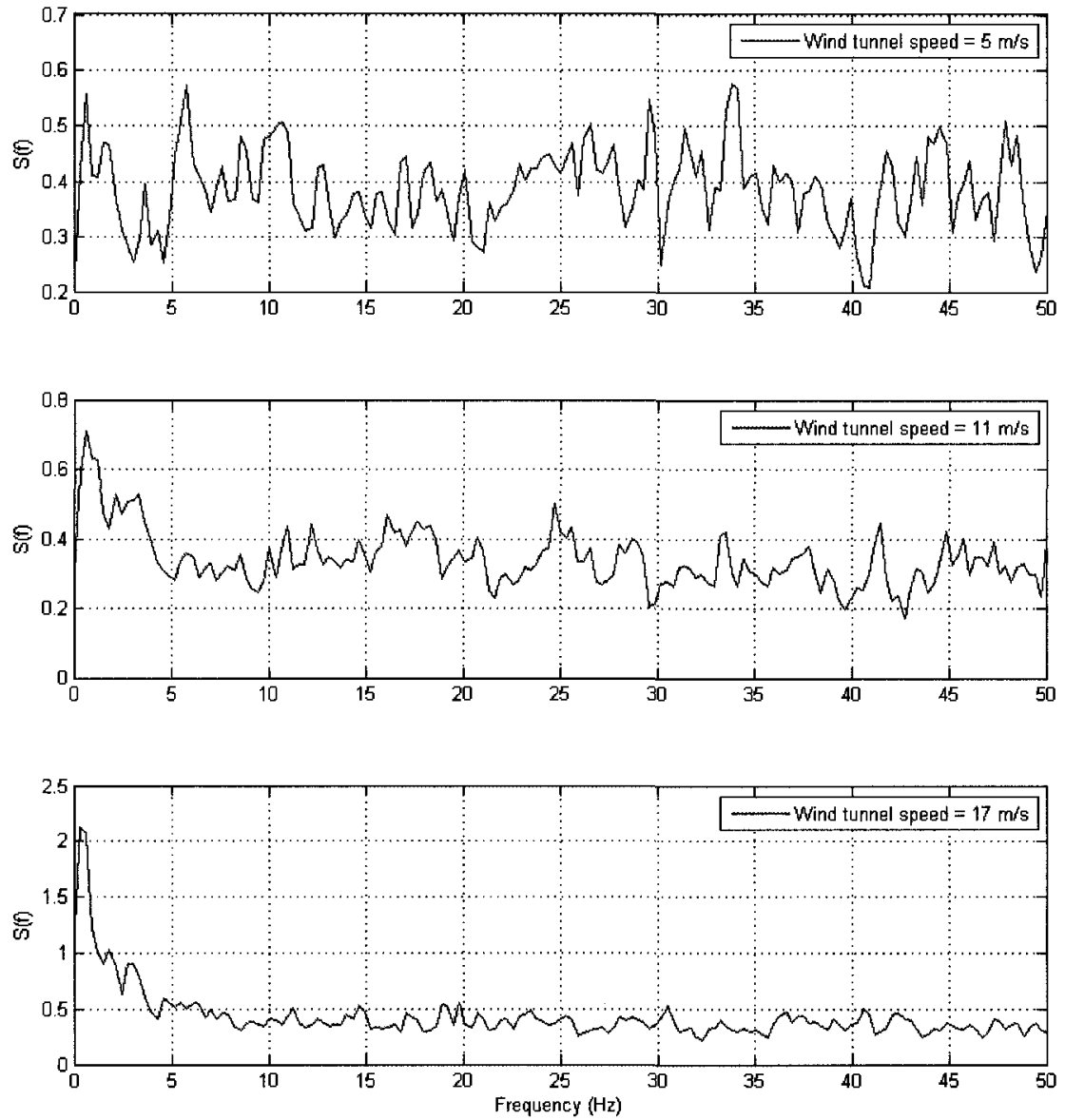

Figure 59: Spectrum of the $v$-component of the wake with a mixed configuration at 5,11 and $17 \mathrm{~m} / \mathrm{s}$. Ride height $=18 \mathrm{~mm}$, pitch angle $=2.2^{\circ}$. 

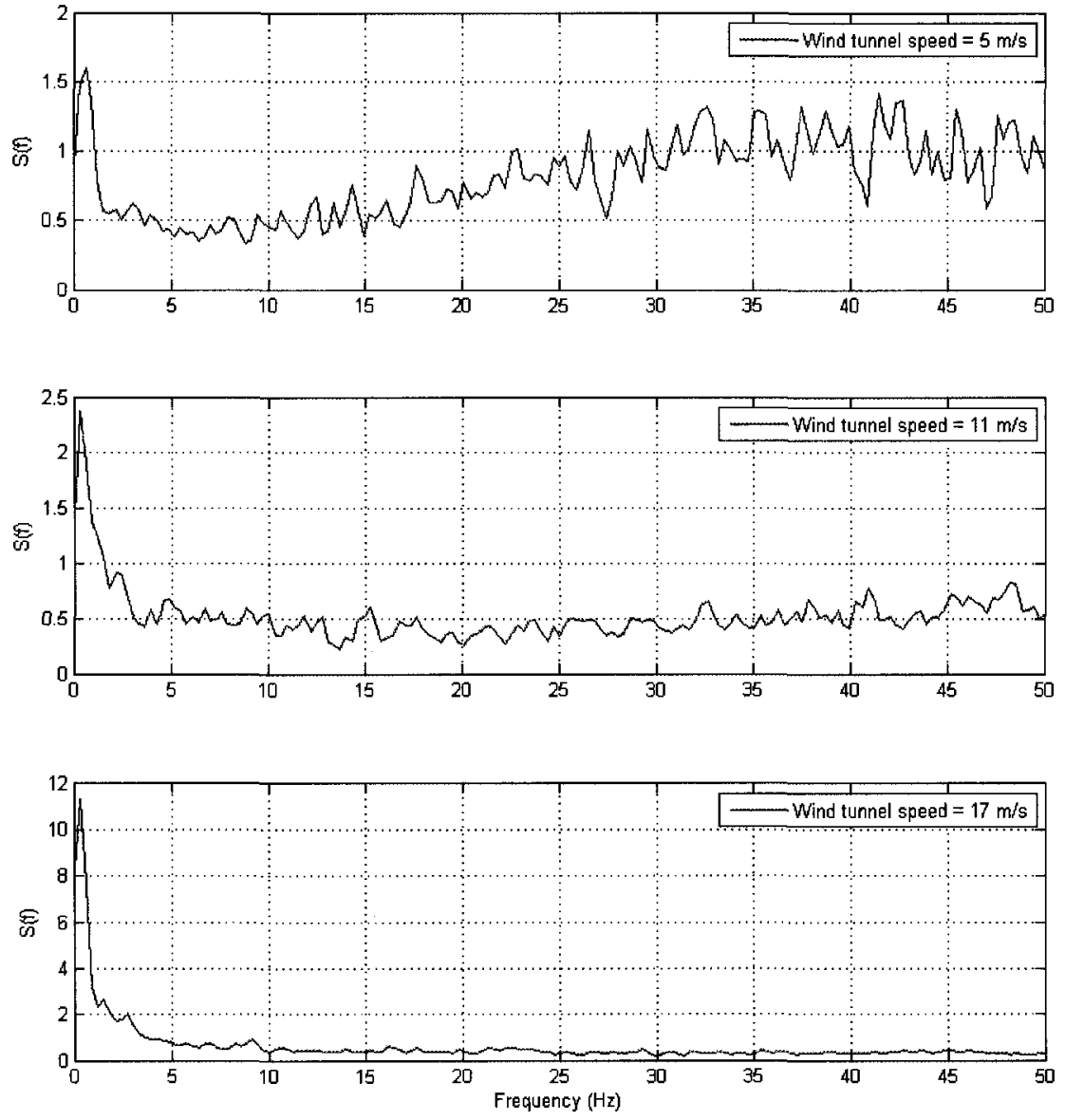

Figure 60: Spectrum of the $w$-component of the wake with a mixed configuration at 5,11 and $17 \mathrm{~m} / \mathrm{s}$. Ride height $=18 \mathrm{~mm}$, pitch angle $=2.2^{\circ}$. 
The large peak at $0.3 \mathrm{~Hz}$ and the smaller one at $1.5 \mathrm{~Hz}$ can be observed in Figure 61 . The peak at $1.5 \mathrm{~Hz}$ is increasing with wind speed, but this augmentation is more important at wind speeds of $11 \mathrm{~m} / \mathrm{s}$ and higher. Once again, it is consistent with the observations made during the non-stationary test, when the amplitude of the movement was increasing faster after $9-11 \mathrm{~m} / \mathrm{s}$. 


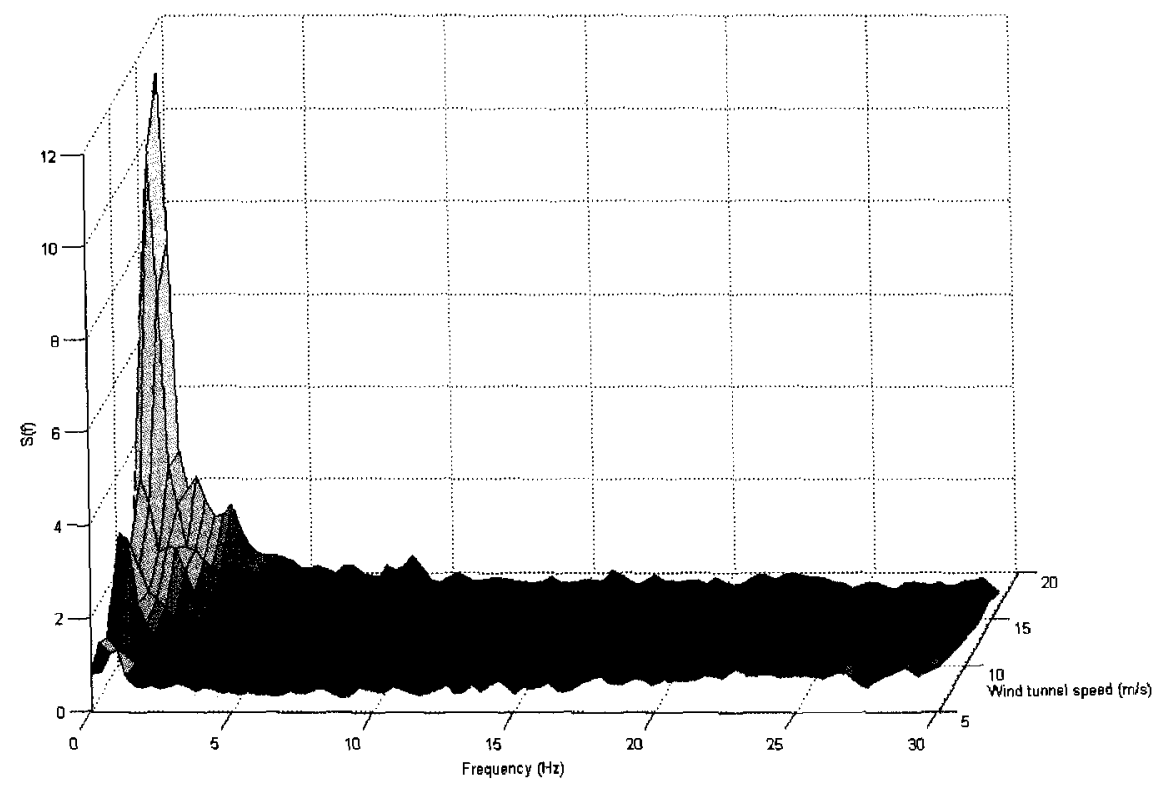

(a) Frequency range $0-30 \mathrm{~Hz}$

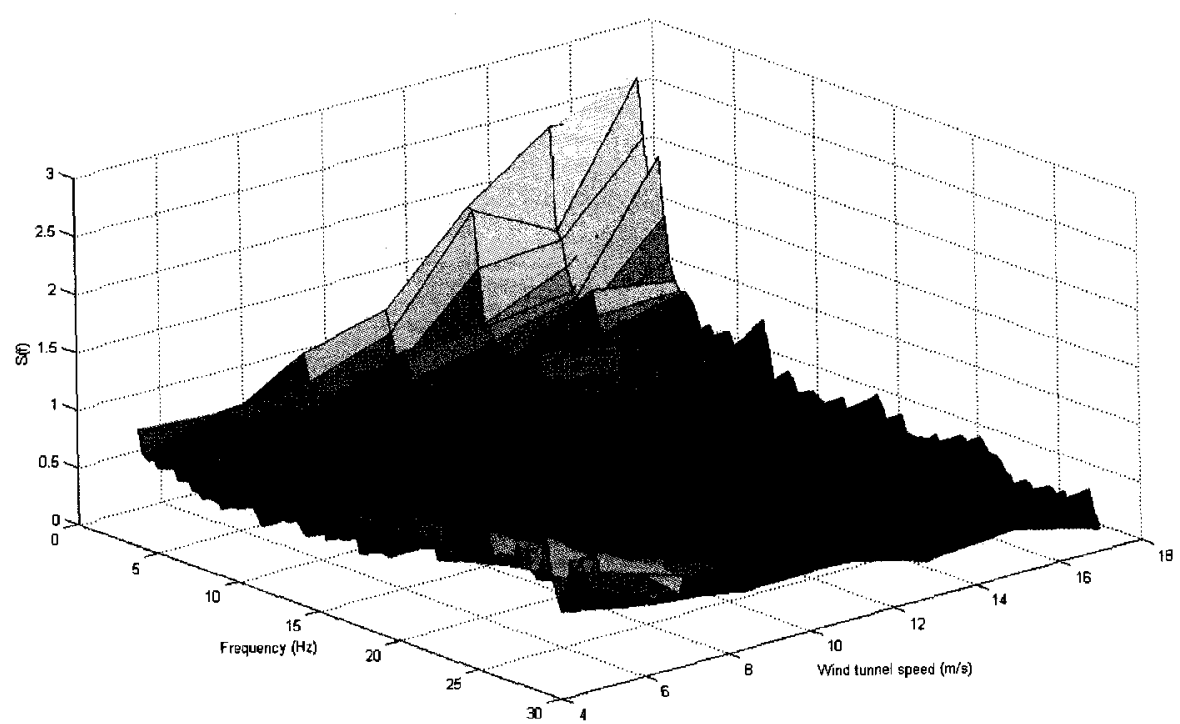

(b) Frequency range 1-30 Hz

Figure 61: 3-D carpet plot of the $w$-component of the wake as a function of wind speed. Ride height $=18 \mathrm{~mm}$, pitch angle $=2.2^{\circ}$. (The top figure is plotted with a frequency ranging from 0 to $30 \mathrm{~Hz}$ while the bottom one starts at $1 \mathrm{~Hz}$.) 
Spectra of the three components for four yaw angles $\left(-4^{\circ}, 0^{\circ},+4^{\circ},+8^{\circ}\right)$ are presented in Figures 62, 63 and 64.

The data acquisition was performed for only 15 seconds at each angle for this test. Due to the high sampling frequency, to obtain a good resolution of the spectrum, the spectral window had to be large. The variance error of this test is $0.46(46 \%)$, therefore the amplitude of the peaks is an estimation but the frequency corresponding to the peak is correct.

There are no particular tendencies observable in the spectra of the different yaw angles. 

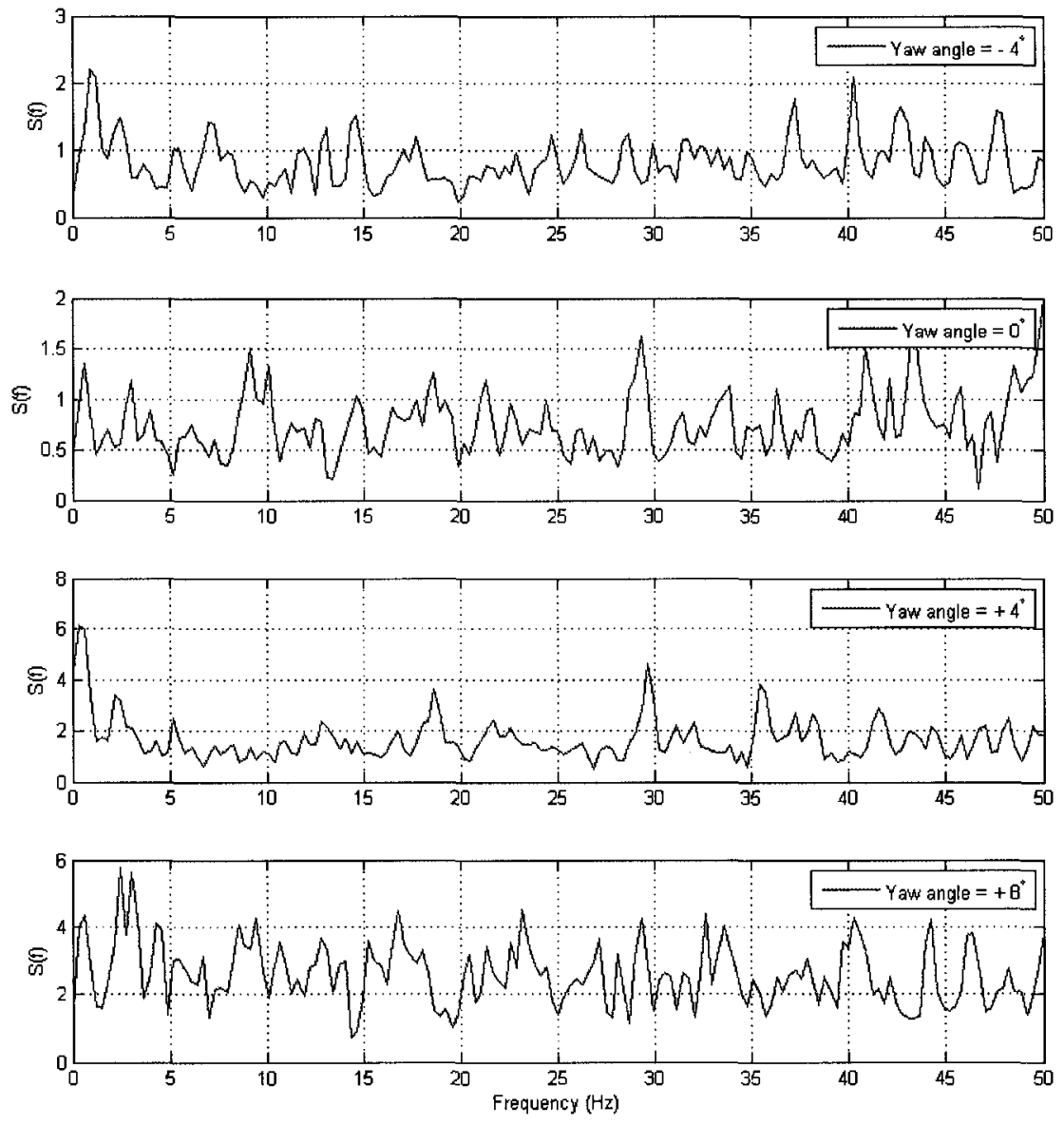

Figure 62: Spectrum of the $u$-component of the wake with a mixed configuration for different yaw angles at $15 \mathrm{~m} / \mathrm{s}$. Ride height $=18 \mathrm{~mm}$, pitch angle $=2.2^{\circ}$. 

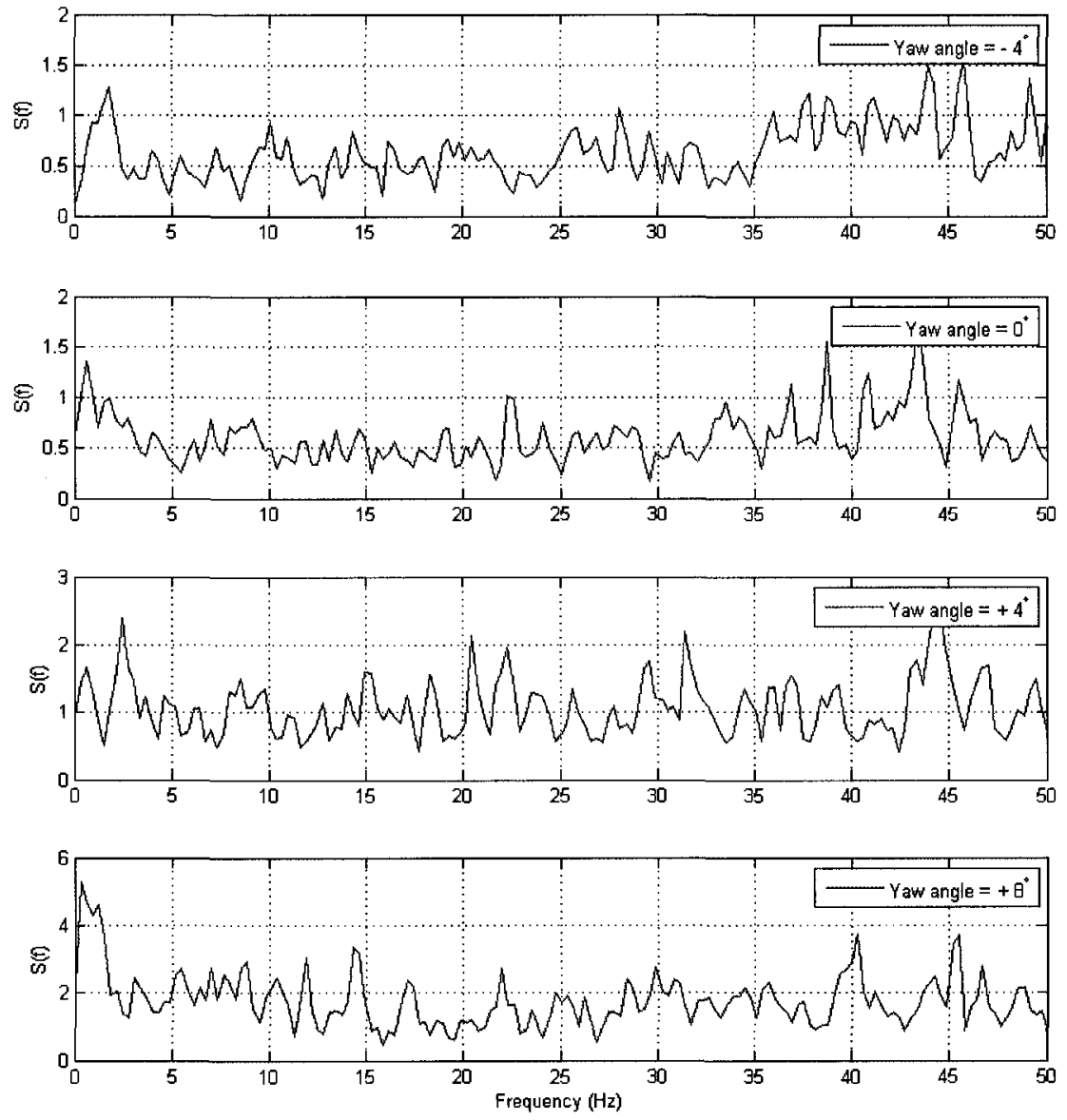

Figure 63: Spectrum of the $v$-component of the wake with a mixed configuration for different yaw angles at $15 \mathrm{~m} / \mathrm{s}$. Ride height $=18 \mathrm{~mm}$, pitch angle $=2.2^{\circ}$. 

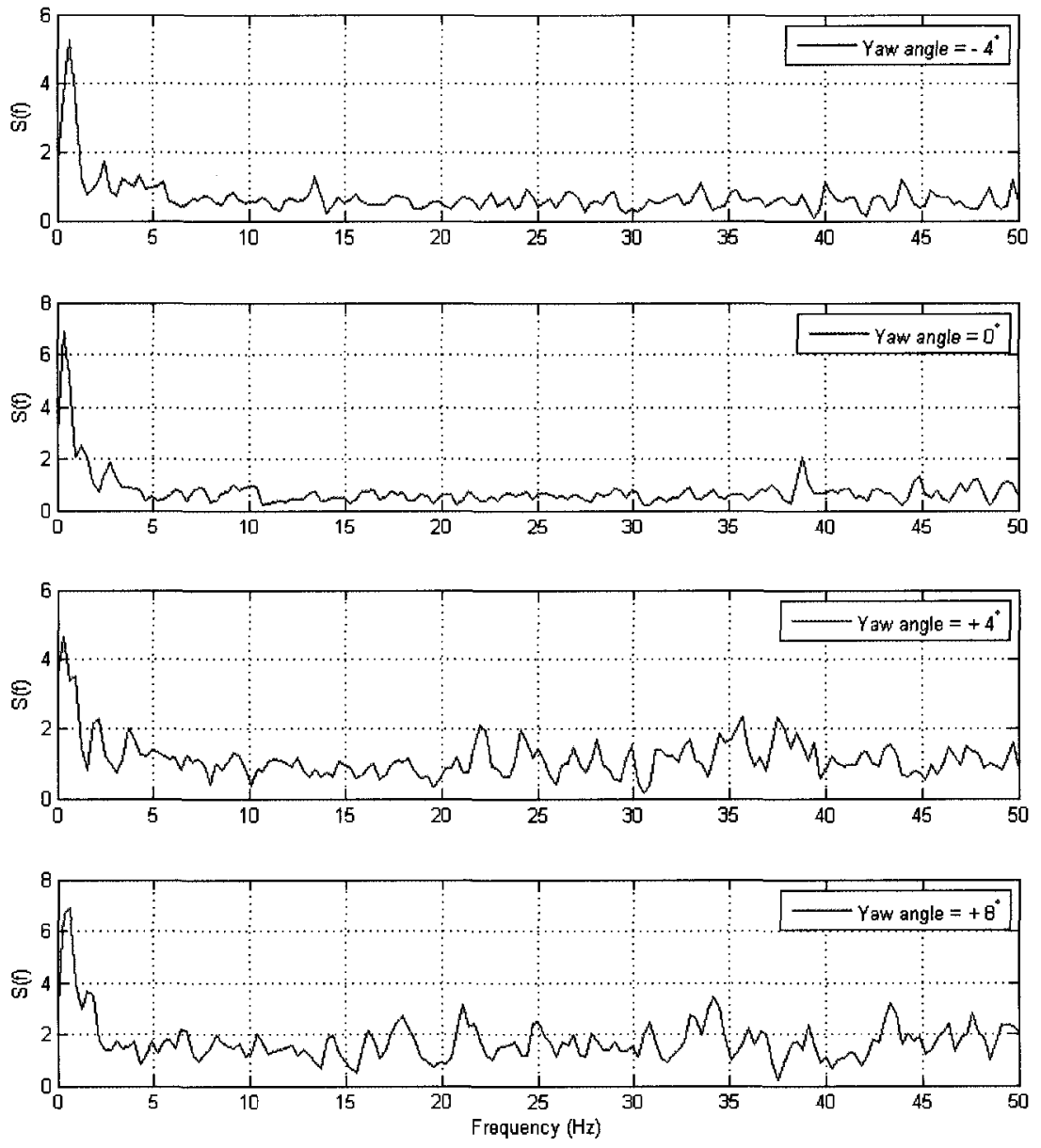

Figure 64: Spectrum of the $w$-component of the wake with a mixed configuration for different yaw angles at $15 \mathrm{~m} / \mathrm{s}$. Ride height $=18 \mathrm{~mm}$, pitch angle $=2.2^{\circ}$. 


\subsection{Conclusions regarding the stationary test}

With the stationary test, the aerodynamic characteristics of the Ahmed body and the steady and unsteady pressure distributions were determined for different configurations. This information was used in the dynamic model presented in Chapter 4.

It was observed that the ride height has a strong influence on the drag and lift coefficients and the pitch angle has a strong influence on the drag, lift and yawing moment coefficients.

The time series of the surface pressure measurements presented a variation of about $10 \%$ of the amplitude around the mean coefficient. Some large peaks were observed in the time series.

The visualization of the pressure coefficient distribution showed a strong variation of the mean and peak pressure distribution as a function of the variation of the pitch angle. Small variations were observed for a ride height variation.

The measurements in the wake of the model showed the presence of a large peak at $0.3 \mathrm{~Hz}$ and the presence of a peak at $1.5 \mathrm{~Hz}$ that is not negligible at wind speeds of more than $9 \mathrm{~m} / \mathrm{s}$. This could be interpreted as the possible source of the excitation of the non-stationary model. 


\section{Chapter 4}

\section{Dynamic model}

A dynamic model has been developed to determine if the displacements of the model observed during the non-stationary test can be predicted by the set-up characteristics measured in the $5 \mathrm{~m}$ Vertical Wind Tunnel and the steady and unsteady aerodynamic forces measured on the stationary model.

This dynamic model will determine if the motion induced forces have an important impact on the behaviour of the model or if the stationary forces and their variations with ride height and pitch angle or the unsteady forces originating from the wake are the main source of the displacements.

\subsection{Model}

\subsubsection{Development of the model}

The set-up characteristics measured in the $5 \mathrm{~m}$ Wind Tunnel are the total damping and the total stiffness in heave, pitch and yaw. When measuring the unsteady forces on the stationary model, the limitation in the number of pressure taps allowed the acquisition of consistent data only in drag, heave and pitch. 
Therefore, the dynamic model will be based on the two degrees-of-freedom common to both tests: heave and pitch.

In the simulation, the stiffness of the model will be modeled by a compression spring for heave and a torsional spring for pitch. A traditional damper and a torsional damper will represent the damping in heave and in pitch, as presented in Figure 65.

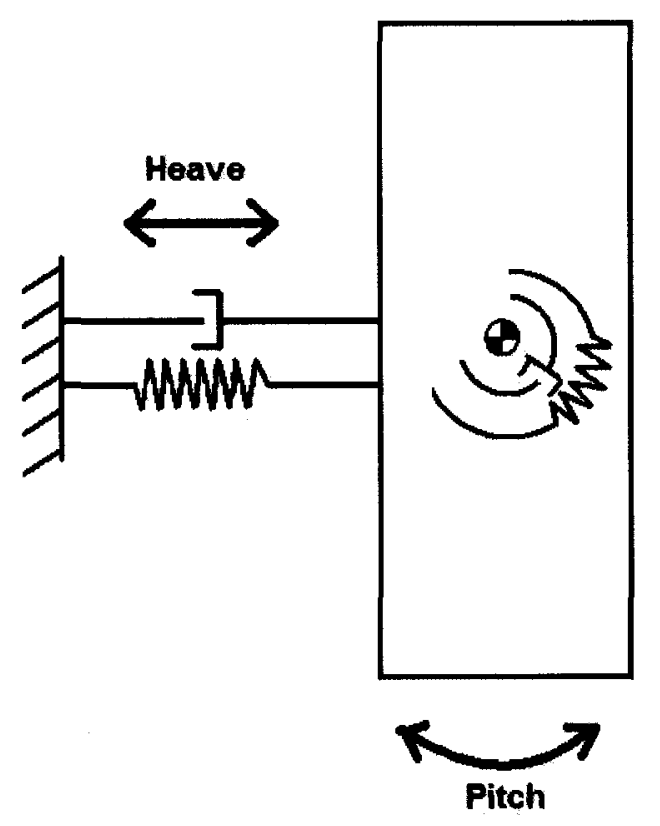

Figure 65: Diagram of the springs and dampers used for the simulation.

The dynamic model is based on the hypothesis that there is no damping or stiffness effect in roll, side, drag or yaw and the lateral damping and stiffness are constant over the whole body.

Newton's second law states that:

$$
\Sigma F=m a
$$


We can apply Newton's second law for the heave degree-of-freedom and its rotational analogue to the pitch degree-of-freedom separately. In heave, it can be expressed as:

$$
m_{t o t a l} a_{h}=-F_{D H}-F_{S H}+F_{A H}
$$

where:

- $m_{\text {total }}$ is the total displaced mass of the model;

- $a_{h}$ is acceleration in heave of the model;

- $F_{D H}$ is the reaction force of the spring;

- $F_{S H}$ is the reaction force of the damper; and

- $F_{A H}$ is the aerodynamic forces applied to the model.

The forces are presented on the free body diagram presented in Figure 66

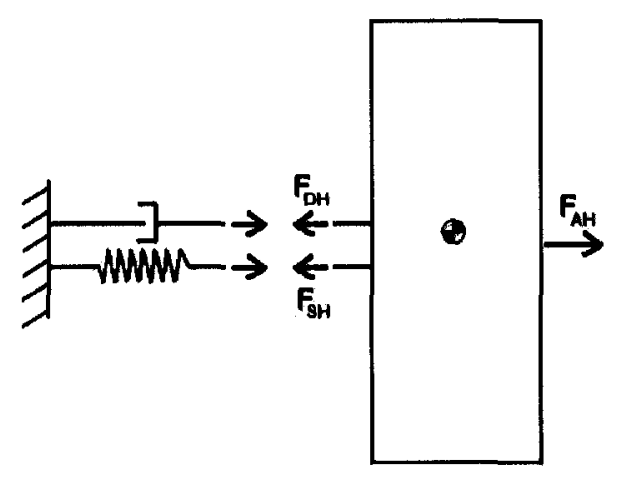

Figure 66: Free body diagram of the forces in heave.

The total displaced mass can be determined as per the equation below that accounts for the portion of the spring mass that is in motion. The effective contribution from the standard helical springs can be assumed to be one third of their total 
mass $[17]$

$$
m_{\text {total }}=m_{\text {model }}+\frac{1}{3} m_{\text {springs }}
$$

Rearranging Equation (26), we can isolate the aerodynamic forces can be isolated:

$$
m_{t o t a l} a_{h}+F_{D H}+F_{S H}=F_{A H}
$$

The reaction forces of the spring and the damper can be expressed as a function of the position, $x_{h}$, and the velocity, $\dot{x}_{h}$, of the model:

$$
\begin{gathered}
F_{S H}=k_{h} x_{h}, \\
F_{D H}=c_{h} \dot{x}_{h} .
\end{gathered}
$$

Therefore, Equation (28) can be expressed as:

$$
F_{A H}=m_{\text {total }} \ddot{x}_{h}+c_{h} \dot{x}_{h}+k_{h} x_{h}
$$

The same reasoning can be applied for pitch for the summation of the moments:

$$
I_{z} a_{p}=-M_{D P}-M_{S P}+M_{A P}
$$

where:

- $a_{p}$ is acceleration in pitch of the model;

- $M_{D P}$ is the reaction moment of the spring;

- $M_{S P}$ is the reaction moment of the damper; and

- $M_{A P}$ is the aerodynamic moment applied on the model. 
Therefore, the final expression of the pitch moment as a function of the position, $x_{p}$, the velocity, $\dot{x}_{p}$, and the acceleration, $\ddot{x}_{h}$, is:

$$
M_{A P}=I_{z} \ddot{x}_{p}+c_{p} \dot{x}_{p}+k_{p} x_{p}
$$

\subsubsection{General formulation of the model}

The general dynamic model formulation is:

$$
[M]\{\ddot{x}\}+[C]\{\dot{x}\}+[K]\{x\}=\{F\}
$$

where $[M]$ is the mass matrix, $[C]$ is the damping matrix, $[K]$ the stiffness matrix, $\{F\}$ the force vector and $\{\ddot{x}\},\{\dot{x}\}$ and $\{x\}$ are the composite acceleration vector, the composite velocity vector and the composite position vector of the model respectively.

Equations (31) and (33) can be rewritten in the uncoupled matrix form:

$$
\left[\begin{array}{cc}
m & 0 \\
0 & I_{z}
\end{array}\right]\left[\begin{array}{l}
\ddot{x}_{h} \\
\ddot{x}_{p}
\end{array}\right]+\left[\begin{array}{cc}
c_{h} & 0 \\
0 & c_{p}
\end{array}\right]\left[\begin{array}{l}
\dot{x}_{h} \\
\dot{x}_{p}
\end{array}\right]+\left[\begin{array}{cc}
k_{h} & 0 \\
0 & k_{p}
\end{array}\right]\left[\begin{array}{l}
x_{h} \\
x_{p}
\end{array}\right]=\left[\begin{array}{l}
F_{A H} \\
M_{A P}
\end{array}\right]
$$

The damping coefficients for the damping matrix can be determined using the total damping measured for each wind speed in the wind tunnel.

Assuming that the system is a dissipative system and that the amplitude of the displacement of the model is small and always in the linear domain, the critical damping coefficient can be calculated from

$$
c_{c r}=2 \cdot m \cdot \omega
$$

The critical damping coefficient is a function of the mass of the system, $m$, and of the damped natural frequency, $\omega$, measured to determine the total stiffness in Section 2.3.3. 
The damping coefficient, $c$, applicable in the damping matrix is a function of the percentage of critical damping, $\varepsilon$, and the critical damping coefficient, $c_{c r}$

$$
c=\varepsilon \cdot c_{c r}=2 \cdot \varepsilon \cdot m \cdot \omega
$$

The damping coefficient is function of the wind speed and therefore remains constant in the model for a given wind speed.

\subsection{Model solution}

\subsubsection{Euler method}

The numerical integration of the ordinary differential equations of the dynamic model has been performed using the Euler method. It is a first order numerical procedure used to solve differential equations with a given initial value.

In this case, the objective was to reproduce the test when the model was initially at rest and self-induced vibrations were observed and compare the amplitude of the oscillations once the build-up phase was completed. Therefore, the initial values for the body's initial positions and initial velocities were:

- initial position in heave : $0 \mathrm{~mm}$;

- initial velocity in heave : $0 \mathrm{~m} / \mathrm{s}$;

- initial position in pitch : $0^{\circ}$; and

- initial velocity in pitch : $0^{\circ} / \mathrm{s}$.

All other parameters such as model mass, damping coefficient, and spring stiffness were obtained from the parameters of the dynamic tests of Chapter 2. 
To enable the calculation of the position and velocity in the two degrees of freedom at the next time step, a force has to be applied on the system to determine the acceleration.

The forces are determined using the integrated pressures presented in Section 3.3.3. The average of the pressure data has been adjusted to match the average of the balance data for each degree of freedom by multiplying the time series by the corresponding factor. This procedure has been performed to decrease the effect of the limited number of pressure taps on the surface of the model. The balance data measured the effect of the flow on the whole body, therefore, the average is more reliable. The corrected integrated force and moment present the same average as the balance data, but contain also the measured variations.

The forces inserted in the dynamic model are dependant on the position of the model. The simulation therefore starts with the data acquired at the initial position. As the pitch angle and/or the ride height change, the force data applied to the model continuously changes to match the corresponding case measured in the wind tunnel. Limits have been assigned to determine the range associated with each set of data acquired during the stationary test of Chapter 3.

The forces are inserted in the model as acquired in the wind tunnel to correspond to the development of the flow around the body. The modification of this signal would not simulate the displacement of the flow along the side, top and bottom panels. Each time that the simulation programme changes the configuration, a random position is picked in the time series to use the data.

Once the forces in heave and pitch at $\mathrm{t}=0$ were determined, the initial acceleration could be determined.

Since the two motions, in heave and pitch, are assumed independent, the equations of motion could be used to determine the state of the system at the next step in time by applying the following integration rule both for the heave and pitch: 


$$
d_{t+\Delta t}=d_{t}+v_{t} \Delta t+\frac{1}{2} a \Delta t^{2}
$$

and

$$
v_{t+\Delta t}=v_{t}+a \Delta t
$$

where:

- $d_{t}$ is the body's initial position;

- $d_{t+\Delta t}$ is the final position;

- $v_{t}$ is the body's initial velocity;

- $v_{t+\Delta t}$ is the final velocity; and

- $a$ is the acceleration that is assumed to remain constant between those two points.

The final position and velocity for both heave and pitch were taken as the initial values of the next step. With the new position of the model, the appropriate unsteady pressure data were selected. Another random force was determined and a new acceleration was calculated, leading to the new final position and velocity. This loop was repeated by small increment of time, 0.0014 second, until the preselected simulation run time of 120 seconds elapsed.

\subsection{Validation of the model}

\subsubsection{Decay traces}

The first validation of the model performed was the reproduction of the decay traces. An initial displacement in heave or in pitch was determined in the model and the 


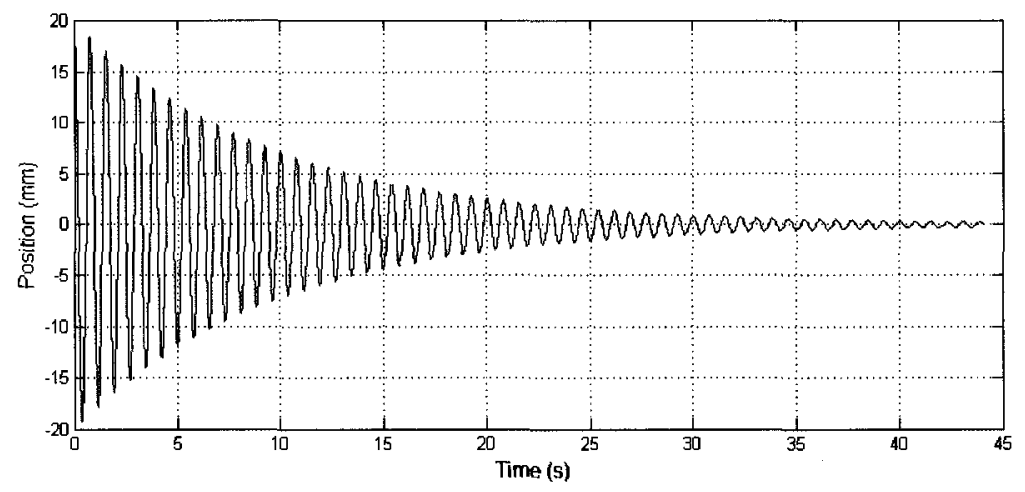

(a) Modeled decay trace

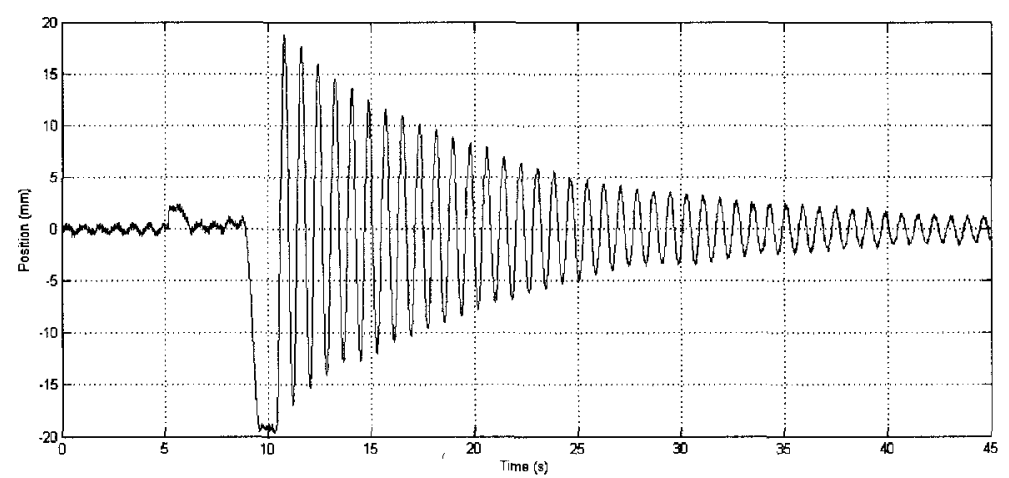

(b) Experimental decay trace

Figure 67: Comparison between the decay trace of the dynamic model and the experimental one in heave for the small weight case.

forces were equal to zero. This allowed validating the amplitude and the frequency of the modeled signal.

For the small weight and large weight cases, the frequency and amplitude of the signals matched very well with the experimental data, as shown in Figures 67 through 70. 


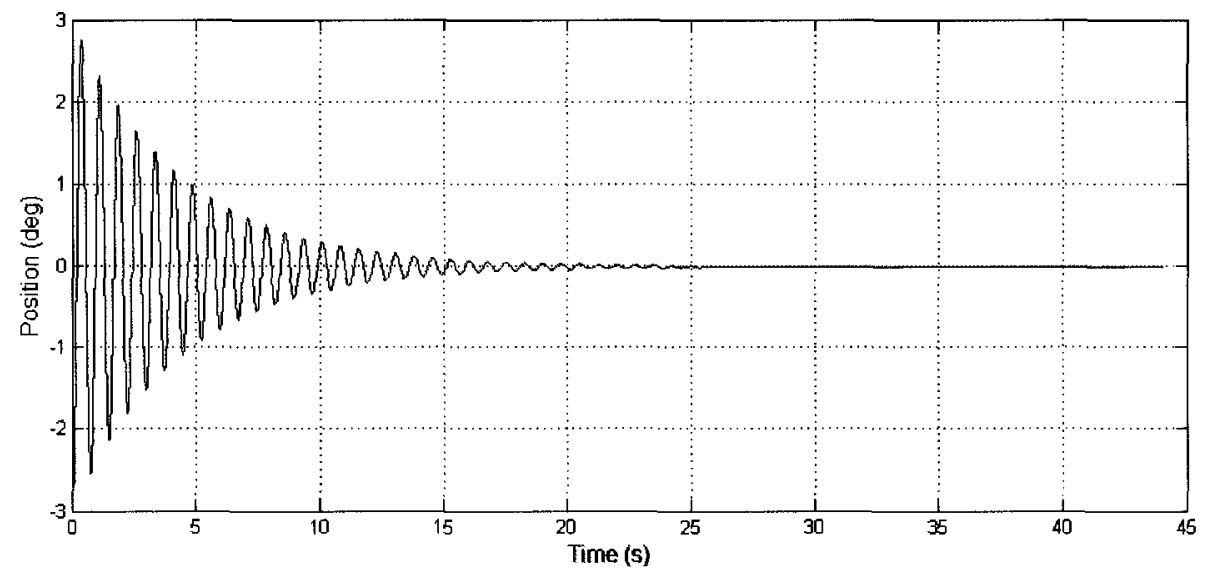

(a) Modeled decay trace

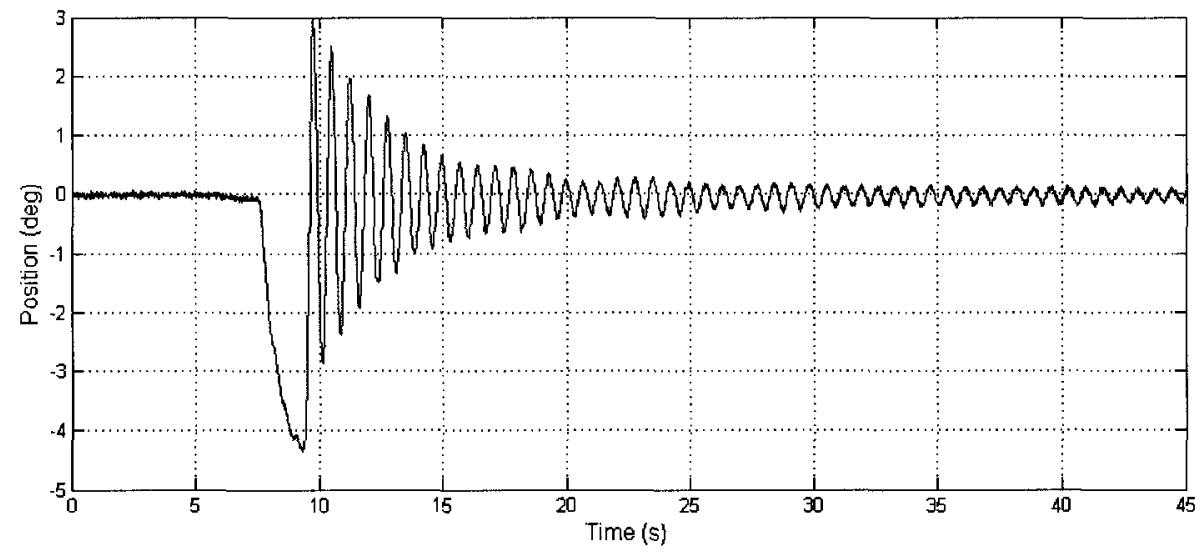

(b) Experimental decay trace

Figure 68: Comparison between the decay trace of the dynamic model and the experimental one in pitch for the small weight case. 


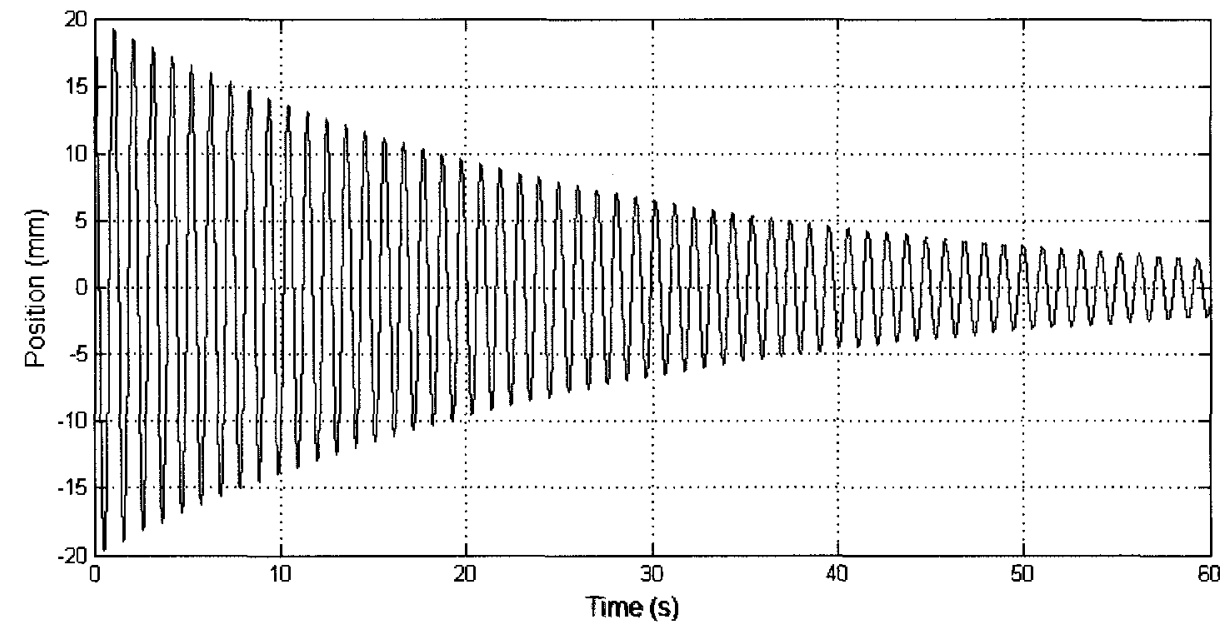

(a) Modeled decay trace

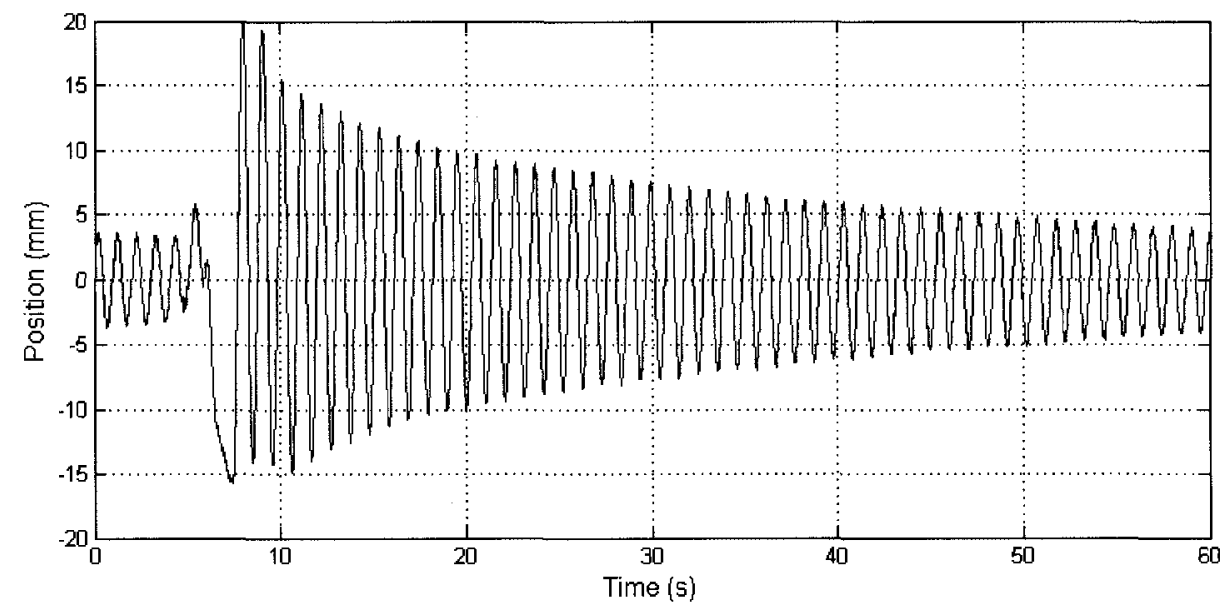

(b) Experimental decay trace

Figure 69: Comparison between the decay trace of the dynamic model and the experimental one in heave for the large weight case. 


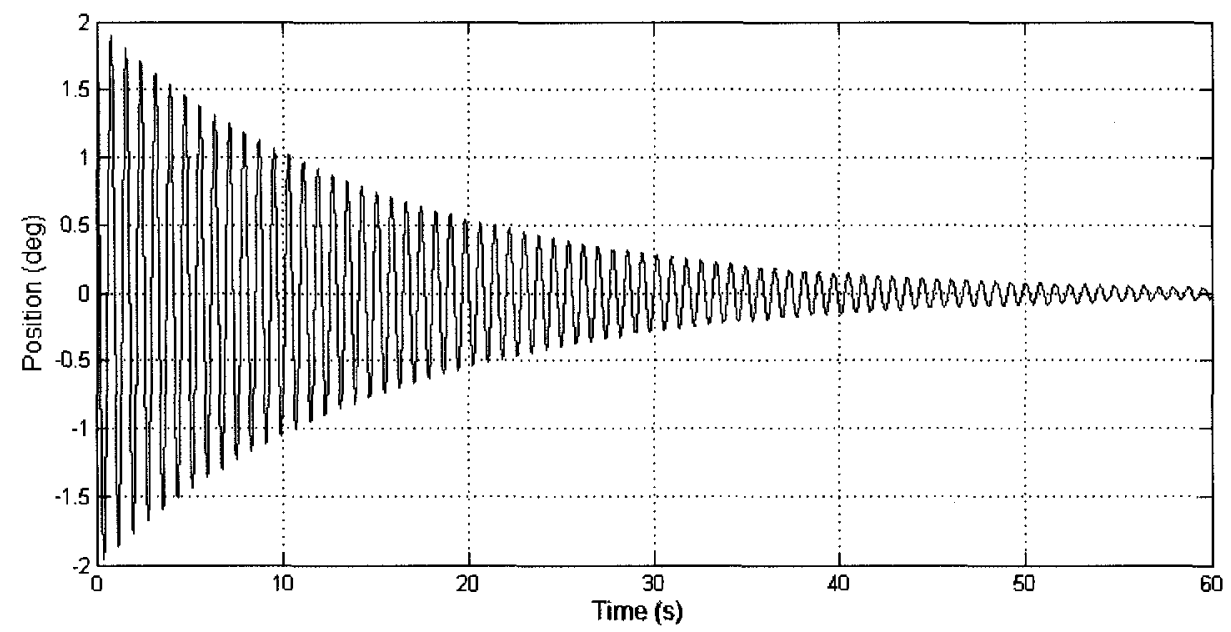

(a) Modeled decay trace

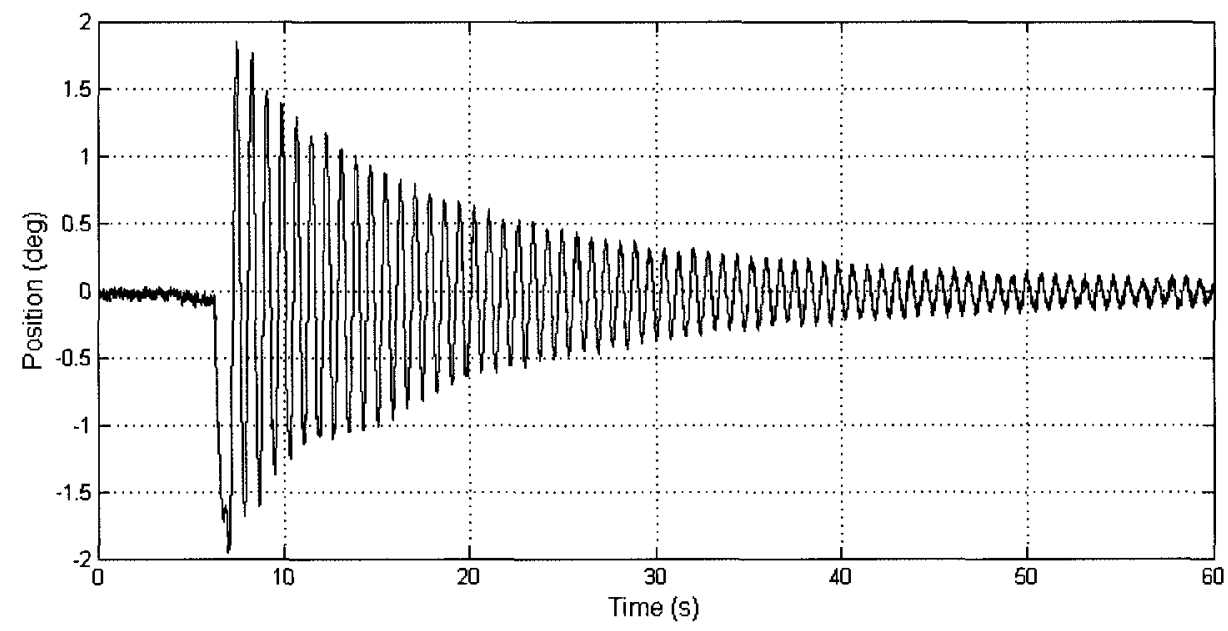

(b) Experimental decay trace

Figure 70: Comparison between the decay trace of the dynamic model and the experimental one in pitch for the large weight case. 


\subsubsection{Application of a steady force and moment}

The second test performed with the dynamic model was to input a steady force and moment corresponding to the mean forces from the reference configuration. This represented the utilization, in the industry, of the aerodynamic force and moment coefficients in simulations.

In the industry, the coefficients used are the structural damping and stiffness coefficients. Using the coefficients measured without wind, the mean forces and moments measured during the stationary test where applied on the system.
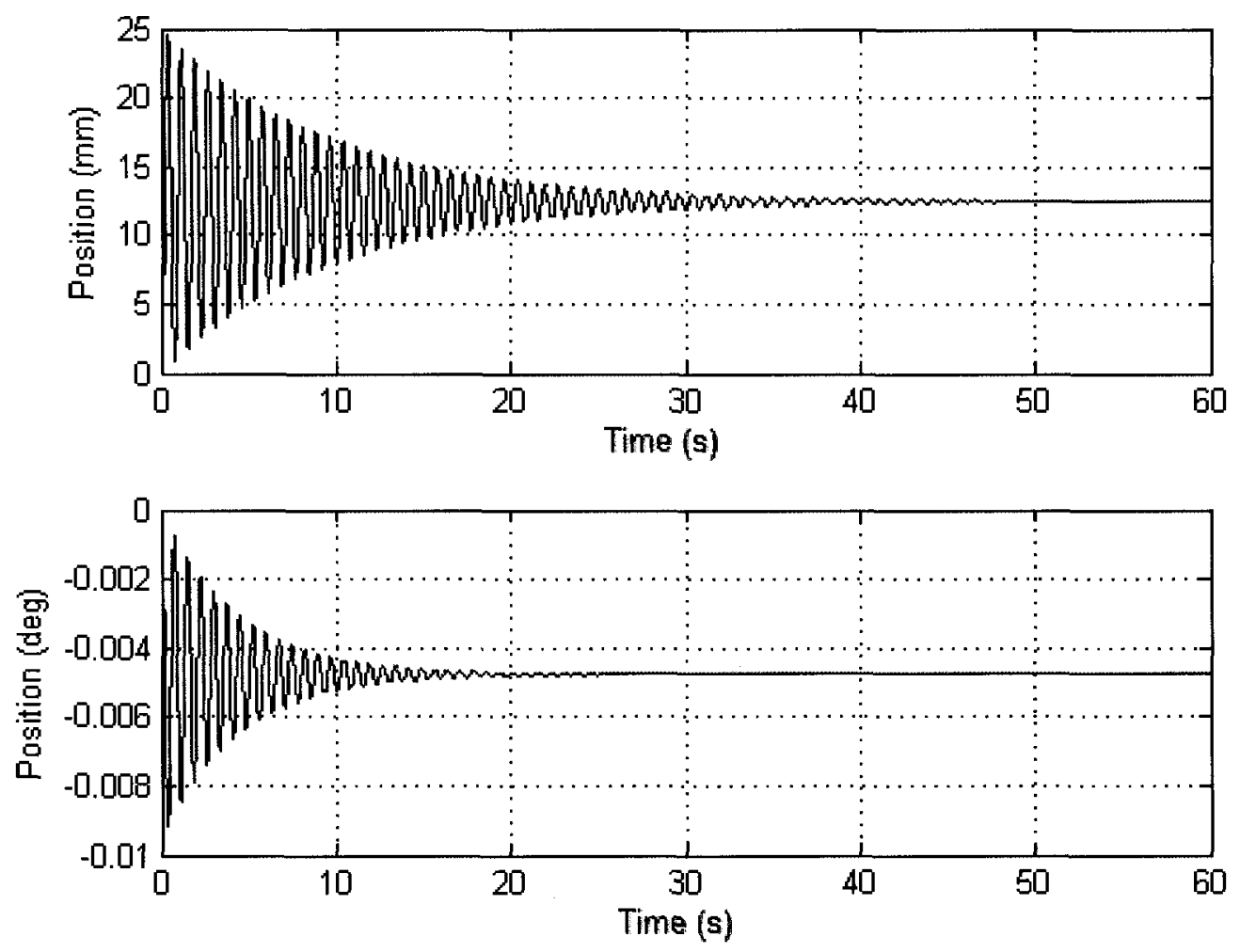

Figure 71: Graph of the simulation of the displacement in heave and pitch of the small weight case at $11 \mathrm{~m} / \mathrm{s}$ for a constant force input, structural coefficients.

As observed in Figures 71 through 73, the oscillations are damped in the three 

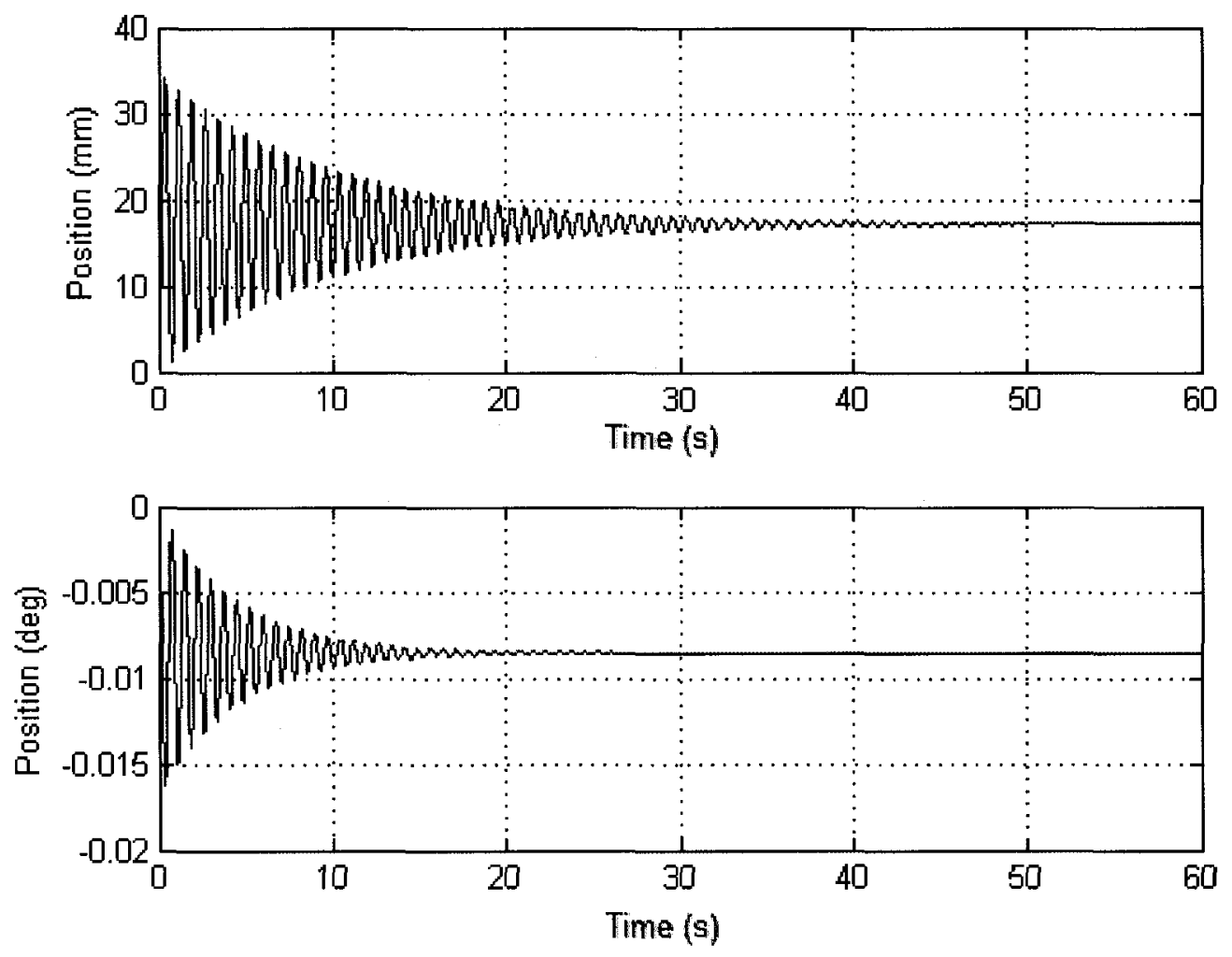

Figure 72: Graph of the simulation of the displacement in heave and pitch of the small weight case at $13 \mathrm{~m} / \mathrm{s}$ for a constant force input, structural coefficients.

cases, with an augmentation of the amplitude of the displacement and the steadystate value. The graphs of the displacement in heave and pitch for the large weight case are presented in Appendix D. The same conclusions can be drawn.

This test was also performed using the total damping and stiffness of the corresponding wind speed with the mean forces and moments applied on the body. This test was applied for the small weight case at $11 \mathrm{~m} / \mathrm{s}$ and for the large weight case at $11 \mathrm{~m} / \mathrm{s}, 13 \mathrm{~m} / \mathrm{s}$ and $15 \mathrm{~m} / \mathrm{s}$. The model with the small weight was too unstable in pitch to obtain valuable data to insert in the model.

The simulation with the small weight case (Figure 74) became unstable because the total damping was negative. Therefore, the movement of the model is amplified. 

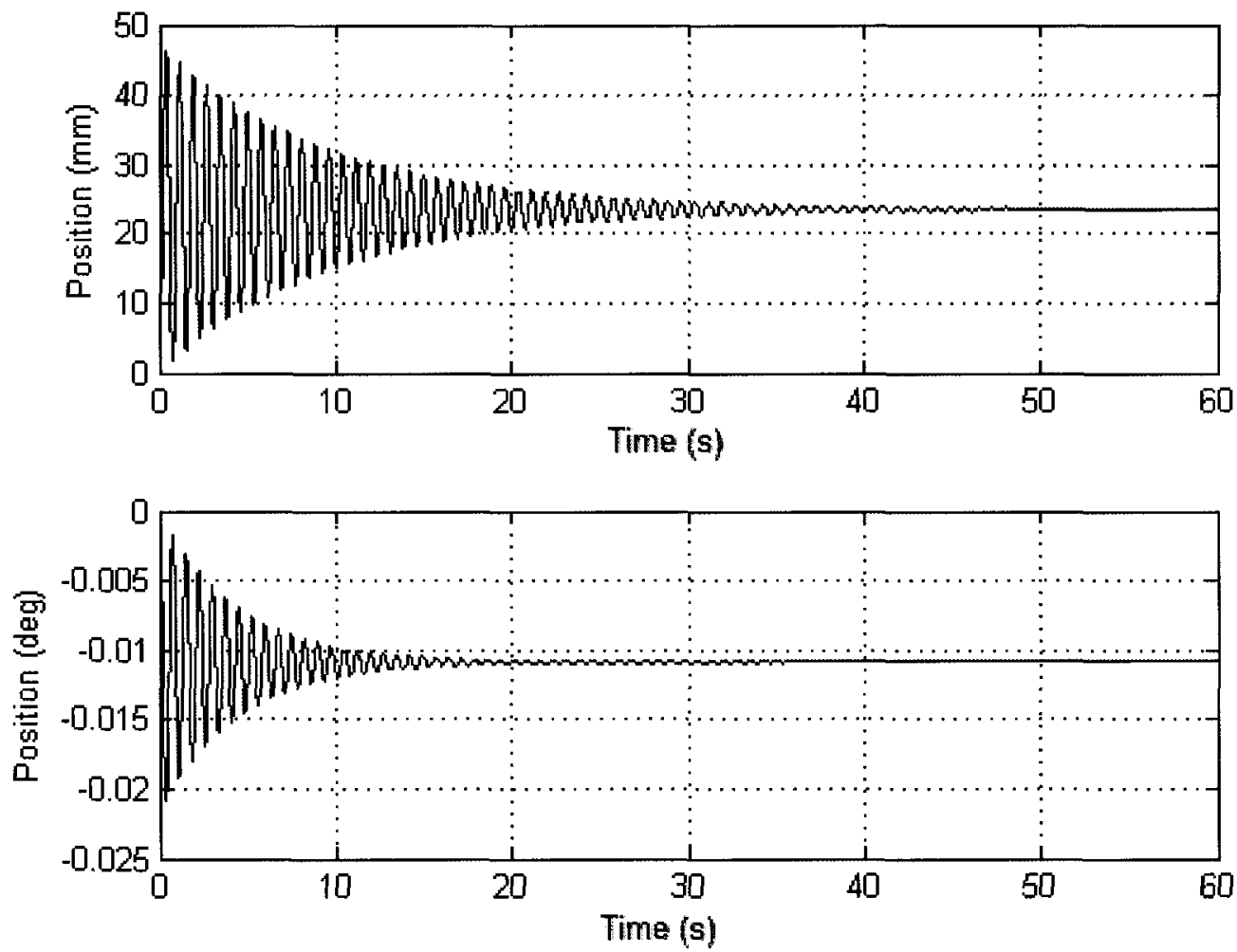

Figure 73: Graph of the simulation of the displacement in heave and pitch of the small weight case at $15 \mathrm{~m} / \mathrm{s}$ for a constant force input, structural coefficients.

In the large weight case (Figure 75), the damping coefficient was positive and the signal was damped in both heave and pitch until the model stabilized at a certain distance and angle. For higher speeds (the figures are presented in Appendix D), the stabilization occured at a higher amplitude in heave and a slightly larger pitch angle.

This test was performed to represent the utilization of the aerodynamic characteristics in the industry and to compare the results with the cases where unsteady measurements are used. 

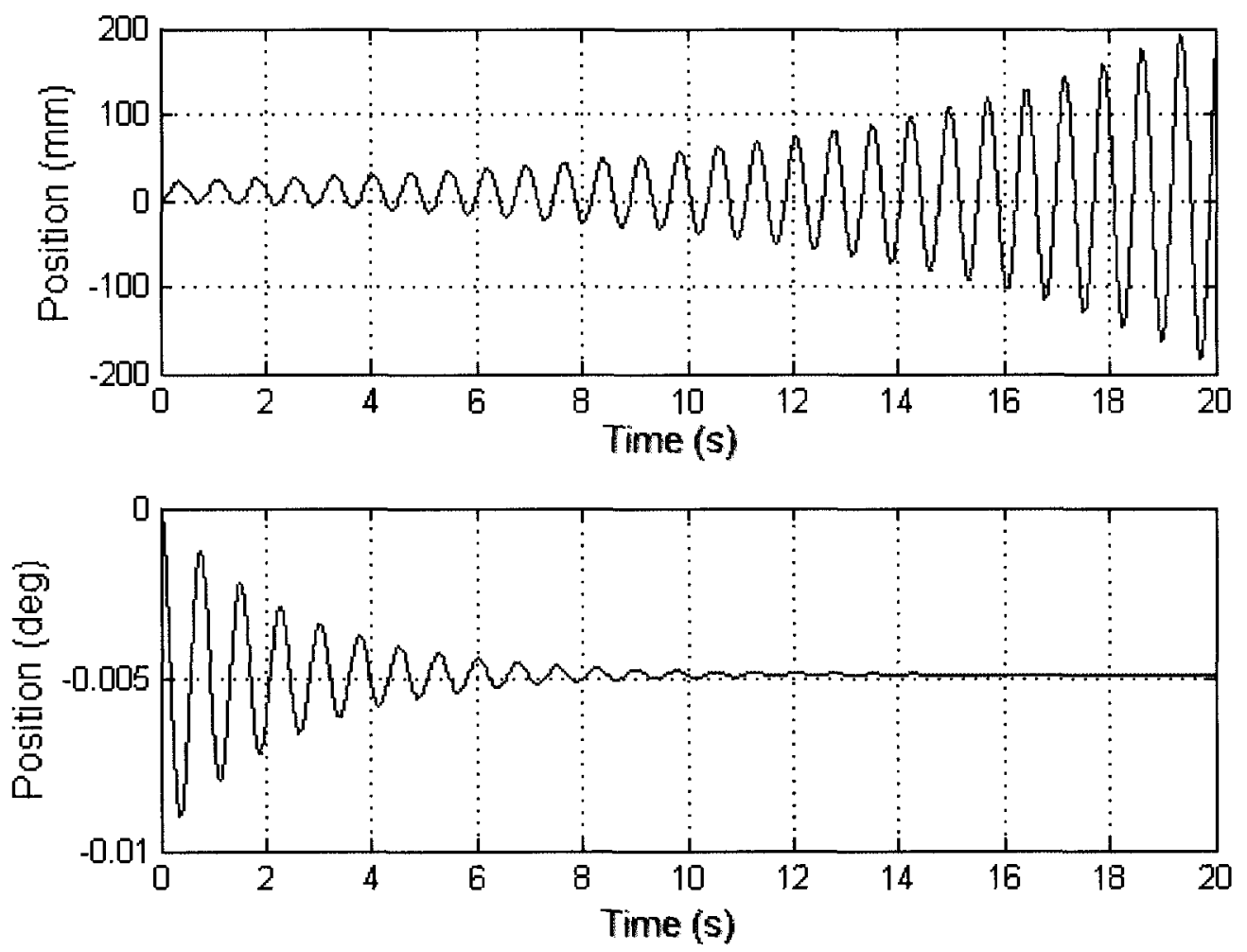

Figure 74: Graph of the simulation of the displacement in heave and pitch of the small weight case at $11 \mathrm{~m} / \mathrm{s}$ for a constant force input. 

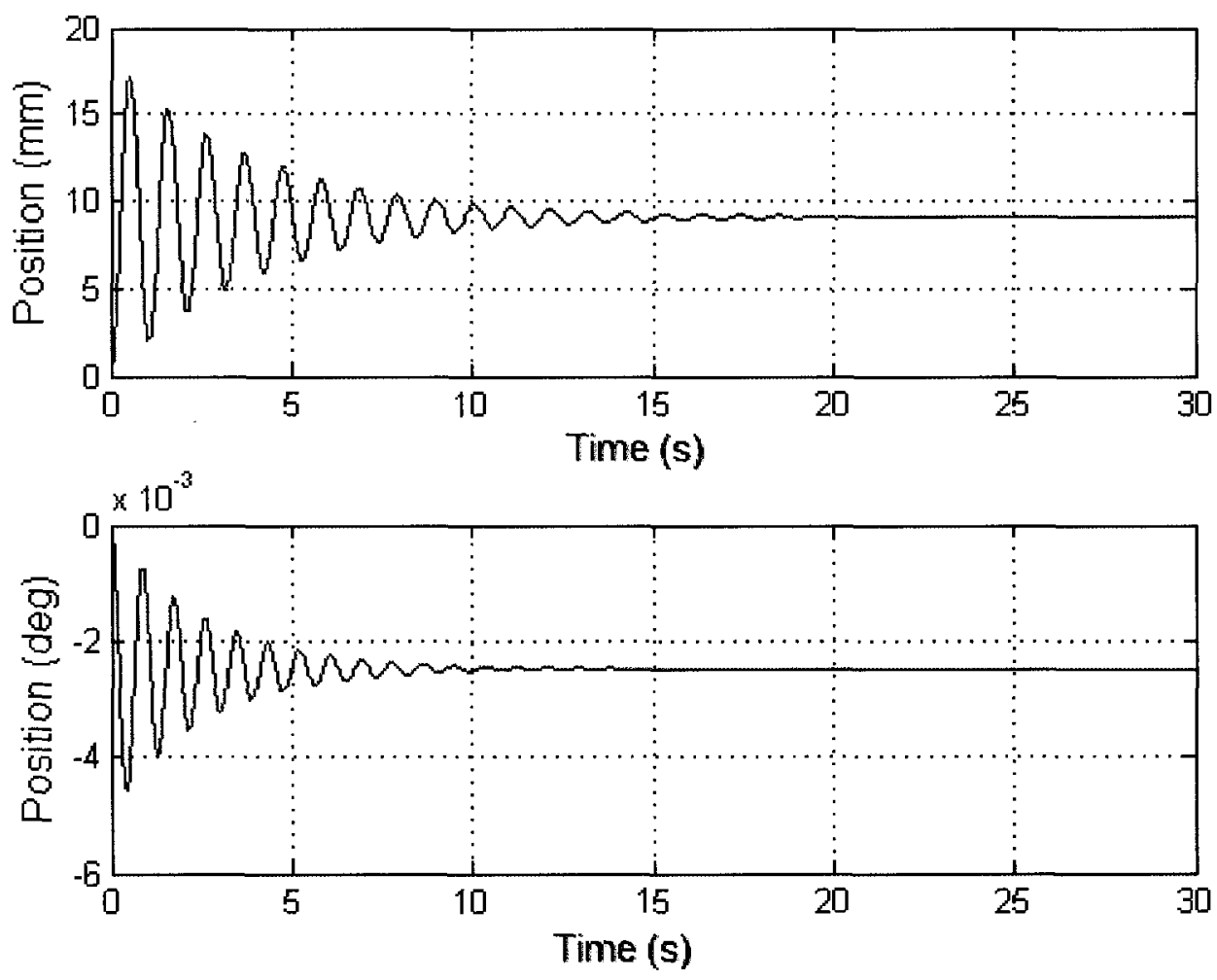

Figure 75: Graph of the simulation of the displacement in heave and pitch of the large weight case at $11 \mathrm{~m} / \mathrm{s}$ for a constant force input. 


\subsubsection{Self-induced movement}

The model developed in the previous section was then used to simulate four different cases of self induced movement, from a stationary position of the model with the small weight at $11 \mathrm{~m} / \mathrm{s}$ and the model with the large weight at $11 \mathrm{~m} / \mathrm{s}, 13 \mathrm{~m} / \mathrm{s}$ and 15 $\mathrm{m} / \mathrm{s}$. The unsteady forces corrected with the balance data measured at different wind speeds during the stationary were input into the model to observe the amplitude and the frequency of the simulated oscillations.
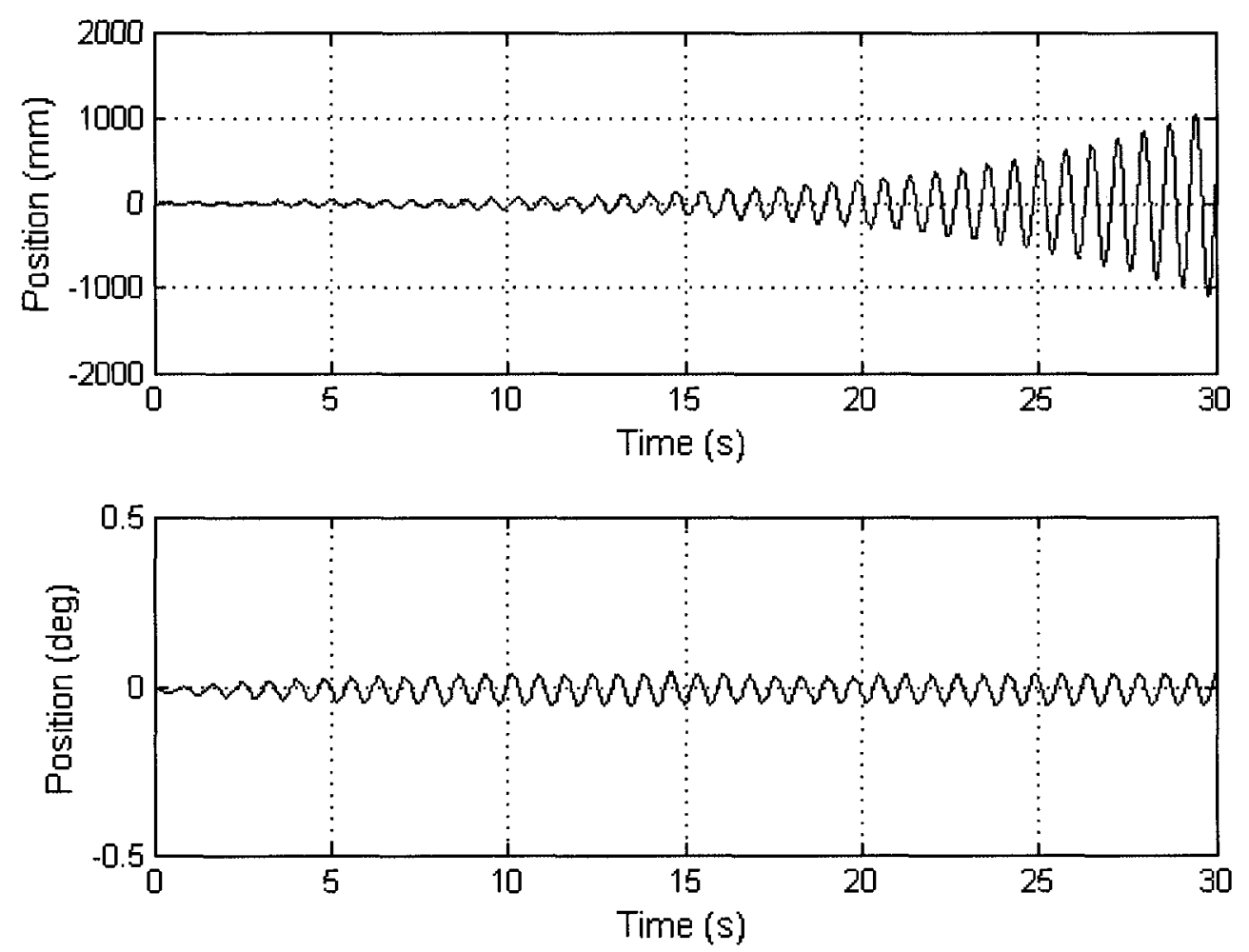

Figure 76: Graph of the simulation of the small weight model position as a function of the time at $11 \mathrm{~m} / \mathrm{s}$.

The self induced movement in the small weight case in the simulation (Figure 76 ) is not similar to the measured time series (Figure 77). The amplitude of the displacement in heave in the simulation increased rapidly and became unstable due 

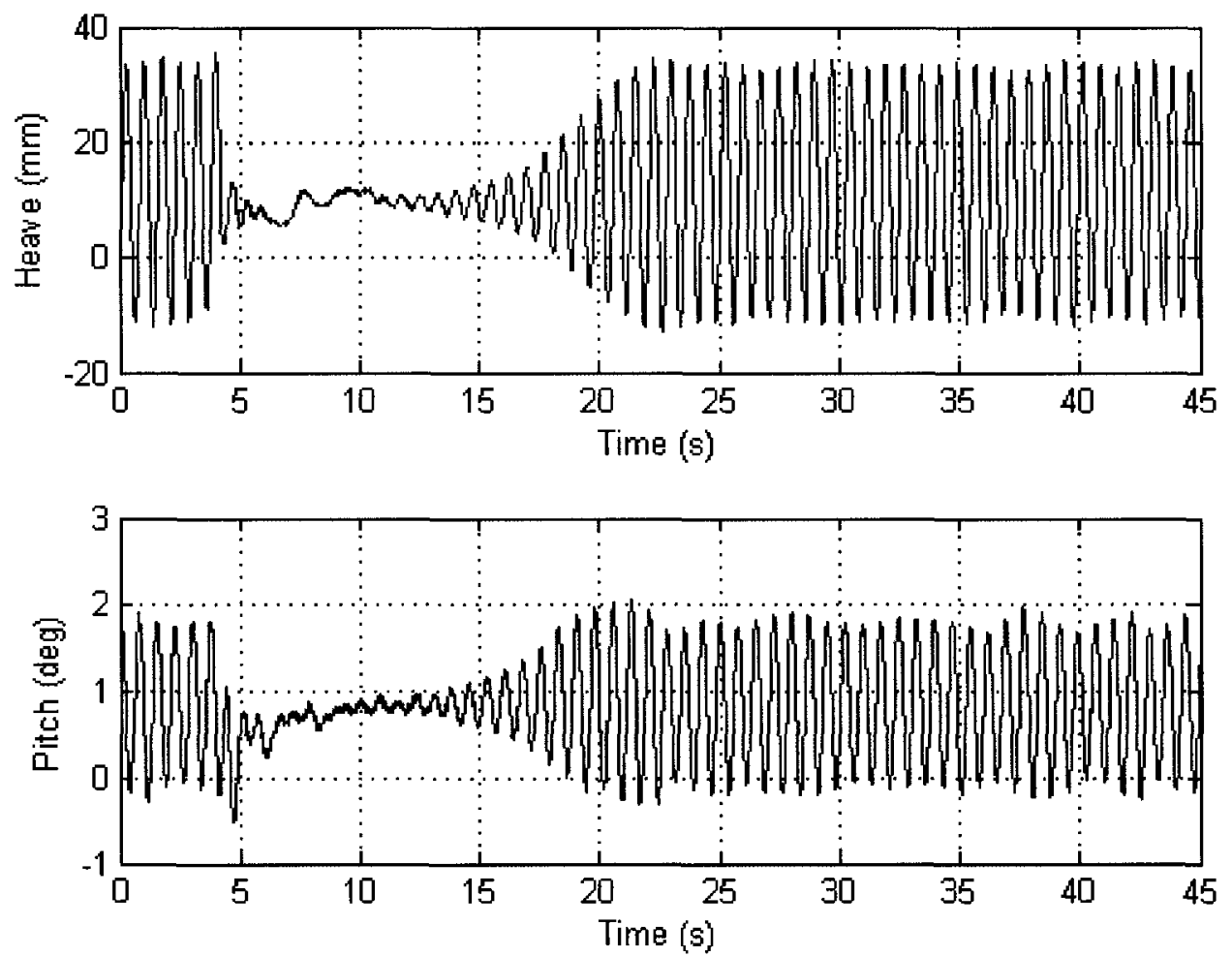

Figure 77: Time series of the displacement as a function of time as measured for the small weight case at $11 \mathrm{~m} / \mathrm{s}$.

to the negative total damping. In pitch, the simulation showed a very small oscillation.

In both cases, motion-induced forces, not represented in this simulation, probably had an effect on the times series. The response to the aerodynamic excitation appeared to be self limited for the experiments of Chapter 2. The forces due to the wake appeared to be limited in amplitude, probably because of the interference of the wall. If the motion induced forces were in phase with the movement of the model and were not limited, they could amplify it.

The frequencies of oscillations in both cases are similar, only the amplitude of the displacements are different.

For the large weight case, the simulation (Figure 78) presents a large displacement 

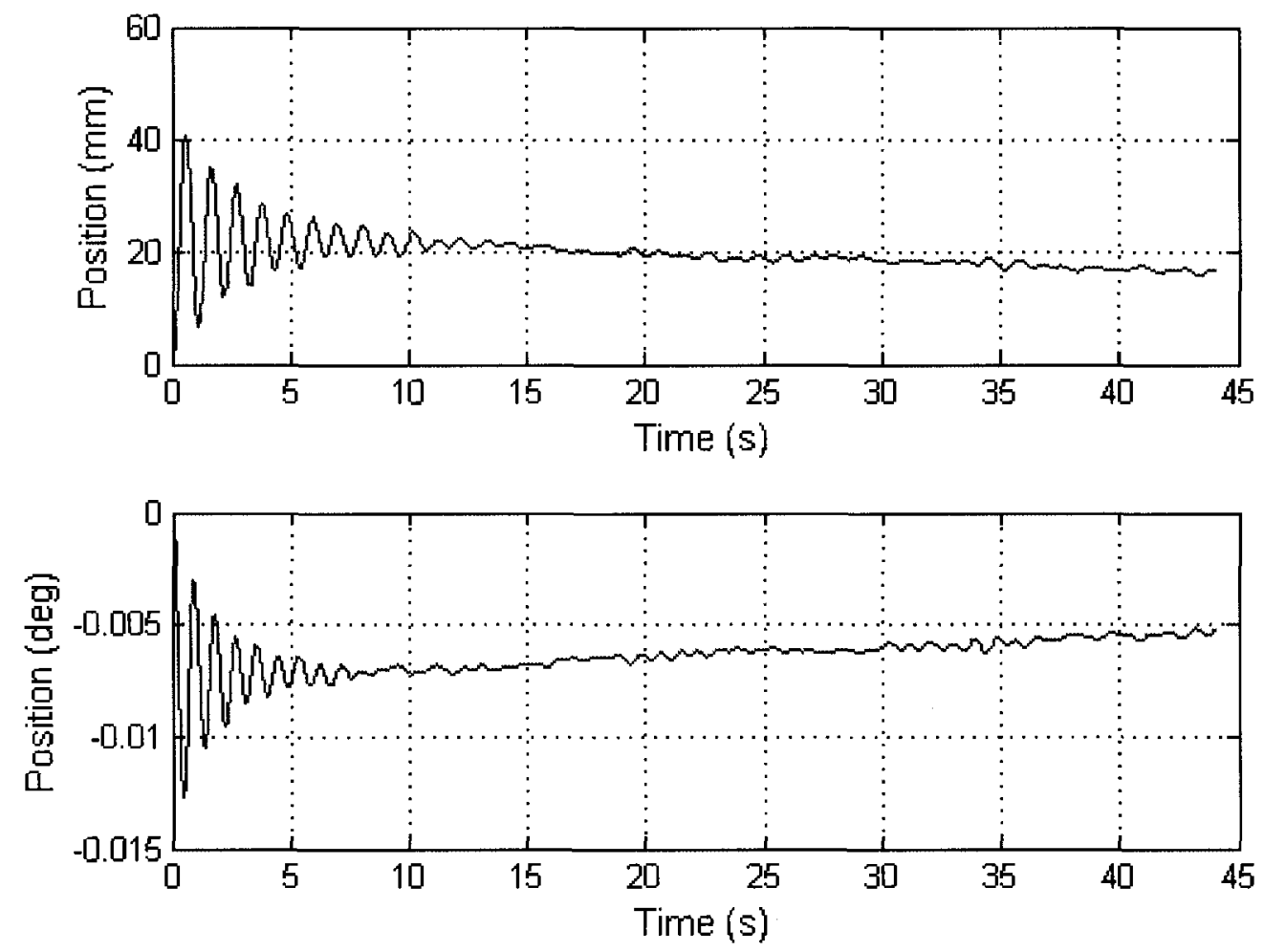

Figure 78: Graph of the simulation of large weight model position in function of time at $13 \mathrm{~m} / \mathrm{s}$.

in heave in the first five seconds, but the amplitude of the displacement decreases and the amplitude of the oscillations, when stabilized are of the same order as the time series measured (13 vs $20 \mathrm{~mm}$ )(Figure 79). The amplitude of the pitch angle is, again, very small compared to the measured data. The conclusions are the same for all the wind speeds. The others cases are presented in Appendix D. 

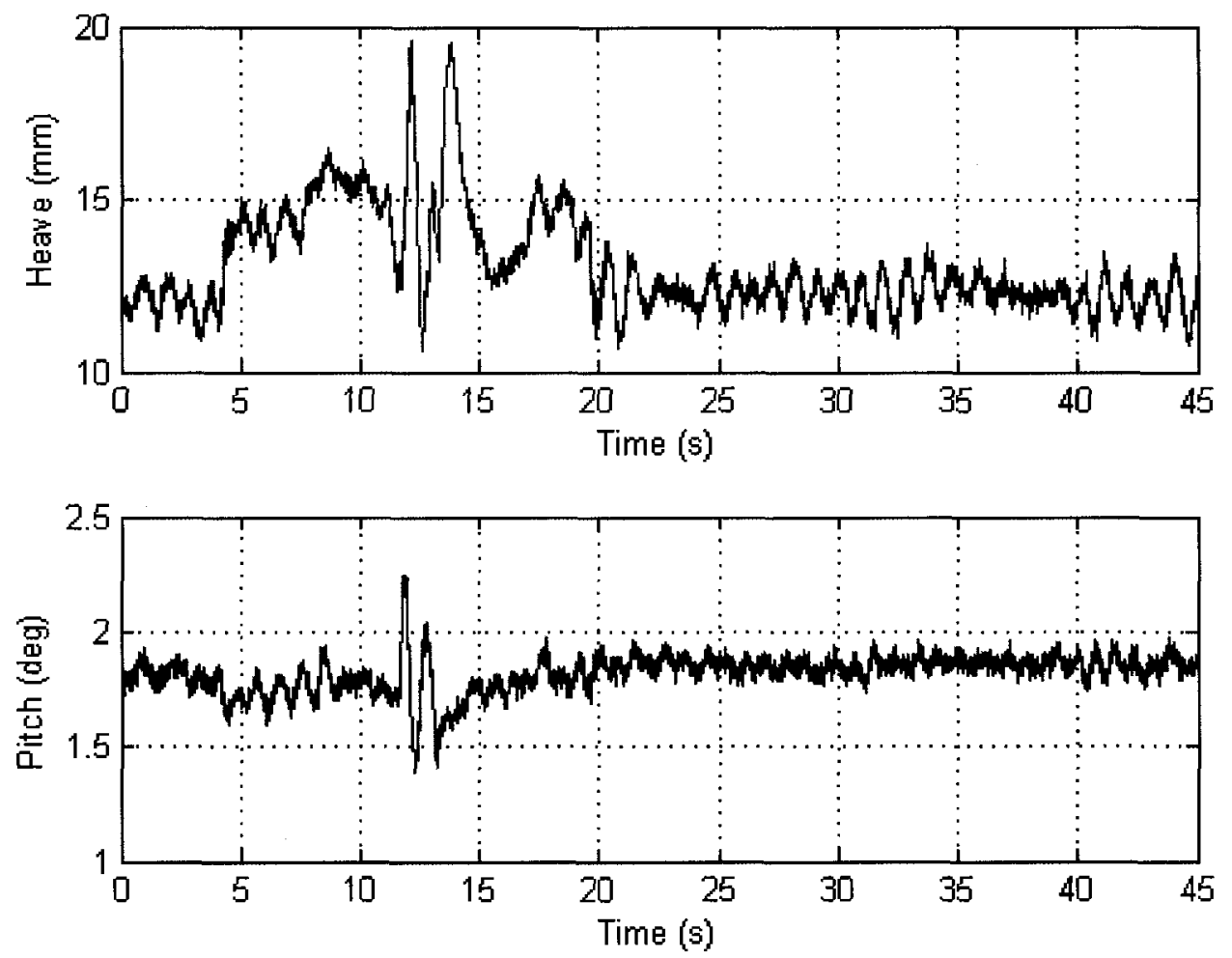

Figure 79: Time series of the displacement in function of time as measured, large weight $13 \mathrm{~m} / \mathrm{s}$. 


\subsection{Conclusions regarding the dynamic model}

The dynamic model presented in this chapter can recreate decay traces without wind using the structural damping and stiffness coefficients measured. The amplitude and the frequency of the time series data can be reproduced with high precision.

For the cases with wind, the results are less accurate. The model doesn't consider the motion-induced forces which might have an influence on the system, particularly in pitch.

The amplitude of the movement in heave for all the small weight cases becomes unstable due to the negative damping measured at $11 \mathrm{~m} / \mathrm{s}$ on the non stationary model. This instability is not observed in the wind tunnel when the self-induced movement experimentation was performed. 


\section{Chapter 5}

\section{Concluding remarks}

\subsection{Motion induced forces}

The main objective of this thesis was to determine if unsteady aerodynamic forces existed around an Ahmed body. This objective was reached when sustained oscillations of the model were observed in the experiments reported in Chapter 2 carried out in the $5 \mathrm{~m}$ Vertical Wind Tunnel. Self-induced vibrations imply unsteady aerodynamic forces. Aerodynamic damping and stiffness of the system were measured for a wide range of speeds, until instability of the system was reached.

The second objective was to determine the type of aerodynamic forces. The measurement performed in the $2 \mathrm{~m} \times 3 \mathrm{~m}$ Wind Tunnel with the Cobra probe did allow the detection of a peak in the vertical component of the wake at a frequency close to the frequency at which the Ahmed body was excited. The amplitude of this peak increased at the same wind speeds at which movement was observed in the nonstationary test; however, this alone is not sufficient to conclude that it is the only cause of the sustained oscillations.

Furthermore, with the surface measurements performed during the stationary test and the acrodynamic characteristics of the Ahmed body calculated in the non stationary test, it has been shown that the aerodynamic characteristics and the unsteady 
forces due to the shape of the model are not sufficient to reproduce the movement observed in the wind tunnel based on the simulation model presented in Chapter 4. The presence of motion induced forces is therefore probable. The displacement of the model towards the wind tunnel wall influenced the behaviour of the body and it is impossible to predict those influences using the surface pressure measurements.

\subsection{Shape sensitive}

The non-stationary and stationary test results are both very sensitive to the shape of the model. Therefore, the results obtained in this research are not applicable to any other vehicle shape.

Measurement of the aerodynamic stiffness and damping curves as a function of wind speed for different body shapes would have to be performed to evaluate their sensitivity to the shape.

The pressure distribution on the body is unique to the Ahmed body and so is the frequency content of the wake. If another body had been used in this project, the results could have been completely different.

\subsection{Other dynamic model}

This thesis focused only on the unsteady aerodynamic forces without interfering with the dynamics of the vehicle.

It would be interesting to investigate this other aspect with a comprehensive vehicle dynamics model to methodically evaluate the impact of the variation of the damping and stiffness characteristics. Currently, vehicle dynamics models consider that the damping and stiffness due to the aerodynamics are constant as a function of wind speed. 
Such a model would determine the sensitivity of a car to unsteady aerodynamic forces in different situations. It would also offer a better understanding of the important aerodynamic characteristics in the handling of a car and the vehicle characteristics that could increase the chance of undesirable behaviour of the vehicle due to unsteady aerodynamic forces.

Such handling problems have been observed on different production cars and have been fixed with aerodynamic devices. The understanding of the causes of the behaviour and their sensitivity could improve the safety of the vehicle, particularly considering the steady trend towards lighter production vehicles that are likely more subject to this kind of problem.

\subsection{Future work}

This thesis is a starting point in understanding the unsteady aerodynamic forces around vehicles. An extensive body of existing work on aircraft flight dynamics and ship dynamics, including their response to air turbulence and roughness is available in the literature. It would be interesting to investigate the extent to which it is possible to take advantage of it to address the problem of unsteady aerodynamic loads and the dynamic response of road vehicles as well as to define the vocabulary of the field [27].

More testing should be done with a set-up allowing the investigation of the movement over a larger range. Therefore, the transitions would be less aggressive and the quality of the mapping on the aerodynamic damping and stiffness, improved.

The set-up should also facilitate the movement in yaw and side to obtain data in the 4 degrees of freedom.

More unsteady measurements should be performed on vehicles with an increased number of pressure taps. Higher speeds should be used to decrease the error on the pressure measurements at low speed. 
The effect of the Reynolds number could also be investigated. These tests were performed at really low Reynolds number and its effect is unknown on the results.

Further, a refined dynamic model should be developed for introducing unsteady aerodynamic loading both to simulations of dynamic experimental models and subsequently to comprehensive vehicle dynamics models. 


\section{List of references}

[1] W.H.Hucho(editor), Aerodynamics of Road Vehicles. Society of Automotive Engineers, Warrendale, $\mathrm{Pa}, 1998$.

[2] A.Larsen(editor), Aerodynamics of Large Bridges. Rotterdam, Netherlands: A.A. Balkema, 1992.

[3] S. Ahmed, G. Ramm, and G. Faltin, "Some salient features of the time-averaged ground vehicle wake," SAE paper 840300, 1984.

[4] R. Strachan, K. Knowles, and N. Lawson, "A CFD and experimental study of an Ahmed reference model," SAE paper 2004-01-0442, 2004.

[5] I. Bayraktar, D. Landman, and O. Baysal, "Experimental and computational investigation of Ahmed body for ground vehicle aerodynamics," SAE paper 200101-2742, 2001.

[6] J. Barlow, W. Rae, and A. Pope, Low-speed Wind Tunnel Testing. United States of America: John Wiley and Sons, 3rd edition ed., 1999.

[7] P. Aschwanden, J. Müller, and U. Knörnschild, "Experimental study on the influence of model motion on the aerodynamic performance of a race car," $S A E$ paper 2006-01-0803, 2006.

[8] F. Cheli, P. Dellach, P. Mandelli, and A. Zasso, "Effects of non-steady aerodynamic forces on car handling: Implementation of a new experimental-numerical model for longitudinal," 2000 North American ADAMS User Conference, June 2000 .

[9] M. Passmore and S. Mansor, "The measurement of transient aerodynamics using an oscillating model facility," SAE paper 2006-01-0338, 2006. 
[10] S. Mansor and M. Passmore, "Estimation of bluff body transient aerodynamics using an oscillation model rig," Summary Papers of the 5th International Colloquium on Bluff Body Aerodynamics and Applications, Ottawa, pp. 529-532, July 2004.

[11] "Wheels in the wind," Bernouilli Aerodynamics International, vol. Spring 2006 Issue 1, pp. 52-55, May 2006.

[12] R. Aerospace Defense Technology, "Model shaker for dynamic testing in the wind tunnel." Newsletter 12, Spring 2006. pp.2-3.

[13] V. Ferrand, P. Dufour, S. Aguinaga, S. Kébreau, F. Chometon, and A. Strzelecki, "Application de la PIV dans le sillage d'un corps automobile oscillant," in Congrès Francophone de Techniques Laser, CFTL 2006, Toulouse, 1988, 19-22 Septembre 2006.

[14] F. Chometon, A. Strzelecki, V. Ferrand, H. Dechipre, P. Dufour, M. Gohlke, and V. Herbert, "Experimental study of unsteady wakes behind an oscillating car model," SAE paper 2005-01-0604, 2005.

[15] J. Howell, "An estimation of the unsteady aerodynamic loads on a road vehicle in windy conditions," SAE paper 2004-01-1310, 2004.

[16] K. Garry and G. L. Good, "On the use of reference models in automotive aerodynamics," SAE paper 2004-01-1308, 2004.

[17] E. Hjorth-Hansen, "Section model tests," in Aerodynamics of Large Bridges (A. Larsen, ed.), pp. 95-112, 1992.

[18] K. Hansen, "Wind tunnel specifications," Personnal Communication, 2007.

[19] G. Larose, "The response of a suspension bridge deck to turbulent wind: The taut trip model approach," Master's thesis, Universty of Western Ontario, March 1992.

[20] P. Paultre, Dynamique des structures, application aux ouvrages de génie civil. Paris: Hermes Science Publications, 1995.

[21] A. Lafrenière and A. Larsen, "Review of damping measurements, Øresund bridge, damping of stays," COWI, Denmark,2005.

[22] G. Larose, A. Lafrenière, and M. Savage, "Essais en soufflerie sur panneaux de signalisation," Laboratory Technical Report NRC-LTR-AL-2002-0071. 
[23] S. Zan, "Determination of the test-section flow parameters in the IAR $2 \mathrm{~m} \times 3 \mathrm{~m}$ Low-Speed Wind Tunnel," Laboratory Technical Report NRC-LTR-AL-009, NRCC, IAR, 1997.

[24] "Scanivalve corp., model ZOC33 electronic pressure scanning module data sheet no.G480." www.scanivalve.com, 2007.

[25] G. Larose, J. Jacobsen, and M. Savage, "Wind tunnel experiments on an inclined and yawed circular cylinder in the critical Reynolds number range," in Proc. of the 11th Intil Conference on Wind Engineering, Lubbock, Texas, June 2003, pp.2165-2173.

[26] D. Sims-Williams and B. Duncan, "The Ahmed model unsteady wake: Experimental and computational analyses," SAE paper 2002-01-1315, 2002.

[27] B. Etkin and L. Reid, Dynamics of fight-stability and control. New York: John Wiley and Sons, 3e ed., November 1995. 


\section{Appendix A}

\section{Location of the pressure taps}

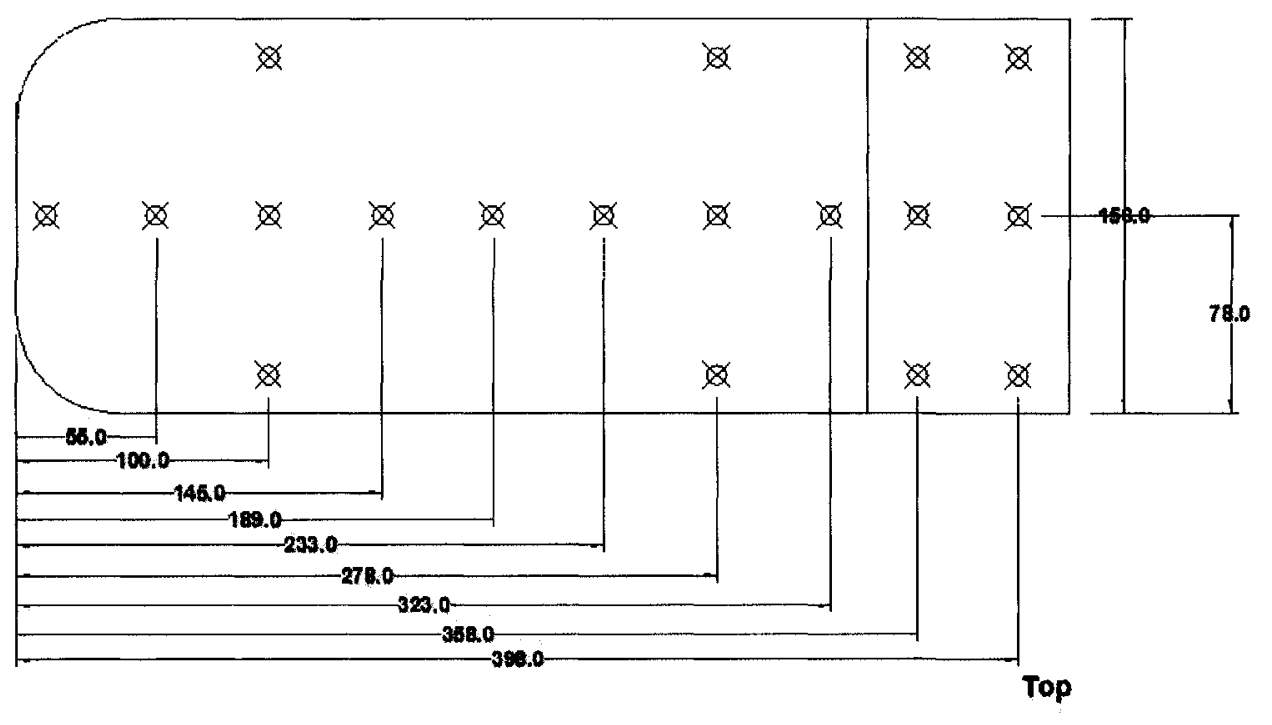

All dimenslons are in $\mathrm{mm}$.

Figure 80: Positioning of the pressure taps in mm (top). 

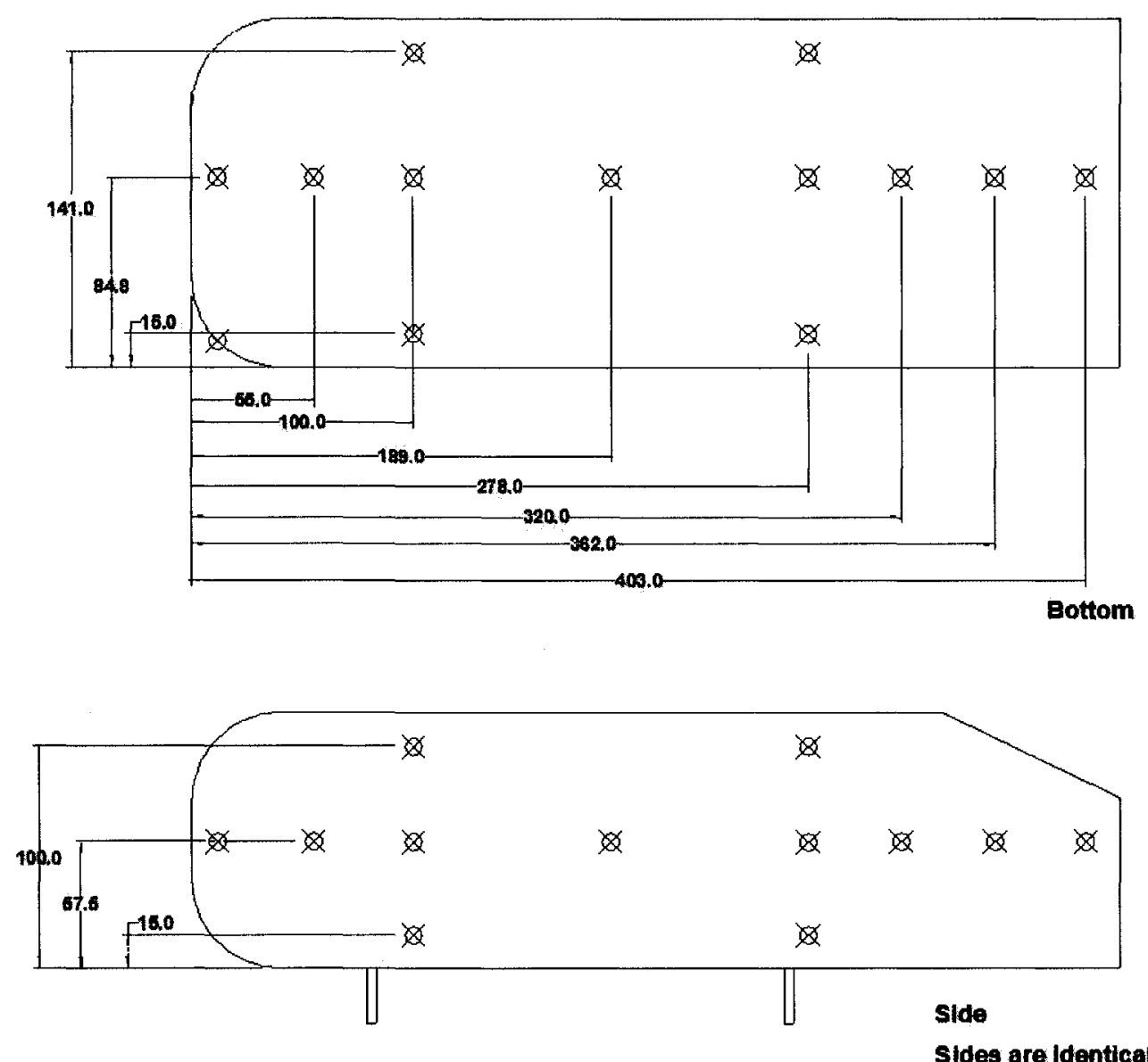

Figure 81: Positioning of the pressure taps in mm (side and bottom). 


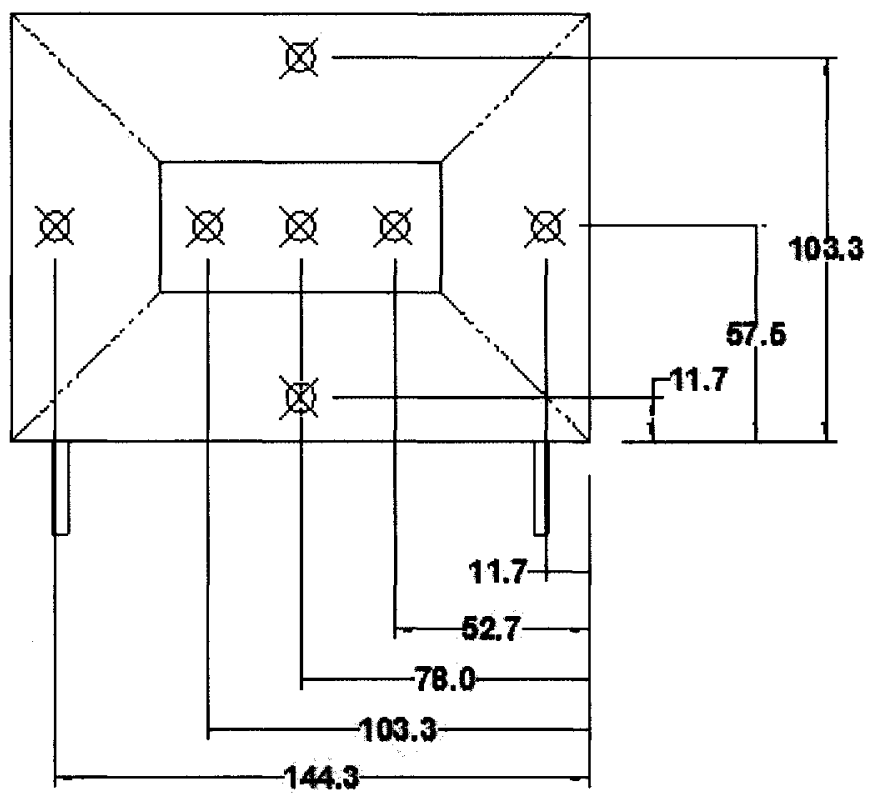

Front

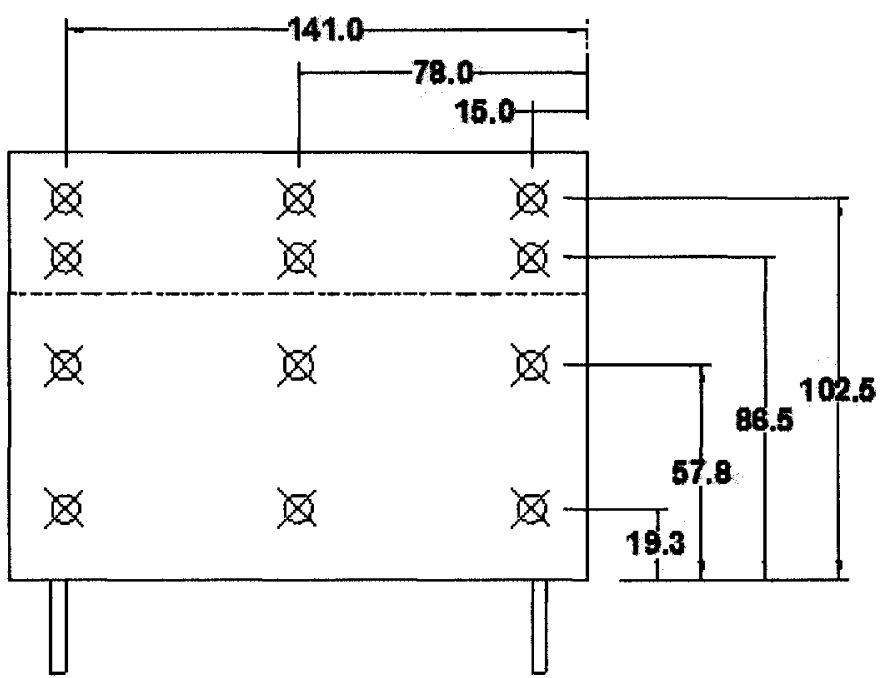

Back

Figure 82: Positioning of the pressure taps in mm (front and back). 
Appendix B

\section{Balance data}



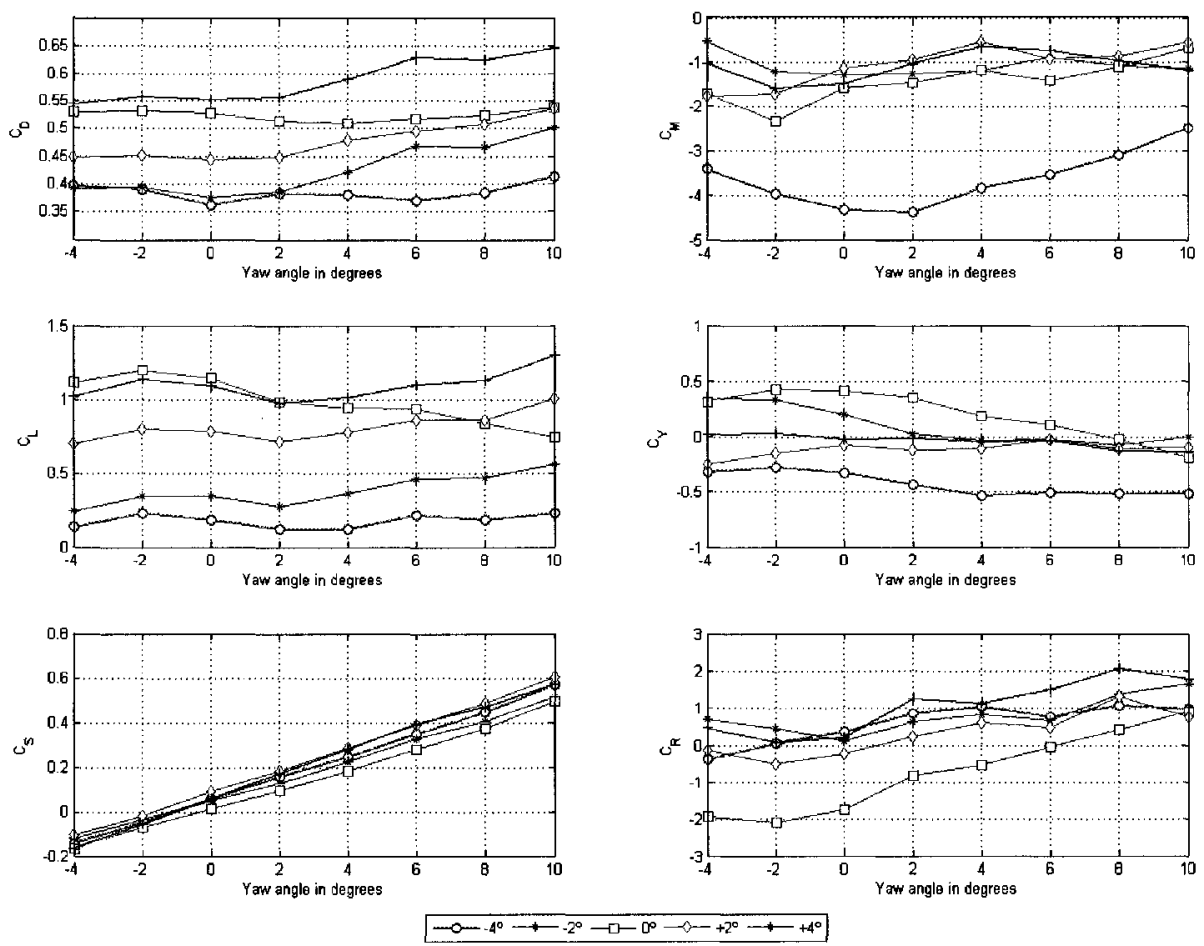

Figure 83: Static force and moment coefficients as a function of pitch angle in degrees, for five pitch angles at a constant ride height of $25 \mathrm{~mm}$ and a constant wind speed of $11 \mathrm{~m} / \mathrm{s}$. 

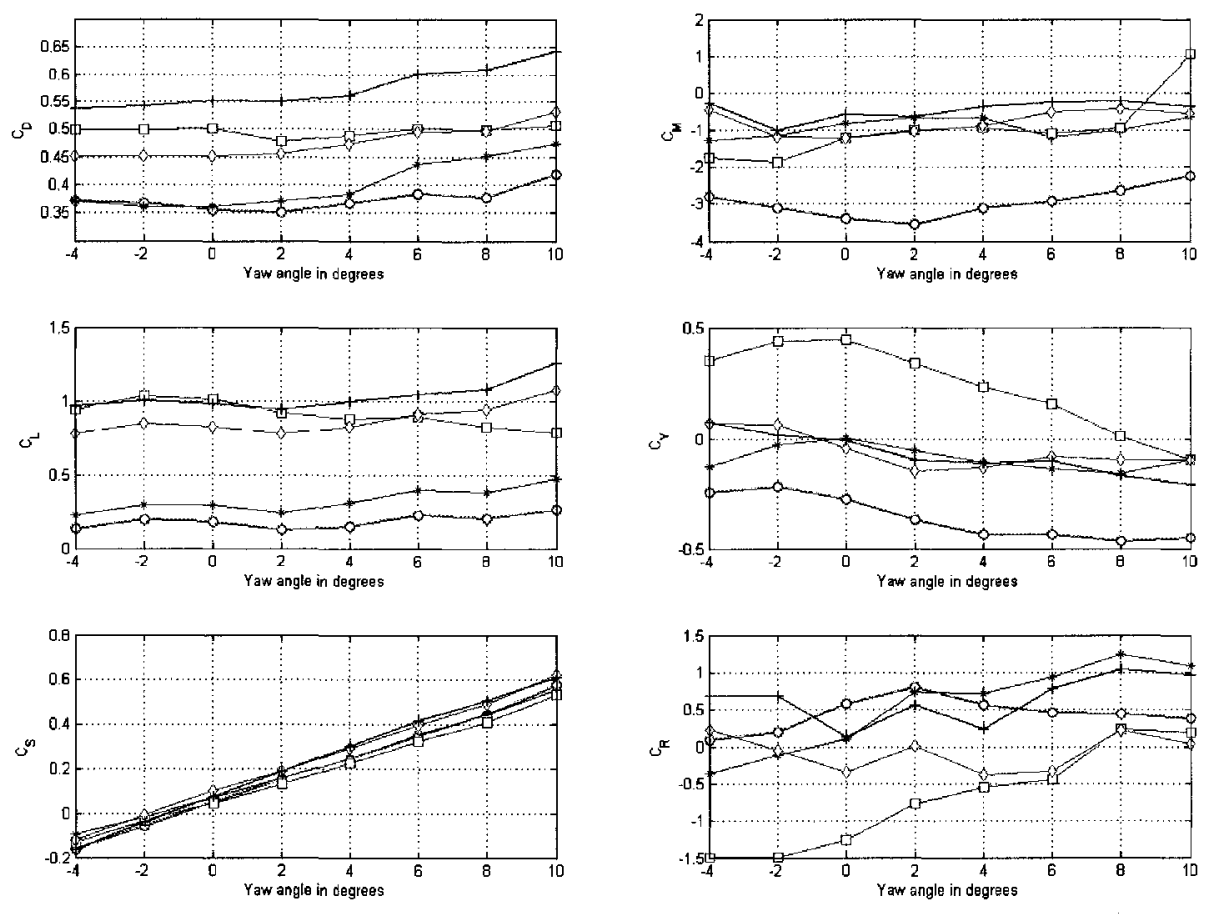

$\square--^{\circ} \rightarrow-4^{\circ}-\square-0^{\circ}-0-+2^{\circ} \longrightarrow++4^{\circ}$

Figure 84: Static force and moment coefficients as a function of pitch angle in degrees, for five pitch angles at a constant ride height of $25 \mathrm{~mm}$ and a constant wind speed of $13 \mathrm{~m} / \mathrm{s}$. 

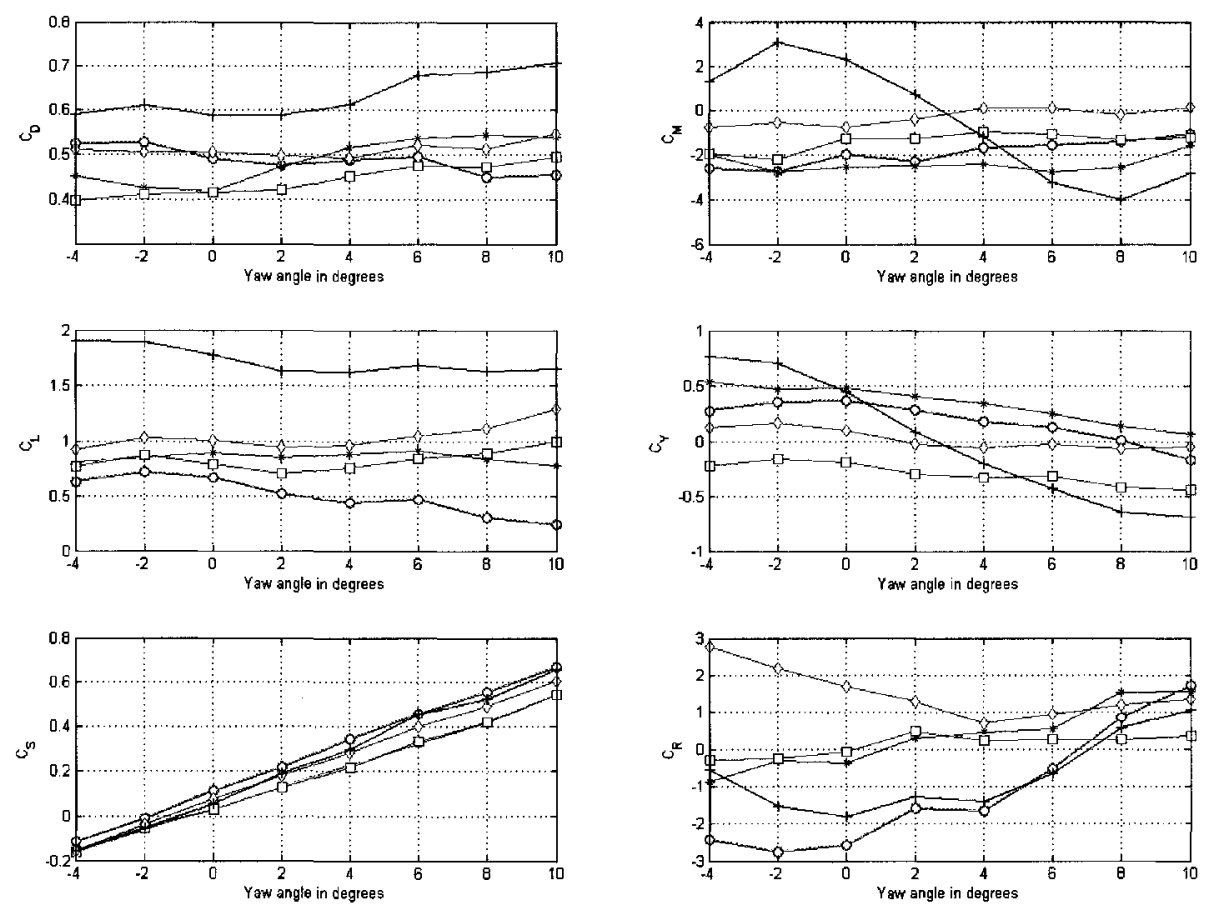

$-0-4^{\circ}-4-2^{\circ}-\square-0^{\circ}-0-+2^{\circ} \longrightarrow+4^{\circ}$

Figure 85: Static force and moment coefficients as a function of pitch angle in degrees, for five pitch angles at a constant ride height of $18 \mathrm{~mm}$ and a constant wind speed of $11 \mathrm{~m} / \mathrm{s}$. 

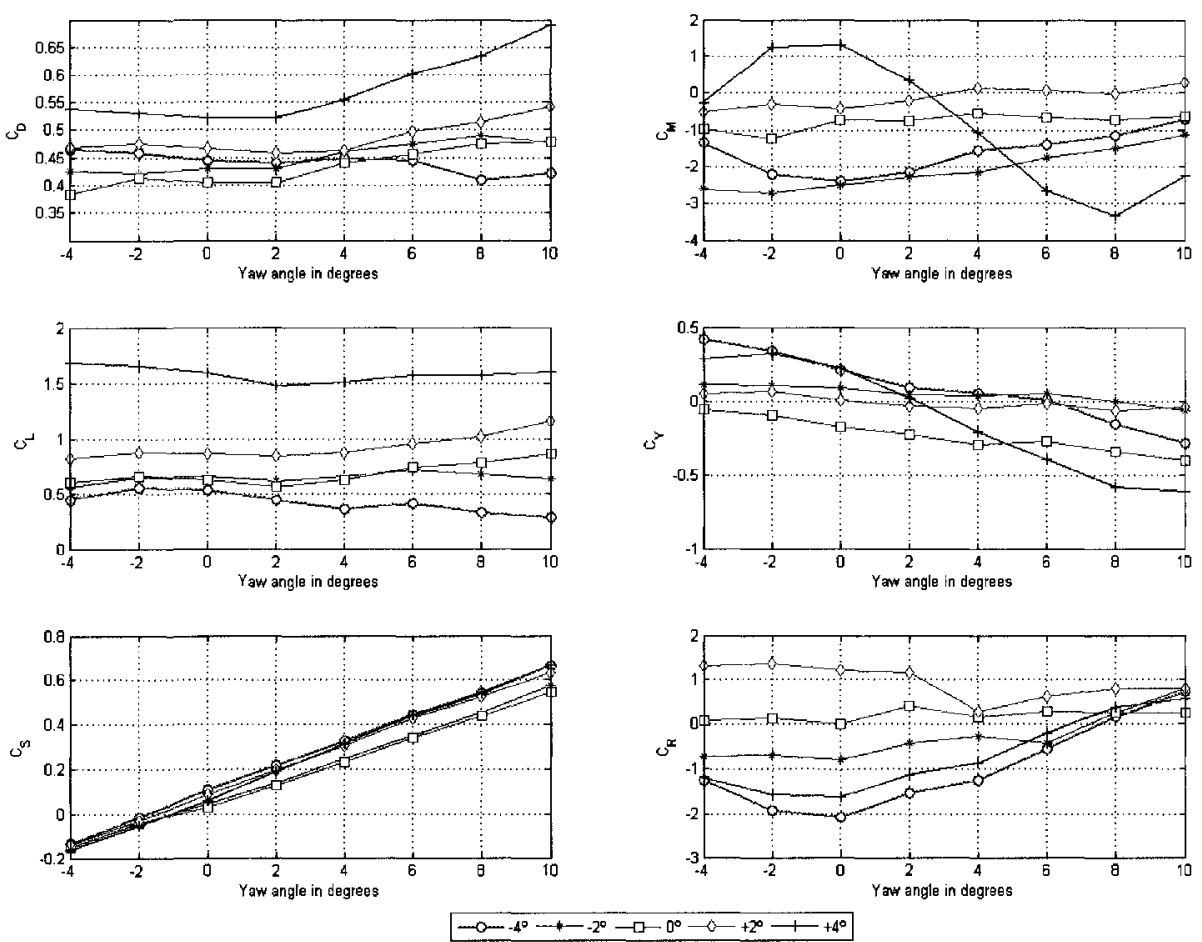

Figure 86: Static force and moment coefficients as a function of pitch angle in degrees, for five pitch angles at a constant ride height of $18 \mathrm{~mm}$ and a constant wind speed of $13 \mathrm{~m} / \mathrm{s}$. 

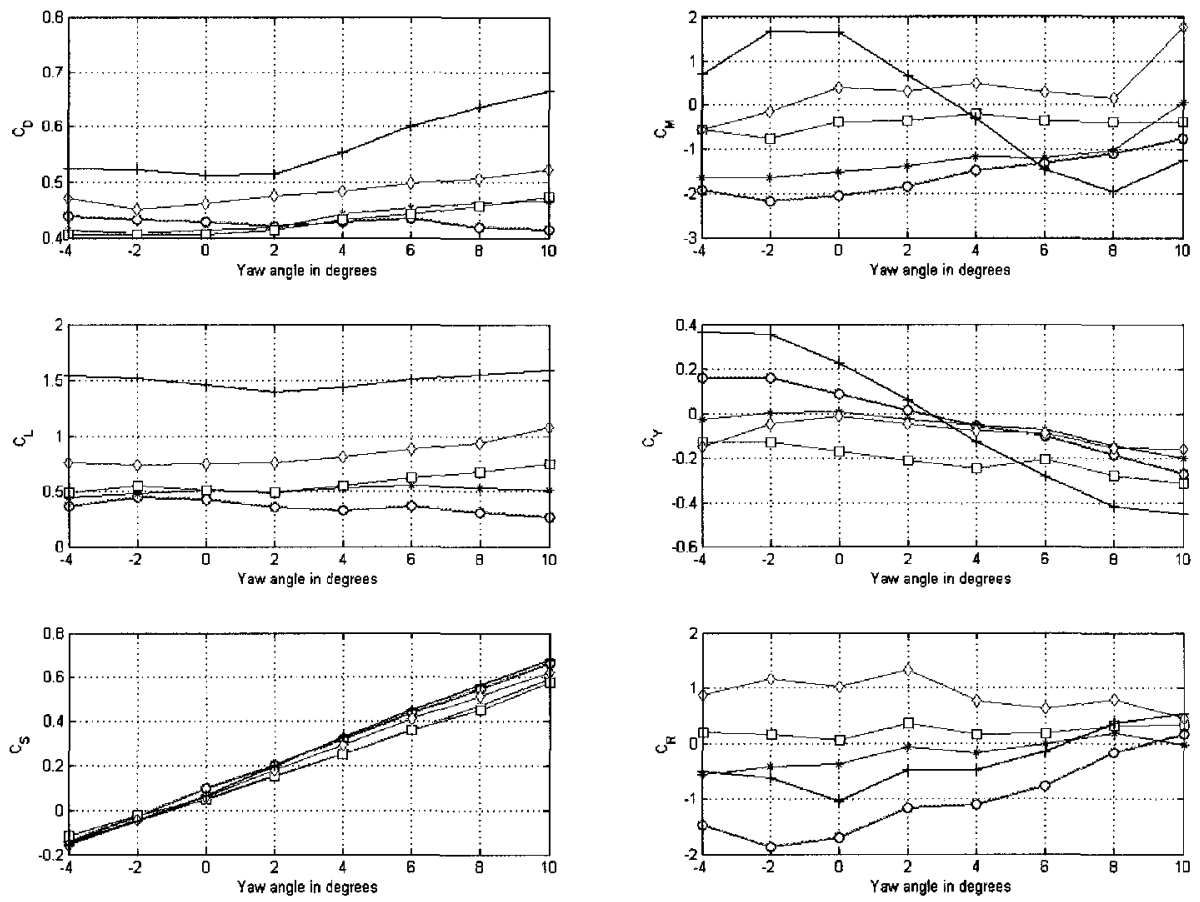

$-0-4^{\circ} \rightarrow-2^{\circ}-\square-0^{\circ}-0^{\infty}-+2^{\circ}+\ldots+4^{\circ}$

Figure 87: Static force and moment coefficients as a function of pitch angle in degrees, for five pitch angles at a constant ride height of $18 \mathrm{~mm}$ and a constant wind speed of $15 \mathrm{~m} / \mathrm{s}$. 

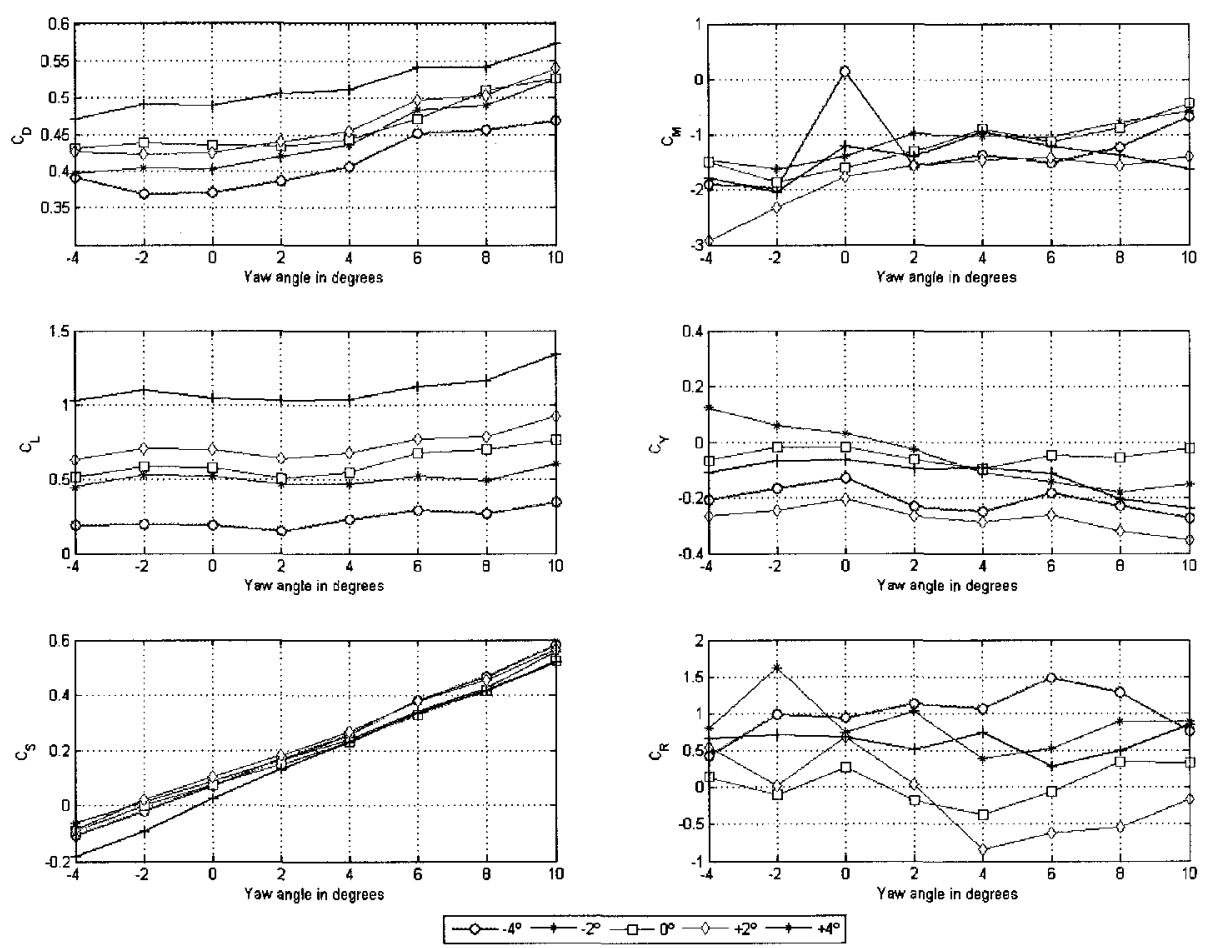

Figure 88: Static force and moment coefficients as a function of pitch angle in degrees, for five pitch angles at a constant ride height of $33 \mathrm{~mm}$ and a constant wind speed of $11 \mathrm{~m} / \mathrm{s}$. 

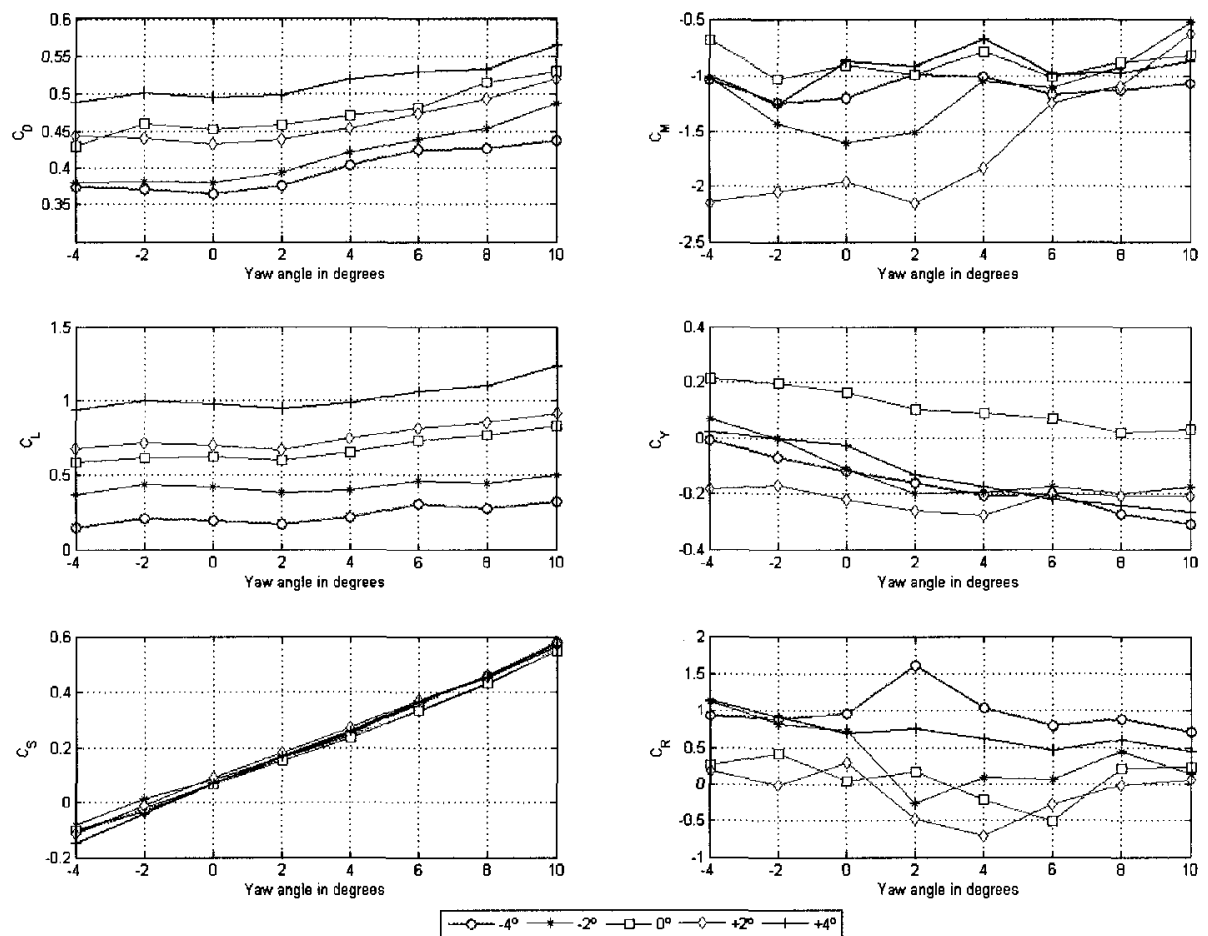

Figure 89: Static force and moment coefficients as a function of pitch angle in degrees, for five pitch angles at a constant ride height of $33 \mathrm{~mm}$ and a constant wind speed of $13 \mathrm{~m} / \mathrm{s}$. 

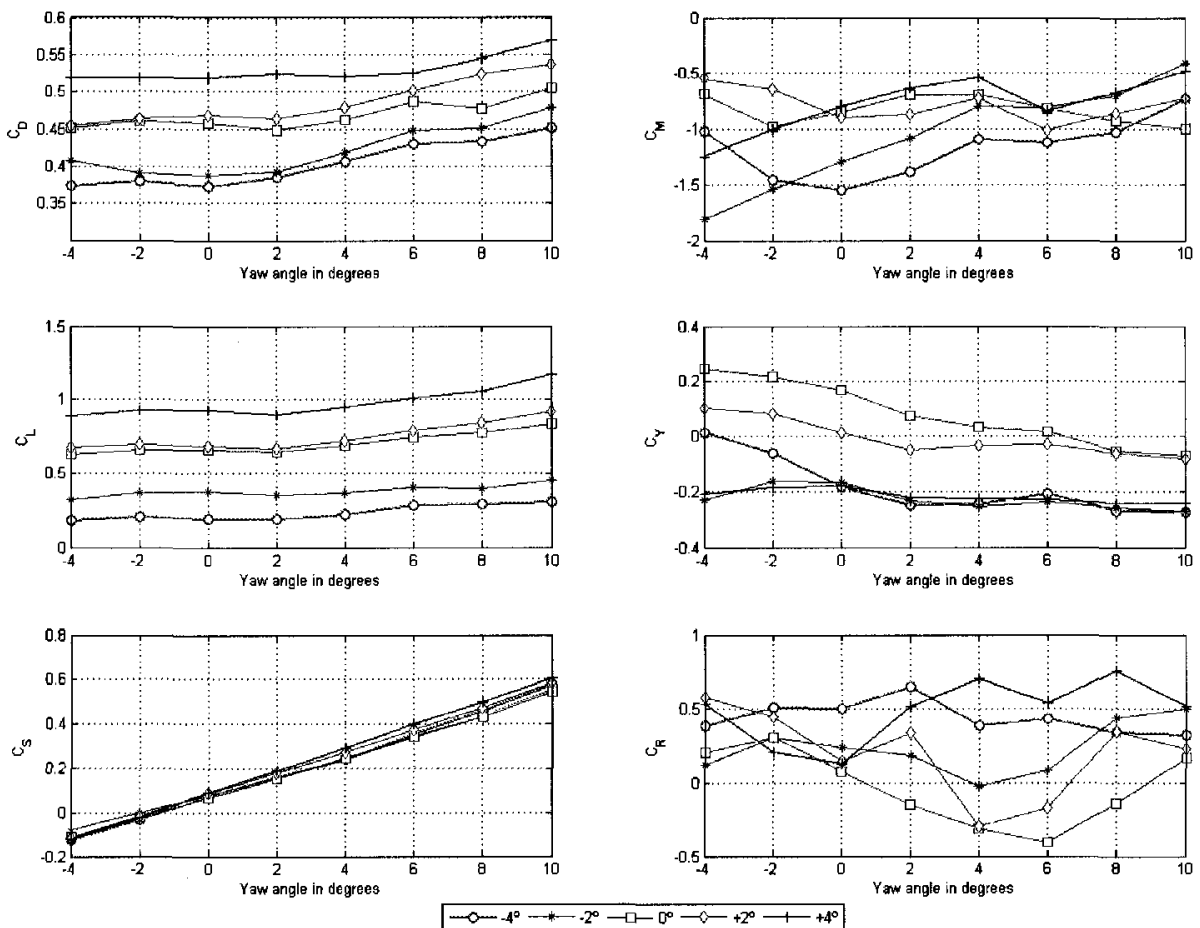

Figure 90: Static force and moment coefficients as a function of pitch angle in degrees, for five pitch angles at a constant ride height of $33 \mathrm{~mm}$ and a constant wind speed of $15 \mathrm{~m} / \mathrm{s}$. 


\section{Appendix C}

\section{Measurements of the frequency response of the pressure measurement system}

Calibration of the pressure measurement system was performed to measure the frequency response of each tube. Since the tubes were all the same length and diameter, the responses are similar. But the bent metal inserts and small variations of the inside diameter of the tube might have an effect on the response. The length of the tubes inside the temperature control unit of the ZOC33 also influenced the frequency response, but this was controlled by turning on the ZOC33 at least one hour before the calibration or the test.

The calibration has been performed using a spectrum analyzer. A band-width limited noise source was sent through a power amplifier to a horn driver. The noise frequency band was $0-800 \mathrm{~Hz}$ to cover all the frequencies acquired at the sampling frequency determined for this project. The horn driver was applied hermetically on a pressure tap of the model to prevent pressure leaks. The horn driver was producing pressure waves corresponding to the noise emitted by the source.

This pressure wave was measured by a calibrated fast response transducer, Kulite, positioned at $6 \mathrm{~mm}$ from the surface of the model. The Kulite measurement is used as a reference and the phase between the lecture at the Kulite and the entrance of 
the port is considered to be zero. Considering that the speed of sound is $343.3 \mathrm{~m} / \mathrm{s}$ at $20^{\circ} \mathrm{C}$, it takes $2.33 \times 10^{-5}$ seconds for the pressure wave to cover the $6 \mathrm{~mm}$.

The pressure is also measured through the pneumatic tubes by the ZOC. The spectrum analyzer acquires the data from the $\mathrm{ZOC}$ on channel B and can compare the signal with the reference. This calibration has to be performed for each port, one at the time. A schematic illustration of the set-up is presented in Figure 91.

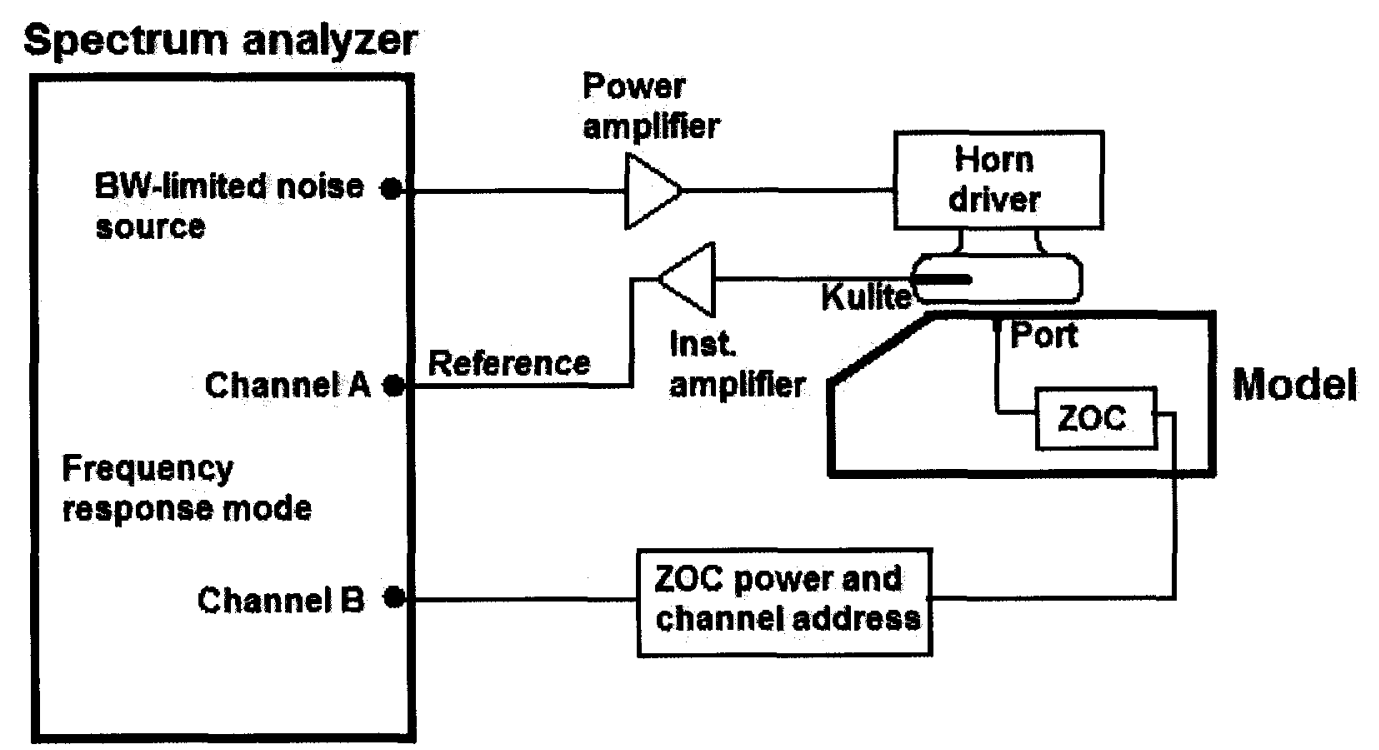

Figure 91: Schematic illustration of the set-up of the pressure taps calibration system. 


\section{Appendix D}

\section{Graphs of the dynamic model}
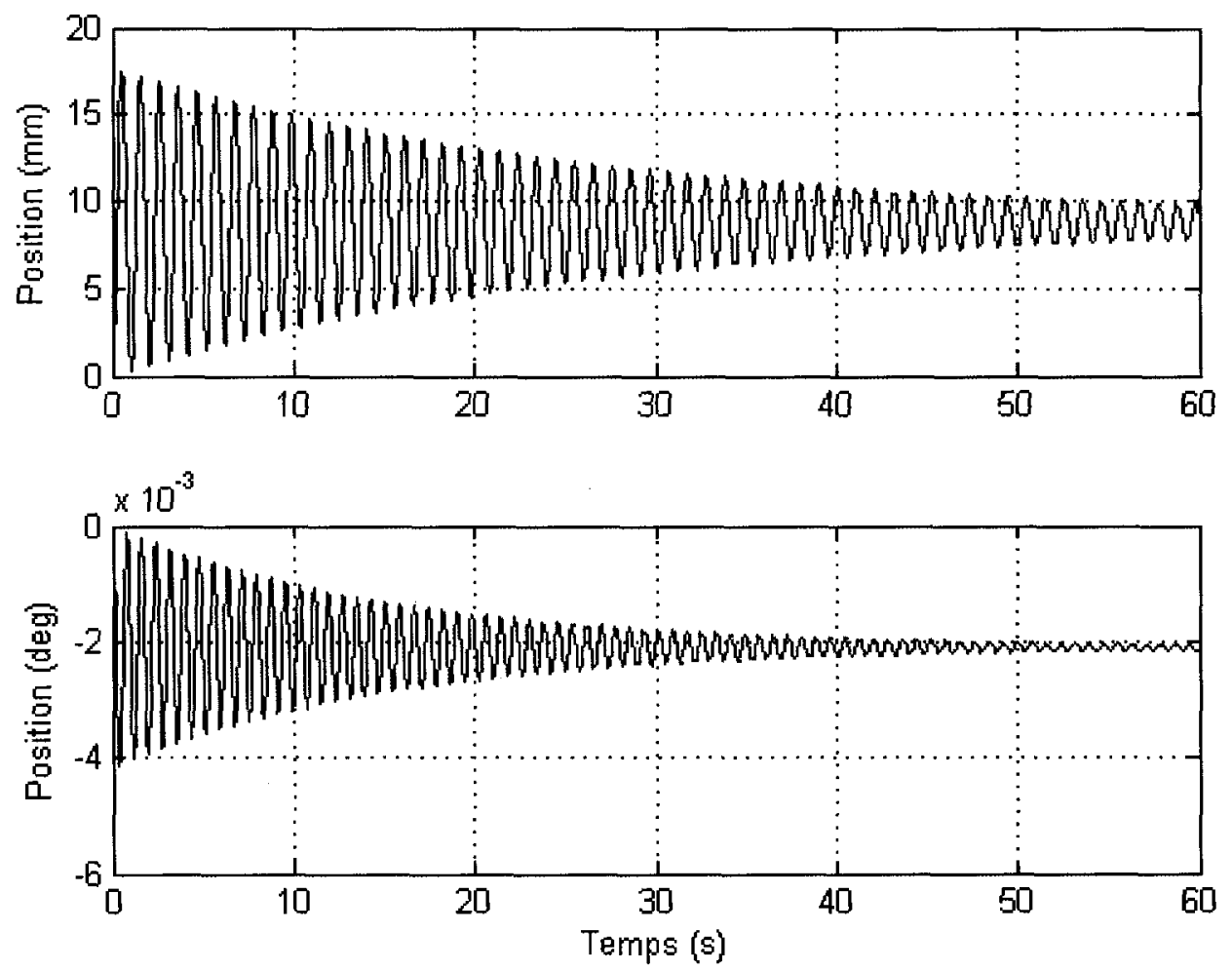

Figure 92: Graph of the simulation of the displacement in heave and pitch of the large weight case at $11 \mathrm{~m} / \mathrm{s}$ for a constant force input, structural coefficients. 

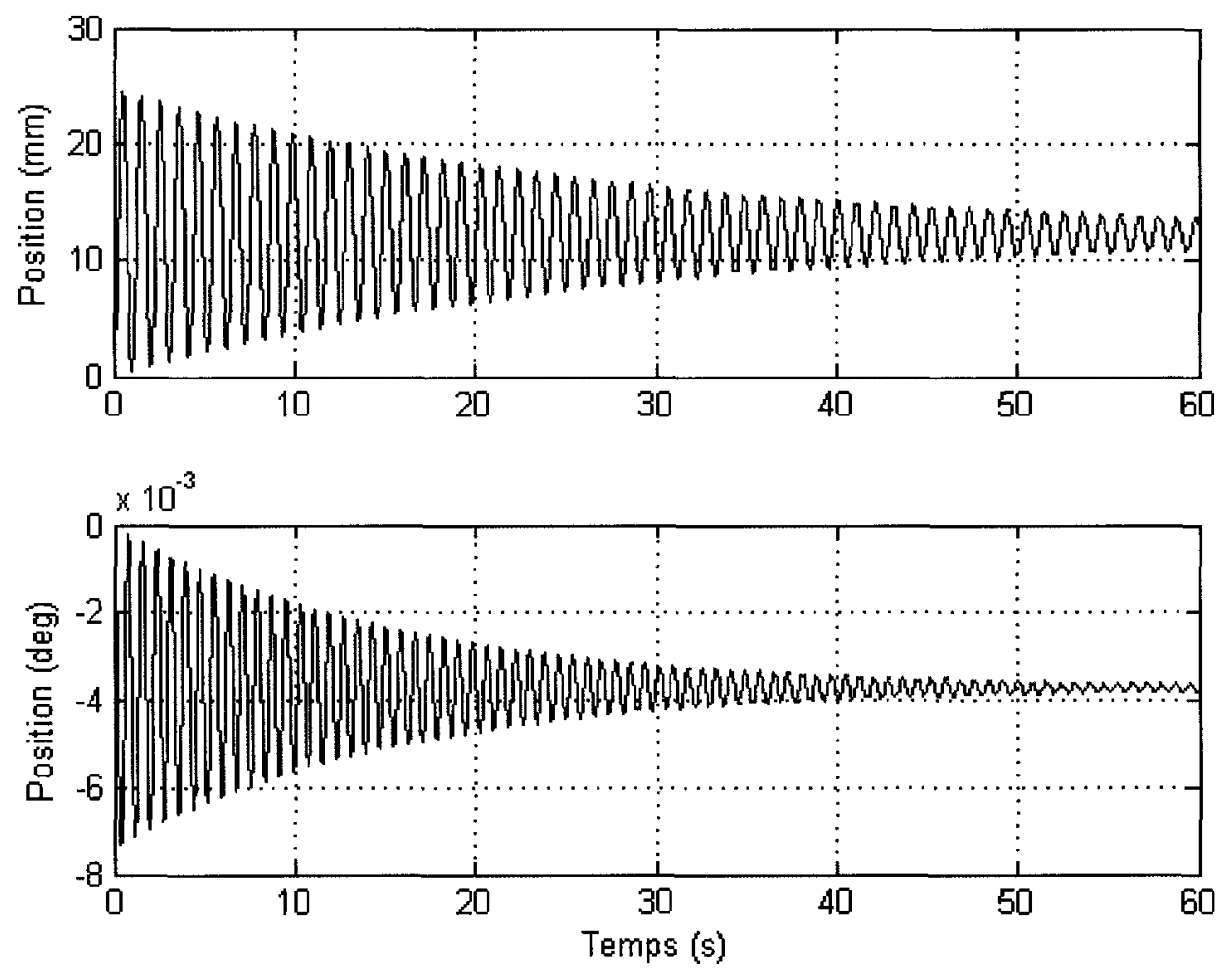

Figure 93: Graph of the simulation of the displacement in heave and pitch of the large weight case at $13 \mathrm{~m} / \mathrm{s}$ for a constant force input, structural coefficients. 

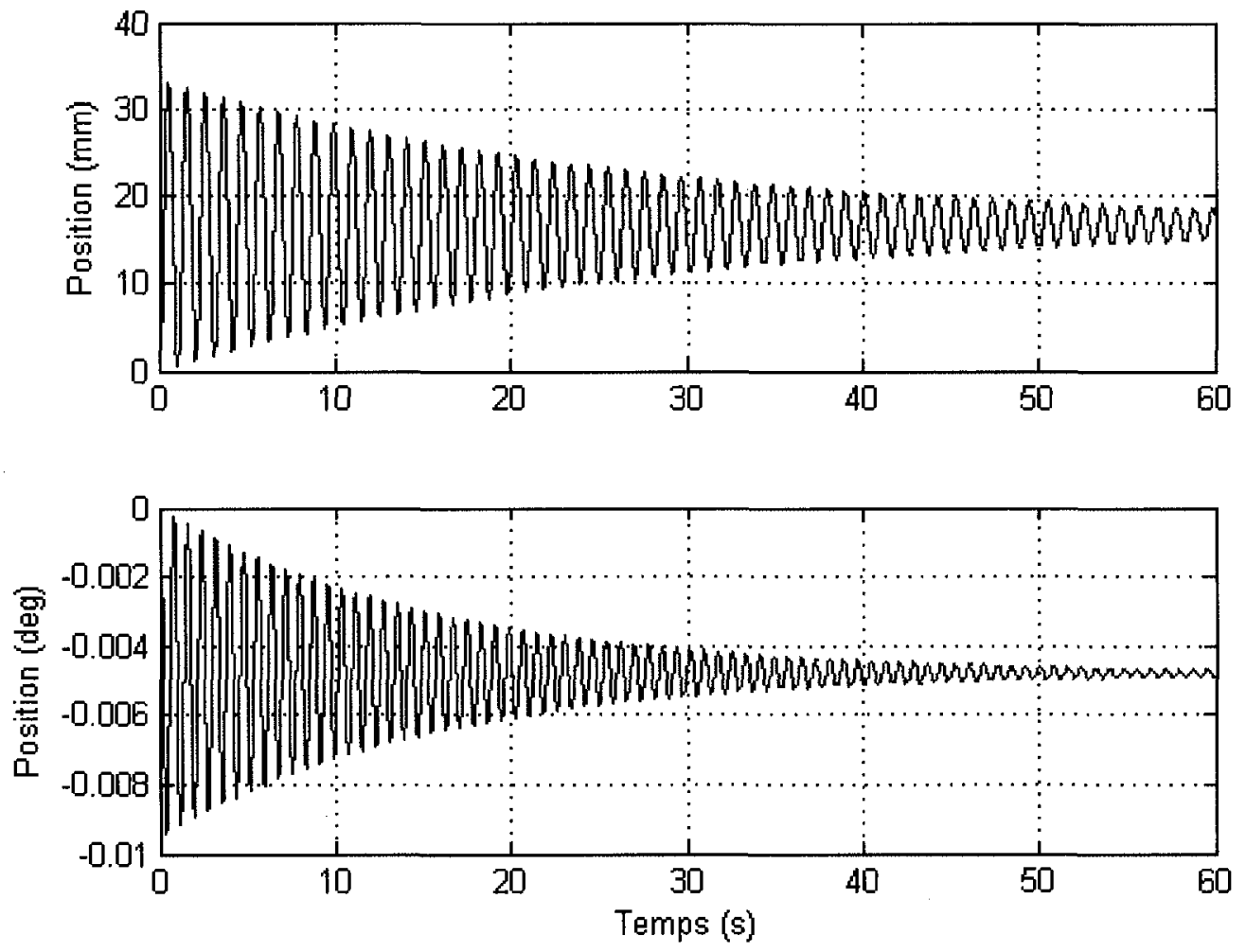

Figure 94: Graph of the simulation of the displacement in heave and pitch of the large weight case at $15 \mathrm{~m} / \mathrm{s}$ for a constant force input, structural coefficients. 

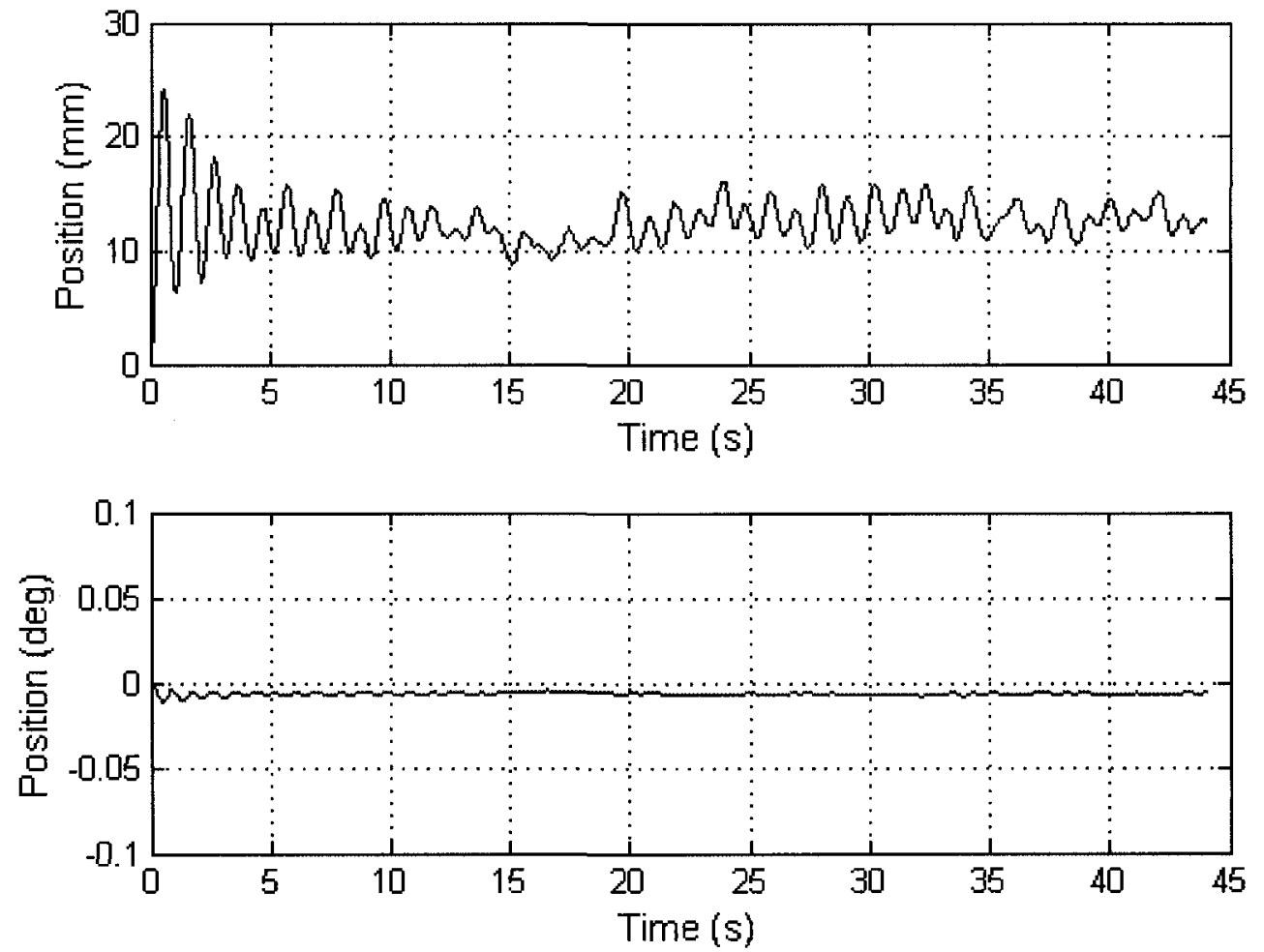

Figure 95: Graph of the simulation of big weight model position in function on the time at $11 \mathrm{~m} / \mathrm{s}$. 

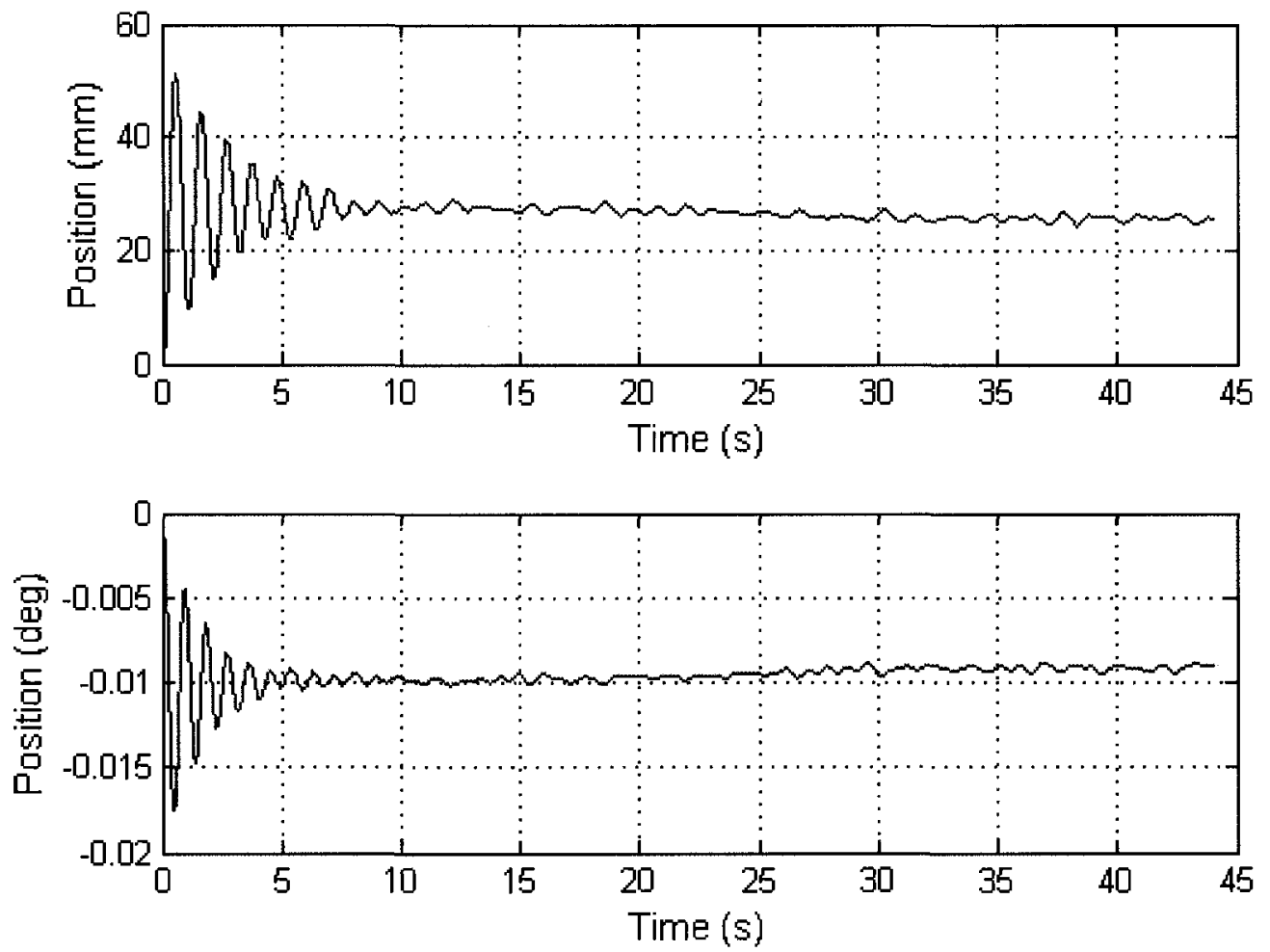

Figure 96: Graph of the simulation of big weight model position in function on the time at $15 \mathrm{~m} / \mathrm{s}$. 